DÓRIS NAGAOKA

Caracterização geoquímica orgânica em sedimentos presentes nos Pocmarks e Diápiros do talude sul do Brasil.

Dissertação apresentada ao Instituto Oceanográfico da Universidade de São Paulo, como parte dos requisitos para obtenção do título de Mestre em Ciências, Programa de Oceanografia, área de Oceanografia Química.

Orientadora:

Profa. Dra. Márcia Caruso Bícego.

São Paulo 
Universidade de São Paulo

Instituto Oceanográfico

\title{
Caracterização geoquímica orgânica em sedimentos presentes nos Pocmarks e Diápiros do talude sul do Brasil.
}

\author{
DÓRIS NAGAOKA
}

Dissertação apresentada ao Instituto Oceanográfico da Universidade de São Paulo, como parte dos requisitos para obtenção do título de Mestre em Ciências, área de Oceanografia Química.

Julgada em 


\section{SUMÁRIO}

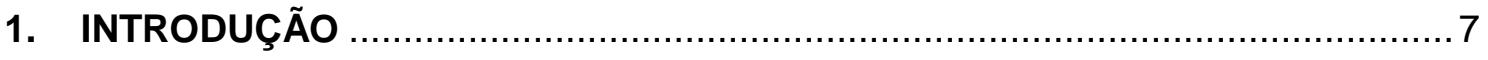

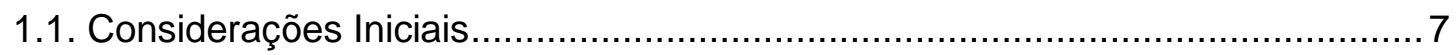

1.2. Marcadores Orgânicos Moleculares .......................................................... 10

1.2.1. Hidrocarbonetos Alifáticos (HAs) …............................................... 10

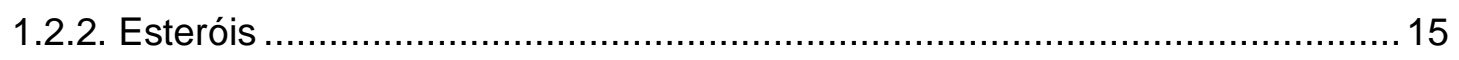

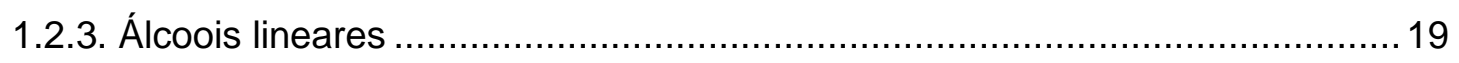

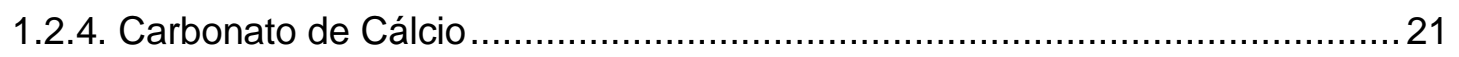

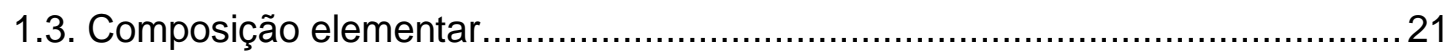

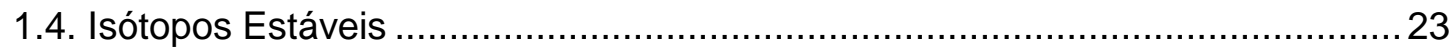

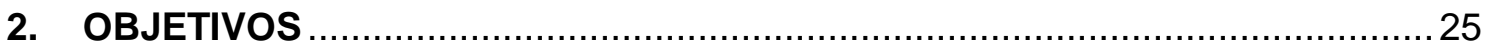

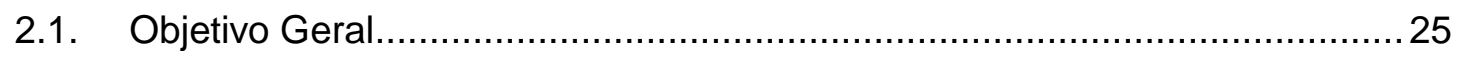

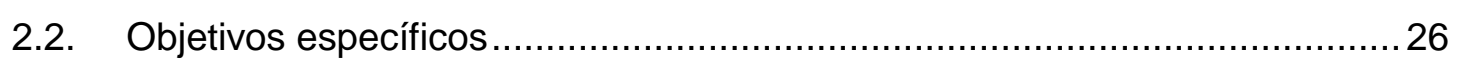

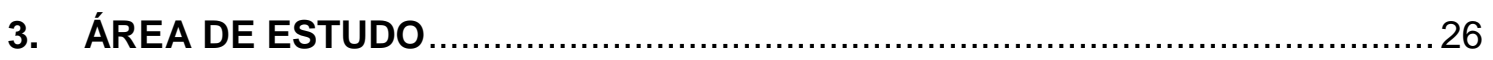

3.1. Aspectos Meteorológicos e Oceanográficos.................................................27

3.2. Geomorfologia e Sedimentologia do Talude Continental ................................. 30

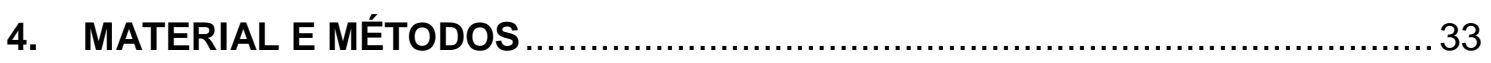

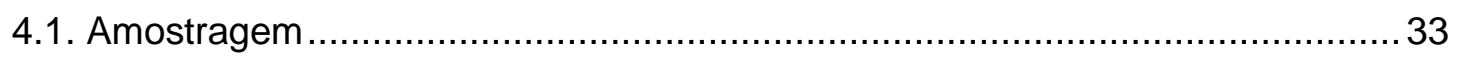

4.2. Características composicionais do sedimento ................................................ 36

4.3. Tratamento dos reagentes e limpeza do material ........................................... 38

4.4. Análise dos marcadores orgânicos moleculares................................................ 38

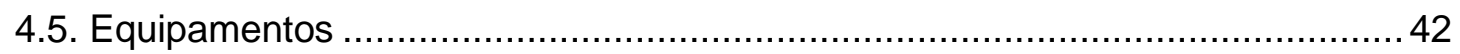

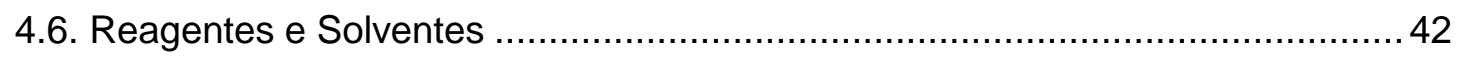

4.7. Avaliação do método analítico .................................................................... 43

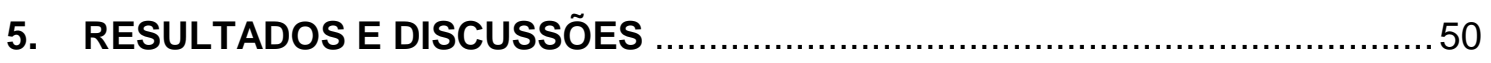

5.1. Amostras de Sedimentos Superficiais................................................ 50

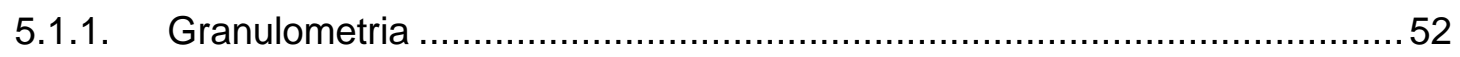

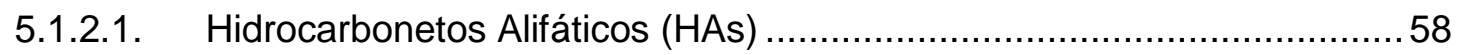

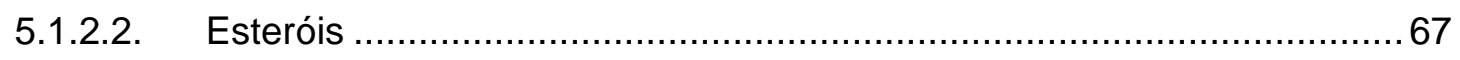

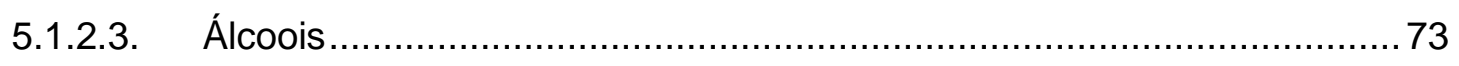

5.2. Amostras de sedimentos ao longo dos testemunhos. ................................ 76

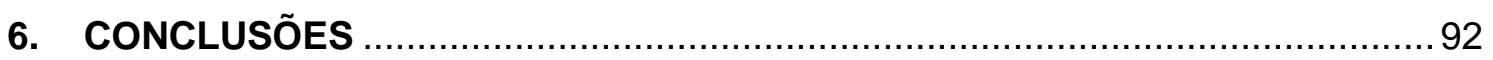

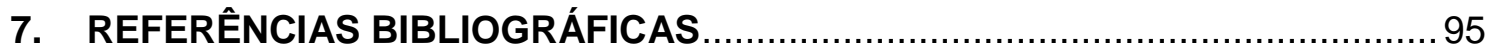

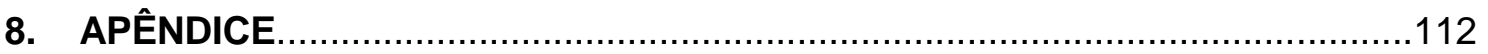




\section{LISTA DE FIGURAS}

Figura 1 - llustração esquemática do diápiro ascendendo. A presença de falhas acima do diápiro facilita a percolação de gás devido ao aumento da permeabilidade, formando os pockmarks e influenciando na formação da espessura das camadas de sal (MAHIQUES et., 2017)................................ 8

Figura 2 - Estrutura básica dos esteróis. 15

Figura 3 - Representação esquemática da circulação do Oceano Atlântico Sul. Corrente Sul Equatorial em seus ramo sul (CSEs), ramo central (CSEc), ramo norte (CSEn); Contracorrente Sul Equatorial (CCSE), Subcorrente Sul Equatorial (SSE) e Subcorrente Equatorial (SE) (SILVEIRA et al., 2000)........ 27

Figura 4 - Limites das massas de água na região oceânica da Bacia de Santos (MAATSURA, 1986). 28

Figura 5 - Influência do Rio da Prata para o inverno (esquerda) e verão (direita). Em verde está a Água da Pluma do Rio da Prata (APP), em vermelho Água Tropical (AT), em azul Água Subantártica (ASA). No verão a região próxima ao Cabo de Santa Marta apresenta intrusão da Água Central do Atlântico Sul (ACAS) na superfície (fenômeno de ressurgência) (Modificado de MÖLLER et al., 2008).

Figura 6 - Mapa do relevo oceânico da área plataforma continental externa, talude e região oceânica adjacente do Sudeste-Sul do Brasil (GASALLA et al., 2007). 32

Figura 7 - Em azul a Corrente Costeira do Brasil (CCB), fluindo para nordeste $(\mathrm{NE})$ até $25^{\circ} \mathrm{S}$, paralela à costa em profundidades menores do que $200 \mathrm{~m}$. Em vermelho a Corrente do Brasil (CB), fluindo para sul (S), paralela à costa em profundidades maiores do que $200 \mathrm{~m}$ (Modificada de NAGAl et al., 2010)...... 33

Figura 8 - Área de estudo e as 13 estações localizados na margem continental sul do Brasil entre as latitudes $26^{\circ}$ e $28^{\circ} \mathrm{S}$. 34

Figura 9 - Exemplo de um perfil sísmico destacando a presença de diápiro e pockmark na área de estudo. (a) Diápiro na estação 256 (b) Pockmark na estação 255 . 35

Figura 10 - Esquema do método analítico utilizado no procedimento laboratorial para obtenção dos marcadores orgânicos geoquímicos. 40 Figura 11 - Condições cromatográficas utilizadas na determinação dos marcadores orgânicos no CG-DIC. 41

Figura 12 - llustração esquemática do padrão de fluxo no interior dos pockmarks (PAU et al. 2013) 
Figura 13 - Distribuição do teor de areia e lama (silte+argila) na área de estudo. 53

Figura 14 - Distribuição de carbonatos (\%) em sedimentos localizados na área de estudo.

Figura 15 - Teores de carbono orgânico total (\%) no sedimento da área de estudo. 56

Figura 16 - Correlação linear entre o carbono orgânico total e o nitrogênio total. 57

Figura 17 - Concentrações do $\Sigma$ HAs em $\left(\mu \mathrm{g} \mathrm{g}^{-1}\right)$ ao longo da área de estudo. 62

Figura 18 - Concentrações do $\Sigma n$-alcanos em $\left(\mu \mathrm{g} \mathrm{g}^{-1}\right)$ ao longo da área de estudo. 63

Figura 19 - Concentração dos $n$-alcanos $\left(\mu \mathrm{g} \mathrm{g}^{-1}\right)$ nas amostras superficiais. . 63

Figura 20 - Imagem de satélite da concentração de clorofila $\left(\mathrm{mg} \mathrm{m}^{-3}\right)$ em julho, derivada de imagens SeaWIFS com médias mensais (1998-2005). As setas indicam a distribuição climatológica do vento derivada do QuikSCAT com médias mensais de julho de 1999 a 2005. (PIOLA et al., 2008). 66

Figura 21 - Concentrações de esteróis totais em $\left(\mu \mathrm{g} \mathrm{g}^{-1}\right)$ ao longo da área de estudo. 69

Figura 22 - Concentrações de Colesterol, Colestanol, Brassicasterol, Brassicastanol, Campesterol, Campestanol, Estigmasterol, Estigmastanol, $\beta$ sitosterol, $\beta$-sitostanol nas amostras superficiais. 71

Figura 23 - Correlação linear entre o carbono orgânico total (\%) e esteróis totais $\mu \mathrm{g} / \mathrm{g}$ 72

Figura 24 - Concentrações de álcoois totais em $\left(\mu \mathrm{g} \mathrm{g}^{-1}\right)$ ao longo da área de estudo. 75

Figura 25 - Box-Plot da \% de lama (silte + argila) nas estações 253, 254, 257, 256, 262 e 264.

Figura 26 - Box-Plot da \% de $\mathrm{CaCO}_{3}$ nas estações 253, 254, 257, 256, 262 e 264.

Figura 27 - Box-Plot da \% de COT nas estações 253, 254, 257, 256, 262 e 264. 
Figura 28 - Correlação linear entre o carbono orgânico total e o nitrogênio total.

Figura 29 - Box-Plot do teor de $\delta^{13} \mathrm{C}$ nas estações $253,254,257,256,262$ e 264.

Figura 30 - Box-Plot das concentrações de HAs totais (a) e $n$-alcanos totais (b) nas estações 253, 254, 257, 256, 262 e 264.

Figura 31 - Concentrações de $n$-alcanos $n$ - $\mathrm{C}_{12}, n$-C $\mathrm{C}_{14}, n$ - $\mathrm{C}_{15}, n$ - $\mathrm{C}_{16}, n-\mathrm{C}_{17}, n$ $\mathrm{C}_{19}, n-\mathrm{C}_{20}, n-\mathrm{C}_{22}, n-\mathrm{C}_{29}, n-\mathrm{C}_{31}$ e $n-\mathrm{C}_{33}$ nas estações $253,254,257,256,262$ e 264. 85

Figura 32 - Box-Plot das concentrações de Esteróis Totais nas estações 253, 254, 257, 256, 262 e 264.

Figura 33 - Médias das concentrações de Colesterol, Brassicasterol, Campesterol, Estigmasterol e de $\beta$-sitosterol nas estações 253, 254, 255, 256, 257, 262 e 264.

Figura 34 - Box-Plot da concentração de Álcoois totais nas estações 253, 254 , 257, 256, 262 e 264.

Figura 35 - Relação entre os $n$-alcanos $n-\mathrm{C}_{12}, n$ - $\mathrm{C}_{14}$ e $n$ - $\mathrm{C}_{16}$ sobre os $n$-alcanos $n-\mathrm{C}_{29}, n-\mathrm{C}_{31}$ e $n-\mathrm{C}_{33}$ nos testemunhos $253,254,256,257$ e 264.

Figura 36 - Perfil dos $n$-alcanos e álcoois leves $(\mu \mathrm{g} / \mathrm{g})$, analisados nos testemunhos 253, 254, 256, 257 e 264 . 


\section{LISTA DE TABELAS}

Tabela 1 - Síntese da distribuição dos $n$-alcanos nos principais organismos que contribuem para a introdução destes compostos no ambiente marinho (modificado de PHILP, 1985) 12

Tabela 2 - Fontes e origens dos esteróis utilizados neste trabalho. 17

Tabela 3 - Álcoois lineares com as devidas nomenclaturas, números de carbonos e de ligações duplas em cada molécula, origem e referência. 20

Tabela 4 - Estações das amostras, latitudes, longitudes, profundidade $(\mathrm{m}) \mathrm{da}$ coluna d'água e data das coletas de julho de 2016 . 35

Tabela 5 - Equipamentos 42

Tabela 6 - Reagentes e solventes utilizados nas etapas de extração e purificação

Tabela 7 - Resultados da avaliação do método analítico dos $n$-alcanos individuais.

Tabela 8 - Resultados da avaliação do método analítico para os esteróis e álcoois.

Tabela 9 - Valores dos parâmetros avaliados no sedimento superficial da área de estudo. Lama = silte + argila; $\mathrm{CaCO}_{3}=$ carbonato de cálcio; $\mathrm{COT}=$ carbono orgânico total; NT = nitrogênio total; $\mathrm{C} / \mathrm{N}$ = razão carbono orgânico/nitrogênio total; $\delta^{13} \mathrm{C}=$ razão isotópica do carbono orgânico; $\delta^{15} \mathrm{~N}=$ razão isotópica do nitrogênio total; $\Sigma$ HAs = somatório dos alifáticos totais; $\Sigma$ Esteróis = somatório dos esteróis; $\Sigma$ Álcoois = somatório dos álcoois.

Tabela 10 - Concentrações dos $n$-alcanos, alcanos isoprenóides, MCNR, em $\mu \mathrm{g} \mathrm{g}^{-1}$, e parâmetros de avaliação de fontes de hidrocarbonetos alifáticos. <LDM: abaixo do limite de detecção; Alcanos totais: somatório dos compostos $n-\mathrm{C}_{10}$ ao $n-\mathrm{C}_{40}$; Pris/Fit: razão entre o pristano e o fitano, $\mathrm{IA}=\left(n-\mathrm{C}_{31} / n-\mathrm{C}_{31}+n-\right.$ $\left.\mathrm{C}_{29}\right), n-\mathrm{C}_{12+14+16}=\sum\left(\mathrm{n}-\mathrm{C}_{12}+\mathrm{n}-\mathrm{C}_{14}+\mathrm{n}-\mathrm{C}_{16}\right)$ e $n-\mathrm{C}_{29+31+33}=\sum\left(\mathrm{n}-\mathrm{C}_{29}+\mathrm{n}-\mathrm{C}_{31}+\mathrm{n}-\right.$ $\left.\mathrm{C}_{33}\right)$

Tabela 11 - Concentrações dos esteróis analisados em $\left(\mu \mathrm{g} \mathrm{g}{ }^{-1}\right)$ e parâmetros de avaliação da origem e transformação da matéria orgânica. <LDM: abaixo do limite de detecção.

Tabela 12 - Concentrações dos álcoois analisados em $\left(\mu \mathrm{g} \mathrm{g}^{-1}\right)$ e parâmetros de avaliação da origem e transformação da matéria orgânica. <LDM: abaixo do limite de detecção. 
Tabela 13 - Parâmetros de caracterização da matéria orgânica sedimentar ao longo dos testemunhos.

Tabela 14 - Concentrações dos $n$-alcanos, alcanos isoprenóides, MCNR, em $\mu \mathrm{g} \mathrm{g}^{-1}$, e parâmetros de avaliação de fontes de hidrocarbonetos alifáticos.< LDM: abaixo do limite de detecção; Alcanos totais: somatório dos compostos $n$ $\mathrm{C}_{12}$ ao $n$ - $\mathrm{C}_{35}$; Pris/Fit: razão entre o pristano e o fitano, $\mathrm{IA}=\left(n-\mathrm{C}_{31} / n-\mathrm{C}_{31}+n-\mathrm{C}_{29}\right)$, ao longo do testemunho 253

Tabela 15 - Concentrações dos $n$-alcanos, alcanos isoprenóides, MCNR, em $\mu \mathrm{g} \mathrm{g}^{-1}$, e parâmetros de avaliação de fontes de hidrocarbonetos alifáticos.< LDM: abaixo do limite de deteç̧ão; Alcanos totais: somatório dos compostos $n$ $\mathrm{C}_{12}$ ao $n$ - $\mathrm{C}_{35}$; Pris/Fit: razão entre o pristano e o fitano, $\mathrm{IA}=\left(n-\mathrm{C}_{31} / n-\mathrm{C}_{31}+n-\mathrm{C}_{29}\right)$ ao longo do testemunho 254 .

Tabela 16 - Concentrações dos $n$-alcanos, alcanos isoprenóides, MCNR, em $\mu \mathrm{g} \mathrm{g}^{-1}$, e parâmetros de avaliação de fontes de hidrocarbonetos alifáticos. <LDM: abaixo do limite de detecção; Alcanos totais: somatório dos compostos $n-\mathrm{C}_{12}$ ao $n$ - $\mathrm{C}_{35}$; Pris/Fit: razão entre o pristano e o fitano, $\mathrm{I} A=\left(n-\mathrm{C}_{31} / n-\mathrm{C}_{31}+n-\right.$ $\mathrm{C}_{29)}$ ao longo do testemunho 256. 123

Tabela 17 - Concentrações dos $n$-alcanos, alcanos isoprenóides, MCNR, em $\mu \mathrm{g} \mathrm{g^{-1 }}$, e parâmetros de avaliação de fontes de hidrocarbonetos alifáticos.< LDM: abaixo do limite de deteç̧ão; Alcanos totais: somatório dos compostos $n$ $\mathrm{C}_{12}$ ao $n-\mathrm{C}_{35}$; Pris/Fit: razão entre o pristano e o fitano, $\mathrm{IA}=\left(n-\mathrm{C}_{31} / n-\mathrm{C}_{31}+n-\mathrm{C}_{29}\right)$ ao longo do testemunho 257 .

Tabela 18 - Concentrações dos $n$-alcanos, alcanos isoprenóides, MCNR, em $\mu \mathrm{g} \mathrm{g}^{-1}$, e parâmetros de avaliação de fontes de hidrocarbonetos alifáticos.< LDM: abaixo do limite de deteç̧ão; Alcanos totais: somatório dos compostos $n$ $\mathrm{C}_{12}$ ao $n-\mathrm{C}_{35}$; Pris/Fit: razão entre o pristano e o fitano, $\mathrm{IA}=\left(n-\mathrm{C}_{31} / n-\mathrm{C}_{31}+n-\mathrm{C}_{29}\right)$ ao longo do testemunho 262

Tabela 19 - Concentrações dos $n$-alcanos, alcanos isoprenóides, MCNR, em $\mu \mathrm{g} \mathrm{g}^{-1}$, e parâmetros de avaliação de fontes de hidrocarbonetos alifáticos.< LDM: abaixo do limite de detecção; Alcanos totais: somatório dos compostos $n$ $\mathrm{C}_{12}$ ao $n$ - $\mathrm{C}_{35}$; Pris/Fit: razão entre o pristano e o fitano, $\mathrm{IA}=\left(n-\mathrm{C}_{31} / n-\mathrm{C}_{31}+n-\mathrm{C}_{29}\right)$ ao longo do testemunho 264 .

Tabela 20 - Concentrações dos esteróis analisados em $\left(\mu \mathrm{g} \mathrm{g}^{-1}\right)$ e parâmetro de avaliação da origem e transformação da matéria orgânica. <LDM: abaixo do limite de detecção, ao longo do testemunho 253. 131

Tabela 21 - Concentrações dos esteróis analisados em $\left(\mu \mathrm{g} \mathrm{g}^{-1}\right)$ e parâmetro de avaliação da origem e transformação da matéria orgânica. <LDM: abaixo do limite de detecção, ao longo do testemunho 254. 132 
Tabela 22 - Concentrações dos esteróis analisados em $\left(\mu \mathrm{g} \mathrm{g}^{-1}\right)$ e parâmetro de avaliação da origem e transformação da matéria orgânica. <LDM: abaixo do limite de detecção, ao longo do testemunho 256. 134

Tabela 23 - Concentrações dos esteróis analisados em $\left(\mu \mathrm{g} \mathrm{g}^{-1}\right)$ e parâmetro de avaliação da origem e transformação da matéria orgânica. <LDM: abaixo do limite de detecção, ao longo do testemunho 257. 135

Tabela 24 - Concentrações dos esteróis analisados em $\left(\mu \mathrm{g} \mathrm{g}^{-1}\right)$ e parâmetro de avaliação da origem e transformação da matéria orgânica. <LDM: abaixo do limite de detecção, ao longo do testemunho 262. 136

Tabela 25 - Concentrações dos esteróis analisados em $\left(\mu \mathrm{g} \mathrm{g}^{-1}\right)$ e parâmetro de avaliação da origem e transformação da matéria orgânica. <LDM: abaixo do limite de detecção, ao longo do testemunho 264.

Tabela 26 - Concentrações dos álcoois analisados em $\left(\mu \mathrm{g} \mathrm{g}^{-1}\right)$ e parâmetro de avaliação da origem e transformação da matéria orgânica. <LDM: abaixo do limite de detecção, ao longo do testemunho 253. 138

Tabela 27 - Concentrações dos álcoois analisados em $\left(\mu \mathrm{g} \mathrm{g}^{-1}\right)$ e parâmetro de avaliação da origem e transformação da matéria orgânica. <LDM: abaixo do limite de detecção, ao longo do testemunho 254. 139

Tabela 28 (Continuação) - Concentrações dos álcoois analisados em $\left(\mu \mathrm{g} \mathrm{g}^{-1}\right) \mathrm{e}$ parâmetro de avaliação da origem e transformação da matéria orgânica. <LDM: abaixo do limite de detecção, ao longo do testemunho 254 . 140

Tabela 29 - Concentrações dos álcoois analisados em $\left(\mu \mathrm{g} \mathrm{g}^{-1}\right)$ e parâmetro de avaliação da origem e transformação da matéria orgânica. <LDM: abaixo do limite de detecção, ao longo do testemunho 256. 141

Tabela 30 - Concentrações dos álcoois analisados em $\left(\mu \mathrm{g} \mathrm{g}^{-1}\right)$ e parâmetro de avaliação da origem e transformação da matéria orgânica. <LDM: abaixo do limite de detecção, ao longo do testemunho 257. 142

Tabela 31 - Concentrações dos álcoois analisados em $\left(\mu \mathrm{g} \mathrm{g}^{-1}\right)$ e parâmetro de avaliação da origem e transformação da matéria orgânica. <LDM: abaixo do limite de detecção, ao longo do testemunho 262. 143

Tabela 32 - Concentrações dos álcoois analisados em $\left(\mu \mathrm{g} \mathrm{g}^{-1}\right)$ e parâmetro de avaliação da origem e transformação da matéria orgânica. <LDM: abaixo do limite de detecção, ao longo do testemunho 264. 144 


\section{LISTA DE ABREVIAÇÕES}

ACAS Água Central do Atlântico do Sul
AIA Água Intermediária Antártica
$\mathrm{C} / \mathrm{N}$ Razão entre a quantidade de Carbono Orgânico e Nitrogênio Total
$\mathrm{n}-\mathrm{C} \quad$ Cadeia carbônica contendo $\mathrm{n}$ átomos de carbono
CCB Corrente Costeira do Brasil
CB Corrente do Brasil
COT Carbono Orgânico Total
GC-FID Cromatógrafo a Gás - Detector por lonização em Chama
GC-MS Cromatógrafo a Gás - Espectrômetro de Massa
IA Índice Alcano
LDM Limite de Detecção do Método
MO Matéria Orgânica
NT Nitrogênio Total
PICG Padrão Interno Cromatográfico
PRD Percentual Relativo de Diferença
$\delta^{13} \mathrm{C} \quad$ Razão Isotópica do Carbono Orgânico
$\delta^{15} \mathrm{~N} \quad$ Razão Isotópica Do Nitrogênio Total
$\Sigma \quad$ Somatório 


\section{AGRAECIMENTOS}

À minha orientadora Prof.a Dra. Márcia Caruso Bícego por todo interesse, motivação, apoio e paciência, dedicando parte do seu tempo a mim. Agradeço pelas leituras atentas, pelas correções oportunas e construtivas, pelas críticas e puxões de orelha, que foram fundamentais para o meu crescimento como pesquisadora e no desenvolvimento deste trabalho. Agradeço também as oportunidades de embarques, foram dias incríveis e enriquecedores.

À Satie Taniguchi, que desde o início me auxiliou nas atividades e procedimentos laboratoriais, pelas inúmeras dúvidas esclarecidas e principalmente pela orientação e disposição à me ajudar sempre.

Ao Lourival por todo o acompanhamento, conversas e instruções no laboratório.

Ao Prof. Dr. Michel Michaelovitch de Mahiques e a Raissa Basti cujos os auxílios tornaram possível a concretização deste projeto.

À toda comissão "TALUDE" pelo comprometimento nas coletas das amostras.

À todos do LABQOM, que compartilharam comigo esses momentos de aprendizado.

À minha família (pai, mãe e irmão) pela compreensão, ao serem privados em muitos momentos da minha companhia e atenção. Obrigada por desejarem sempre o melhor para mim, pelo esforço que fizeram para que eu pudesse superar cada obstáculo e chegar até aqui. À vocês, sou eternamente grata por tudo que sou, que consegui conquistar e pela felicidade que eu tenho.

Ao Ronald por toda paciência, compreensão e amor. Você foi a pessoa que compartilhou comigo os momentos de tristezas e alegrias.

Aos funcionários do Instituto Oceanográfico, em especial ao pessoal da secretaria de pós graduação, que sempre tiraram minhas dúvidas e me ajudaram.

A CAPES pelo apoio financeiro. 


\section{RESUMO}

Os marcadores orgânicos moleculares (hidrocarbonetos alifáticos, esteróis e álcoois) em amostras de sedimentos superficiais e de testemunhos curtos coletados em diápiros e pockmarks localizados no talude sul do Brasil, foram utilizados para identificar as possíveis contribuições biogênicas (autóctones / alóctones). De modo geral, tanto nas amostras superficiais como ao longo dos testemunhos, o maior acúmulo de carbono orgânico total nos pockmarks foi observado, indicando o possível aprisionamento de sedimentos e de matéria orgânica no interior das concavidades. A presença de $\beta$-sitosterol, campesterol, álcoois e $n$-alcanos pesados, indicaram contribuições terrígenas para a área de estudo, que pode ser advinda da descarga continental do Rio da Prata, uma vez que a predominância terrígena é proveniente das pradarias, típica vegetação do Uruguai e do sul do Rio Grande do Sul. O transporte de sedimentos terrígenos ocorre em direção ao norte, ao longo da plataforma continental sul brasileira, pela Corrente Costeira do Brasil. A presença de detritos de fitoplâncton e zooplâncton também ocorre devido à influência dos nutrientes do Rio da Prata. As possíveis liberações de gás/fluido, que sustentaram ecossistemas quimiossintéticos em diferentes intervalos de dois testemunhos em pockmark e diápiro foram constatadas através da presença relativamente maior de $n$-alcanos leves com número par de carbonos.

Palavras Chaves: biomarcadores moleculares, n-alcanos, esteróis, álcoois lineares 


\begin{abstract}
Organic molecular markers (aliphatic hydrocarbons, sterols and alcohols) in superficial and short cores sediment samples collected in diapirs and pockmarks located in the southern slope of Brazil were used in order to identify the possible biogenic contributions (autochthonous / allochthonous). In general, in surface samples and throughout the cores samples, the greatest accumulation of total organic carbon in the pockmarks was observed, indicating the possible entrapment of sediments and organic matter inside the concavities. The presence of $\beta$-sitosterol, campesterol, alcohols and heavy $n$-alkanes indicated terrigenous contributions to the study area, which may be due to the continental discharge of Río de la Plata, since the terrigenous predominance is due to the prairies, a typical vegetation of Uruguay and the south of Rio Grande do Sul. The terrigenous sediments transport is carried through the North, along the Brazilian continental shelf, by the Coastal Stream of Brazil. The presence of phytoplankton and zooplankton debris is also due to the influence of the nutrients contribution from Río de la Plata. Possible gas / fluid releases, which sustained chemosynthetic ecosystems at different intervals of two pockmark and diaper cores, were verified by the relative predominance of even-numbered carbon $n$-alkanes.
\end{abstract}

Key Words: molecular biomarkers, hydrocarbons, $n$-alkanes, sterols, linear alcohols. 


\section{INTRODUÇÃO}

\subsection{Considerações Iniciais}

O Talude Continental é a região fisiográfica da Margem Continental que apresenta os mais elevados valores de declividade dos oceanos. São áreas localizadas na quebra da plataforma, constituindo-se numa encosta geralmente estreita (de 10 a $200 \mathrm{~km}$ ), onde as profundidades ampliam-se bruscamente e apresentam gradientes geralmente íngremes (BATISTA NETO \& SILVA, 2004). Neste local estão presentes inúmeras feições geológicas, entre elas pockmarks, diápiros, contornitos e os cânions submarinos, que são as maiores feições erosivas da margem, que dão suporte exclusivo a comunidades faunísticas e microbiológicas (RAMIREZ-LLODRA et al., 2010). Essas regiões são caracterizadas por sedimentos finos e com predomínio de lama ou substrato duro, como os bancos de corais de águas profundas, sendo que a maior parte da biota é representada por um grupo de animais, geralmente invertebrados, que vivem associados ao fundo (WRAY, 1995).

O diápiro é uma massa de sal que se move gravitacionalmente para cima através das camadas sobrejacentes (HUDEC \& JACKSON, 2011). As camadas de sal se tornam instáveis por gravidade e se movem por flutuabilidade quando soterradas a uma profundidade em que sua densidade se torna menor que a densidade média das rochas sobrejacentes (CHAPMAN, 1983). A migração ascendente do diápiro promove fraturas, permitindo a infiltração de gases e fluidos nas camadas superficiais (TAYLOR et al., 2000; HOVLAND, 2002). Uma diminuição da tensão da camada sedimentar pode levar à expulsão violenta de gases e fluidos, podendo contribuir para a formação dos pockmarks (RIBOULOT et al., 2013) (Figura 1). 


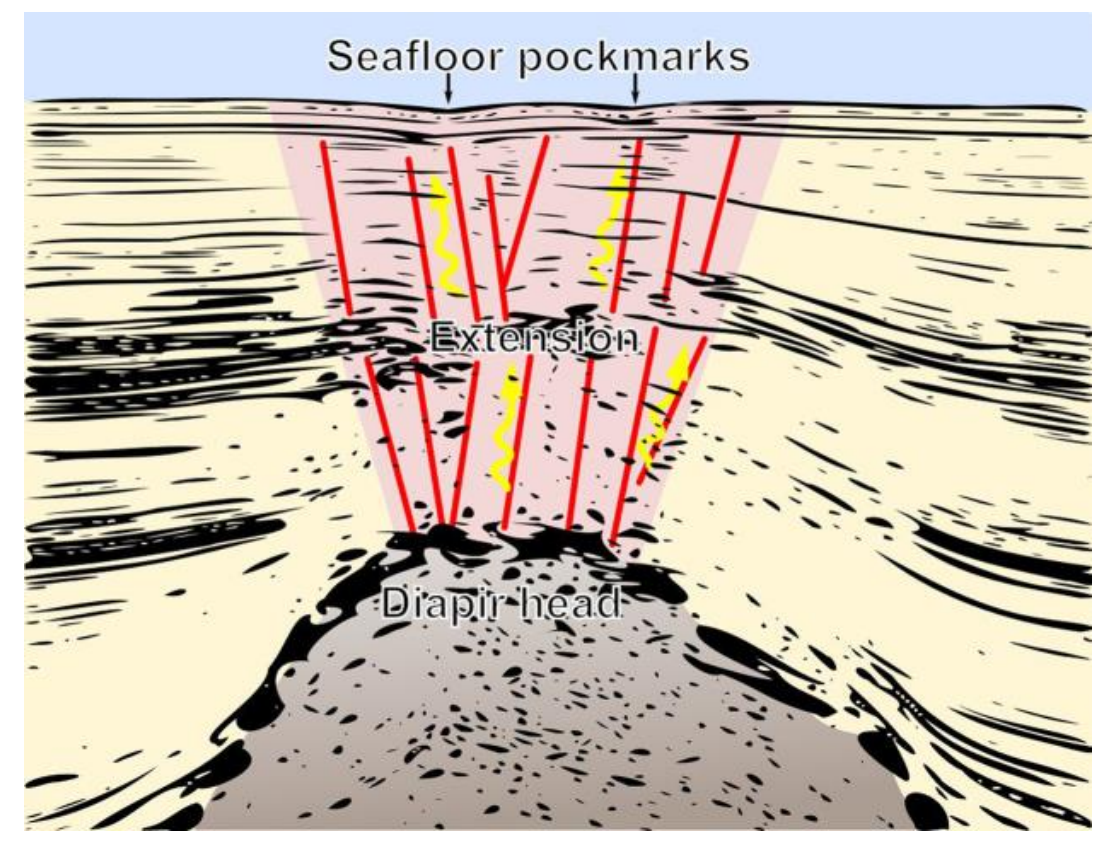

Figura 1 - llustração esquemática do diápiro ascendendo. A presença de falhas acima do diápiro facilita a percolação de gás devido ao aumento da permeabilidade, formando os pockmarks e influenciando na formação da espessura das camadas de sal (MAHIQUES et al., 2017).

Os pockmarks são depressões circulares associadas às emanações frias, que ocorrem tanto nas regiões costeiras (KELLEY et al., 1994; BROTHERS et al., 2011 e 2012), como nas plataformas e taludes continentais (KING \& MACLEAN, 1970; GAY et al., 2006). Eles não possuem nenhuma restrição geográfica e foram observados em altas latitudes (SOLHEIM \& ELVERHØI, 1985; GARCÍA et al., 2009) e zonas tropicais e equatoriais (ROLLET et al., 2006; PILCHER \& ARGENT, 2007).

Podem ser atribuídos à expulsão de grandes volumes de gases ao longo do leito marinho, principalmente metano e outros fluidos de baixa permeabilidade (HOVLAND \& JUDD, 1988). O gás pode migrar pra cima através de falhas e pela litologia porosa até que seja bloqueado por uma camada de vedação ou ser liberados no fundo do mar. A permeabilidade da camada de vedação e a tensão da camada sedimentar controlam a taxa de vazamentos de gás/fluido do reservatório para a superfície. Uma diminuição da tensão da camada sedimentar pode levar à expulsão violenta e a formação de pockmarks (RIBOULOT et al., 2013). Podem permanecer ativos, ou seja, os gases são liberados lentamente por longos períodos, abastecendo diversas comunidades bentônicas quimiossimbióticas (HOVLAND et al, 1987; DANDO et 
al, 1991; ONDRÉAS et al., 2005; SAHLING et al., 2008), ou podem se manter dormentes entre os episódios de liberação, entretanto, na maioria das áreas, 0 tempo de liberação e dormência são desconhecidos. JUDD \& HOVLAND (2007) levantaram a hipótese de que a maioria dos pockmarks descobertos até o momento estão de fato inativos, porém, evidências de exsudações próximos à região de estudo são descritos por KOWSMANN \& CARVALHO, (2002).

A presença contínua de emanações frias, por grandes períodos geológicos, leva ao desenvolvimento de uma topografia com características únicas, onde as reações entre o metano e a água intersticial, rica em íons sulfato, produzem a precipitação de carbonatos, em função da oxidação anaeróbica do metano e da redução de sulfatos (THIEL et al., 1999; MERINERO, 2008). KOWSMANN \& CARVALHO (2002) descreveram pilares carbonáticos expostos pela erosão do leito do mar durante o último mínimo Glacial na parte superior do talude continental da Bacia de Santos (aproximadamente $22^{\circ} \mathrm{S}$ e $40^{\circ} \mathrm{O}$ ). Os reservatórios de sal dos diápiros ao longo da Bacia de Santos são, provavelmente, uma das possíveis origens desses pockmarks na área de estudo (Figura 1).

SUMIDA et al. (2004) reconheceram a existência de depressões circulares no fundo do mar. A presença de corais e a fauna associada foi relacionada aos pockmarks que, segundo os autores chegam a diâmetros maiores que $1 \mathrm{~km}$ e profundidades maiores do que 100 metros abaixo da topografia adjacente. Provas convincentes vieram da ocorrência de densas populações endêmicas do molusco Calyptogena birmani. Este grupo de bivalves é normalmente encontrado em ambientes reduzidos, tais como as fontes hidrotermais e emanações frias de metano (TURNER, 1985; BENNETT et al., 1994).

A maior parte do talude continental não possui um detalhamento geoquímico orgânico, sendo que a maior parte das pesquisas são direcionadas na plataforma continental, especialmente em suas partes internas e médias. Isso se deve aos elevados custos dos cruzeiros oceanográficos e da grande dificuldade de manusear tais instrumentos em grandes profundidades. Dessa maneira, este estudo visa caracterizar geoquímicamente os diápiros e pockmarks a fim de compreender as fontes terrígenas e marinhas da matéria orgânica na região de estudo. 
Através do uso de marcadores moleculares ou biomarcadores, é possível avaliar as fontes de matéria orgânica de origem natural em uma região (COSTA et al., 2010). São substâncias caracterizadas pela resistência aos processos de degradação, já que possuem propriedades químicas que as tornam resistentes no meio ambiente, sofrendo pouca ou nenhuma modificação ao longo do tempo (COLOMBO et al., 1989). Alguns dos principais marcadores geoquímicos associados às atividades biogênicas são os $n$-alcanos, $n$-alcanóis, alquenonas, ácidos graxos, esteróis, hidrocarbonetos alifáticos (HAs) e hidrocarbonetos policíclicos aromáticos (HPAs), sendo os $n$-alcanos, $n$-alcanóis e esteróis os compostos que serão analisados neste trabalho.

\subsection{Marcadores Orgânicos Moleculares}

1.2.1. Hidrocarbonetos Alifáticos (HAs)

Os hidrocarbonetos alifáticos correspondem a um amplo grupo de compostos orgânicos de baixa polaridade que apresentam átomos de carbono e hidrogênio estruturados em cadeias abertas ou fechadas não aromáticas. Como exemplo temos os $n$-alcanos e alcanos isoprenóides, que são hidrocarbonetos saturados, de cadeia aberta e sem ramificações, que podem ser sintetizados por organismos terrestres, como plantas superiores, bactérias e fungos, ou organismos aquáticos, como o fitoplâncton e o zooplâncton (COLOMBO et al., 1989). Podem ser associados as emanações naturais de petróleo a partir de fendas submarinas e erosão de rochas antigas (TISSOT \& WELTE, 1978). Deste modo, a distribuição de hidrocarbonetos alifáticos no ambiente pode variar muito de uma região para outra.

É possível diferenciar a fonte desses hidrocarbonetos através do tamanho da cadeia carbônica (Tabela 1). Compostos de origem terrestre tendem a apresentar cadeias maiores, enquanto hidrocarbonetos de origem marinha tendem a serem menores (DUAN, 2000; SILLIMAN \& SCHELSKE, 2003). As fontes naturais como as microalgas e cianobactérias, são identificadas pela predominância de $n$-alcanos de cadeias curtas e ímpares, 
com a dominância de $n$ - $\mathrm{C}_{15}, n-\mathrm{C}_{17}, n-\mathrm{C}_{19}$ (BLUMER et al., 1971; VOLKMAN et al., 1992).

As macrófitas aquáticas são caracterizadas por conter $n$-alcanos de cadeias médias e impares $n$ - $\mathrm{C}_{21}, n-\mathrm{C}_{23}, n$-C 25 (BRAY \& EVANS, 1961; COLOMBO et al., 1989). A presença de $n$-alcanos pares $n$ - $\mathrm{C}_{12}, n-\mathrm{C}_{14}, n-\mathrm{C}_{16}$ podem apontar a presença de microorganismos como fungos, bactérias e leveduras. No entanto, cadeias longas entre $n-C_{24}$ a $n$ - $C_{34}$ também podem indicar a presença de bactérias (NISHIMURA \& BAKER, 1986, WANG et al., 2010).

Os aportes naturais de origem terrestre, associados principalmente às plantas superiores, são constituídos, em sua maioria, por $n$-alcanos derivados de ceras cuticulares, que oferecem proteção contra dessecação (BRASSEL, 1993). São caracterizados por compreender os $n$-alcanos de maior massa molar e com o predomínio de cadeias ímpares entre $n-\mathrm{C}_{23}$ a $n-\mathrm{C}_{35}$ (SALIOT et al., 1991; VOLKMAN et al., 1992), com destaque aos compostos mais abundantes $n-\mathrm{C}_{27}, n-\mathrm{C}_{29}$ e $n$ - $\mathrm{C}_{31}$, conforme características da vegetação local (EGLINTON \& HAMILTON, 1967) e líquens (ANDERSSON \& MEYERS, 2012; ALVES et al., 2010). O n-C $\mathrm{C}_{31}$ e $\circ n-\mathrm{C}_{33}$ são característicos por dominar as gramíneas e ervas, enquanto o $n-\mathrm{C}_{27}$ e $\circ n-\mathrm{C}_{29}$ foram relatados por dominar a maioria das árvores e arbustos (ZECH et al., 2009).

As diferentes fontes e as principais propriedades físico-químicas dos hidrocarbonetos determinam seu destino no ambiente marinho. Devido a sua baixa solubilidade na água e a natureza hidrofóbica, os hidrocarbonetos tendem a se associar com o material particulado, no qual poderão finalmente ser acumulados no sedimento (TOLOSA et al., 2004). A estabilidade química e a resistência aos processos de degradação no ambiente são características que possibilitam classificar os hidrocarbonetos como marcadores geoquímicos, já que apresentam uma estrutura molecular estável de modo a sofrer pouca ou nenhuma alteração ao longo do tempo (YUNKER et al., 2003). 
Tabela 1 - Síntese da distribuição dos $n$-alcanos nos principais organismos que contribuem para a introdução destes compostos no ambiente marinho (modificado de PHILP, 1985)

\begin{tabular}{|c|c|c|c|c|}
\hline Organismos & Ambiente & Carbono dominante & $\begin{array}{c}\text { Faixa de números de átomos de } \\
\text { carbonos }\end{array}$ & Referências \\
\hline $\begin{array}{l}\text { Bactérias } \\
\text { fotossintéticas }\end{array}$ & $\begin{array}{l}\text { Aquático } \\
\text { (pelágico) }\end{array}$ & $n-\mathrm{C}_{17}, n-\mathrm{C}_{26}$ & $n-\mathrm{C}_{14}-n-\mathrm{C}_{29}$ & CRAWELL et al., 1987 \\
\hline \multirow{3}{*}{$\begin{array}{l}\text { Bactérias não } \\
\text { fotossintéticas }\end{array}$} & & $\begin{array}{c}n-\mathrm{C}_{17} \text { a } n-\mathrm{C}_{20} ; n-\mathrm{C}_{17} \mathrm{e} \\
n-\mathrm{C}_{25}\end{array}$ & $\begin{array}{c}n-\mathrm{C}_{15}-n-\mathrm{C}_{28} ; \mathrm{n}-\mathrm{C}_{15}-\mathrm{n}-\mathrm{C}_{29} ; n-\mathrm{C}_{15}- \\
n-\mathrm{C}_{29}\end{array}$ & HAN \& CALVIN, 1969 \\
\hline & Aquático (bêntico) & $n-C_{12}, n-C_{14}, n-C_{16}$ & $n-C_{11}-n-C_{16}$ & $\begin{array}{l}\text { VENKATESAN \& KAPLAN, 1982; } \\
\text { EKPO et al., } 2005\end{array}$ \\
\hline & & $n-\mathrm{C}_{12}-n-\mathrm{C}_{24}$ & $n-\mathrm{C}_{12}-n-\mathrm{C}_{26}$ & $\begin{array}{c}\text { COLOMBO et al., 1989; } \\
\text { ABOUL-KASSIM \& SIMONEIT, } \\
1995\end{array}$ \\
\hline Fungos & Terrestre & $n-\mathrm{C}_{29}$ & $n-\mathrm{C}_{25}-n-\mathrm{C}_{29}$ & YEN, 1975 \\
\hline Cianobactérias & $\begin{array}{l}\text { Aquático } \\
\text { (pelágico) }\end{array}$ & $n-C_{17}$ & $n-\mathrm{C}_{14}-n-\mathrm{C}_{19}$ & BLUMER et al., 1971 \\
\hline Algas verdes & $\begin{array}{l}\text { Aquático } \\
\text { (pelágico) }\end{array}$ & $n-\mathrm{C}_{15}$ & $n-\mathrm{C}_{15}-n-\mathrm{C}_{21}$ & GELPI et al., 1970 \\
\hline Algas pardas & Aquático (bêntico) & $n-C_{17}$ & $n-C_{13}-n-C_{26}$ & YOUNGBLOOD \& BLUMER, 1973 \\
\hline $\begin{array}{c}\text { Algas } \\
\text { vermelhas }\end{array}$ & Aquático (bêntico) & $n-\mathrm{C}_{18}$ e $n-\mathrm{C}_{24}$ & $n-\mathrm{C}_{15}-n-\mathrm{C}_{24}$ & YOUNGBLOOD et al., 1971 \\
\hline Zooplâncton & $\begin{array}{l}\text { Aquático } \\
\text { (pelágico) }\end{array}$ & $n-\mathrm{C}_{18}$ e $n-\mathrm{C}_{24}$ & $n-\mathrm{C}_{18}-n-\mathrm{C}_{34}$ ou $n-\mathrm{C}_{20}-n-\mathrm{C}_{28}$ & CRAWELL et al., 1987 \\
\hline
\end{tabular}


Plantas

superiores
$n-\mathrm{C}_{27}, n-\mathrm{C}_{29}$ ou $n-\mathrm{C}_{31}$

$n-\mathrm{C}_{33}$
$n-\mathrm{C}_{15}-n-\mathrm{C}_{37}$

$n-\mathrm{C}_{27}-n-\mathrm{C}_{33}$
CALDICOTT, 1973

CELINO et al., 2007 
HORIKAWA et al. (2010) observaram que a adaptação fisiológica das plantas sob estresse hídrico faz com que haja uma diferença entre a distribuição dos homólogos $n-C_{31}$ e $n$ - $C_{29}$, uma vez que as plantas terrestres tendem a produzir n-alcanos com cadeias carbônicas maiores para promover uma cobertura de cera mais eficiente e assim evitar a perda de água (RULLKÖTTER, 2006; SACHSE et al., 2006). Plantas terrestres sob um maior estresse hídrico exibem o máximo da distribuição de $n$-alcanos no $n$ - $C_{31}$, enquanto as de clima mais úmido possuem máximo no $n$-C $\mathrm{C}_{29}$. Há ainda uma distinção entre os $n$-alcanos de origem terrígena introduzidos por plantas vasculares $\left(\mathrm{C}_{3}\right)$ e aqueles produzidos por gramíneas ( $\left.\mathrm{C}_{4}\right)$ (ZHANG et al., 2006). Plantas de clima mais seco e/ou do tipo $\mathrm{C}_{4}$ exibem o máximo da distribuição de n-alcanos no $n$ - $\mathrm{C}_{31}$ e $n$ - $\mathrm{C}_{33}$, plantas de clima mais úmido e/ou do tipo $\mathrm{C}_{3}$ possuem máximo no $n-\mathrm{C}_{27}$ e $n$ - $\mathrm{C}_{29}$ (ZHANG et al., 2006).

Os alcanos isoprenóides são hidrocarbonetos de cadeia ramificada com estrutura molecular derivada do isopreno $\left(\mathrm{C}_{5} \mathrm{H}_{8}\right)$. O fitano $(2,6,10,14-$ tetrametilhexadecano) e o pristano (2,6,10,14-tetrametilpentadecano) são gerados a partir da degradação do fitol $\left(\mathrm{C}_{20} \mathrm{H}_{40} \mathrm{O}\right)$, que é um álcool abundante na natureza e constituinte da clorofila-a. A formação do pristano é associada a condições oxidantes do ambiente marinho, enquanto que a formação do fitano é associado a condições redutoras (VOLKMAN et al., 1992).

A formação do pristano é favorecida nos sedimentos recentes, sendo o pristano encontrado em concentrações superiores ao fitano no meio marinho (CRIPPS, 1989). Este fato sugere que a formação do fitano talvez ocorra após a decomposição da matéria orgânica no sedimento e que o processo de transformação do fitol em fitano é muito lento em sedimentos recentes, ocorrendo somente em sedimentos antigos (VOLKMAN et al., 1992). O pristano faz parte da composição lipídica de algumas espécies de zooplâncton, fitoplâncton e bactérias (MEDEIROS et al., 2005; VOLKMAN, 2006) enquanto que o fitano pode ser originado a partir de lipídios de arqueobactérias metanogênicas e da degradação química de lipídeos naturais (READMAN et al., 2002; VOLKMAN, 2006). 


\subsubsection{Esteróis}

Os esteróis são lipídios pertencentes ao grupo dos álcoois, pois apresentam um grupo hidroxila na posição três. Sua estrutura química é formada por um esqueleto carbônico básico, contendo de 17 a 29 átomos de carbono. São compostos constituídos de anéis alifáticos na sua estrutura, podendo apresentar cadeia carbônica lateral na posição $C_{17}$ e grupos metila nas posições $\mathrm{C}_{10}$ e $\mathrm{C}_{13}$ (Figura 2). A presença ou ausência da instauração no sistema de anéis e o comprimento da cadeia carbônica alifática na posição $C_{17}$ são os responsáveis por diversos tipos de esteróis (MEYERS et al., 1994).

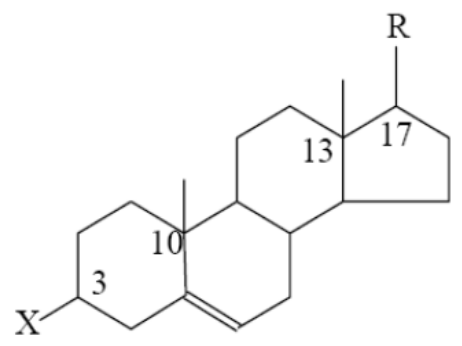

$-\mathrm{X}:-\mathrm{OH},=\mathrm{O}$

$-\mathrm{R}: \mathrm{M},-\mathrm{OH},-\mathrm{H}$, etc.

Figura 2 - Estrutura básica dos esteróis.

Devido alguns esteróis estarem amplamente distribuídos e outros existirem em grupos específicos de eucariontes, perfis moleculares de esteróis têm sido frequentemente aplicados na avaliação de fontes biológicas da matéria orgânica sedimentar (HUANG \& MEINSCHEIN, 1979; HARVEY, 1994; CARREIRA et al, 2002). Desse modo, são utilizados em estudos ecológicos para descrever ciclos sazonais na qualidade e degradação da matéria orgânica sedimentar (GRIMALT et al., 1990). São caracterizados como hidrofóbicos, cuja origem pode ser natural, tendo como distinção entre contribuições marinhas (fitoplâncton, zooplâncton, macroalgas, dinoflagelados e bactérias) ou terrestres (plantas vasculares e bactérias) (HUDSON et al., 2001; MADUREIRA, 2002), além de serem indicadores de poluição fecal, devido ao lançamento de efluentes urbanos e industriais, no qual o homem é a sua principal fonte (MOSS, 1989; BRAUN,2006). 
Os esteróis podem se associar ao material particulado devido ao caráter lipofílico e apresentam resistência à degradação anaeróbica, se acumulando nos resíduos sólidos e nos sedimentos, permanecendo nas matrizes por longos períodos, viabilizando a sua determinação (NGUYEN et al., 1995; HUDSON et al., 2001; AZEVEDO, 2003).

Os esteróis de origem biogênica são: colesterol, brassicasterol, dehidrocolesterol, dinosterol, campesterol, estigmasterol, $\beta$-sitosterol e suas moléculas não insaturadas (colestanol, brassicastanol, dehidrocolestanol, campestanol, estigmastanol e sitostanol) (Figura 5). São encontrados nos sedimentos alguns esteróis em pares, ou seja, o esterol parental e o isômero não insaturado (VOLKMAN, 2005). A conversão do isômero insaturado para o não insaturado por bactérias é lenta em superfícies bem oxigenadas, de modo que a proporção entre o composto parental e 0 não insaturado pode indicar processos de preservação e degradação da matéria orgânica (JENG \& HUH, 2004), com exceção do colestanol, que é biossintetizado por organismos planctônicos (MUDGE et al., 1999).

O colesterol (5-colesteno-3 $\beta$-ol), está presente em algumas espécies de microalgas, cianobactérias, no zooplâncton, e nas suas pelotas fecais, sendo esta a principal fonte de colesterol para o sedimento marinho (VOLKMAN, 1986).

O brassicasterol e o dehidrocolesterol estão presentes em regiões onde há a presença de florações fitoplanctônicas como as diatomáceas, primnesiófitas e dinoflagelados (VOLKMAN, 1986; MUDGE et al., 1999).

O $\beta$-sitosterol (24-etil-5-colesteno-3ß-ol) e o estigmasterol (24-etil-5,22colestdieno-3ß-ol), são comumente associados ao aporte de plantas superiores, diatomáceas e dinoflagelados (VOLKMAN, 1986; PENG et al., 2005).

O campesterol (24-metil-5-colesteno-3 $\beta$-ol), é um esterol $\mathrm{C}_{28}$, que pode estar relacionado com a presença de fungos (VOLKMAN, 2003), ou seja, são utilizados como marcadores de matéria orgânica terrígena.

O dinosterol e seus produtos de degradação são esteróis específicos, sendo relacionado à presença de dinoflagelados (VOLKMAN, 1986). A Tabela 2 relaciona vários esteróis com suas respectivas fontes de origem. 
Tabela 2 - Fontes e origens dos esteróis utilizados neste trabalho.

\begin{tabular}{|c|c|c|c|c|c|}
\hline Nome usual & Fórmula & $\begin{array}{l}\text { Massa molecular } \\
(\mathrm{g} / \mathrm{mol})\end{array}$ & Fonte(s) & Origem & Referência \\
\hline $\begin{array}{c}\text { Dehidrocolesterol } \\
\qquad\left(27 \Delta^{5,22 E}\right)\end{array}$ & & 384 & Fitoplâncton & Marinha & $\begin{array}{c}\text { MUDGE et al., } \\
1999\end{array}$ \\
\hline $\begin{array}{l}\text { Colesterol } \\
\qquad\left(27 \Delta^{5}\right)\end{array}$ & $\mathrm{C}_{27} \mathrm{H}_{46} \mathrm{O}$ & 386 & $\begin{array}{c}\text { Zoo, fitoplâncton e } \\
\text { organismos da } \\
\text { fauna } \\
\text { marinha }\end{array}$ & Marinha & $\begin{array}{l}\text { MUDGE et al., } \\
1999 ; \\
\text { VOLKMAN, } \\
2005\end{array}$ \\
\hline Colestanol & $\mathrm{C}_{27} \mathrm{H}_{48} \mathrm{O}$ & 388 & Diatomáceas & Marinha & \\
\hline $\begin{array}{c}\text { Brassicasterol } \\
\qquad\left(28 \Delta^{5,22 E}\right)\end{array}$ & $\mathrm{C}_{28} \mathrm{H}_{46} \mathrm{O}$ & 398 & $\begin{array}{c}\text { Blooms de } \\
\text { diatomáceas, } \\
\text { primnesiófitas e } \\
\text { dinoflagelados }\end{array}$ & Marinha & $\begin{array}{l}\text { VOLKMAN, } \\
\text { 1986; MUDGE } \\
\text { et al., } 1999\end{array}$ \\
\hline Brassicastanol & $\mathrm{C}_{28} \mathrm{H}_{48} \mathrm{O}$ & 400 & $\begin{array}{c}\text { Idem ao } \\
\text { Brassicasterol }\end{array}$ & Marinha & \\
\hline $\begin{array}{l}\text { Campesterol } \\
\qquad\left(28 \Delta^{5}\right)\end{array}$ & $\mathrm{C}_{28} \mathrm{H}_{42} \mathrm{O}$ & 400 & $\begin{array}{c}\text { Plantas superiores, } \\
\text { clorófitas e } \\
\text { primnesiófitas }\end{array}$ & $\begin{array}{l}\text { Terrestre } \\
\text { Marinha }\end{array}$ & $\begin{array}{l}\text { VOLKMAN, } \\
\text { 1986; } \\
\text { LAUREILLARD } \\
\text { et al., }\end{array}$ \\
\hline
\end{tabular}




\begin{tabular}{|c|c|c|c|c|c|}
\hline & & & & & 1993 \\
\hline Campestanol & $\mathrm{C}_{28} \mathrm{H}_{50} \mathrm{O}$ & 402 & $\begin{array}{c}\text { Idem ao } \\
\text { Campesterol }\end{array}$ & $\begin{array}{l}\text { Terrestre } \\
\text { Marinha }\end{array}$ & \\
\hline $\begin{array}{l}\text { Estigmasterol } \\
\qquad\left(29 \Delta^{5,22 \mathrm{E}}\right)\end{array}$ & $\mathrm{C}_{29} \mathrm{H}_{48} \mathrm{O}$ & 412 & $\begin{array}{l}\text { Plantas superiores } \\
\text { (podem ser } \\
\text { encontrados em } \\
\text { primnesiófitas e } \\
\text { diatomáceas) }\end{array}$ & $\begin{array}{l}\text { Terrestre } \\
\text { Marinha }\end{array}$ & $\begin{array}{c}\text { VOLKMAN, } \\
\text { 1986; } \\
\text { LAUREILLARD } \\
\text { et al., } \\
1993\end{array}$ \\
\hline Estigmastanol & $\mathrm{C}_{29} \mathrm{H}_{50} \mathrm{O}$ & 414 & $\begin{array}{c}\text { Idem ao } \\
\text { Estigmasterol }\end{array}$ & $\begin{array}{l}\text { Terrestre } \\
\text { Marinha }\end{array}$ & \\
\hline $\begin{array}{c}\text { Sitosterol } \\
\left(29 \Delta^{5}\right)\end{array}$ & $\mathrm{C}_{29} \mathrm{H}_{50} \mathrm{O}$ & 414 & $\begin{array}{c}\text { Plantas superiores e } \\
\text { microalgas } \\
\text { (primnesiófitas e } \\
\text { cianobactérias) }\end{array}$ & $\begin{array}{l}\text { Terrestre } \\
\text { Marinha }\end{array}$ & $\begin{array}{l}\text { VOLKMAN, } \\
\text { 1986; } \\
\text { MUDGE et al., } \\
1999\end{array}$ \\
\hline Sitostanol & $\mathrm{C}_{29} \mathrm{H}_{52} \mathrm{O}$ & 416 & Idem ao Sitosterol & & \\
\hline $\begin{array}{c}\text { Dinosterol } \\
\left(30 \Delta^{22 \mathrm{E}}\right)\end{array}$ & $\mathrm{C}_{30} \mathrm{H}_{52} \mathrm{O}$ & 428 & Dinoflagelados & Marinha & $\begin{array}{c}\text { VOLKMAN, } \\
1986\end{array}$ \\
\hline Dinostanol & $\mathrm{C}_{30} \mathrm{H}_{54} \mathrm{O}$ & 430 & Idem ao Dinosterol & Marinha & $\begin{array}{c}\text { VOLKMAN, } \\
1986\end{array}$ \\
\hline
\end{tabular}




\subsection{3. Álcoois lineares}

Os álcoois são compostos saturados de carbono e hidrogênio, dispostos em uma cadeia linear com um grupo funcional $(-\mathrm{OH})$. A composição de álcoois em sedimentos marinhos é originada através de ésteres de ácidos graxos, utilizados para avaliar as contribuições marinhas e terrígenas da matéria orgânica sedimentar (SEGUEL et al., 2001, MUDGE et al., 1999).

Apresentam cadeia carbônica entre $\mathrm{C}_{12}-\mathrm{OH}$ a $\mathrm{C}_{32}-\mathrm{OH}$ (VOLKMAN, 1986) e através do seu tamanho é possível indicar a origem desses compostos para os sedimentos. Exibem um forte predomínio de números pares de átomos de carbono sobre os ímpares (JAFFÉ et al., 2001), uma vez que os álcoois são biossintetizados a partir de ácidos graxos por redução enzimática, onde não ocorre perda ou ganho de átomos de carbono na cadeia.

Quanto a sua origem (Tabela 3), os álcoois de cadeia curta com menor massa molar $\left(<\mathrm{C}_{22}-\mathrm{OH}\right)$ são produzidos por fitoplâncton, zooplâncton e bactérias, sendo que o fitoplâncton e as bactérias produzem principalmente 0 $\mathrm{C}_{16}-\mathrm{OH}$ e os compostos de cadeia $\mathrm{C}_{18}-\mathrm{OH}$ podem ser atribuídos ao zooplâncton (WAKEHAM et al., 1980).

Os álcoois de cadeia longa, com alta massa molar $\left(>\mathrm{C}_{22}-\mathrm{OH}\right)$ são geralmente encontrados em sedimentos recentes, indicando aportes de vegetais terrestre, devido à presença desses compostos nas ceras epicuticulares de vegetais superiores (FERNANDES et al., 1999; SALIOT et al., 2002; JENG et al., 2004; TREIGNIER et al., 2006), predominantemente os compostos $\mathrm{C}_{22}-\mathrm{OH}$ e $\mathrm{C}_{24}-\mathrm{OH}$, são derivados de folhas cuticulares de vegetais terrestres, cuja função é reduzir a evaporação de água (MUDGE et al., 1999) (Tabela 3). Desta forma, a distinção entre o somatório dessas contribuições relativas de álcoois lineares de cadeia curta e longa pode servir como ferramenta para inferir sobre a origem da matéria orgânica sedimentar. 
Tabela 3 - Álcoois lineares com as devidas nomenclaturas, números de carbonos e de ligações duplas em cada molécula, origem e referência.

\begin{tabular}{|c|c|c|}
\hline Abreviações & Origem & Referência \\
\hline $\mathrm{C}_{12}-\mathrm{OH}$ & \multirow{7}{*}{$\begin{array}{l}\text { Fitoplâncton e } \\
\text { Zooplâncton }\end{array}$} & \multirow{7}{*}{$\begin{array}{c}\text { (FERNANDES et al., } 1999 \\
\text { VOLKMAN, 2005) }\end{array}$} \\
\hline $\mathrm{C}_{13}-\mathrm{OH}$ & & \\
\hline $\mathrm{C}_{14-} \mathrm{OH}$ & & \\
\hline $\mathrm{C}_{16}-\mathrm{OH}$ & & \\
\hline $\mathrm{C}_{18-} \mathrm{OH}$ & & \\
\hline $\mathrm{C}_{20}-\mathrm{OH}$ & & \\
\hline $\mathrm{C}_{21}-\mathrm{OH}$ & & \\
\hline $\mathrm{C}_{22}-\mathrm{OH}$ & \multirow{11}{*}{$\begin{array}{c}\text { Plantas } \\
\text { superiores }\end{array}$} & \multirow{11}{*}{$\begin{array}{l}\text { (FERNANDES et al., } 1999 \\
\text { VOLKMAN, 2005) }\end{array}$} \\
\hline $\mathrm{C}_{23}-\mathrm{OH}$ & & \\
\hline $\mathrm{C}_{24}-\mathrm{OH}$ & & \\
\hline $\mathrm{C}_{25}-\mathrm{OH}$ & & \\
\hline $\mathrm{C}_{26}-\mathrm{OH}$ & & \\
\hline $\mathrm{C}_{27}-\mathrm{OH}$ & & \\
\hline $\mathrm{C}_{28}-\mathrm{OH}$ & & \\
\hline $\mathrm{C}_{29}-\mathrm{OH}$ & & \\
\hline $\mathrm{C}_{30}-\mathrm{OH}$ & & \\
\hline $\mathrm{C}_{31}-\mathrm{OH}$ & & \\
\hline $\mathrm{C}_{32}-\mathrm{OH}$ & & \\
\hline
\end{tabular}

Geralmente o estudo da distribuição dos álcoois está relacionado a outros compostos, tais como os esteróis, uma vez que possuem modificações diagenéticas semelhantes, com taxas de degradação igualmente baixas. Vários pesquisadores utilizam essa distribuição para que, juntamente com outros parâmetros, possam inferir sobre a origem (terrestre ou marinha) de um determinado aporte sedimentar (KAWAMURA et al., 1987; CRANWEL et al., 1987; JAFFÉ et al., 2001). 


\subsubsection{Carbonato de Cálcio}

$\mathrm{O}$ carbonato de cálcio $\left(\mathrm{CaCO}_{3}\right)$ corresponde a um dos principais componentes biogênicos dos sedimentos marinhos. $\mathrm{O}$ acúmulo de $\mathrm{CaCO}_{3}$ depende da produção fitoplanctônica e bentônica e da dissolução na coluna d'água durante a sedimentação.

Em ambientes próximos à costa e nas plataformas continentais as principais fontes de acumulação de carbonato são os organismos bentônicos, tais como, moluscos, briozoários, algas, equinodermas e corais. Em contrapartida, a produção de carbonato no talude e no ambiente pelágico dos oceanos é feita quase que exclusivamente por organismos planctônicos, principalmente cocolitoforídeos, foraminíferos e em menor dimensão por pterópodas e dinoflagelados calcários (RÜHLEMAN et al. 1999).

As variações na produtividade planctônica, dissolução das testas calcárias durante e após a deposição e a diluição por material não-carbonático através do aumento no aporte de material terrígeno são fatores que governam o conteúdo de $\mathrm{CaCO}_{3}$ encontrados nos sedimentos (DAMUTH, 1975; VOLAT et al., 1980).

\subsection{Composição elementar}

Os principais elementos constituintes da matéria orgânica são o carbono $(C)$, hidrogênio $(H)$, nitrogênio $(N)$, oxigênio $(O)$, enxofre $(S)$ e o fosforo (P) (EMERSON \& HEDGES, 2008), que são capazes de fornecer informações sobre as fontes e a ciclagem da matéria orgânica sedimentar. O conteúdo de carbono orgânico nos sedimentos superficiais depende de uma série de fatores, tais como as características sedimentares, produtividade da coluna d'água, taxa de degradação microbiana, além das condições oceanográficas locais. De acordo com Rashid, 1985, um baixo conteúdo de carbono orgânico $(<0,5 \%)$ é típico das bacias oceânicas, particularmente ás de mares abertos.

Em algumas áreas do oceano foi assumido que o fluxo de carbono orgânico que chega ao sedimento é proporcional à sua produção exportada da 
superfície dos oceanos. No entanto, há uma forte dependência da profundidade, devido aos processos de degradação na coluna de água. Além disso, apenas uma pequena fração da matéria orgânica, que chega ao sedimento, é soterrada (PAYTAN, 2006). As concentrações de nitrogênio orgânico aumentam em direção às áreas costeiras, particularmente em regiões onde ocorre a ressurgência de águas profundas.

A composição elementar é uma ferramenta muito usada para distinguir as origens autóctone (produção interna) e alóctone (terrestre) da matéria orgânica, devido as diferenças nos componentes estruturais das fontes (carboidratos, proteínas, lipídios, etc) que compõe a matéria orgânica depositada de cada grupo de organismo (MEYERS et al., 1994), ou seja, diversos grupos de organismos produzem matéria orgânica contendo diferentes conteúdos de C e N (STEIN, 1991). As plantas terrestres são constituídas por compostos ricos em carbono, como a lignina e a celulose, elevando a razão $\mathrm{C} / \mathrm{N}$, visto que possuem menos $\mathrm{N}$, enquanto as proteínas, mais abundantes na matéria orgânica algal, reduzem a razão $\mathrm{C} / \mathrm{N}$ devido ao seu alto teor de $\mathrm{N}$ e ausência de celulose (BIANCHI \& CANUEL, 2011, MEYERS, 1997). As algas marinhas apresentam valores de $\mathrm{C} / \mathrm{N}$ que variam entre 4 e 8 , enquanto que as plantas terrestres possuem valores de C/N acima de 12 (MEYERS, 1997; PRAHL et al., 1980).

A utilização da razão $\mathrm{C} / \mathrm{N}$ requer alguns cuidados, pois a degradação seletiva de alguns compostos durante a diagênese pode aumentar os valores de $\mathrm{C} / \mathrm{N}$ na matéria orgânica sedimentar, devido a ação de microorganismos que utilizam o $\mathrm{N}$ como fonte de energia (BIANCHI \& CANUEL, 2011). A granulometria é outro fator que interfere na razão $\mathrm{C} / \mathrm{N}$. O efeito do tamanho do grão reflete dois fatores: os tipos de detritos orgânicos e as composições minerais, que variam de acordo com o tamanho da partícula. Sedimentos mais grossos podem conter uma proporção maior de detritos de plantas terrestres intactas em relação as frações mais finas, desse modo, apresentam elevadas taxas de $\mathrm{C} / \mathrm{N}$, no entanto, sedimentos mais finos podem conter maiores proporções de minerais de argila, que apresentam maior superfície de contato e cargas elétricas negativas dos grãos e portanto, absorvem bem a amônia, gerando valores mais baixos de C/N (MEYERS, 1997), normalmente verificado em oceanos profundos, no qual o carbono orgânico apresenta baixos valores. 
No geral, as concentrações de nitrogênio inorgânico são menores em comparação ao nitrogênio orgânico, gerando razões de $\mathrm{C} / \mathrm{N}$ que fielmente representam a origem da matéria orgânica. Amostras contendo uma baixa concentração de matéria orgânica podem conter uma alta fração de nitrogênio inorgânico, que por sua vez acaba gerando valores subestimados da razão $\mathrm{C} / \mathrm{N}$ (MEYERS, 1997).

A natureza do nitrogênio (orgânico ou inorgânico) pode ser verificada através da plotagem dos teores de carbono orgânico em relação aos teores de nitrogênio total. Uma correlação linear positiva confirma a natureza orgânica do nitrogênio e valida a utilização da razão $\mathrm{C} / \mathrm{N}$ para avaliar a fonte da matéria orgânica sedimentar (continental/marinha). No caso de uma correlação linear fraca, os valores da razão $\mathrm{C} / \mathrm{N}$ podem ser subestimados, em função do nitrogênio total não ser de origem essencialmente orgânica.

A razão $\mathrm{C} / \mathrm{N}$ é uma maneira de inferir a provável fonte da $\mathrm{MO}$, entretanto é necessário o uso de outras ferramentas para complementar os resultados, tornando as conclusões mais robustas.

\subsection{Isótopos Estáveis}

Isótopos são espécies atômicas de um mesmo elemento químico que possuem massas diferentes, pelo fato do número de nêutrons em seus núcleos ser distinto. São bons traçadores naturais, sendo bem preservadas ao longo dos processos de mineralização, transporte e acumulação no sedimento (BOUILLON et al., 2011). A aplicação do uso de isótopos estáveis como traçadores naturais da origem da matéria orgânica está baseada nas diferenças de suas assinaturas entre as fontes, baseado principalmente nas variações da concentração relativa do isótopo mais leve a partir de processos bióticos (respiração, fotossíntese, etc.) e abióticos (precipitação, evaporação, congelamento, etc.), sendo a fotossíntese o processo mais importante (WHITE, 2011). A composição isotópica do carbono orgânico, durante a fotossíntese, é controlada pelas fontes de carbono, pelo fracionamento durante os processos de assimilação, de metabolismo e de biossíntese (BIANCHI \& CANUEL, 2011).

Produtos de reações na natureza são geralmente enriquecidos de isótopos leves devido à cinética da reação mais rápida do isótopo mais leve de 
um determinado elemento, uma vez que formam ligações covalentes mais fracas que os isótopos pesados. O carbono possui dois isótopos estáveis, ${ }^{12} \mathrm{C} \mathrm{e}$ ${ }^{13} \mathrm{C}$, cujas abundâncias na natureza estão em torno de $98,89 \%$ e $1,11 \%$, respectivamente (BIANCHI \& CANUEL, 2011). O nitrogênio também possui dois isótopos estáveis, ${ }^{14} \mathrm{~N}$ e ${ }^{15} \mathrm{~N}$, cujas abundâncias estão em torno de $99,63 \%$ e $0,37 \%$, respectivamente (BIANCHI \& CANUEL, 2011). Esse processo de discriminação isotópica é chamado de fracionamento isotópico e a proporção entre os isótopos leves e pesados é dada pela razão isotópica entre os mais pesados sobre os mais leves (ex.: ${ }^{13} \mathrm{C} /{ }^{12} \mathrm{C}$ e $\left.{ }^{15} \mathrm{~N} /{ }^{14} \mathrm{~N}\right)(\mathrm{FRY}, 2006)$.

Plantas que utilizam o caminho fotossintético de Calvin (ou $\mathrm{C}_{3}$ ) incorporam o carbono na sua biomassa, de forma a produzir uma mudança nos valores de $\delta^{13} \mathrm{C}$, em relação ao padrão do PDB, de cerca de $-20 \%$ entre o $\delta^{13} \mathrm{C}$ das plantas $\mathrm{C}_{3}\left(\delta^{13} \mathrm{C}=-27 \%\right.$ ) e a fonte de dióxido de carbono inorgânico, neste caso $\mathrm{O} \mathrm{CO}_{2}$ atmosférico $\left(\delta^{13} \mathrm{C}=7 \%\right.$ ) (MEYERS, 1997). Esse metabolismo é característico de plantas arbóreas e de algumas plantas de cultivo como arroz e trigo. Já as plantas do tipo $\mathrm{C}_{4}$, como por exemplo as gramíneas, cana de açúcar, milho, etc., utilizam um mecanismo de fixação do $\mathrm{CO}_{2}$ chamado Ciclo de Hatch-Slack que possui um procedimento para evitar a perda de água, fazendo com que não ocorra a discriminação do $\delta^{13} \mathrm{C}$. Com isso o fracionamento durante a fixação do $\mathrm{CO}_{2}$ nas plantas $\mathrm{C}_{4}$ é menor do que nas plantas $\mathrm{C}_{3}$ gerando valores maiores de $\delta^{13} \mathrm{C}$ (LEHNINGER, 1982; PANCOST \& PAGANI, 2006). Existe ainda um terceiro caminho fotossintético chamado CAM (Crassulacean Acid Metabolism "metabolismo do ácido crassuláceo"), utilizado principalmente por suculentas, que usam o caminho $C_{3}$ durante o dia e o $C_{4}$ durante a noite, ou seja, as variações de $\delta^{13} \mathrm{C}$ dependem da dinâmica de crescimento das plantas (HAYES, 1993).

Valores de $\delta^{13} \mathrm{C}$ da matéria orgânica sedimentar produzida a partir do $\mathrm{CO}_{2}$ atmosférico em plantas $\mathrm{C}_{3}$ (o que inclui quase todas as árvores e a maioria dos arbustos) variam entre $-23 \%$ e $-34 \%$, e em plantas $\mathrm{C}_{4}$ (gramíneas) entre $9 \%$ e $-17 \%$ (SCHUBERT \& CALVERT, 2001; ZHOU et al., 2006). Algas marinhas usam bicarbonato dissolvido como fonte carbono inorgânico, o qual contém valores de $\delta^{13} \mathrm{CPDB}$ próximos a $0 \%$. Como consequência, a matéria orgânica marinha apresenta valores típicos de $\delta^{13} \mathrm{CPDB}$ variando entre $-20 \%$ e -22\%o (MEYERS, 1994). 
A razão isotópica do nitrogênio $\left(\delta^{15} \mathrm{~N}\right)$ também pode ser utilizada na distinção entre as fontes marinhas e terrestres da matéria orgânica através da diferença na composição isotópica das fontes do nitrogênio inorgânico (MEYERS, 1997). O valor de $\delta^{15} \mathrm{~N}$ do nitrato dissolvido na água do mar varia entre $7 \%$ e $10 \%$, enquanto que o do nitrogênio atmosférico é de aproximadamente $\% \%$. A matéria orgânica sedimentar produzida pelo plâncton marinho apresenta valores da razão isotópica do nitrogênio entre 5\% e 7\%, e a produzida pelas plantas terrestre um valor em torno de $2 \%$.

Processos microbianos tais como mineralização, fixação de nitrogênio, assimilação, nitrificação e desnitrificação influenciam $0 \quad \delta^{15} \mathrm{~N}$ das espécies orgânicas e inorgânicas de nitrogênio (BIANCHI; CANUEL, 2011). Em condições sub-óxicas, há um enriquecimento do isótopo mais pesado $\left({ }^{15} \mathrm{~N}\right)$ na coluna d'água em função do processo de denitrificação do $\mathrm{NO}_{3}{ }^{-}$dissolvido, que faz com que ocorra a liberação do $\delta{ }^{14} \mathrm{~N}$ para a atmosfera, tornando o nitrato dissolvido enriquecido em $\delta^{15} \mathrm{~N}$. Por outro lado, o processo de fixação faz com que haja um empobrecimento da razão isotópica do nitrogênio (SCHUBERT \& CALVERT, 2001; GAYE-HAAKE et al., 2005). Além disso, a degradação seletiva de compostos orgânicos e o fracionamento isotópico durante a degradação são alguns dos processos diagenéticos que também podem afetar a assinatura isotópica do nitrogênio (FREUDENTHAL et al., 2001).

\section{OBJETIVOS}

\subsection{Objetivo Geral}

Caracterizar a distribuição dos marcadores orgânicos geoquímicos na matriz sedimentar, a fim de identificar as possíveis contribuições biogênicas (autóctones / alóctones) entre as amostras superficiais e ao longo de testemunhos curtos em diápiros e pockmarks localizados no talude sul do Brasil. 


\subsection{Objetivos específicos}

- Identificar as principais fontes naturais da matéria orgânica sedimentar presentes nos pockmarks e diápiros, utilizando marcadores orgânicos geoquímicos de origem natural (biogênica marinha e/ou terrestre, diagenética), como $n$-alcanos, álcoois e esteróis;

- Associar os diferentes marcadores orgânicos com as características sedimentológicas (granulometria) dos pontos amostrais, a fim de identificar os sítios preferenciais de acumulação dos compostos orgânicos no ambiente marinho;

- Avaliar os processos geoquímicos envolvendo as taxas de carbono orgânico total, nitrogênio total e os isótopos $\delta^{13} \mathrm{C}$ e $\delta^{15} \mathrm{~N}$, a fim de compreender e complementar os resultados de $n$-alcanos, álcoois e esteróis.

- Avaliar as possíveis emanações de gás/fluidos nos pockmarks e diápiros da região de estudo, através do uso de biomarcadores moleculares.

\section{3. ÁREA DE ESTUDO}

A área de estudo está localizada no talude continental sul do Brasil, sendo demarcadas pelas latitudes $27^{\circ} \mathrm{S}$ e $26^{\circ} \mathrm{N}$. Está inserida na Bacia de Santos, que recobre uma área de cerca de $350000 \mathrm{~km}^{2}$, limitada ao norte pelo Alto de Cabo Frio, enquanto o Alto de Florianópolis marca o limite sul (PEREIRA \& FEIJÓ, 1994). O limite batimétrico da bacia de Santos é considerado atualmente em cerca de $2.000 \mathrm{~m}$ de lâmina d'água.

A quebra da plataforma demarca a passagem do suave gradiente da plataforma para o forte declive do talude. As margens continentais estão entre os ambiente mais dinâmicos da Terra e a sua morfologia é o resultado da interação entre a tectônica, mudanças climáticas e processos oceanográficos presentes na região. 


\subsection{Aspectos Meteorológicos e Oceanográficos}

A circulação da região sobre o talude continental é ocupada pelo sistema de correntes que compõe a borda oeste do Giro Subtropical do Atlântico Sul (Figura 3). A formação da Corrente do Brasil (CB) ocorre ao longo da margem continental brasileira como parte da corrente de contorno oeste do giro subtropical do Atlântico Sul. A CB se resfria e se torna menos salina, refletindo tanto as trocas do oceano com a atmosfera, quanto a mudança da composição de suas águas, devido à mistura com outras águas adjacentes (PETERSON \& STRAMMA, 1990).

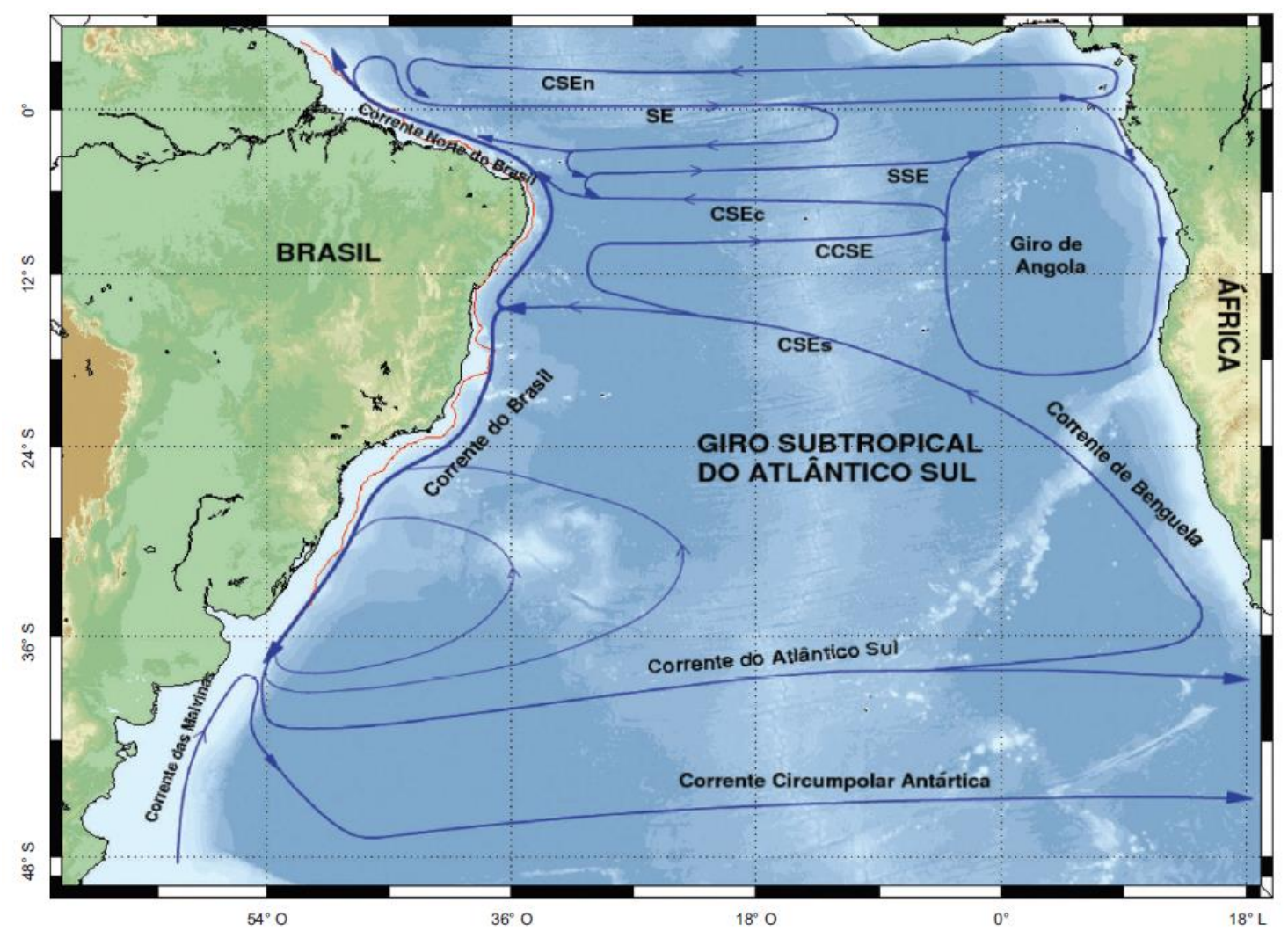

Figura 3 - Representação esquemática da circulação do Oceano Atlântico Sul. Corrente Sul Equatorial em seus ramo sul (CSEs), ramo central (CSEc), ramo norte (CSEn); Contracorrente Sul Equatorial (CCSE), Subcorrente Sul Equatorial (SSE) e Subcorrente Equatorial (SE) (SILVEIRA et al., 2000).

A região da $\mathrm{CB}$ é formada pelo empilhamento das massas de água características do Atlântico Sul (Figura 4), transportando a Água Tropical (AT) e a Água Central do Atlântico Sul (ACAS) em direção ao sul-sudoeste; a CCI transporta Água Intermediária Antártica (AIA) e Água Circumpolar Superior 
(ACS) para norte-nordeste; e a CCP carrega Água Profunda do Atlântico Norte (APAN) em direção ao sul (CASTRO FILHO et al., 2006).

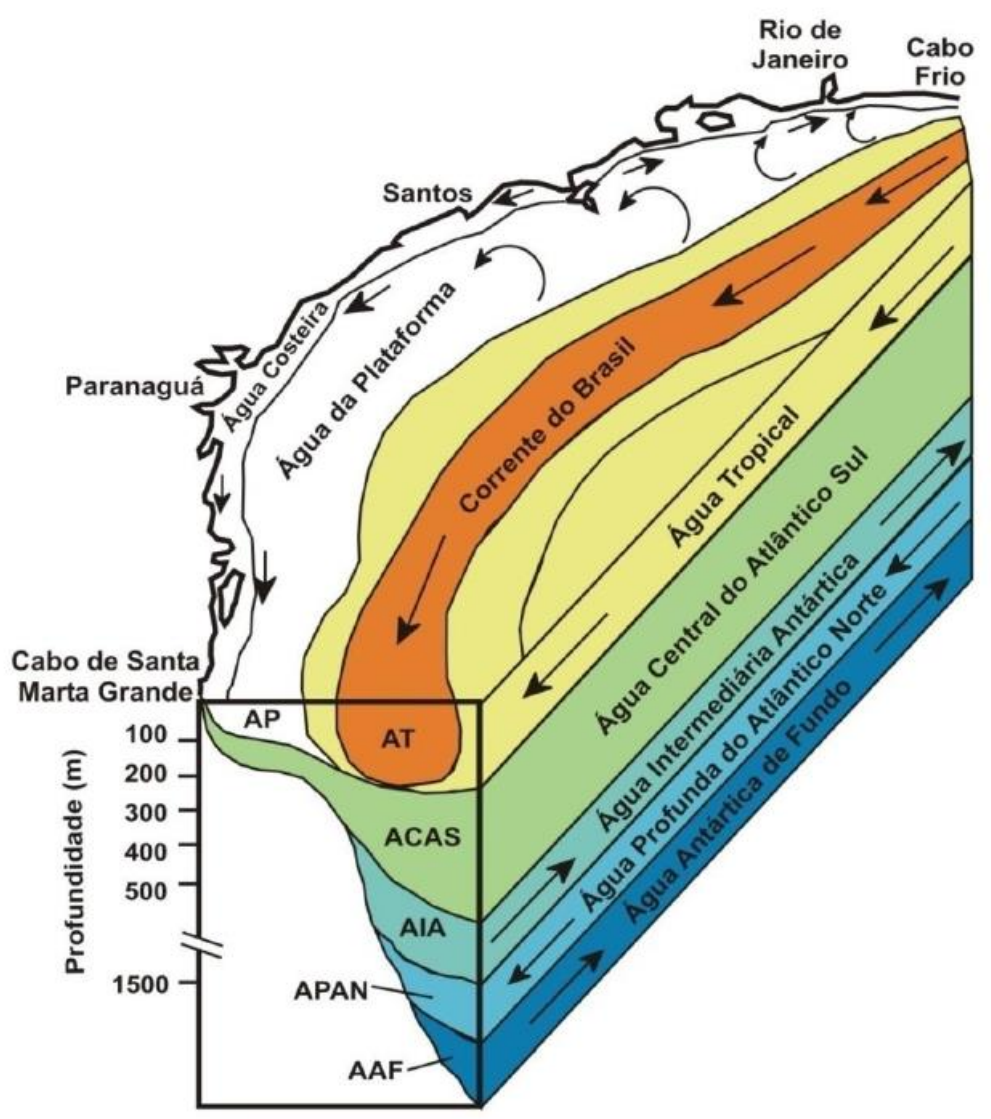

Figura 4 - Limites das massas de água na região oceânica da Bacia de Santos (MAATSURA, 1986).

Água Tropical (AT): flui na porção superior da Corrente do Brasil em direção sul (0-200 $\mathrm{m})$, próximo à quebra da plataforma continental. A partir de $23^{\circ} \mathrm{S}$ tanto a Água Costeira (AC) quanto a Água Central do Atlântico Sul (ACAS), provavelmente oriunda da recirculação do giro subtropical, contribuem para este aumento de transporte. Apresenta baixas concentrações de nutrientes e altas concentrações de oxigênio dissolvido, temperatura $\left(20^{\circ} \mathrm{C}\right)$ e salinidade (acima de 36 ups) (MIRANDA, 1982). É reconhecidamente tratada na literatura como água de máxima salinidade (MÉMERY et al., 2000; TSUCHIYA et al.,1994). Em seu trajeto para o sul, mistura-se com águas de origem costeira mais frias e de baixa salinidade. Essa água de superfície é formada como consequência da intensa radiação e excesso de evaporação em relação à precipitação, característicos do Atlântico Tropical. 
Água Central do Atlântico Sul (ACAS): está situada logo abaixo da AT (100-500m de profundidade) (CAMPOS, 2006) e apresenta temperatura entre $6^{\circ} \mathrm{C}$ a $20^{\circ} \mathrm{C}$ e salinidade entre 34.6 e 36 ups. Flui em sentido norte e no verão alcança a plataforma continental, podendo aflorar em diversos pontos do litoral brasileiro, representando um importante mecanismo de suprimento de águas ricas em nutrientes para as camadas da superfície, o qual propicia alta produtividade (MIRANDA, 1982).

Água Intermediária da Antártica (AIA): está situada entre 500-1200m de profundidade (CAMPOS, 2006) e apresenta temperatura e salinidade respectivamente de $3^{\circ} \mathrm{C}$ a $6^{\circ} \mathrm{C}$, e 34,2 a $34,6^{\circ} \mathrm{C}$. A AIA e ACAS são massas de água inseridas na circulação profunda do Giro Subtropical, que penetram na bacia oceânica sudeste Brasileira e se dividem aproximadamente na latitude $28^{\circ} \mathrm{S}$ em dois braços, no talude da Bacia de Santos, com a AIA fluindo ao norte de 25 @S em direção ao equador (MÜLLER et al. 1998).

A disponibilidade de nutrientes determina altas taxas de produtividade primária, com aumento da concentração de organismos fitoplanctônicos e, em consequência, elevação da biomassa de organismos zooplanctônicos (ODEBRECHT \& CASTELLO, 2001; GAETA \& BRANDINI, 2006). As ressurgências na quebra da plataforma podem influenciar na produção desses organismos, sendo que o vento nessa região pode provocar a ressurgência próximo ao Cabo de Santa Marta e deslocar a pluma do Rio da Prata para o norte (MÖLLER et al., 2008) (Figura 5). A ocorrência da ressurgência do Cabo de Santa Marta depende da duração e intensidade dos ventos de nordeste/norte (NE/N), assim sendo, tais eventos ocorrem predominantemente no verão, pois é a época onde os ventos de $\mathrm{NE} / \mathrm{N}$ são mais frequentes. $A$ ação de Coriolis, que no Hemisfério Sul é para esquerda, faz com que os ventos de NE direcionem o transporte de Ekman para o oceano aberto, forçando a subida de água das camadas subsuperficiais, nesse caso a Água Central do Atlântico Sul (ACAS).

Já o deslocamento da pluma do Rio da Prata depende da ação de ventos de sudoeste/sul (SW/S). Durante o outono e o inverno, quando predominam tais ventos, as águas de baixa salinidade decorrentes da descarga do Rio da Prata se estendem por mais de $1.200 \mathrm{~km}$, até o norte da ilha de Florianópolis, podendo chegar excepcionalmente até o litoral paulista (Figura 
5). Por outro lado, na primavera e no verão, quando predominam ventos de NE/N, a pluma costeira se retrai até a latitude de Rio Grande (32ㅇ) (PIOLA et al., 2005).

Inverno

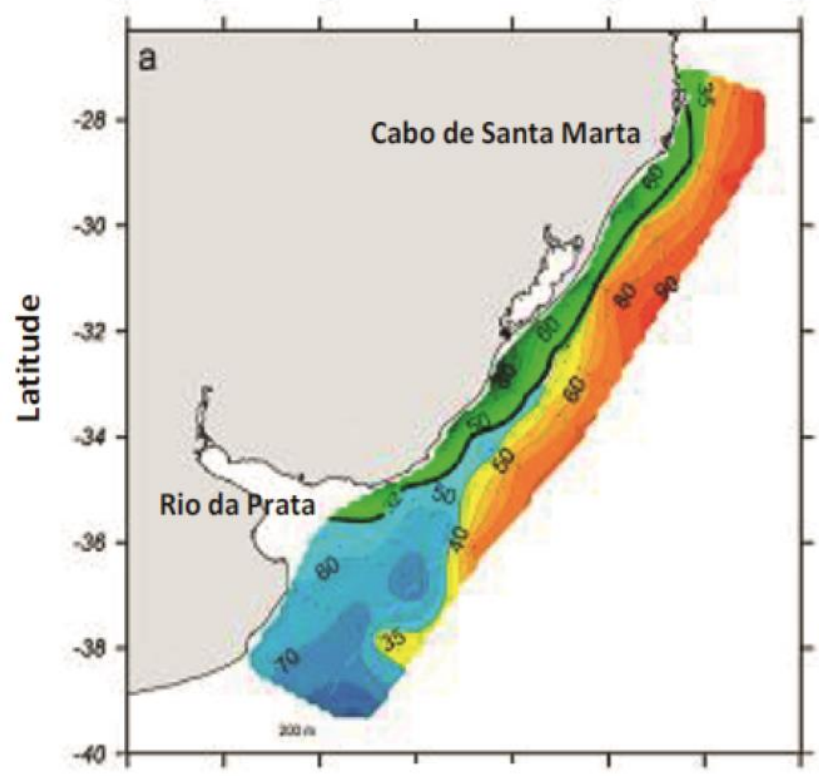

Verão

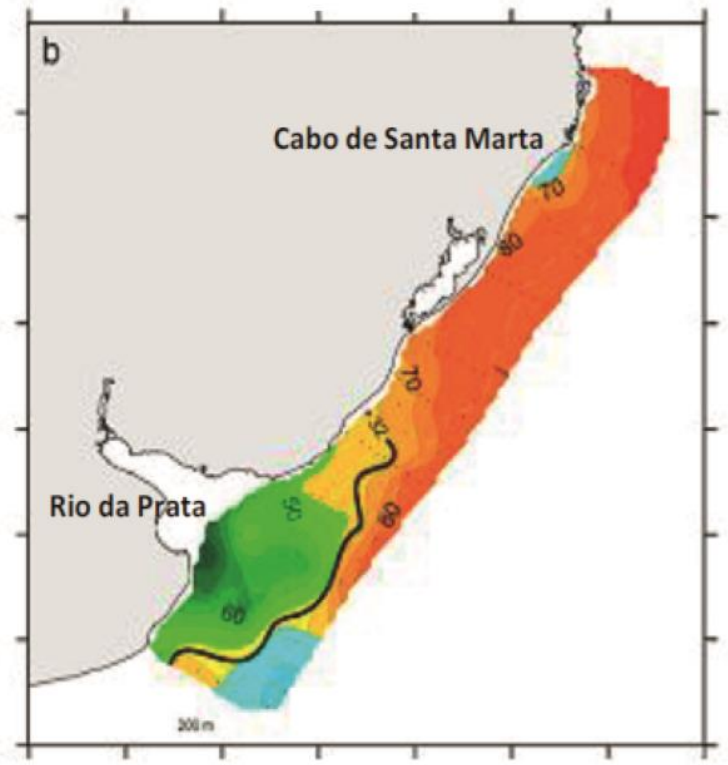

Figura 5 - Influência do Rio da Prata para o inverno (esquerda) e verão (direita). Em verde está a Água da Pluma do Rio da Prata (APP), em vermelho Água Tropical (AT), em azul Água Subantártica (ASA). No verão a região próxima ao Cabo de Santa Marta apresenta intrusão da Água Central do Atlântico Sul (ACAS) na superfície (fenômeno de ressurgência) (Modificado de MÖLLER et al., 2008).

\subsection{Geomorfologia e Sedimentologia do Talude Continental}

O talude continental é a província fisiográfica da margem continental que apresenta os mais elevados valores de declividade do fundo do mar. A quebra da plataforma é situada entre 120 e 180 metros e, em geral, a sua variação acompanha a largura da plataforma, com quebras que ocorrem nas porções superficiais da plataforma interna. O talude continental varia de extremamente íngreme (1:10) a suavemente inclinado (1:190). As áreas mais íngremes estão entre: Cidade de Rio Grande - Arroio Chuí, com gradientes entre 1:13 e 1:8. As áreas menos inclinadas estão desde a área sul do Estado de São Paulo (1:132) até a área norte da cidade do Rio Grande (1:190) (FIGUEIREDO \& TESSLER, 2004). 
As características morfológicas mais evidentes no talude, entre 100 e $1000 \mathrm{~m}$ de profundidade, corresponde aos cones e platôs de diversas dimensões na altura de Rio Grande, ao largo de Torres, de Florianópolis, ao norte de Paranaguá, de Cabo Frio e de São Tomé (Figura 6). Irregularidades no talude, indicando a presença de cânions e cicatrizes, são encontradas ao sul do cone do Rio Grande, no platô de Rio Grande, na face norte do cone de Rio Grande e ao norte de Paranaguá (FIGUEIREDO \& TESSLER, 2004). Os cânions submarinos, juntamente com as diversas cicatrizes, constituem os principais canais para o transporte de sedimentos da plataforma para as bacias oceânicas (LASTRAS et al., 2009; MOUNTJOY et al., 2009). No talude, estes processos ocorreram preferencialmente durante os períodos de nível relativo de mar baixo (KOWSMANN et al., 2002).

O processo de recuo do nível do mar foi responsável pela exposição da plataforma a uma intensa erosão, levando ao desenvolvimento de planícies costeiras e vales fluviais, que depositavam seus sedimentos diretamente no talude (KOWSMANN \& COSTA, 1979). Dentre os impactos que esse fenômeno ocasionou sobre os sistemas oceânicos, podemos citar: (1) a elevação das taxas de sedimentação terrígena; (2) o resfriamento das massas de água superficiais; (3) a intensificação da circulação de fundo; (4) o menor acúmulo de vasas calcárias no Atlântico Sul e (5) a modificação da fauna planctônica (KOWSMANN \& COSTA, 1979). 


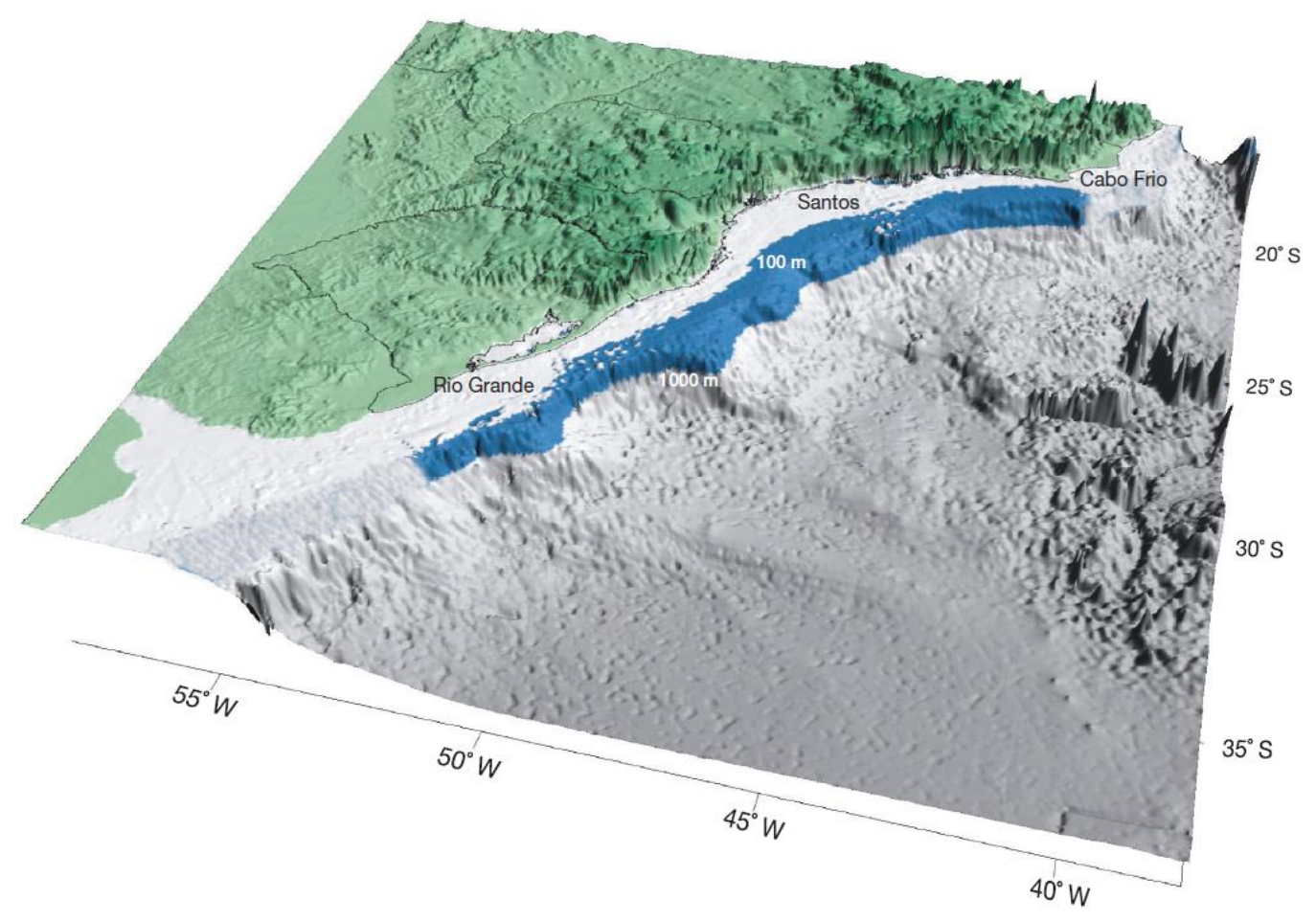

Figura 6 - Mapa do relevo oceânico da área plataforma continental externa, talude e região oceânica adjacente do Sudeste-Sul do Brasil (GASALLA et al., 2007).

O talude sul do Brasil apresenta siltes e areias siliciclástica muito finas, com quantidades variáveis de argila e carbonato de cálcio. Sedimentos mais grossos e carbonáticos representam menos de $5 \%$ dos sedimentos dos fundos atuais e são predominantemente formada por foraminíferos planctônicos e esqueletos de corais, além de estarem relacionados aos sedimentos relíquias, depositados sob condições de nível do mar mais baixo (ROCHA et al., 1975).

Os processos deposicionais ao sul estariam associados a penetração sazonal de águas de baixa salinidade e temperatura relacionadas a descarga do Rio da Prata (MAHIQUES et al., 2004). A água da pluma é carregada para norte, ao longo da plataforma continental sul Brasileira, pela Corrente Costeira do Brasil (CCB). A CCB (Figura 7) é descrita como uma corrente costeira relativamente lenta, mas energética, que flui em direção oposta a Corrente do Brasil (CB). A corrente ocorre na plataforma continental sul Brasileira na primavera e no inverno, atingindo o ponto mais ao norte $\left(\sim 25^{\circ} \mathrm{S}\right)$ em agosto de cada ano (SOUZA \& ROBINSON, 2004).

Dados fundamentais extraídos de profundidades de águas rasas $(<100$ m) através do declive continental de Santos produziu uma taxa de $\sim 40 \mathrm{~cm} / \mathrm{mil}$ 
anos. Isso diminui acentuadamente e é quase zero a uma profundidade de água de 500 m (MAHIQUES et al., 2011).

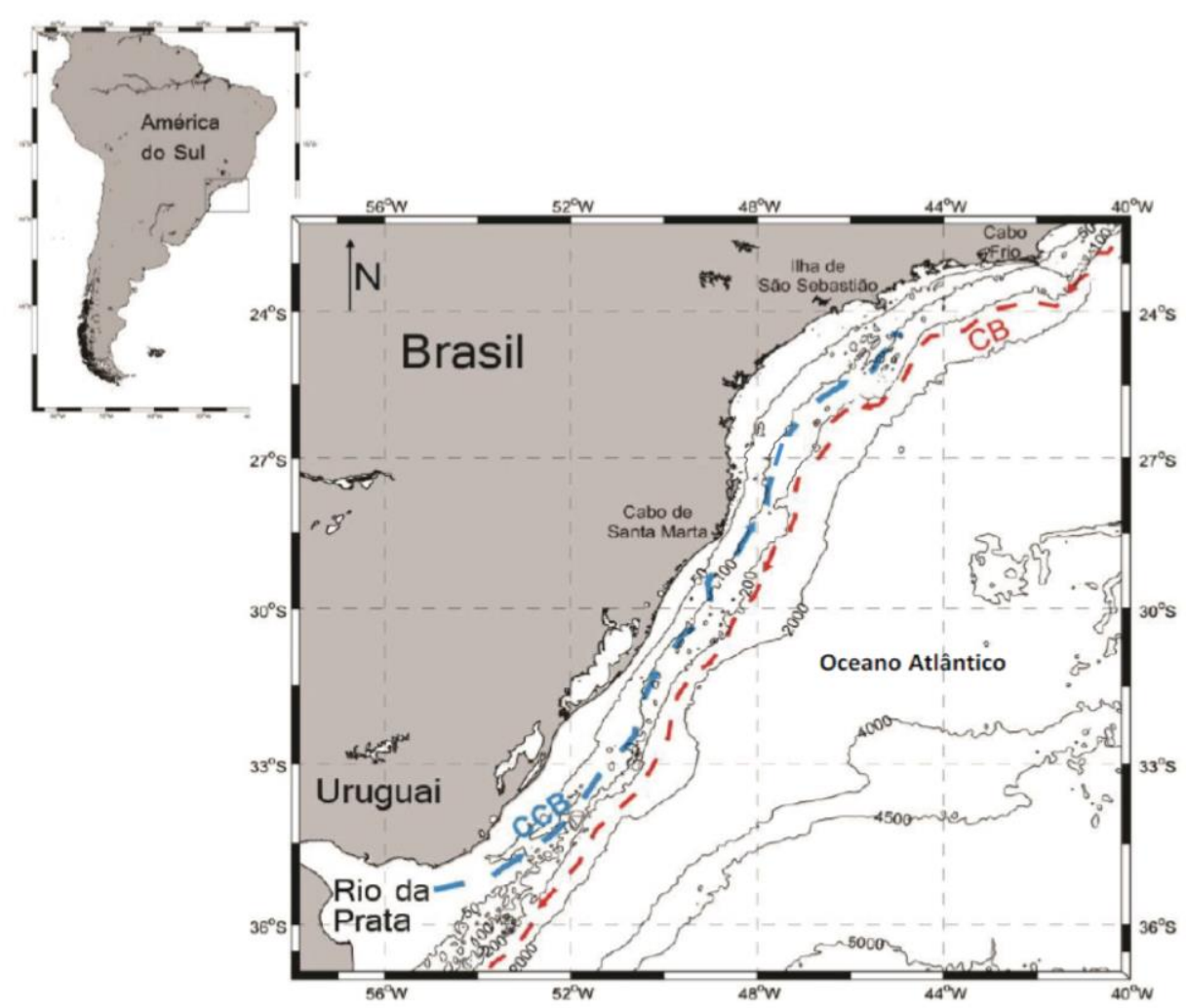

Figura 7 - Em azul a Corrente Costeira do Brasil (CCB), fluindo para nordeste (NE) até $25^{\circ} \mathrm{S}$, paralela à costa em profundidades menores do que $200 \mathrm{~m}$. Em vermelho a Corrente do Brasil (CB), fluindo para sul (S), paralela à costa em profundidades maiores do que 200 m (Modificada de NAGAl et al., 2010).

\section{MATERIAL E MÉTODOS}

\subsection{Amostragem}

Foram realizadas 13 estações de coletas de sedimento superficial em torno do talude sul do Brasil (Figura 8) com o auxílio do Navio Oceanográfico Alpha-Crucis do Instituto Oceanográfico da Universidade de São Paulo no mês de julho de 2016, através do projeto de pesquisa "Continental slope morphological features on the SE Brazilian margin: Active tectonics versus modern oceanographic conditions"(Processo FAPESP No 2014/08266-2), em desenvolvimento no Departamento de Oceanografia Física, Química e 
Geológica do Instituto Oceanográfico da USP, sob coordenação do Prof. Dr. Michel Michaelovitch de Mahiques. O sedimento foi coletado utilizando o Box Corer (BX-650), cuja unidade possui uma caixa de $0,25 \mathrm{~m}^{2}$ de aço inoxidável $(50 \mathrm{~cm} \times 50 \mathrm{~cm}$ ) e uma penetração máxima de $60 \mathrm{~cm}$.

As amostras foram fracionadas a cada $2 \mathrm{~cm}$, exceto nos primeiros dois centímetros que foram fracionadas a cada $1 \mathrm{~cm}$, para obter uma resolução maior na superfície do sedimento. Posteriormente foram armazenadas em bandejas de alumínio, previamente calcinadas em forno mufla, e em seguida foram conservadas a $-15^{\circ} \mathrm{C}$. A Tabela 4 apresenta a localização (latitude e longitude), e a profundidade de cada estação de coleta.
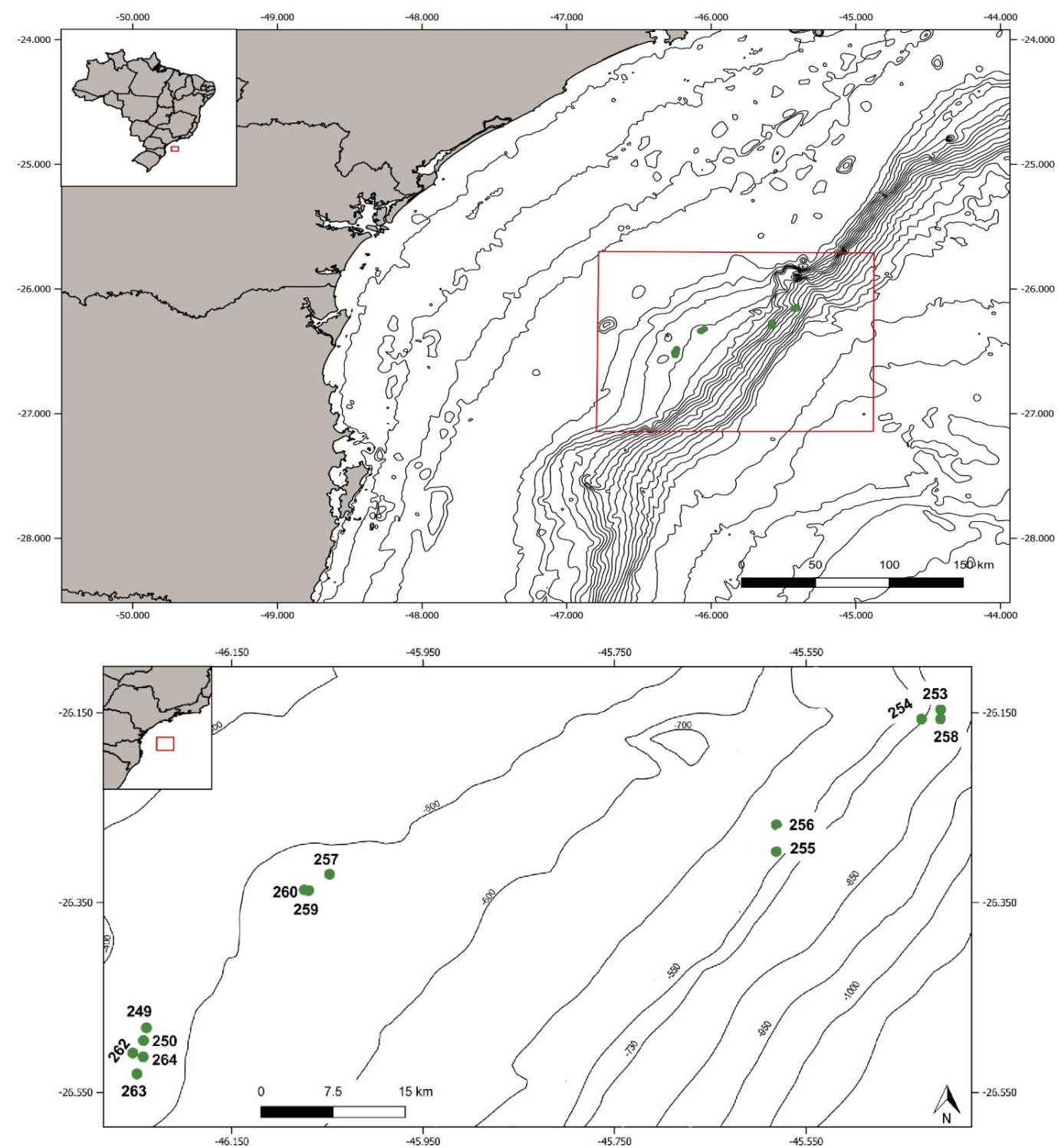

Figura 8 - Área de estudo e as 13 estações localizados na margem continental sul do Brasil entre as latitudes $26^{\circ}$ e $28^{\circ} \mathrm{S}$. 
Tabela 4 - Estações das amostras, latitudes, longitudes, profundidade $(\mathrm{m}) \mathrm{da}$ coluna d'água e data das coletas de julho de 2016.

\begin{tabular}{cccccc}
\hline Estação & Latitude & Longitude & Profundidade & Zona & Data \\
\hline $\mathbf{2 4 9}$ & $26^{\circ} 48.26^{\prime} \mathrm{S}$ & $46^{\circ} 23.96^{\prime} \mathrm{W}$ & 430 metros & Diápiro & $06 / 07 / 2016$ \\
$\mathbf{2 5 0}$ & $26^{\circ} 49.590^{\prime} \mathrm{S}$ & $46^{\circ} 24.27^{\prime} \mathrm{W}$ & 433 metros & Diápiro & $06 / 07 / 2016$ \\
$\mathbf{2 5 6}$ & $26^{\circ} 26.854^{\prime} \mathrm{S}$ & $45^{\circ} 58.132^{\prime} \mathrm{W}$ & 569 metros & Diápiro & $14 / 07 / 2016$ \\
$\mathbf{2 5 9}$ & $26^{\circ} 33.776$ 'S & $46^{\circ} 07.008^{\prime} \mathrm{W}$ & 559 metros & Diápiro & $15 / 07 / 2016$ \\
$\mathbf{2 6 0}$ & $26^{\circ} 33.710^{\prime} \mathrm{S}$ & $46^{\circ} 07.470^{\prime} \mathrm{W}$ & 517 metros & Diápiro & $15 / 07 / 2016$ \\
$\mathbf{2 6 2}$ & $26^{\circ} 50.910^{\prime} \mathrm{S}$ & $46^{\circ} 25.382^{\prime} \mathrm{W}$ & 402 metros & Diápiro & $16 / 07 / 2016$ \\
$\mathbf{2 6 3}$ & $26^{\circ} 53.107$ 'S & $46^{\circ} 24.951^{\prime} \mathrm{W}$ & 477 metros & Diápiro & $16 / 07 / 2016$ \\
$\mathbf{2 6 4}$ & $26^{\circ} 51.3155^{\prime} \mathrm{S}$ & $46^{\circ} 24.296^{\prime} \mathrm{W}$ & 458 metros & Diápiro & $12 / 07 / 2016$ \\
$\mathbf{2 5 3}$ & $26^{\circ} 14.72^{\prime} \mathrm{S}$ & $45^{\circ} 40.97^{\prime} \mathrm{W}$ & 730.97 metros & Pockmark & $12 / 07 / 2016$ \\
$\mathbf{2 5 4}$ & $26^{\circ} 15.715^{\prime} \mathrm{S}$ & $45^{\circ} 42.971^{\prime} \mathrm{W}$ & 747 metros & Pockmark & $13 / 07 / 2016$ \\
$\mathbf{2 5 5}$ & $26^{\circ} 29.677$ 'S & $45^{\circ} 58.153^{\prime} \mathrm{W}$ & 652 metros & Pockmark & $14 / 07 / 2016$ \\
$\mathbf{2 5 7}$ & $26^{\circ} 32.075^{\prime} \mathrm{S}$ & $46^{\circ} 04.822^{\prime} \mathrm{W}$ & 543 metros & Pockmark & $14 / 07 / 2016$ \\
$\mathbf{2 5 8}$ & $26^{\circ} 15.715^{\prime} \mathrm{S}$ & $45^{\circ} 40.97^{\prime} \mathrm{W}$ & 730.97 metros & Região externa & $12 / 07 / 2016$ \\
\hline
\end{tabular}

As localizações dos pontos amostrados foram estabelecidas através da prévia investigação geofísica, empregando o perfilador sísmico de fonte acústica do tipo chirp $(12 \mathrm{KHz})$, de alta frequência, a fim de identificar a morfologia (Figura 9) e a localização precisa dos pockmarks e diápiros.
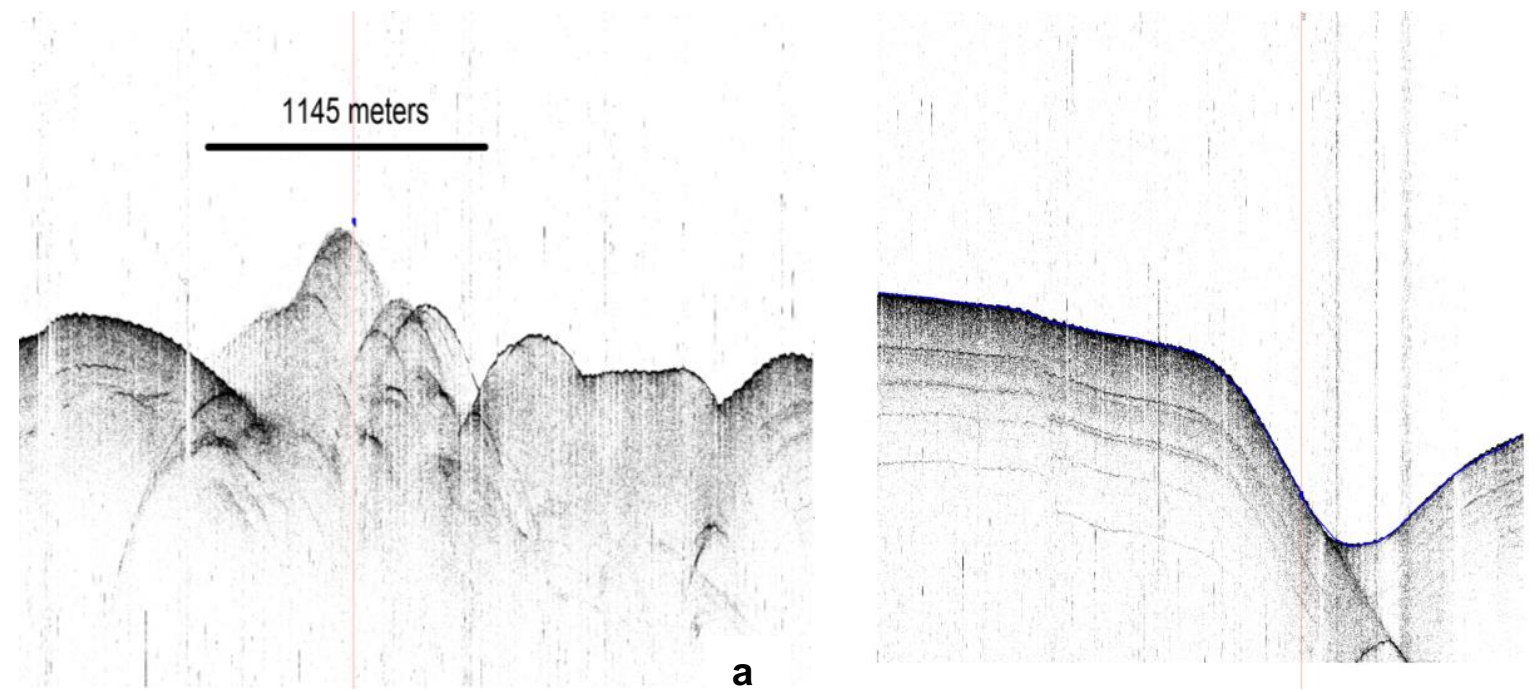

b

Figura 9 - Exemplo de um perfil sísmico destacando a presença de diápiro e pockmark na área de estudo. (a) Diápiro na estação 256 (b) Pockmark na estação 255. Imagens cedidas pelo Laboratório de Geologia de Margens Continentais IOUSP. 


\subsection{Características composicionais do sedimento}

As características composicionais do sedimento foram determinadas segundo os seguintes descritores: teor de carbonato de cálcio (\% $\left.\mathrm{CaCO}_{3}\right)$; teor de carbono orgânico total (\% COT); teor do nitrogênio total (\% NT); razão isotópica do carbono orgânico $\left(\delta^{13} \mathrm{C}\right)$ e do nitrogênio total $\left(\delta^{15} \mathrm{~N}\right)$ e granulometria.

O teor de $\mathrm{CaCO}_{3}$ no sedimento foi determinado mediante a digestão ácida do material biodetrítico. Cerca de 1 grama foi pesado em balança analítica e posteriormente foi tratada com $2 \mathrm{~mL}$ de ácido clorídrico (HCL, $2 \mathrm{~mol}$ $\mathrm{L}^{-1}$ ) e homogeneizada através de um vortéx, mantendo-se em repouso no ácido por 24 horas. No dia seguinte, foram adicionadas três a quatro gotas de HCL concentrado, com o propósito de certificar a total remoção do $\mathrm{CaCO}_{3} . \mathrm{Em}$ seguida, o sedimento foi lavado com $8 \mathrm{~mL}$ de água Mili-Q, para posterior centrifugação a $2500 \mathrm{rpm}$ durante 12 minutos. Esse procedimento foi repetido por 5 vezes para que todo o ácido clorídrico, verificado com papel universal de $\mathrm{pH}$, fosse retirado do sedimento. Após as lavagens, os tubos com as amostras foram colocadas na estufa a $60^{\circ} \mathrm{C}$ por 3 dias e o teor de $\mathrm{CaCO}_{3}$ (expresso em $\%$ foi determinado pela diferença de massa de sedimento inicial e final através da equação 1 , a variação de massa antes e após o ataque com ácido clorídrico reflete o teor de $\mathrm{CaCO}_{3}$ do sedimento.

$$
\text { Teor de } \mathrm{CaCO}_{3}=\left\lceil\frac{(\text { Massa inicial }- \text { Massa final })}{\text { Massa inicial }}\right\rceil \times 100
$$

(Equação 1)

Massa inicial: massa da amostra seca antes de acidifica-la;

Massa final: massa da amostra após sua acidificação e secagem.

O teor de carbono orgânico total e razão isotópica de carbono orgânico foram determinados em alíquota de sedimento submetido à remoção do $\mathrm{CaCO}_{3}$. Após a remoção de carbonato, o sedimento seco foi homogeneizado em almofariz com pistilo. Cerca de 6 a $8 \mathrm{mg}$ de amostra foram pesados em cartuchos de estanho $(5 \times 9 \mathrm{~mm})$ e colocados no analisador elementar Costec 
Instruments Elemental Combustion System acoplado ao detector de espectrometria de massas com razão isotópica Thermo Scientific Delta Advantage Isotope Ratio MS (EA-IRMS).

O teor de nitrogênio total e a sua razão isotópica foram determinados através da alíquota de 6 a $8 \mathrm{mg}$ de sedimento seco, sem a remoção de $\mathrm{CaCO}_{3}$ embrulhadas em capsula de estanho, sendo submetidas a análise elementar e isotópica no EA-IRMS. Os teores de carbono orgânico e nitrogênio total foram expressos em porcentagem (\%). As razões isotópicas do carbono orgânico e nitrogênio total foram expressas como valor de $\delta$ (delta) por mil(\%), de acordo com a equação 2 :

$$
\delta \mathrm{X}=\left[\left(\frac{\text { Ramostra }}{\text { R padrão }}\right)-1\right] \times 1000
$$

(Equação 2)

$\mathrm{Na}$ qual, $\mathrm{X}$ é o ${ }^{13} \mathrm{C}$ ou ${ }^{15} \mathrm{~N}$ e R representa a razão isotópica ${ }^{13} \mathrm{C} /{ }^{12} \mathrm{C}$ ou ${ }^{15} \mathrm{~N} /{ }^{14} \mathrm{~N}$ da amostra e do padrão de referência. O resultado da fórmula é expresso em partes por mil (\%o) (BIANCHI \& CANUEL, 2011).

A proporção em massa (\%) de carbono e nitrogênio foi obtida através da relação entre as proporções do padrão e das áreas correspondentes aos picos do padrão e da amostra:

$$
\% \text { Amostra }=\left(\frac{\% \text { padrão } x \text { massa padrão }}{\text { área do padrão }}\right) \times \text { área da amostra }
$$

(Equação 3)

O padrão adotado na quantificação em massa foi o Solo LECO 502309 - LECO Corporation. Os teores de carbono e nitrogênio são, respectivamente, 17,64\% e 0,062\%. A calibração para as análises isotópicas do carbono orgânico e do nitrogênio total foram feitas através de dois padrões: um certificado pela United State Geological Survey (USGS): o USGS-40 (ácido glutamínico: $\delta^{13} \mathrm{C}=-25,67 \pm 0,03 \% ; \quad \delta^{15} \mathrm{~N}=-3,24 \pm 0,08 \%$ ) e outro pela 
International Atomic Energy Agency (IAEA): o IAEA-600 (cafeína: $\delta^{13} \mathrm{C}=-$ $26,541 \pm 0,036 \% ; \delta^{15} \mathrm{~N}+1,5 \pm 0,3 \%$ ).

A caracterização granulométrica foi realizada pelo Laboratório de Sedimentologia do Instituto Oceanográfico da Universidade de São Paulo através de um sedimentômetro Malvern 2000, segundo as fórmulas de Folk e Ward (1957). Foi processada através da remoção total de $\mathrm{CaCO}_{3}$, sendo que, o procedimento para a remoção foi idêntico ao realizado para o carbono orgânico total.

\subsection{Tratamento dos reagentes e limpeza do material}

A análise dos marcadores orgânicos requer uma limpeza rigorosa de todo o material empregado Toda a vidraria utilizada foi lavada previamente com detergente Extran alcalino (Merck) por 8 horas, enxaguada com água corrente. Após o enxague o material foi seco em estufa e em seguida calcinados em mufla à temperatura de $450^{\circ} \mathrm{C}$ durante 4 horas, com exceção da vidraria volumétrica, pinças e espátulas, que em seguida, foram secos à temperatura ambiente e limpos com $n$-hexano e diclorometano antes do uso.

Os reagentes sólidos, como por exemplo o sulfato de sódio, sílica gel e alumina foram calcinados em uma mufla a $450^{\circ} \mathrm{C}$ por 4 horas, a fim de eliminar os possíveis interferentes orgânicos, em seguida, foram armazenados em frascos de vidro calcinados e estocados em um dessecador a vácuo com o intuito de evitar a umidade.

Antes de serem utilizadas nas colunas de adsorção, a sílica e a alumina foram ativadas em uma estufa a $140^{\circ} \mathrm{C}$ por 2 horas e, em seguida, foram resfriadas em dessecador sob vácuo e desativadas com $5 \%$ em massa de água Mili-Q extraída em $n$-hexano ( 5 vezes com $20 \mathrm{~mL}$ de $n$-hexano/2L de água).

\subsection{Análise dos marcadores orgânicos moleculares}

O método analítico dos $n$-alcanos, esteroides e álcoois está descrito para a análise de matriz sedimentar e foi adaptado de LOURENÇO (2007). Baseiase no tratamento prévio dos sedimentos e nas etapas de extração, purificação, 
fracionamento, e injeção dos extratos em cromatógrafos a gás com um detector de ionização de chama e espectrômetro de massas (Figura 10).

Depois da liofilização dos sedimentos, aproximadamente 20 gramas do sedimento macerado foram extraídos em Soxhlet durante 8 horas, utilizando 80 $\mathrm{mL}$ de uma mistura de diclorometano (DCM) e $n$-hexano (1:1, v:v). No balão, foram adicionadas esferas de ebulição, para serem centros de nucleação e evitarem um borbulhamento excessivo da mistura de solventes, e anéis de cobre ativado, para a remoção do enxofre, pois a sua presença interfere no sinal cromatográfico. Em cada uma das amostras foram adicionados $50 \mu \mathrm{L}$ de uma solução de $50 \mathrm{ng} \mathrm{HL}^{-1}$ de padrões surrogate contendo 1-eicoseno (para a quantificação de $n$-alcanos entre $n$ - $\mathrm{C}_{20}$ e $n$ - $\mathrm{C}_{35}$ ) e 1-hexadeceno (para a quantificação de $n$-alcanos entre $n-\mathrm{C}_{12}$ e $n$ - $\mathrm{C}_{19}$, pristano e fitano). Para análises dos esteroides e álcoois, foram adicionados $50 \mu \mathrm{L}$ do padrão padrões surrogate contendo $5 \alpha$-androstanol a $50 \mathrm{ng} \mathrm{\mu L}^{-1}$. A cada bateria de análises, foi realizada a extração de um branco do método como parte do controle analítico.

O extrato resultante foi concentrado em evaporador rotativo a vácuo com a temperatura de $45^{\circ} \mathrm{C}$ até $0,5 \mathrm{~mL}$. $\mathrm{O}$ extrato concentrado foi submetido à purificação em coluna de adsorção contendo $1 \mathrm{~g}$ de alumina e $2 \mathrm{~g}$ de sílica, desativadas a $5 \%$ com água 5 vezes extraídas com $n$-hexano, além de sulfato de sódio. Para fracionar em diferentes classes orgânicas foram utilizados duas eluições de solventes. A primeira eluição (F1) foi feita com $6 \mathrm{~mL}$ de $n$-hexano e $10 \mathrm{~mL}$ de mistura de diclorometano/ $n$-hexano (9:2 $\mathrm{v} / \mathrm{v})$ para se separar os hidrocarbonetos alifáticos. Para obtenção da fração F2 foram utilizados $15 \mathrm{~mL}$ de metanol para a eluição dos esteroides e álcoois. Os extratos resultantes da fração $\mathrm{F} 1$ foram concentrados a $0,5 \mathrm{~mL}$ e transferidos para ampolas de vidro

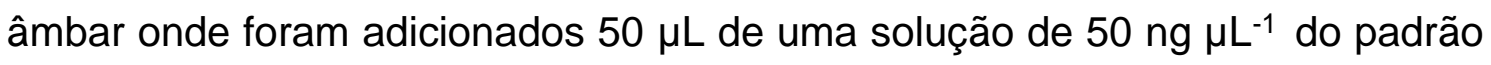
interno cromatográfico (1-tetradeceno). Já os eluatos da fração F2 foram totalmente secos no evaporador rotativo a vácuo, e os resíduos resultantes foram recuperados com diclorometano e transferidos para frascos com tampa de rosca. Esses extratos foram secos com nitrogênio gasoso, e neles foram adicionados $40 \mu \mathrm{L}$ do reagente $\mathrm{N}, \mathrm{O}$-bis(trimetilsilil trifluoracetamida)/trimetilclorosilano (BSTFA/TMCS - 99:1), para a realização da reação de derivatização. Os frascos foram mantidos por $90 \mathrm{~min}$ a $60^{\circ} \mathrm{C}$, e, após esse período, o reagente foi seco em nitrogênio. O resíduo resultante da 
derivatização foi recuperado com $n$-hexano, transferidos para ampolas de vidro

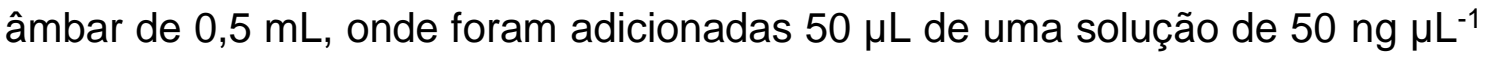
do padrão interno cromatográfico $5 a-$ colestano.

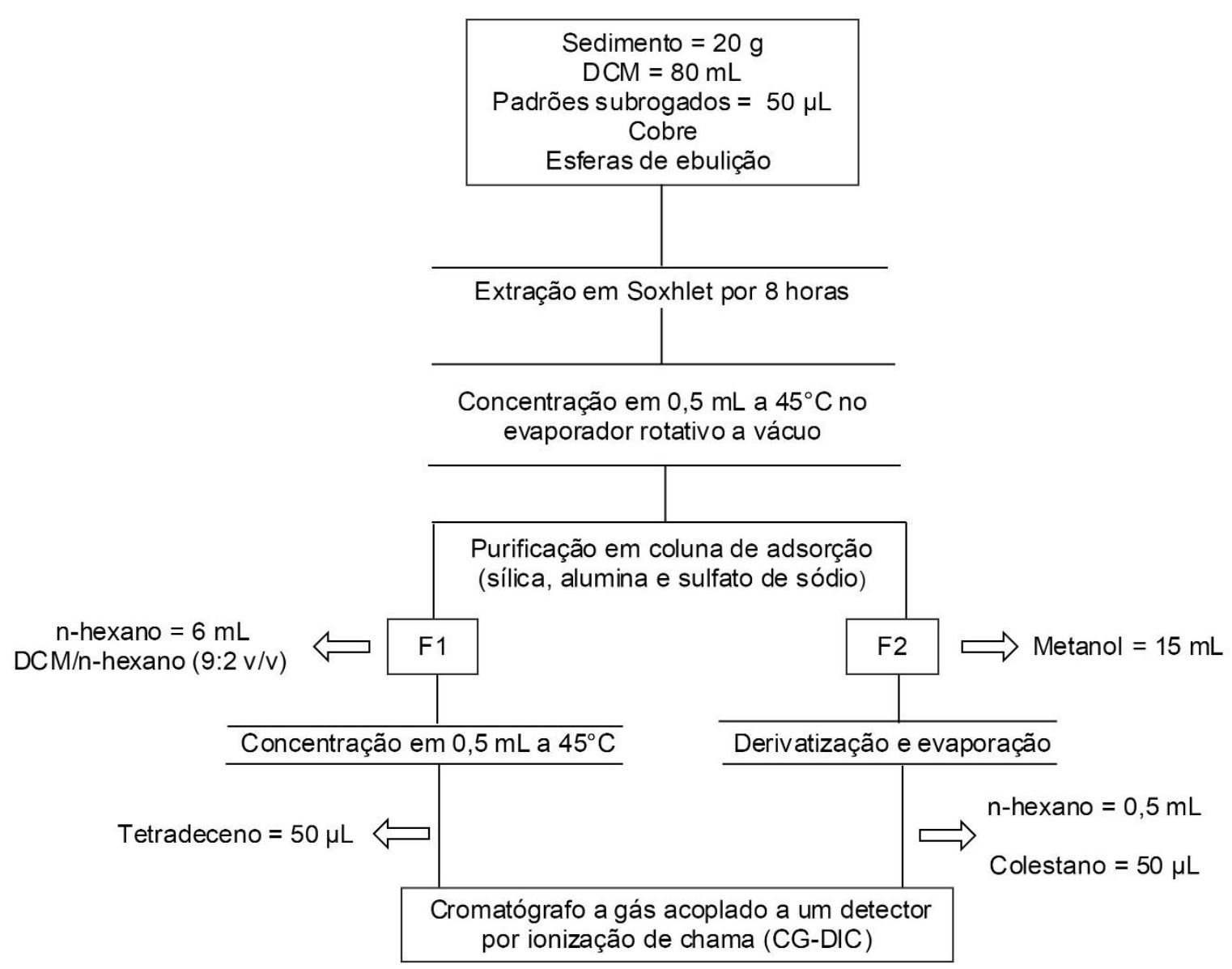

Figura 10 - Esquema do método analítico utilizado no procedimento laboratorial para obtenção dos marcadores orgânicos geoquímicos.

Os HAs, esteroides e álcoois foram identificados e quantificados através da injeção de $1 \mu \mathrm{L}$ do extrato final em um cromatógrafo a gás acoplados a um detector por ionização de chama CG-DIC (Agilent GC System 7683 Series). Foi utilizada uma coluna cromatográfica de $50 \mathrm{~m}$ de comprimento x 0,32 $\mathrm{mm}$ de diâmetro interno $\times 0,17 \mu \mathrm{m}$ de espessura do filme, sendo a fase estacionária composta por $5 \%$ difenil e $95 \%$ dimetilpolisiloxano. O gás de arraste foi $\circ \mathrm{H}_{2}$ (pureza $>99,999 \%$ ), com pressão constante de 7,24 psi no injetor. A temperatura no injetor foi constante a $280^{\circ} \mathrm{C}$ e as injeções foram feitas em modo splitless, com detector mantido a $325^{\circ} \mathrm{C}$. As condições cromatográficas utilizadas nas análises encontram-se resumidas na Figura 11. 


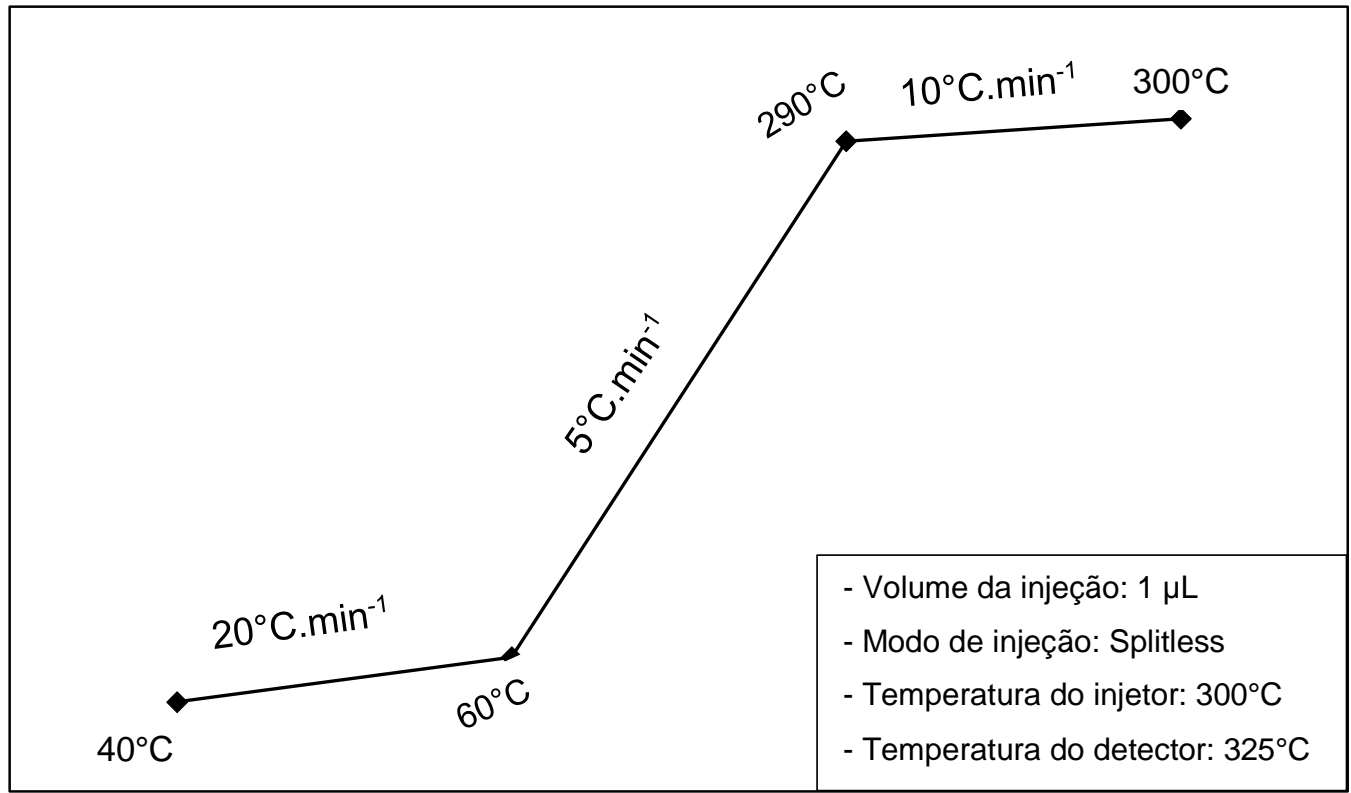

Figura 11 - Condições cromatográficas utilizadas na determinação dos marcadores orgânicos no CG-DIC.

A quantificação dos compostos foi realizada através do programa HP Chemstation (G2070 BA). O critério utilizado para aceitação da curva analítica de um determinado composto foi o índice de correlação linear de Pearson igual ou superior a 99,5\% ( $\left.r^{2}=0,995\right)$, construída com $0 ; 1,0 ; 2,5 ; 5,0 ; 7 ; 5,10$ e 20 $\mu \mathrm{L}^{-1}$. A identificação dos compostos foi feita através da relação massa/área dos padrões surrogate com o padrão interno cromatográfico, os tempos de retenção coincidentes com o verificado nas amostras foram considerados como sendo dos mesmos compostos. 
4.5. Equipamentos

A tabela 5 apresenta todos os equipamentos utilizados nesse trabalho.

Tabela 5 - Equipamentos

\begin{tabular}{cc}
\hline Equipamento & Modelo \\
\hline Agitador de tubo vortex & Fisherbrand \\
Balança semi-analítica & Marte - AL 500 \\
Centrífuga & KASVI - K14-0815 \\
Estufa & Fanem - 515 \\
Mufla & \\
Evaporador rotativo a vácuo & Fisatom - RPM 802 \\
Cromatógrafo a gás (CG- & Agilent Technologies \\
DIC) & Modelo 6890 \\
\hline
\end{tabular}

4.6. Reagentes e Solventes

Os reagentes e solventes utilizados durante a extração e purificação das amostras de sedimento estão descritos na Tabela 6. O ácido clorídrico e os solventes orgânicos diclorometano e n-hexano foram descartados em recipientes adequados e foram doados para o Instituto de Química da USP para serem neutralizados, já o metanol é incinerado. 
Tabela 6 - Reagentes e solventes utilizados nas etapas de extração e purificação.

\begin{tabular}{cc}
\hline Reagente ou solvente & Fabricante \\
\hline Ácido clorídrico & Synth \\
Alumina & Merck \\
Sílica gel & Merck \\
Sulfato de sódio & Merck \\
Nitrogênio & Gama \\
Extran & Merck \\
n-hexano & Honeywell Riedel-de \\
& Haën \\
Metanol & Panreac \\
Diclorometano & Panreac \\
BSTFA/TMCS & Sigma-Aldrich \\
\hline
\end{tabular}

\subsection{Avaliação do método analítico}

As análises químicas realizadas em amostras ambientais demandam de diversos cuidados analíticos e etapas de controle metodológico para que os resultados obtidos sejam confiáveis. O controle de qualidade do método é o conjunto de técnicas e atividades operacionais que são usadas para fornecer requerimentos de qualidade que descreve medidas individuais, as quais são referentes à qualidade das análises das amostras, individual ou em grupo (CITAC/EURACHEM, 2002). O controle da qualidade foi baseado através da determinação do limite de detecção, análise de brancos, brancos fortificados, material de referência certificado e uma matriz fortificada com padrões externos (WADE \& CANTILLO, 1994). As tabelas 7 e 8 apresentam os resultados da avaliação do controle de qualidade para os HAs, esteróis e álcoois. 
Tabela 7 - Resultados da avaliação do método analítico dos $n$-alcanos individuais.

\begin{tabular}{|c|c|c|c|c|c|c|c|c|c|c|}
\hline & $\begin{array}{c}\text { LDM } \\
\left(\mathrm{ng} \mathrm{g}^{-1}\right)\end{array}$ & $\begin{array}{l}\text { Branco } \\
\left(\mathrm{ng} \mathrm{g}^{-1}\right)\end{array}$ & $\begin{array}{c}\text { Branco } \\
\text { fortificado } \\
\left(n g g^{-1}\right)\end{array}$ & $\begin{array}{c}\text { Rec. do } \\
\text { Branco } \\
\text { fortificado } \\
(\%)\end{array}$ & $\begin{array}{c}\text { Amostra } \\
\left(\mathrm{ng} \mathrm{g}^{-1}\right)\end{array}$ & $\begin{array}{c}\text { Amostra } \\
\text { duplicata } \\
\left(\mathrm{ng} \mathrm{g}^{-1}\right)\end{array}$ & $\begin{array}{c}\text { Amostra } \\
\text { fortificada } \\
\left(n g g^{-1}\right)\end{array}$ & $\begin{array}{c}\text { Rec. da } \\
\text { amostra } \\
\text { fortificada } \\
(\%)\end{array}$ & $\begin{array}{c}\text { IAEA-417 } \\
\left(\mathrm{ng} \mathrm{g}^{-1}\right)\end{array}$ & PRD (\%) \\
\hline $\begin{array}{l}n-C_{12} \\
n-C_{13}\end{array}$ & $\begin{array}{l}0,003 \\
0,001\end{array}$ & $\begin{array}{l}<\mathrm{LDM} \\
<\mathrm{LDM}\end{array}$ & $\begin{array}{l}0,151 \\
0,216\end{array}$ & $\begin{array}{l}60 \\
86\end{array}$ & $\begin{array}{l}0,000 \\
0,004\end{array}$ & $\begin{array}{l}0,000 \\
0,003\end{array}$ & $\begin{array}{l}0,151 \\
0,210\end{array}$ & $\begin{array}{l}61 \\
84\end{array}$ & $\begin{array}{l}<\text { LDM } \\
0,044\end{array}$ & $\begin{array}{l}0 \\
7\end{array}$ \\
\hline$n-C_{14}$ & 0,002 & 0,004 & 0,276 & 110 & 0,005 & 0,008 & 0,276 & 110 & 0,115 & 11 \\
\hline$n-C_{15}$ & 0,004 & 0,007 & 0,251 & 101 & 0,010 & 0,006 & 0,256 & 102 & 0,109 & 11 \\
\hline$n-C_{16}$ & 0,001 & 0,011 & 0,259 & 103 & 0,000 & 0,000 & 0,265 & 106 & 0,482 & 0 \\
\hline$n-C_{17}$ & 0,005 & 0,006 & 0,271 & 108 & 0,017 & 0,014 & 0,283 & 113 & 0,358 & 4 \\
\hline Pristano & 0,008 & $<$ LDM & 0,273 & 109 & 0,001 & 0,001 & 0,272 & 109 & 0,246 & 9 \\
\hline$n-C_{18}$ & 0,002 & $<$ LDM & 0,280 & 112 & 0,012 & 0,019 & 0,268 & 107 & 0,524 & 11 \\
\hline Fitano & 0,002 & $<$ LDM & 0,276 & 110 & 0,006 & 0,005 & 0,277 & 111 & 0,215 & 6 \\
\hline$n-C_{19}$ & 0,005 & $<$ LDM & 0,272 & 109 & 0,011 & 0,009 & 0,276 & 110 & 0,536 & 4 \\
\hline$n-C_{20}$ & 0,008 & 0,037 & 0,275 & 110 & 0,021 & 0,019 & 0,236 & 94 & 0,111 & 2 \\
\hline$n-C_{21}$ & 0,011 & $<$ LDM & 0,265 & 106 & 0,012 & 0,011 & 0,263 & 105 & 0,121 & 2 \\
\hline$n-C_{22}$ & 0,003 & $<$ LDM & 0,241 & 96 & 0,008 & 0,007 & 0,262 & 105 & 0,045 & 1 \\
\hline$n-C_{23}$ & 0,006 & $<\mathrm{LDM}$ & 0,285 & 114 & 0,009 & 0,009 & 0,256 & 102 & 0,167 & 0 \\
\hline$n-C_{24}$ & 0,006 & $<$ LDM & 0,290 & 116 & 0,002 & 0,002 & 0,269 & 108 & 1,143 & 2 \\
\hline$n-C_{25}$ & 0,027 & $<$ LDM & 0,245 & 98 & 0,010 & 0,010 & 0,262 & 105 & 0,265 & 1 \\
\hline$n-C_{26}$ & 0,007 & $<$ LDM & 0,210 & 84 & 0,005 & 0,005 & 0,257 & 103 & 0,694 & 0 \\
\hline$n-C_{27}$ & 0,034 & $<\mathrm{LDM}$ & 0,298 & 119 & 0,017 & 0,016 & 0,265 & 106 & 0,541 & 1 \\
\hline$n-C_{28}$ & 0,034 & $<$ LDM & 0,223 & 89 & 0,006 & 0,005 & 0,259 & 104 & 0,243 & 3 \\
\hline$n-C_{29}$ & 0,028 & $<$ LDM & 0,287 & 115 & 0,037 & 0,063 & 0,294 & 117 & 0,891 & 12 \\
\hline
\end{tabular}




\begin{tabular}{|c|c|c|c|c|c|c|c|c|c|c|}
\hline$n-C_{30}$ & 0,028 & $<$ LDM & 0,275 & 110 & 0,014 & 0,014 & 0,258 & 103 & 0,570 & 1 \\
\hline$n-C_{31}$ & 0,026 & $<$ LDM & 0,288 & 115 & 0,054 & 0,066 & 0,288 & 115 & 0,640 & 4 \\
\hline$n-C_{32}$ & 0,026 & $<$ LDM & 0,390 & 156 & 0,010 & 0,018 & 0,215 & 86 & 2,217 & 14 \\
\hline$n-C_{33}$ & 0,012 & $<$ LDM & 0,295 & 118 & 0,023 & 0,028 & 0,271 & 108 & 3,851 & 5 \\
\hline$n-C_{34}$ & 0,012 & $<$ LDM & 0,282 & 112 & 0,009 & 0,008 & 0,243 & 97 & 0,533 & 1 \\
\hline$n-C_{35}$ & 0,012 & $<$ LDM & 0,279 & 111 & 0,009 & 0,008 & 0,249 & 100 & 0,231 & 2 \\
\hline
\end{tabular}


Tabela 8 - Resultados da avaliação do método analítico para os esteróis e álcoois.

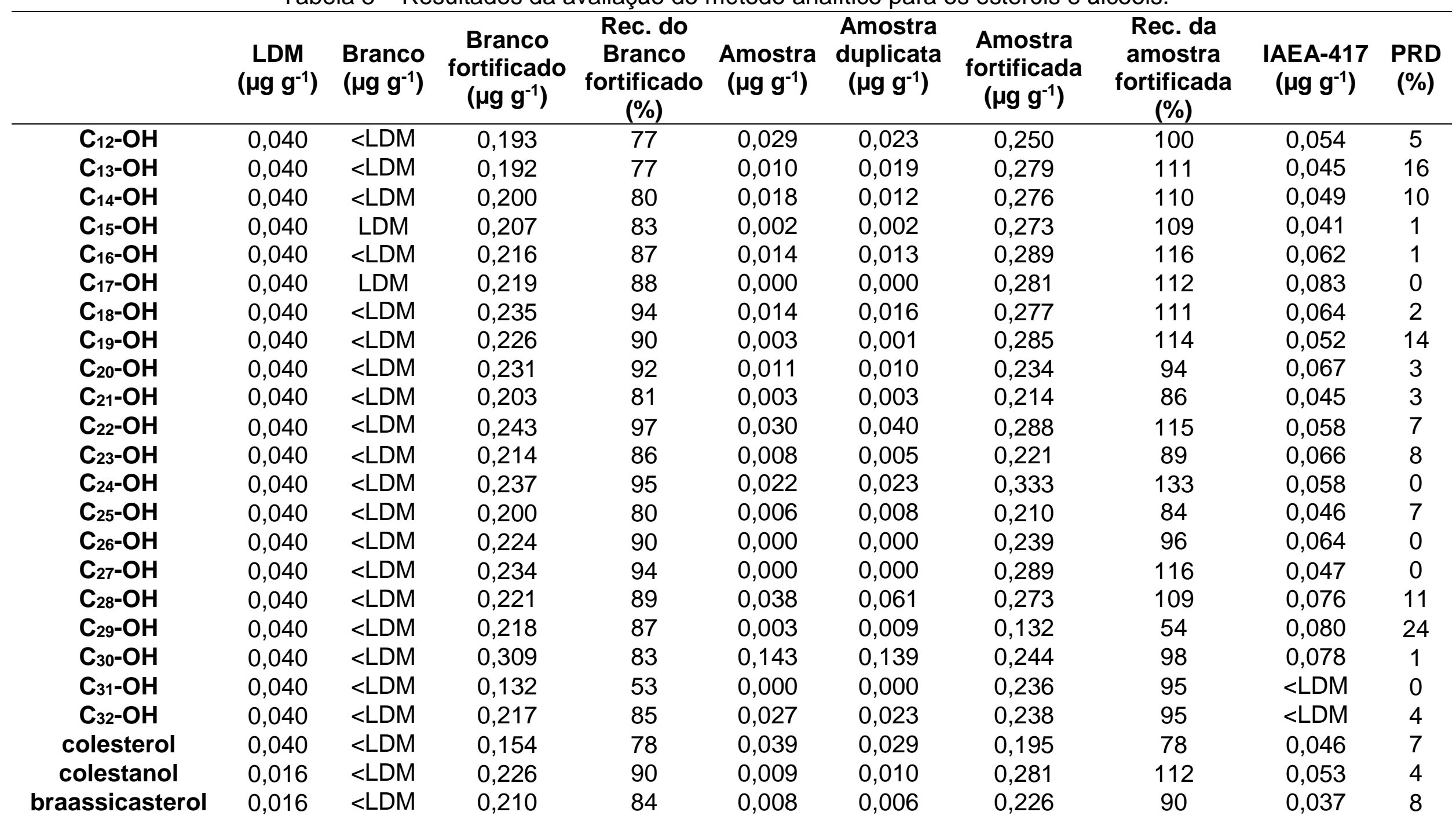




\begin{tabular}{ccccccccccc} 
brassicastanol & 0,016 & LLDM & 0,204 & 82 & 0,087 & 0,099 & 0,164 & 65 & 0,053 & 3 \\
campesterol & 0,016 & LLDM & 0,150 & 60 & 0,009 & 0,004 & 0,169 & 68 & 0,007 & 15 \\
campestanol & 0,016 & LLDM & 0,139 & 56 & 0,191 & 0,133 & 0,221 & 89 & 0,061 & 9 \\
estigmasterol & 0,023 & LLDM & 0,159 & 64 & 0,035 & 0,029 & 0,191 & 76 & 0,047 & 5 \\
estigmastanol & 0,023 & LLDM & 0,195 & 78 & 0,004 & 0,005 & 0,258 & 103 & 0,044 & 5 \\
b-sitosterol & 0,026 & LLDM & 0,159 & 64 & 0,051 & 0,036 & 0,212 & 85 & 0,058 & 9 \\
b-sitostanol & 0,028 & LLDM & 0,210 & 84 & 0,010 & 0,011 & 0,220 & 88 & 0,066 & 3 \\
\hline
\end{tabular}


O limite de detecção do método (LDM) pode ser definido como a concentração mínima que uma substância pode ser mensurada, garantindo que a concentração do analito é maior do que zero (WADE \& CANTILLO, 1994), neste trabalho o LDM foi determinado pelo menor valor da curva analítica, no qual a substância pôde ser detectada (RIBANI et al., 2004).

O branco é preparado a cada bateria de extração, sem incluir a matriz (sedimento). Para que seja aceitável, o branco não pode apresentar mais que três picos referentes aos compostos analisados e a sua concentração não pode ser superior que 3 vezes o limite de detecção do método (WADE \& CANTILLO, 1994). Essa análise tem como objetivo identificar os possíveis interferentes ao longo do processamento das amostras, especificamente as contaminações de solventes, reagentes, adsorventes ou vidrarias. Caso contrário, as amostras analisadas com esse branco devem ser refeitas (WADE \& CANTILLO, 1994). No branco do método de $n$-alcanos 5 compostos apresentaram valores acima do limite de detecção. No método dos esteróis e álcoois 5 compostos avaliados apresentaram concentração superior ao limite de detecção estabelecido.

O branco fortificado é utilizado para indicar os valores das recuperações dos compostos adicionados nas amostras (brancos), em concentrações conhecidas e a sua exatidão. Um resultado aceitável deve apresentar $80 \%$ dos analitos com recuperação entre 50 a 120\%. A recuperação do branco fortificado apresentou valores dentro da faixa esperada.

$\%$ Recuperação (fortificado) $=\frac{\text { quantidade encontrada (final) }}{\text { quantidade adicionada (inicial) }} \times 100$

(Equação 4)

Matriz fortificada: avalia a recuperação dos analitos na presença de uma matriz sedimentar. E a duplicata é usada para verificar a presença de uma matriz representativa, representando a respeitabilidade do método. Uma recuperação aceitável tem que estar entre 50 a 120\% (DENOUX et al., 1998) para $80 \%$ dos analitos e as análises em duplicata devem apresentar um percentual relativo de diferença (PRD) menor ou igual a $25 \%$. O PRD é estabelecido através da equação: 


$$
\operatorname{PRD}(\%)=\left[\frac{\text { amostra-amostra duplicata }}{\text { média }(\text { amostra }+ \text { duplicata })}\right] \times 100
$$

(Equação 5)

Para as amostras fortificadas, além de adicionar $100 \mu \mathrm{L}$ do padrão surrogate de uma concentração de $50 \mathrm{ng} \mathrm{\mu L}^{-1}$, também foram adicionados 50 $\mu \mathrm{L}$ do padrão fortificado (spike), de uma concentração de $50 \mathrm{ng} \mu \mathrm{L}^{-1}$, em uma amostra com $20 \mathrm{~g}$ de sulfato de sódio para a avaliação dos $n$-alcanos, esteróis e álcoois.

O Material de Referência Certificado (MRC) é analisado para avaliar a exatidão dos resultados obtidos com o uso da metodologia utilizada no trabalho com os valores do certificado. O MRC utilizado nesse projeto foi o IAEA-417, sedimento proveniente da Lagoa de Veneza, na Itália, que foi fornecido e creditado pela Agência Internacional de Energia Atômica da Organização das Nações Unidas. Para que o resultado seja considerado satisfatório, 95\% dos compostos de interesse devem ser encontrados próximos aos valores certificados. Os valores do MRC analisados neste estudo ficaram dentro do esperado.

A recuperação do padrão surrogate consiste na comparação entre a quantidade adicionada no início e a obtida ao término do processo, permitindo assim, correções quanto a perdas durante as análise das amostras. No cálculo da porcentagem de recuperação, a quantidade de padrão interno cromatográfico (PICG) é conhecida, e a sua concentração é calculada em função do padrão surrogate. A partir dele são feitas as correções nas quantificações de todos os compostos analisados. O intervalo de recuperação adotado como satisfatório é de 50 a 120\% (DENOUX et al, 1998). 


\section{RESULTADOS E DISCUSSÕES}

\subsection{Amostras de Sedimentos Superficiais}

Para avaliar a distribuição da influência marinha e continental na área de estudo foram analisados marcadores marinhos e terrígenos nos sedimentos superficiais. A Tabela 9 a seguir apresenta as porcentagens (COT, NT, $\delta^{13} \mathrm{C}$, $\left.\delta^{15} \mathrm{~N}\right)$ e as concentrações totais dos HAs, Esteróis e Álcoois. Os resultados individuais de cada parâmetro estão inseridos em apêndice (Tabela I a XVIII). 
Tabela 9 - Valores dos parâmetros avaliados no sedimento superficial da área de estudo. $\mathrm{Lama}=$ silte + argila; $\mathrm{CaCO}_{3}=$ carbonato de cálcio; COT = carbono orgânico total; NT = nitrogênio total; $\mathrm{C} / \mathrm{N}$ = razão carbono orgânico/nitrogênio total; $\delta^{13} \mathrm{C}=$ razão isotópica do carbono orgânico; $\delta^{15} \mathrm{~N}=$ razão isotópica do nitrogênio total; $\Sigma$ HAs = somatório dos alifáticos totais; $\Sigma$ Esteróis = somatório dos esteróis; $\Sigma$ Álcoois = somatório dos álcoois.

\begin{tabular}{|c|c|c|c|c|c|c|c|c|c|c|c|}
\hline Estações & $\begin{array}{c}\text { Areia } \\
(\%)\end{array}$ & $\begin{array}{c}\text { Lama } \\
(\%)\end{array}$ & $\begin{array}{c}\mathrm{CaCO}_{3} \\
(\%)\end{array}$ & $\begin{array}{c}\text { COT } \\
(\%)\end{array}$ & $\begin{array}{l}\text { NT } \\
(\%)\end{array}$ & $\mathrm{C} / \mathrm{N}$ & $\begin{array}{l}\delta^{13} \mathrm{C} \\
(\%)\end{array}$ & $\begin{array}{l}\delta^{15} \mathrm{~N} \\
(\%)\end{array}$ & $\begin{array}{c}\mathbf{\Sigma} \\
\mathbf{H A s} \\
\left(\mu \mathrm{g} \mathrm{g}^{-1}\right)\end{array}$ & $\begin{array}{c}\Sigma \\
\text { Esteróis } \\
\left(\mu g^{-1}\right)\end{array}$ & $\begin{array}{c}\Sigma \\
\text { Álcoois } \\
\left(\mu \mathrm{g} \mathrm{g}^{-1}\right)\end{array}$ \\
\hline 249 & 38,30 & 61,70 & 32,20 & 0,43 & 0,08 & 5,12 & $-21,72$ & 5,44 & 0,77 & 0,98 & 0,42 \\
\hline 250 & 56,20 & 43,80 & 53,30 & 0,30 & 0,05 & 6,59 & $-20,95$ & 3,10 & 0,82 & 0,76 & 0,27 \\
\hline 253 & 40,40 & 59,60 & 33,45 & 0,88 & 0,11 & 7,88 & $-21,36$ & 5,02 & 0,82 & 1,09 & 0,49 \\
\hline 254 & 27,70 & 72,30 & 25,96 & 0,92 & 0,15 & 6,04 & $-20,91$ & 6,14 & 1,34 & 1,65 & 0,64 \\
\hline 255 & 48,10 & 51,90 & 41,34 & 0,71 & 0,10 & 7,10 & $-21,57$ & 6,36 & 3,17 & 2,47 & 1,25 \\
\hline 256 & 33,30 & 66,70 & 49,90 & 0,52 & 0,08 & 6,11 & $-21,42$ & 5,57 & 0,78 & 1,03 & 0,49 \\
\hline 257 & 31,70 & 68,30 & 27,01 & 1,05 & 0,10 & 10,39 & $-21,12$ & 5,38 & 0,75 & 1,59 & 0,58 \\
\hline 258 & 29,20 & 70,80 & 42,63 & 0,62 & 0,10 & 6,11 & $-21,18$ & 5,79 & 1,21 & 1,33 & 0,50 \\
\hline 259 & 42,10 & 57,90 & 55,06 & 0,41 & 0,08 & 4,83 & $-20,86$ & 4,46 & 1,25 & 1,10 & 0,81 \\
\hline 260 & 38,80 & 61,20 & 68,57 & 0,38 & 0,11 & 3,60 & $-20,86$ & 4,81 & 0,86 & 1,18 & 0,74 \\
\hline 262 & 45,30 & 54,70 & 41,99 & 0,38 & 0,06 & 6,64 & $-20,40$ & 5,67 & 0,58 & 0,87 & 0,45 \\
\hline 263 & 33,80 & 66,20 & 29,50 & 0,69 & 0,07 & 9,67 & $-20,86$ & 3,45 & 0,98 & 1,17 & 0,83 \\
\hline 264 & 68,20 & 31,80 & 43,60 & 0,28 & 0,06 & 4,38 & $-21,94$ & 3,58 & 0,71 & 0,58 & 0,37 \\
\hline
\end{tabular}




\subsubsection{Granulometria}

A distribuição granulométrica das amostras de sedimento superficial indicou uma predominância da fração lamosa (silte+argila) em relação a fração arenosa, exceto nos pontos 250 e 264, nos quais houve a predominância de areia, com teores de 56 e $68 \%$, respectivamente.

Os maiores teores de silte + argila foram obtidos nas estações 254 (72\%) e 257 (68\%), nos pockmarks e 258 (71\%), na região externa. A granulometria mais fina é um padrão encontrado frequentemente nos pockmarks (USSLER et al., 2003; MANLEY et al., 2004; WEBB et al., 2009). A presença de uma maior porcentagem de lama nas estações 254 e 257 pode estar relacionada à atuação da corrente de fundo, que ao passar nas depressões, enfraquece a velocidade da corrente devido a profundidade dos pockmarks, ocasionando o aprisionamento de sedimentos finos (Figura 12). Essa acumulação de sedimentos finos normalmente ocorre em pockmarks inativos, em razão da ausência de exsudações, facilitando a deposição nessas concavidades (PAU et al. 2013).

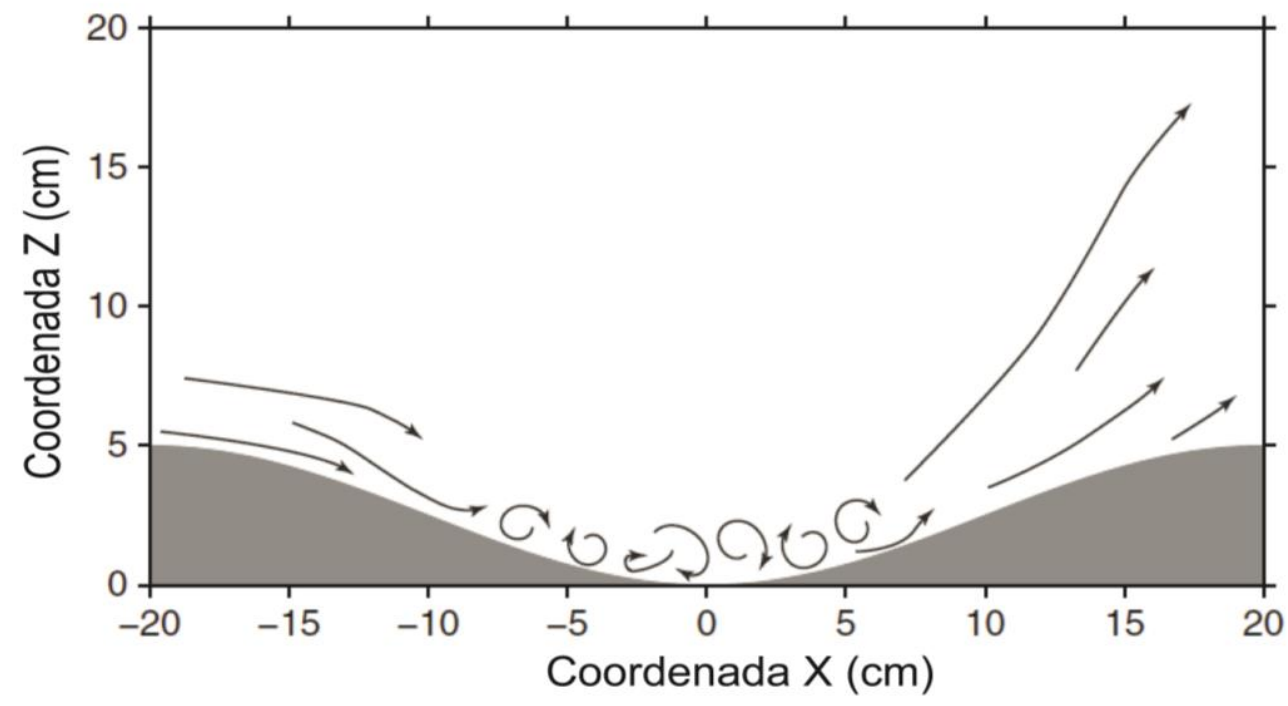

Figura 12 - llustração esquemática do padrão de fluxo no interior dos pockmarks (PAU et al. 2013).

Os maiores teores de areia foram observados nas estações 264 $(68,2 \%)$ e 250 (56,2\%), que podem estar relacionados à morfologia dos 
diápiros, que apresentam paredes cilíndricas, reduzindo a deposição de sedimentos finos devido ao fluxo da ACAS ser atuante na região de estudo.

A Figura 13 apresenta os teores de lama (silte + argila) e areia das amostras analisadas na região.

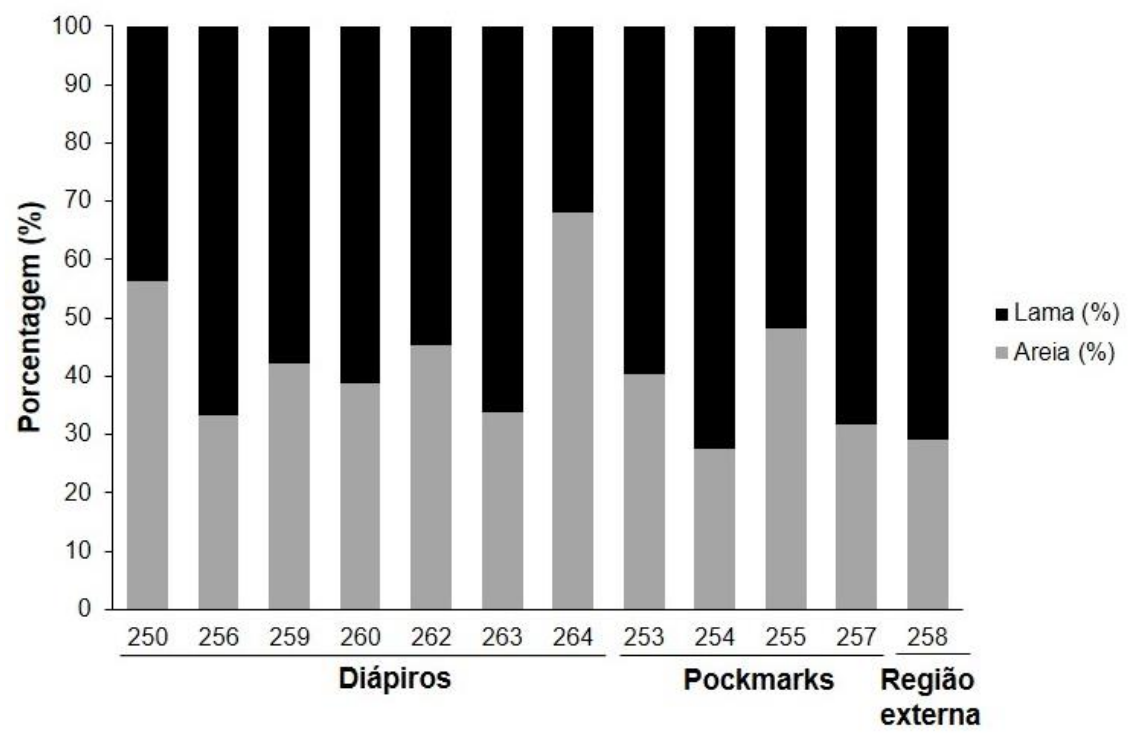

Figura 13 - Distribuição do teor de areia e lama (silte+argila) na área de estudo.

Outros fatores que controlam a entrada e a redistribuição de sedimentos nas margens passivas são o deslocamento de massas, taxas de produção primária e mudanças no nível do mar. A região de estudo é composta por cânions submarinos que podem gerar fluxos gravitacionais de massa, que transportam sedimentos de origem continental depositados em plataforma para o talude continental. Esta combinação que caracteriza um ambiente intermediário entre áreas de domínio de sedimentação de origem continental e pelágica, é típica de talude continental (PONZI, 2004).

\subsubsection{Características composicionais das amostras de sedimento de superfície}

Os dados dos teores de carbono orgânico e carbonato de cálcio nos sedimentos podem refletir a produtividade oceânica. No entanto, as variações na porcentagem de $\mathrm{CaCO}_{3}$ ocorrem em função do balanço entre a produtividade primária da zona eufótica, sua dissolução e diluição, ocasionada 
pelo aumento do fluxo de sedimentos terrígenos (DITTERT et al., 1999; RUHLEMAN et al., 1999; NAGAl, 2009). Segundo estudos de SCHATTNER et al., 2016 e MAHIQUES et al., 2017, os pockmarks e diapiros próximos da região de estudo foram marcadas pela sedimentação carbonática.

Os maiores teores de carbonato de cálcio $\left(\mathrm{CaCO}_{3}\right)$ foram obtidos nas estações 260 (68,5\%) e 259 (55,0\%), localizados nos diápiros. Já os menores teores foram localizados nas estações 254 (25,9\%) e 257 (27,0\%), nos pockmarks (Tabela 9).
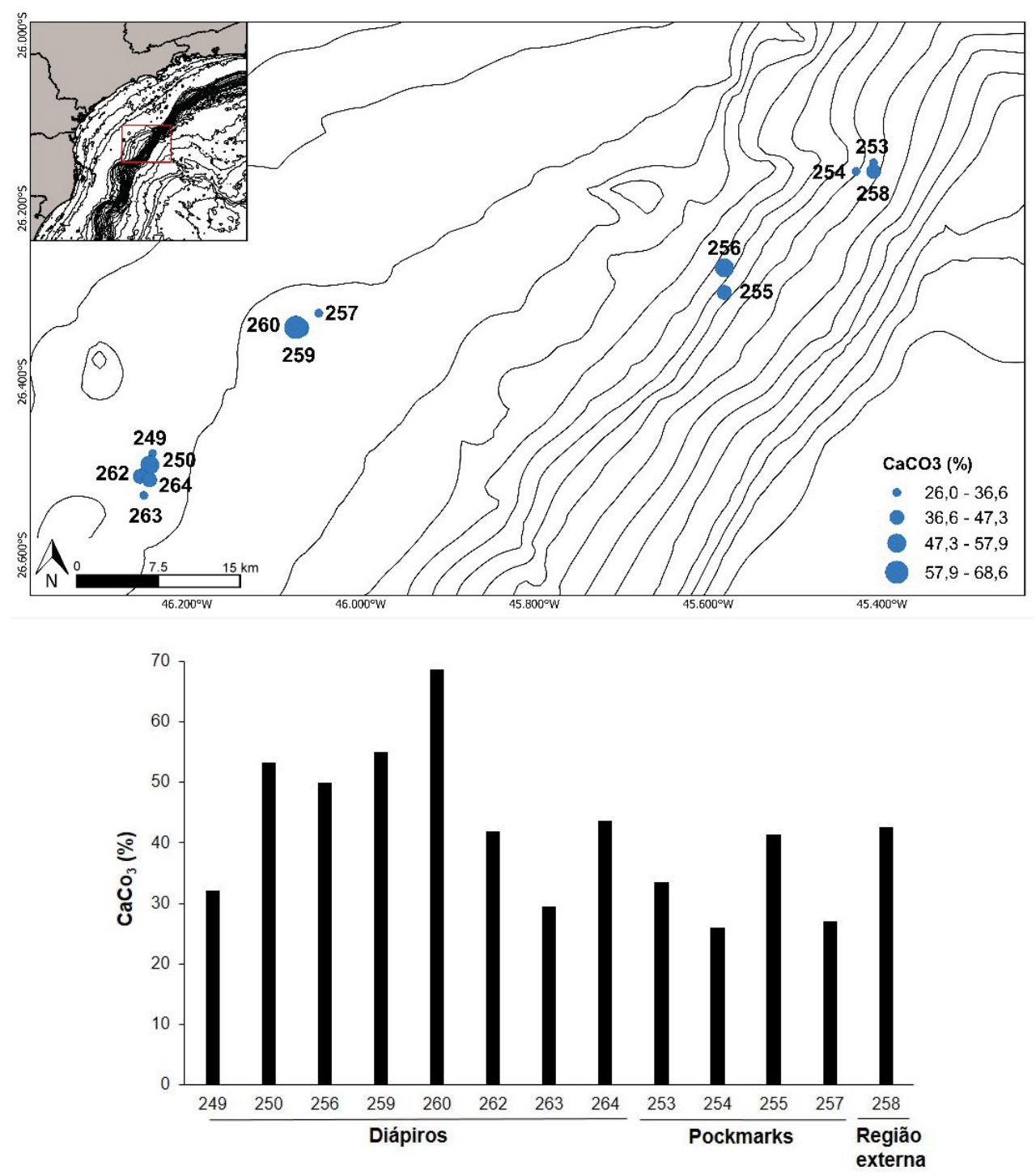

Figura 14 - Distribuição de carbonatos (\%) em sedimentos localizados na área de estudo.

Através da Figura 14 foi possível observar que os pockmarks 254 e 257 apresentaram os menores teores de $\mathrm{CaCO}_{3}$, por causa da maior diluição do 
carbonato por aporte de material terrígeno nas depressões, resultante das interações entre a corrente de fundo e a morfologia dos pockmarks, aprisionando sedimentos nas depressões mais profundas.

Os menores teores de $\mathrm{CaCO}_{3}$ observados nos diápiros 249, 262, 263, 264, ao sul da região de estudo, pode ser atribuídas às contribuições de sedimentos oriundos dos canais de drenagem continental e pela maior influência da Pluma do Rio da Prata no inverno, com exceção da estação 250, que apresentou altos teores de $\mathrm{CaCO}_{3}$.

As maiores concentrações verificadas nas estações 260 (68,5\%) e 259 $(55,0 \%)$ podem ser resultantes da formação das estruturas dômicas dos diápiros, devido à atuação da corrente de fundo (ACAS), que transporta os sedimentos mais finos para outros locais, permanecendo os detritos de $\mathrm{CaCO}_{3}$. O carbonato nos sedimentos são derivados da produção fitoplanctônica, transportada da zona fótica até o assoalho oceânico.

Segundo as subdivisões de LARSONNEUR, 1977, as amostras foram classificadas como depósitos litoclásticos (menos de $30 \%$ de $\mathrm{CaCO}_{3}$ ) e biolitoclástico (de 30 a 70\% de $\mathrm{CaCO}_{3}$ ). As estações 254, 257 e 263 foram classificadas como litoclásticas, caracterizadas por sedimentos terrígenos de origem continental. A presença de depósitos litoclásticos na parte interna dos pockmarks pode estar associado ao aprisionamento de sedimentos alóctones proveniente da ação de correntes de fundo, aumentando a dissolução de $\mathrm{CaCO}_{3}$ nessas regiões. A existência de sedimentos terrígenos no diápiro da região sul (estação 263), pode estar relacionada as menores profundidades, favorecendo a deposição do sedimento alóctone no assoalho oceânico. As demais estações foram classificadas como biolitoclásticas, apresentando sedimentos continentais e biológicos.

O teor de Carbono Orgânico Total (COT) analisados em sedimentos superficiais variou entre 0,27 a $1,05 \%$ nas estações 264 e 257, respectivamente (Figura 15). 

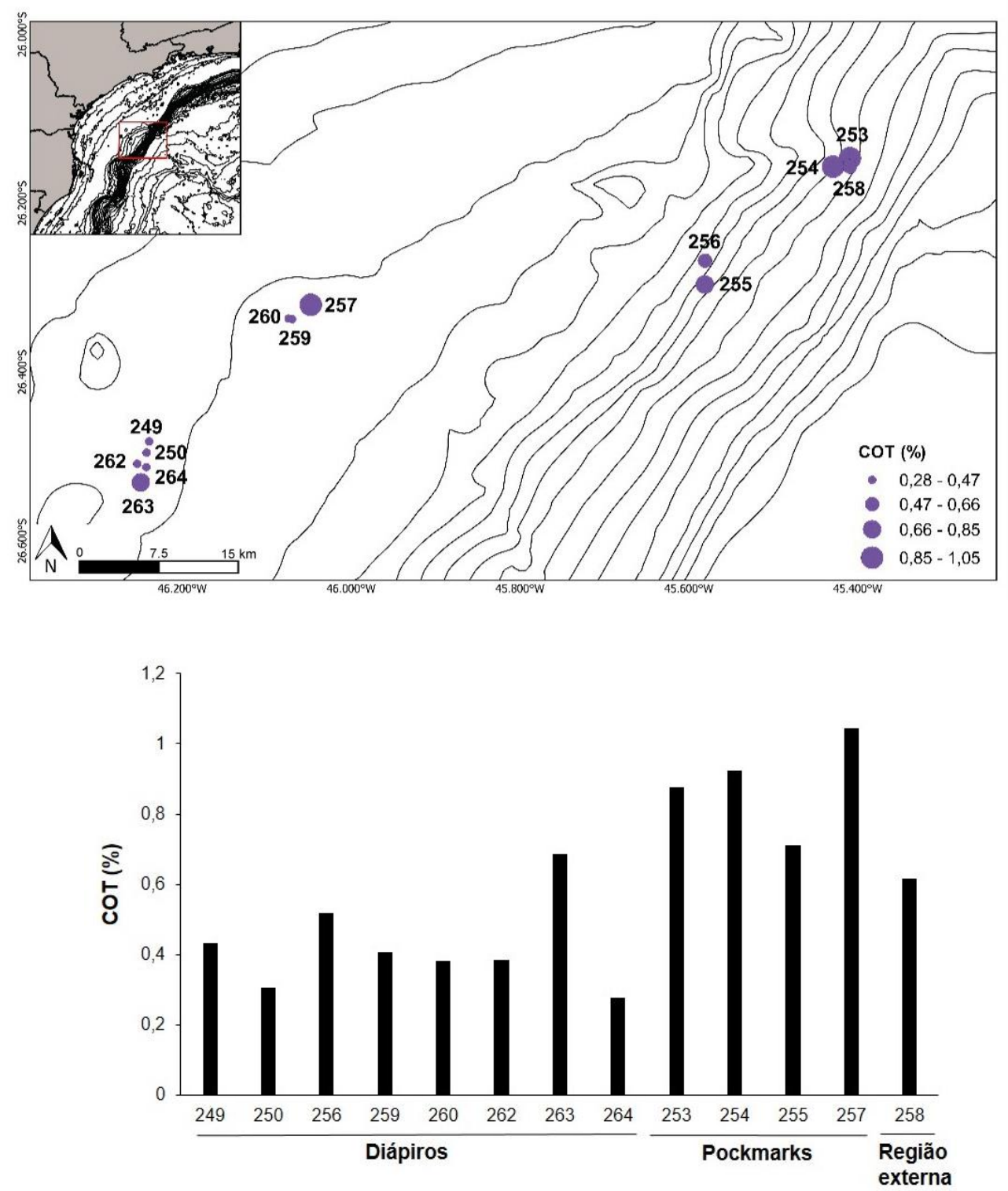

Figura 15 - Teores de carbono orgânico total (\%) no sedimento da área de estudo.

De acordo com Rashid, (1985), um baixo conteúdo de carbono orgânico $(<0,5 \%)$ é típico de mares abertos, porém os teores neste estudo foram superiores, atribuindo-se os resultados de COT aos aportes de matéria orgânica continental e marinha na região. Os valores mais altos de COT foram encontrados nas estações 257 (1,05\%), 254 (0,92\%) e 253 (0,88\%) nos pockmarks e pode estar relacionada ao aprisionamento de sedimentos, acumulando matéria orgânica dentro dos pockmarks mais profundos.

A presença significativa de COT na estação 258 , localizado na região externa, pode estar associada a sua profundidade de 730,9 metros e pela porcentagem de lama (silte+argila) de 70,8\%. O COT nas depressões indica 0 
possível fluxo de produtividade primária nas águas superficiais para o assoalho oceânico e da deposição de matéria orgânica alóctone.

Os menores teores de COT encontrados nas estações $250(0,30 \%)$ e $264(0,27 \%)$, localizados nos diápiros ao sul da área de estudo foram associados a presença de sedimentos arenosos 68,2\% (Estação 264) e 56,2\% (Estação 250), uma vez que a característica cilíndrica dos diápiros corrobora para a maior deposição de areia, que é um mineral de comportamento químico inerte ou que adsorve quantidades insignificantes de matéria orgânica, exceto na estação 263 onde os teores de COT (0,68\%) e a porcentagem de lama $(66,2 \%)$ são relativamente elevados em relação aos outros diápiros.

A correlação entre COT e NT presentes na amostra, pode indicar se o nitrogênio orgânico é predominante. A falta de uma correlação linear positiva entre os dados é um indicativo da predominância da fração inorgânica do nitrogênio. Através do cálculo, foi possível observar uma correlação fraca, ou seja, apenas uma pequena parcela da variação dos dados do nitrogênio total pode ser explicada pelo carbono orgânico total $\left(R^{2}=0,48\right)$, o que indica que 0 nitrogênio presente nas amostras não é predominantemente orgânico, sendo assim, a razão $\mathrm{C} / \mathrm{N}$ e a razão isotópica do nitrogênio total $\left(\delta^{15} \mathrm{~N}\right)$ para verificar a origem da matéria orgânica no sedimento não pode ser utilizada (Figura 16).

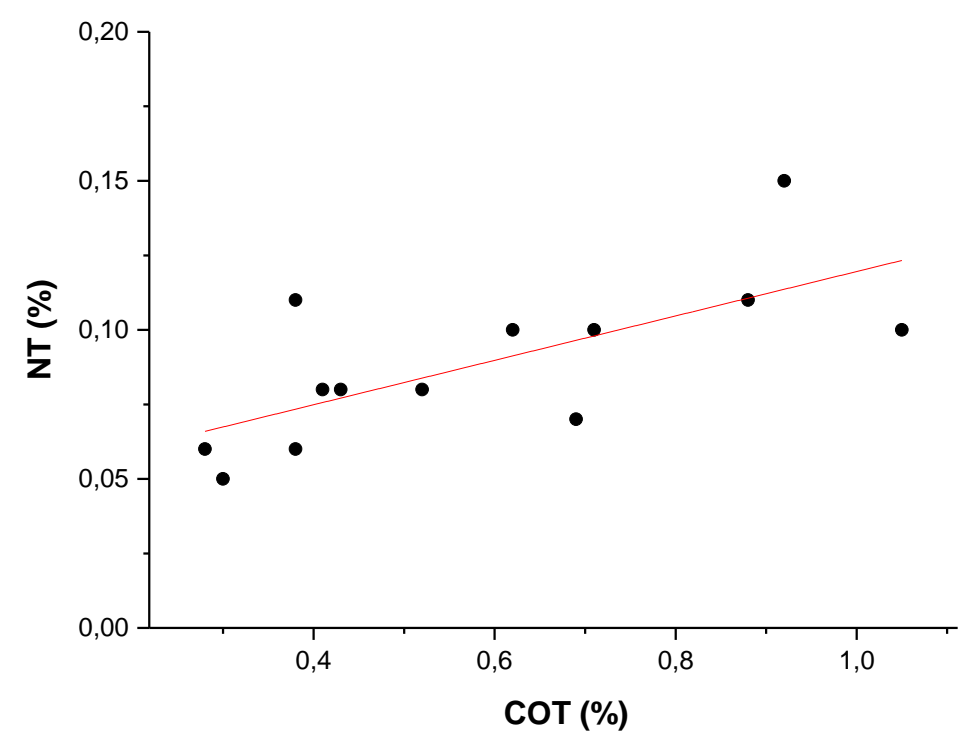

Figura 16 - Correlação linear entre o carbono orgânico total e o nitrogênio total. 
Através da utilização da razão isotópica do carbono orgânico total $\left(\delta^{13} \mathrm{C}\right)$ é possível identificar as possíveis fontes da matéria orgânica depositada (LAMN et al., 2006). A matéria orgânica de origem terrestre possui valores das razões $\delta^{13} \mathrm{C}$ que variam entre -23\%o e -34\%o (MEYERS, 1997). Já a matéria orgânica de origem marinha, enriquecidos com material de predomínio planctônico, possui valores de $\delta^{13} \mathrm{C}$ entre $-20 \%$ e $-22 \%$ (MEYERS, 1994). O $\delta^{13} \mathrm{C}$ normalmente encontrado em emanações frias, apresentam valores tipicamente mais negativos, entre -45 a $-60 \%$ (WHITICAR et al., 1986; USSLER et al., 2003). As análises de $\delta^{13} \mathrm{C}$ mostraram que todas as estações apresentaram os valores variando entre $-22 \%$ e $-20 \%$, indicando que a composição isotópica do carbono orgânico é tipicamente fitoplanctônica (MEYERS, 1994), não havendo evidências de liberação de gases/fluídos nos sedimentos superficiais da área de estudo.

A presença de detritos de fitoplâncton no assoalho é proveniente do transporte da matéria orgânica presente na coluna d'água para a plataforma e no talude continental. A produção primária nas águas superficiais pode ser advinda da penetração sazonal de águas frias, pouco salinas e ricas em nutrientes provenientes da drenagens de importantes rios (PIOLA et al., 2008; CAMPOS et al., 2013).

\section{Marcadores Orgânicos Moleculares}

\subsubsection{Hidrocarbonetos Alifáticos (HAs)}

A origem de hidrocarbonetos pode ser inferida a partir da distribuição dos compostos individuais, definida por um conjunto de parâmetros e índices que são úteis para distinguir as contribuições de hidrocarbonetos de origens biogênicas (marinho/terrestre). De modo geral, as amostras apresentaram a predominância de $n$-alcanos com cadeias longas ímpares sobre as pares (Tabela 10). A influência de $n$-alcanos de cadeia longa em amostras de sedimento é comum nos hidrocarbonetos alifáticos naturais. Isto porque, estes compostos são mais persistentes e a composição lipídica é maior se comparada ao do fitoplâncton (3-5\%) (BIANCHI e CANUEL, 2011). Adicionalmente, os $n$-alcanos marinhos são preferencialmente degradados 
durante a sua deposição, enquanto que os $n$-alcanos terrestres são compostos mais resistentes o que faz com que eles permaneçam no registro sedimentar ao longo do tempo (MEYERS, 1997). Desta forma, pode-se considerar que a contribuição de hidrocarbonetos biogênicos para a região do talude é a de origem continental, ou seja, alóctone. 
Tabela 10 - Concentrações dos $n$-alcanos, alcanos isoprenóides, MCNR, em $\mu \mathrm{g} \mathrm{g}^{-1}$, e parâmetros de avaliação de fontes de hidrocarbonetos alifáticos. <LDM: abaixo do limite de detecção; Alcanos totais: somatório dos compostos $n$ - $\mathrm{C}_{10}$ ao $n$-C 40 ; Pris/Fit: razão entre o pristano e o fitano, $\mathrm{IA}=\left(n-\mathrm{C}_{31} / n-\mathrm{C}_{31}+n-\mathrm{C}_{29}\right), n-\mathrm{C}_{12+14+16}=\sum\left(\mathrm{n}-\mathrm{C}_{12}+\mathrm{n}-\mathrm{C}_{14}+\mathrm{n}-\mathrm{C}_{16}\right)$ e $n-\mathrm{C}_{29+31+33}=\sum(\mathrm{n}-$ $\left.\mathrm{C}_{29}+\mathrm{n}-\mathrm{C}_{31}+\mathrm{n}-\mathrm{C}_{33}\right)$.

\begin{tabular}{|c|c|c|c|c|c|c|c|c|c|c|c|c|c|}
\hline $\begin{array}{c}\text { n-alcanos } \\
\left(\mu \mathrm{g} \mathrm{g}^{-1}\right)\end{array}$ & 249 & 250 & 253 & 254 & 255 & 256 & 257 & 258 & 259 & 260 & 262 & 263 & 264 \\
\hline$n-C_{12}$ & 0,004 & 0,006 & 0,009 & 0,008 & 0,060 & 0,150 & 0,013 & 0,246 & 0,238 & 0,008 & 0,009 & 0,008 & 0,003 \\
\hline$n-C_{13}$ & 0,004 & 0,005 & 0,005 & 0,008 & 0,008 & 0,008 & 0,011 & 0,010 & 0,010 & 0,005 & 0,006 & 0,007 & 0,003 \\
\hline$n-C_{14}$ & 0,009 & 0,012 & 0,007 & 0,011 & 0,013 & 0,074 & 0,012 & 0,128 & 0,126 & 0,014 & 0,010 & 0,012 & 0,005 \\
\hline$n-C_{15}$ & 0,009 & 0,010 & 0,006 & 0,010 & 0,011 & 0,007 & 0,009 & 0,008 & 0,010 & 0,019 & 0,006 & 0,012 & 0,004 \\
\hline$n-C_{16}$ & 0,016 & 0,012 & 0,006 & 0,017 & 0,016 & 0,013 & 0,012 & 0,014 & 0,019 & 0,007 & 0,012 & 0,012 & 0,004 \\
\hline$n-C_{17}$ & 0,015 & 0,013 & 0,008 & 0,018 & 0,011 & 0,006 & 0,009 & 0,009 & 0,011 & 0,009 & 0,008 & 0,013 & $<$ LDM \\
\hline$n-C_{18}$ & 0,009 & 0,007 & 0,006 & 0,013 & 0,006 & 0,004 & 0,005 & 0,008 & 0,011 & 0,005 & 0,005 & 0,008 & 0,003 \\
\hline$n-C_{19}$ & 0,007 & $<$ LDM & $<$ LDM & 0,014 & 0,010 & 0,005 & 0,005 & 0,005 & 0,008 & 0,006 & 0,005 & 0,007 & $<$ LDM \\
\hline$n-C_{20}$ & 0,009 & 0,009 & 0,010 & $<$ LDM & 0,006 & $<$ LDM & $<$ LDM & 0,008 & 0,009 & $<$ LDM & 0,009 & 0,008 & $<$ LDM \\
\hline$n-C_{21}$ & $<$ LDM & $<$ LDM & 0,013 & $<$ LDM & 0,010 & $<$ LDM & $<$ LDM & $<$ LDM & 0,013 & $<$ LDM & $<$ LDM & $<$ LDM & $<$ LDM \\
\hline$n-C_{22}$ & 0,008 & 0,008 & 0,017 & 0,007 & 0,009 & 0,009 & 0,007 & 0,033 & 0,041 & 0,009 & 0,012 & 0,007 & 0,013 \\
\hline$n-C_{23}$ & 0,009 & 0,008 & 0,017 & 0,008 & 0,017 & 0,013 & 0,008 & 0,063 & 0,068 & 0,009 & 0,014 & 0,006 & 0,016 \\
\hline$n-C_{24}$ & 0,009 & 0,009 & 0,015 & 0,011 & 0,011 & 0,016 & 0,008 & 0,063 & 0,058 & 0,010 & 0,011 & 0,006 & 0,016 \\
\hline$n-C_{25}$ & $<$ LDM & $<$ LDM & $<$ LDM & $<$ LDM & 0,013 & $<$ LDM & $<$ LDM & 0,037 & 0,030 & $<$ LDM & $<$ LDM & $<$ LDM & $<$ LDM \\
\hline$n-C_{26}$ & 0,007 & $<$ LDM & 0,025 & $<$ LDM & 0,017 & 0,007 & 0,021 & 0,015 & 0,013 & 0,007 & 0,018 & $<$ LDM & 0,008 \\
\hline$n-C_{27}$ & $<$ LDM & $<$ LDM & $<$ LDM & $<$ LDM & 0,012 & $<$ LDM & $<$ LDM & $<$ LDM & $<$ LDM & $<$ LDM & $<$ LDM & $<$ LDM & $<$ LDM \\
\hline$n-C_{28}$ & $<$ LDM & $<$ LDM & $<\mathrm{LDM}$ & $<$ LDM & 0,020 & $<\mathrm{LDM}$ & $<$ LDM & $<\mathrm{LDM}$ & $<\mathrm{LDM}$ & $<\mathrm{LDM}$ & $<$ LDM & $<\mathrm{LDM}$ & $<$ LDM \\
\hline$n-C_{29}$ & 0,035 & 0,028 & 0,053 & 0,063 & 0,052 & 0,031 & 0,046 & 0,032 & 0,041 & 0,044 & $<$ LDM & 0,040 & 0,040 \\
\hline$n-C_{30}$ & $<$ LDM & $<$ LDM & $<$ LDM & $<$ LDM & 0,012 & $<$ LDM & $<$ LDM & $<$ LDM & $<$ LDM & 0,028 & $<$ LDM & $<$ LDM & $<$ LDM \\
\hline$n-C_{31}$ & 0,053 & 0,045 & 0,051 & 0,090 & 0,068 & 0,042 & 0,064 & 0,043 & 0,052 & 0,059 & 0,035 & 0,060 & 0,057 \\
\hline$n-C_{32}$ & $<$ LDM & $<$ LDM & $<$ LDM & $<$ LDM & 0,018 & $<$ LDM & $<$ LDM & $<$ LDM & $<$ LDM & $<$ LDM & $<$ LDM & $<$ LDM & $<$ LDM \\
\hline$n-C_{33}$ & 0,040 & 0,035 & 0,053 & 0,072 & 0,070 & 0,031 & 0,060 & 0,038 & 0,048 & 0,059 & 0,029 & 0,052 & 0,042 \\
\hline$n-C_{34}$ & 0,022 & 0,026 & 0,018 & 0,022 & 0,037 & $<$ LDM & 0,020 & 0,021 & $<$ LDM & $<$ LDM & $<$ LDM & $<$ LDM & $<$ LDM \\
\hline$n-C_{35}$ & 0,022 & 0,024 & 0,032 & 0,035 & 0,013 & 0,014 & 0,029 & 0,021 & 0,020 & 0,036 & 0,013 & 0,028 & 0,016 \\
\hline
\end{tabular}




\begin{tabular}{|c|c|c|c|c|c|c|c|c|c|c|c|c|c|}
\hline $\begin{array}{c}\text { Pristano } \\
\text { Fitano }\end{array}$ & $\begin{array}{l}0,050 \\
0,006 \\
\end{array}$ & $\begin{array}{l}0,037 \\
<\text { LDM }\end{array}$ & $\begin{array}{l}<\text { LDM } \\
0,003\end{array}$ & $\begin{array}{l}0,009 \\
0,006\end{array}$ & $\begin{array}{l}0,049 \\
0,004\end{array}$ & $\begin{array}{l}<\text { LDM } \\
0,002\end{array}$ & $\begin{array}{l}<\text { LDM } \\
0,003\end{array}$ & $\begin{array}{l}0,054 \\
0,004 \\
\end{array}$ & $\begin{array}{l}0,016 \\
0,004\end{array}$ & $\begin{array}{l}<\text { LDM } \\
0,003\end{array}$ & $\begin{array}{l}<\text { LDM } \\
0,004\end{array}$ & $\begin{array}{l}0,188 \\
0,005\end{array}$ & $\begin{array}{l}<\text { LDM } \\
<\text { LDM }\end{array}$ \\
\hline $\begin{array}{l}\text { n-alcanos } \\
\text { Totais }\end{array}$ & 0,365 & 0,348 & 0,438 & 0,516 & 0,520 & 0,497 & 0,425 & 0,868 & 0,898 & 0,396 & 0,284 & 0,369 & 0,330 \\
\hline $\begin{array}{l}\text { Alifáticos } \\
\text { Totais }\end{array}$ & 0,773 & 0,820 & 0,817 & 1,343 & 1,166 & 0,777 & 0,749 & 1,207 & 1,245 & 0,862 & 0,575 & 0,980 & 0,715 \\
\hline MCNR & $<$ LDM & $<$ LDM & $<$ LDM & $<$ LDM & $<$ LDM & $<$ LDM & $<$ LDM & $<$ LDM & $<$ LDM & $<$ LDM & $<\mathrm{LDM}$ & $<$ LDM & $<$ LDM \\
\hline \multicolumn{14}{|l|}{$\begin{array}{l}\text { Parâmetros de } \\
\text { avaliação }\end{array}$} \\
\hline$n-C_{12}+14+16$ & 0,030 & 0,030 & 0,022 & 0,036 & 0,090 & 0,237 & 0,037 & 0,389 & 0,383 & 0,029 & 0,031 & 0,032 & 0,013 \\
\hline$n-\mathrm{C}_{29+31}+33$ & 0,127 & 0,108 & 0,158 & 0,225 & 0,190 & 0,103 & 0,171 & 0,113 & 0,140 & 0,162 & 0,063 & 0,153 & 0,139 \\
\hline IA & 0,603 & 0,620 & 0,490 & 0,586 & 0,569 & 0,575 & 0,582 & 0,573 & 0,559 & 0,571 & 0,566 & 0,597 & 0,587 \\
\hline Pris/Fit & 7,668 & $<$ LDM & $<$ LDM & 1,447 & 2,377 & $<$ LDM & $<$ LDM & 15,183 & 4,213 & $<$ LDM & $<$ LDM & 39,891 & $<$ LDM \\
\hline Pristano/n- $\mathrm{C}_{17}$ & 3,246 & $<$ LDM & $<$ LDM & 0,492 & 0,844 & $<$ LDM & $<$ LDM & 5,906 & 1,413 & $<$ LDM & $<$ LDM & 14,831 & 0,439 \\
\hline
\end{tabular}


O somatório de alifáticos totais ( $\Sigma$ HAs) indica a concentração total dos compostos presentes na fração $\mathrm{F} 1$, incluindo os compostos não resolvidos (MCNR) e resolvidos ( $\Sigma$ HAs resolvidos). Os valores de $\Sigma$ HAs para as estações amostradas variaram de $0,57 \mu g^{-1}$ (estação 249) a $1,03 \mu g^{-1}$ (estação 254 ) (Figura 17). $O$ somatório de $n$-alcanos totais ( $\Sigma n$-alcanos) indica a soma das concentrações de $n$-alcanos entre $n-C_{12}$ a $n$ - $C_{35}$. Os valores do $\Sigma n$ alcanos variaram de $0,28 \mu \mathrm{g} \mathrm{g}^{-1}$ (estação 262) a $0,51 \mu \mathrm{g} \mathrm{g}^{-1}$ (estação 254) (Figura 18).
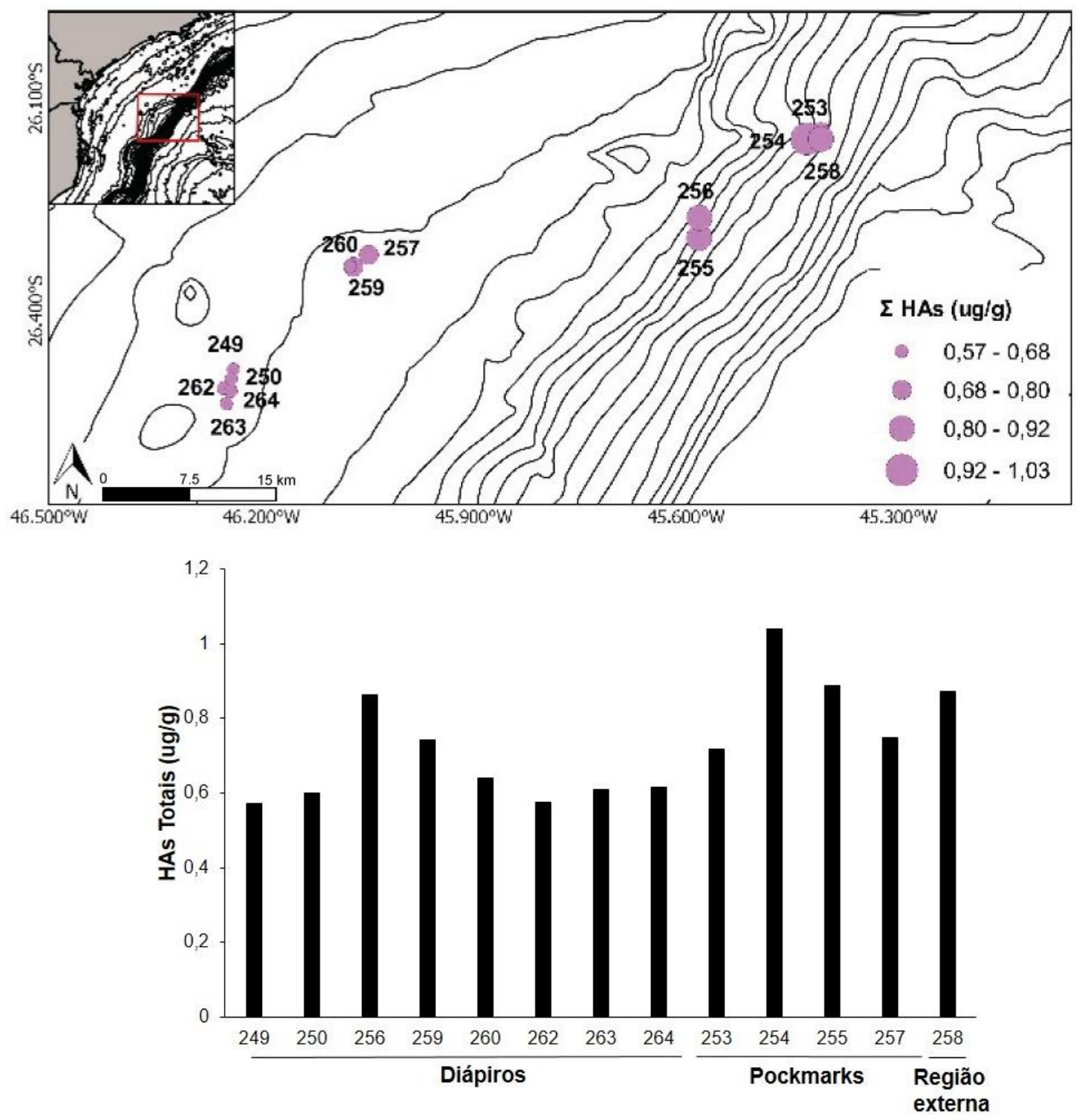

Figura 17 - Concentrações do $\Sigma$ HAs em $\left(\mu \mathrm{g} \mathrm{g}^{-1}\right)$ ao longo da área de estudo. 


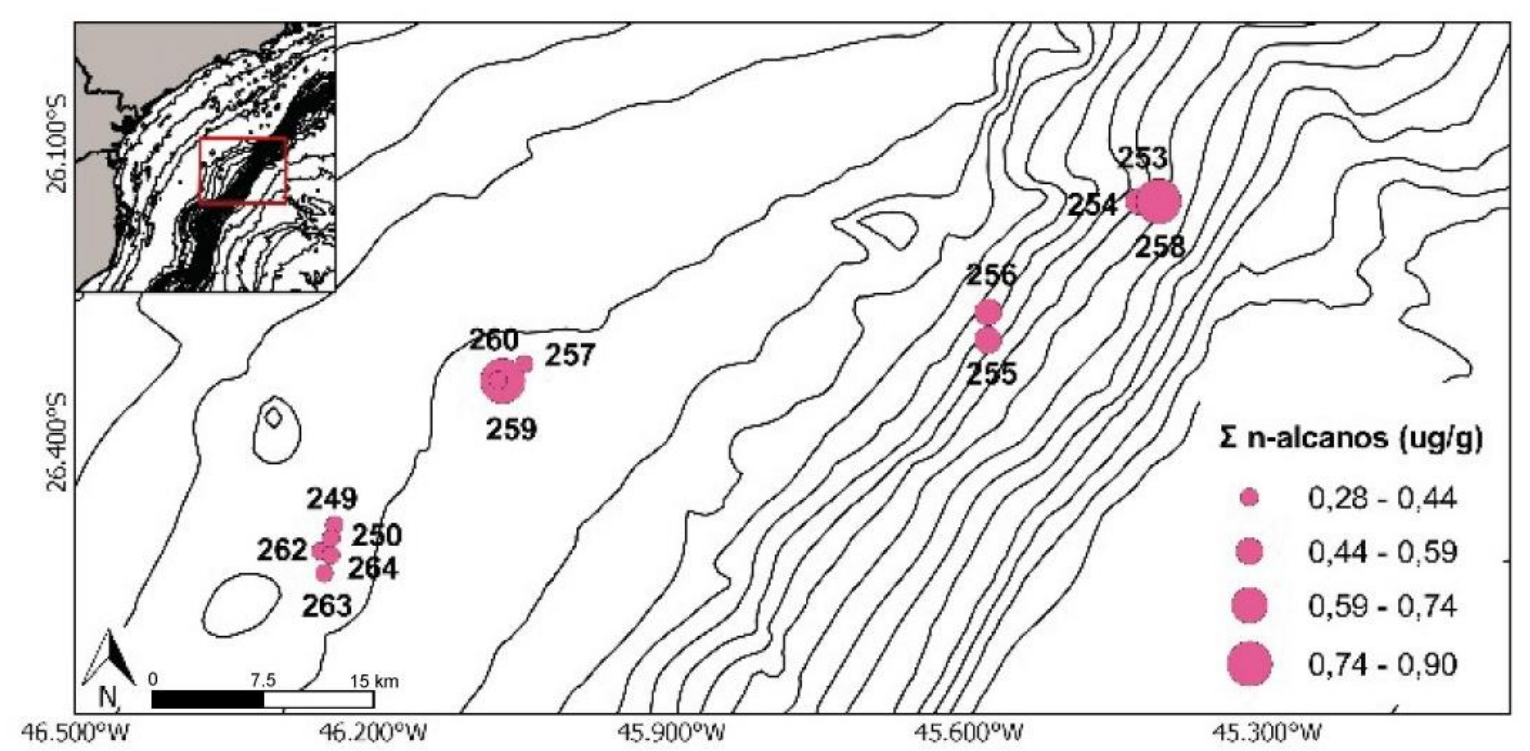

Figura 18 - Concentrações do $\Sigma n$-alcanos em $\left(\mu \mathrm{g} \mathrm{g}^{-1}\right)$ ao longo da área de estudo.

Na maioria das amostras, os $n$-alcanos de cadeia curta apresentaram o predomínio do $n$ - $\mathrm{C}_{14}$, e a ordem de concentração decrescente dos $n$-alcanos foi $n$ - $\mathrm{C}_{16}>n$ - $\mathrm{C}_{22}$, enquanto que o $n$ - $\mathrm{C}_{31}$ predominou entre os $n$-alcanos de cadeia longa de maior massa molecular, seguida dos $n$-alcanos $n$ - $\mathrm{C}_{33}>n$-C $\mathrm{C}_{29}$ (Figura 19).

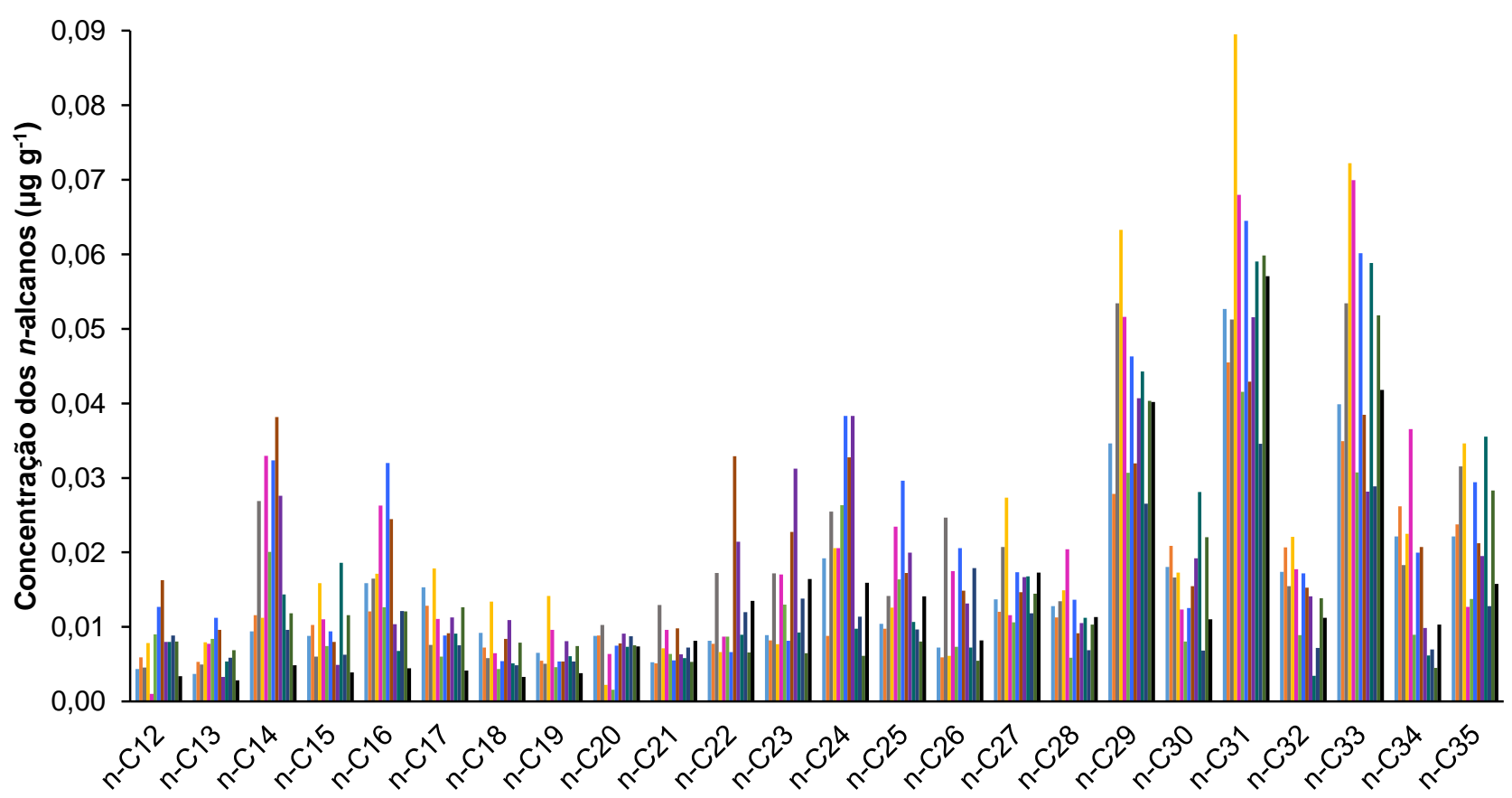

Figura 19 -Concentração dos $n$-alcanos $\left(\mu \mathrm{g} \mathrm{g}^{-1}\right)$ nas amostras superficiais. 
A presença de $n$-alcanos leves com a predominância par foram encontradas nas estações 256, 258 e 259, estabelecidos nos diápiros e região externa. Vários relatos mostram que é relativamente comum que as bactérias produzam $n$-alcanos pares entre $n$ - $\mathrm{C}_{12}$ a $n$-C 22 (DAVIS, 1968; JONES, 1969; JONES \& YOUNG, 1970; NACCARATO et al., 1974, HAN et al., 1980; GRIMALT et al., 1985, 1986; NISHIMURA \& BAKER, 1986; GRIMALT \& ALBAIGÉS, 1987; EKPO et al., 2005). Essa distribuição também foi encontrada em sedimentos oxigenados (GRIMALT et al., 1985). Além disso, as espécies de fungos (JONES \& YOUNG, 1970; WALKER \& COONEY, 1973; FISHERD et al., 1972) e diatomáceas (GRIMALT \& ALBAIGÉS, 1987) também foram relatadas por biossintetizar tais $n$-alcanos. Sendo assim, sugere-se que as origens de $n$-alcanos de cadeia curta par neste estudo sejam provenientes da matéria orgânica de origem autóctone, associados a entrada de detritos de fitoplâncton e zooplâncton, oriundo da exportação de águas superficiais e da degradação bacteriana de detritos de vegetais e algas.

A presença de $n$-alcanos pesados com a predominância par entre $n$ - $\mathrm{C}_{24}$ a $n$ - $\mathrm{C}_{34}$, indicam a presença de bactérias (WELTE \& EHARDT, 1968, NISHIMURA \& BAKER, 1986, WANG et al., 2010) para a região de estudo. A existência de bactérias tanto nos pockmarks como nos diápiros, também pode estar relacionada ás possíveis liberações de fluídos no passado, sustentando comunidades bióticas através dos gases como o metano. Pesquisas recentes realizadas próximas a área de estudo, afirmaram a existência de comunidades quimiossintéticas, associadas ás infiltrações frias (GIONGO et al., 2016; FUJIKURA et al., 2017). Evidências de exsudações próximos à região de estudo foram descritos por KOWSMANN \& CARVALHO, (2002).

A presença de $n$-alcanos leves com a predominância ímpar foram presentes na maioria das estações, sendo associadas ao fitoplâncton, zooplâncton marinho e algas bentônicas, frequentemente relacionada a origem biogênica marinha. Segundo CIOTTI et al. (1995), a região entre as latitudes $28^{\circ}$ e $34^{\circ} \mathrm{sul}$ (próxima à área de estudo) apresenta variabilidade na biomassa fitoplanctônica, que estaria também relacionada à disponibilidade de nutrientes provenientes da descarga do Rio da Prata. Além disso, a presença de ressurgência no talude têm implicações importantes na produção primária de áreas oceânicas. A ACAS é caracterizada pelas concentrações significativas de 
nutrientes que, ao alcançarem a zona eufótica através da ressurgência, possibilita o aumento na produção fitoplanctônica e consequentemente do zooplâncton.

Houve a predominância de $n$-alcanos ímpares de cadeia longa em todas as amostras, indicando a contribuição de matéria orgânica de origem terrestre. As estações 254, 255 e 257 apresentaram as maiores concentrações desses compostos, expondo também, as menores porcentagens de $\mathrm{CaCO}_{3} \mathrm{e}$ os maiores teores de COT, mostrando o possível acúmulo de sedimentos nos pockmarks, devido a sua concavidade.

Não é descartada a ocorrência das contribuições marinhas na área de estudo, devido a maior degradação dos $n$-alcanos leves. A degradação desses compostos se inicia ainda na coluna d'água, portanto, quanto maior a coluna d'água maior a degradação que esses compostos podem sofrer. Apesar dos $n$ alcanos apontarem uma origem terrígena da matéria orgânica, outros parâmetros indicaram forte presença da matéria orgânica de origem marinha. Os valores encontrados para os isótopos estáveis de carbono estiveram em sua maioria dentro do intervalo entre -22 e $-20 \%$, considerados tipicamente fitoplanctônica.

Por meio da análise dos hidrocarbonetos alifáticos, foi possível identificar que as amostras da área de estudo possuem assinaturas semelhantes quando comparadas as amostras coletadas próximo ao Rio da Prata (MAGNOU, 2016). A predominância de $n-C_{31}$ em todas as amostras são associados a vegetação de clima mais seco, do tipo $\mathrm{C}_{4}$, que podem estar relacionadas a presença de pampas, típica vegetação do Uruguai (ESCUDERO, 2004) e do Rio Grande do Sul. O parâmetro que elucida a presença de vegetação típica da região sul do Brasil é o Índice Alcano (IA). Comparando os valores do IA, observou-se que a predominância terrígena se deve à contribuição de pradarias, uma vez que os valores foram maiores que 0,5, indicando planta $\mathrm{C}_{4}$ (ROMMERSKIRCHEN et al., 2003).

A entrada do material terrígeno para a região de estudo pode ser proveniente da descarga continental de rios, principalmente do Rio da Prata, uma vez que, o alcance da pluma em direção ao Oceano Atlântico varia sazonalmente. No inverno, há a predominância dos ventos de sul e as águas com baixa salinidade atingem latitudes em torno de $28^{\circ} \mathrm{S}$ (Figura 20) (PIOLA et 
al., 2000). Sendo assim, o transporte de sedimentos terrígenos é carregada para norte, ao longo da plataforma continental sul Brasileira, pela Corrente Costeira do Brasil (CCB), consequentemente, a presença de cânions submarinos na área de estudo, juntamente com as diversas cicatrizes, levam os sedimentos depositados na plataforma para o talude continental.

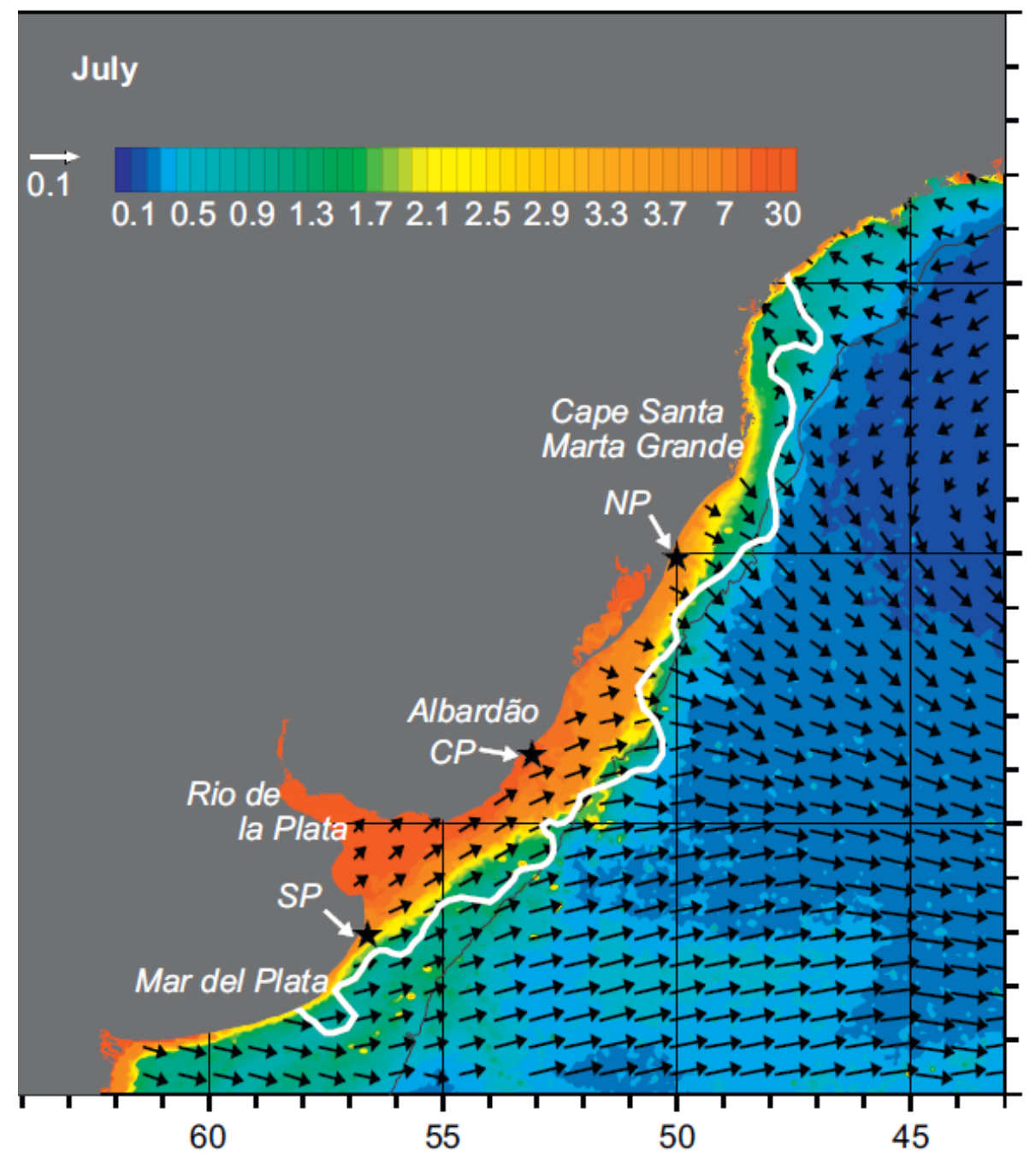

Figura 20 - Imagem de satélite da concentração de clorofila $\left(\mathrm{mg} \mathrm{m}^{-3}\right)$ em julho, derivada de imagens SeaWIFS com médias mensais (1998-2005). As setas indicam a distribuição climatológica do vento derivada do QuikSCAT com médias mensais de julho de 1999 a 2005. (PIOLA et al., 2008).

Os isoprenóides pristano e fitano variaram entre LDM a $0,188 \mu \mathrm{g} \mathrm{g}^{-1} \mathrm{e}$ 0,002 a $0,006 \mu \mathrm{g} \mathrm{g}^{-1}$, respectivamente. $O$ pristano foi $\mathrm{o}$ isoprenóide mais evidente se comparado ao fitano, ressaltando a presença de fitoplâncton, zooplâncton e bactérias (VENKATESAN \& KAPLAN, 1982; HARADA et al., 1995). 
A relação entre pristano/fitano pode ser usada para verificar as condições oxidantes ou redutoras do sedimento. Quando essa relação apresenta resultados acima de 1 refletem as condições óxicas do ambiente, por outro lado, valores menores que 1 , demonstram condições redutoras (DICK et al., 1978; POWELL, 1988). A razão Pristano/Fitano foi utilizada nas estações $249,254,255,258,259$ e 263, no qual, variou entre 1,4 a 6,7, caracterizando condições óxicas, possivelmente relacionadas ao enriquecimento de matéria orgânica (terrestre/marinha), devido ao fluxo da corrente de fundo e da morfologia dos pockmarks e diápiros. Nas demais estações, não foi possível calcular a razão, devido as baixas concentrações de pristano e fitano na região.

\subsubsection{Esteróis}

As concentrações dos esteróis analisados na área de estudo pode ser verificada na Tabela 11. O estudo dos esteróis na área de estudo pode fornecer informações da ocorrência de possíveis transformações diagenéticas no sedimento e indicar a origem da matéria orgânica no ambiente. 
Tabela 11 - Concentrações dos esteróis analisados em $\left(\mu \mathrm{g} \mathrm{g}^{-1}\right)$ e parâmetros de avaliação da origem e transformação da matéria orgânica. <LDM: abaixo do limite de detecção.

\begin{tabular}{|c|c|c|c|c|c|c|c|c|c|c|c|c|c|}
\hline & 249 & 250 & 253 & 254 & 255 & 256 & 257 & 258 & 259 & 260 & 262 & 263 & 264 \\
\hline Colesterol & 0,03 & 0,08 & 0,09 & 0,08 & 0,05 & 0,07 & 0,04 & 0,14 & 0,13 & 0,05 & 0,09 & 0,06 & 0,09 \\
\hline Colestanol & $<$ LDM & $<$ LDM & $<$ LDM & $<$ LDM & 0,02 & $<$ LDM & 0,03 & 0,05 & 0,02 & $<$ LDM & 0,02 & 0,03 & $<$ LDM \\
\hline Braassicasterol & $<\mathrm{LDM}$ & 0,03 & 0,05 & 0,02 & 0,05 & $<$ LDM & 0,02 & 0,09 & $<$ LDM & 0,07 & 0,01 & 0,05 & $<$ LDM \\
\hline Brassicastanol & $<$ LDM & $<$ LDM & $<$ LDM & $<$ LDM & $<$ LDM & $<$ LDM & $<$ LDM & $<$ LDM & $<$ LDM & $<$ LDM & $<$ LDM & $<$ LDM & $<$ LDM \\
\hline Campesterol & 0,08 & 0,09 & 0,09 & 0,09 & 0,16 & 0,12 & 0,15 & 0,10 & 0,13 & 0,04 & 0,09 & 0,07 & $<$ LDM \\
\hline Campestanol & $<$ LDM & $<$ LDM & $<$ LDM & $<$ LDM & $<$ LDM & $<$ LDM & $<$ LDM & $<$ LDM & $<$ LDM & $<$ LDM & $<$ LDM & $<$ LDM & $<$ LDM \\
\hline Estigmasterol & 0,03 & $<$ LDM & 0,10 & 0,10 & 0,15 & 0,05 & 0,18 & 0,18 & 0,07 & 0,17 & 0,07 & 0,15 & 0,07 \\
\hline Estigmastanol & $<$ LDM & $<$ LDM & $<$ LDM & $<$ LDM & $<$ LDM & $<$ LDM & $<$ LDM & $<$ LDM & $<$ LDM & $<$ LDM & $<$ LDM & $<$ LDM & $<$ LDM \\
\hline B-sitosterol & 0,35 & 0,25 & 0,16 & 0,59 & 0,62 & 0,20 & 0,52 & 0,32 & 0,22 & 0,15 & 0,12 & 0,08 & 0,09 \\
\hline B-sitostanol & $<$ LDM & $<$ LDM & $<$ LDM & $<$ LDM & $<$ LDM & $<$ LDM & $<$ LDM & $<$ LDM & $<$ LDM & $<$ LDM & $<$ LDM & 0,05 & 0,06 \\
\hline Esteróis Totais & 0,98 & 0,76 & 1,09 & 1,65 & 1,47 & 1,03 & 1,59 & 1,33 & 1,10 & 1,18 & 0,87 & 1,17 & 0,58 \\
\hline \multicolumn{14}{|l|}{ Parâmetros de avaliação } \\
\hline colestanol/colesterol & $<\mathrm{LDM}$ & $<$ LDM & $<$ LDM & $<\mathrm{LDM}$ & 0,41 & $<$ LDM & 0,74 & 0,38 & 0,18 & 0,38 & 0,27 & 0,59 & $<$ LDM \\
\hline sitostanol/sitosterol & $<$ LDM & $<$ LDM & $<$ LDM & $<\mathrm{LDM}$ & $<\mathrm{LDM}$ & $<$ LDM & $<\mathrm{LDM}$ & $<\mathrm{LDM}$ & $<$ LDM & $<$ LDM & $<\mathrm{LDM}$ & 0,58 & 0,68 \\
\hline colesterol/ $\beta$-sitosterol & 0,09 & 0,31 & 0,57 & 0,14 & 0,09 & 0,36 & 0,09 & 0,44 & 0,62 & 0,38 & 0,77 & 0,78 & 1,00 \\
\hline
\end{tabular}


O somatório do total de esteróis ( $\Sigma$ esteróis) variou de 0,58 a 1,65 $\mu \mathrm{g} \mathrm{g}$ ${ }^{1}$, nas estações 264 e 254, respectivamente. As maiores concentrações foram observadas nos pockmarks $254\left(1,65 \mu \mathrm{g} \mathrm{g}^{-1}\right)$ e $257\left(1,59 \mu \mathrm{g} \mathrm{g}^{-1}\right)$ (Figura 21). A maior presença nesses pontos pode estar relacionada às maiores profundidades dos pockmarks, trapeando sedimentos e contribuindo com a matéria orgânica alóctone e autóctone na área de estudo.

As menores concentrações foram estabelecidas nos diápiros ao sul do talude $264\left(0,58 \mu \mathrm{g} \mathrm{g}^{-1}\right), 250\left(0,76 \mu \mathrm{g} \mathrm{g}^{-1}\right), 262\left(0,87 \mu \mathrm{g} \mathrm{g}^{-1}\right)$, sendo associadas as estruturas cônicas que impedem a deposição de matéria orgânica, devido ao fluxo de correntes de fundo.
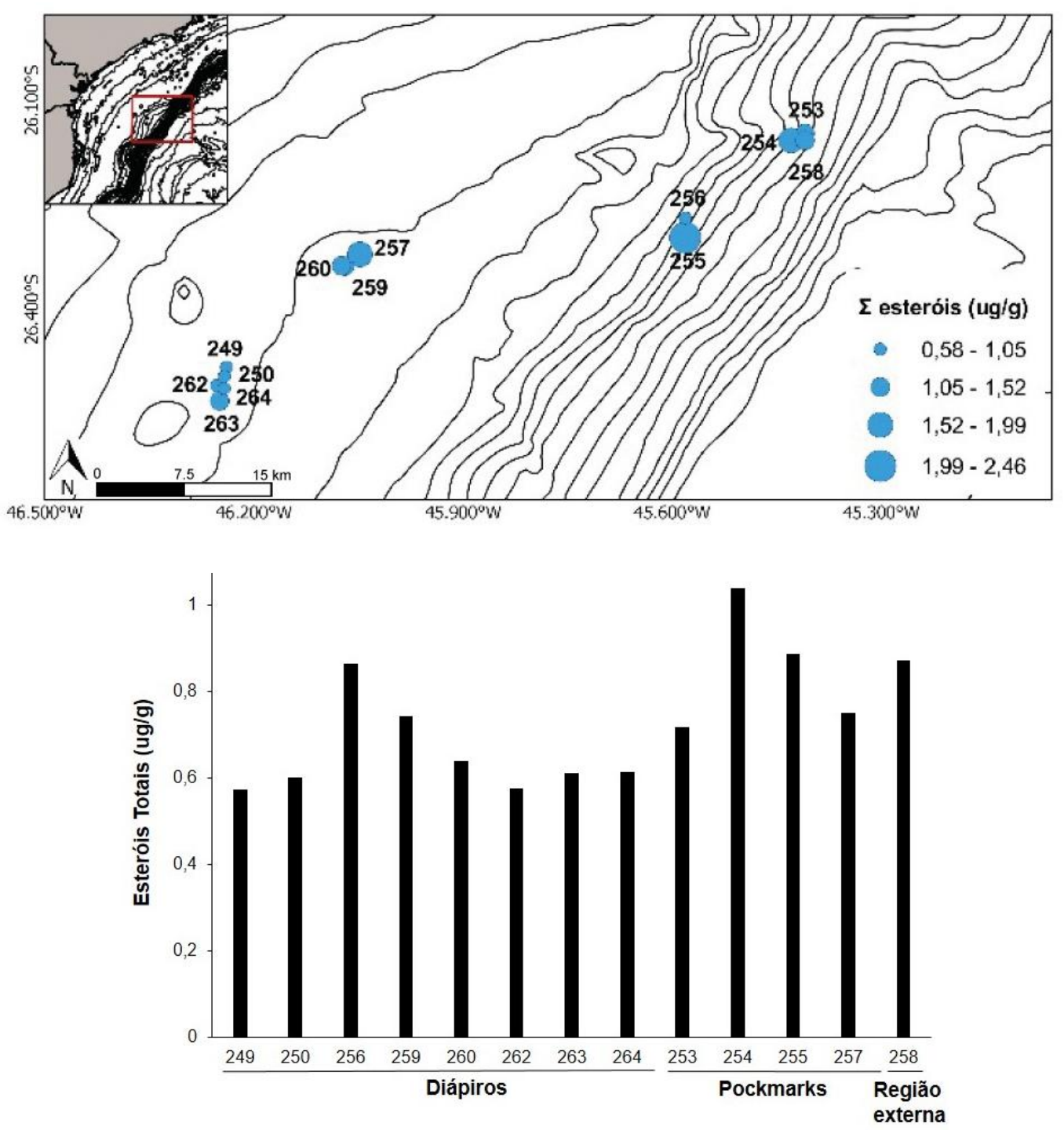

Figura 21 - Concentrações de esteróis totais em $\left(\mu \mathrm{g} \mathrm{g}^{-1}\right)$ ao longo da área de estudo. 
A análise individual dos compostos por pontos mostrou maior contribuição de esteróis de fontes terrestres (campesterol, estigmasterol e $\beta$ sitosterol) quando comparados aos esteróis de origem marinha (colesterol e brassicasterol) (Figura 22), evidenciando a importância de fontes naturais terrestres para os sedimentos.

O colesterol variou de $0,03 \mu \mathrm{g} \mathrm{g}^{-1}$ a $014 \mu \mathrm{g} \mathrm{g}^{-1}$ nas estações 249 e 258 respectivamente. As maiores concentrações foram localizadas nos pontos 258 e 259, situados na região externa e diápiros, já os menores valores foram 0,03 $\mu \mathrm{g} \mathrm{g}^{-1}$ (estação 249) e $0,04 \mu \mathrm{g} \mathrm{g}^{-1}$ (estação 257). A presença do colesterol indica detritos de zooplâncton e fitoplâncton que pode ser proveniente do afundamento de detritos de plâncton produzidos em águas superficiais.

$\mathrm{O} \beta$-sitosterol esteve presente em todas as amostras, contribuindo com as concentrações mais altas entre os esteróis avaliados neste trabalho. As maiores concentrações foram situadas nos pockmarks (estações 254, 255 e 257), indicando tanto contribuições autóctones (fitoplâncton, zooplâncton, macroalgas e bactérias), como alóctones (plantas vasculares) (VOLKMAN, 1986; VOLKMAN et al., 2008). A presença deste composto indica o possível aprisionamento de sedimentos e o acúmulo de detritos de origem terrígena e marinha nos pockmarks.

As menores concentrações foram situadas nos diápiros (estações 262, 263 e 264), o estigmasterol variou entre <LDM (estação 250) a $0,15 \mu \mathrm{g} \mathrm{g}^{-1}$ (estações 257 e 258) e também indica a presença de bactérias, fitoplâncton e macroalgas. O campesterol variou entre <LDM (estação 264) a 0,16 $\mu \mathrm{g} \mathrm{g}^{-1}$ (estação 255), indicando a maior influência dos aportes terrígenos. 


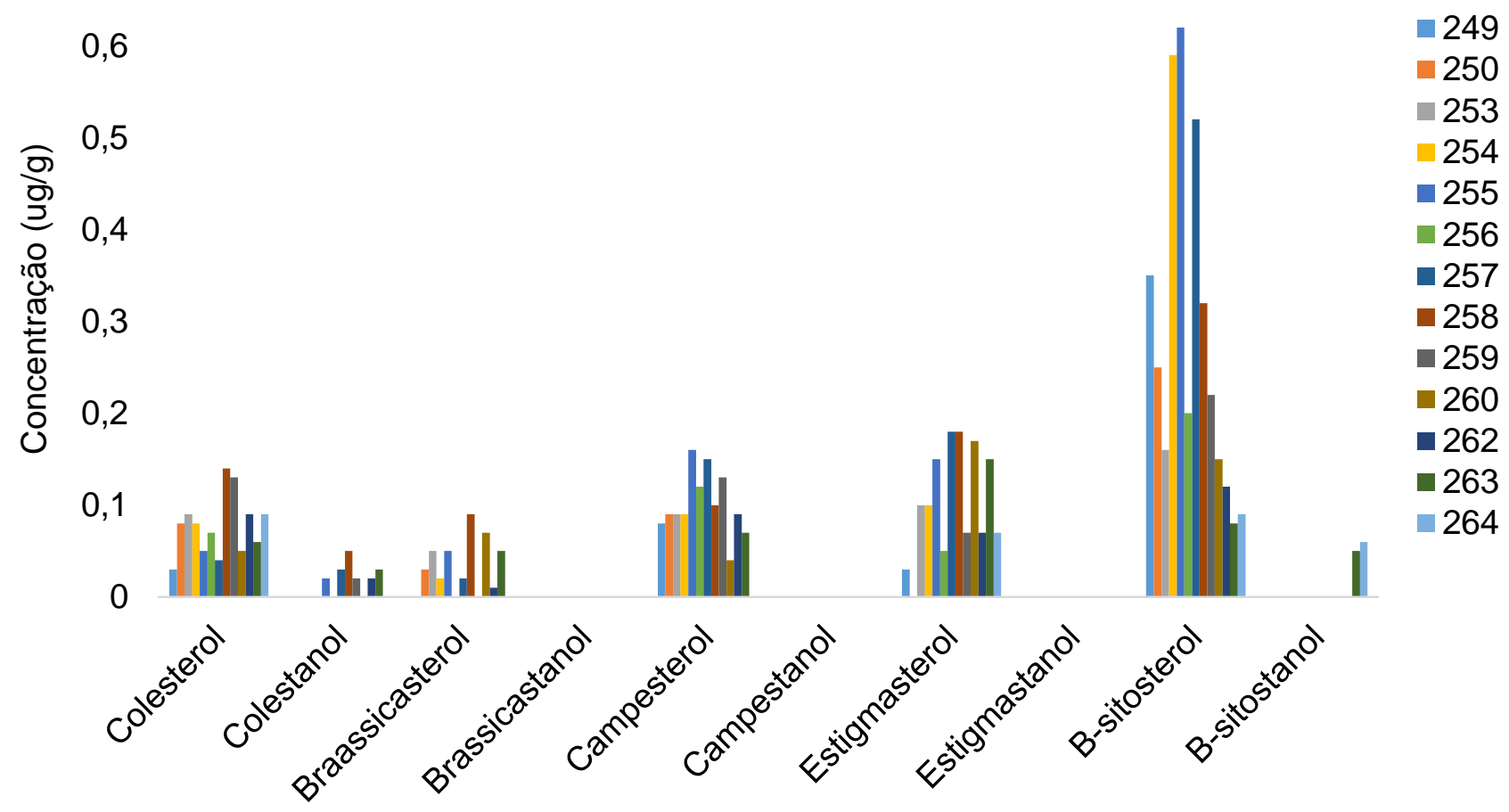

Figura 22 - Concentrações de Colesterol, Colestanol, Brassicasterol, Brassicastanol, Campesterol, Campestanol, Estigmasterol, Estigmastanol, $\beta$-sitosterol, $\beta$-sitostanol nas amostras superficiais.

No geral, as fontes dos esteróis foram semelhantes aos encontrados nas análises dos HAs, indicando tanto a presença de detritos de origem marinha (algas da coluna d'água e bactérias) como a terrígena (plantas terrestres).

O $\beta$-sitosterol pode ser associado com o colesterol através da razão colesterol/ $\beta$-sitosterol, onde valores próximos a zero indicam a matéria orgânica de origem terrígena, enquanto que valores acima de 1 apontam para origem planctônica (MUDGE \& LINTERN, 1999). Através da análise da razão, foi possível determinar que a matéria orgânica encontrada no sedimento possui a influência de aporte terrígeno nas estações 255, 257, 258, 259, 262 e 263, uma vez que, os valores ficaram próximos a zero. As demais estações não foram calculadas devido as baixas concentrações de colesterol e $\beta$-sitosterol nas amostras.

As distribuições de esteróis totais tiveram correlação linear positiva com os teores de COT $\left(R^{2}=0,68\right)$, sendo as maiores concentrações encontradas nos pockmarks e na região externa e os menores valores nos 
diápiros (Figura 23), sugerindo que o acúmulo de matéria orgânica atribui-se ás origens alóctones e autóctones, visto que a presença do sitosterol prevaleceu em todas as amostras da área de estudo. Em relação aos outros marcadores orgânicos (HAs e Álcoois), não foi possível obter uma correlação positiva entre os teores de COT.

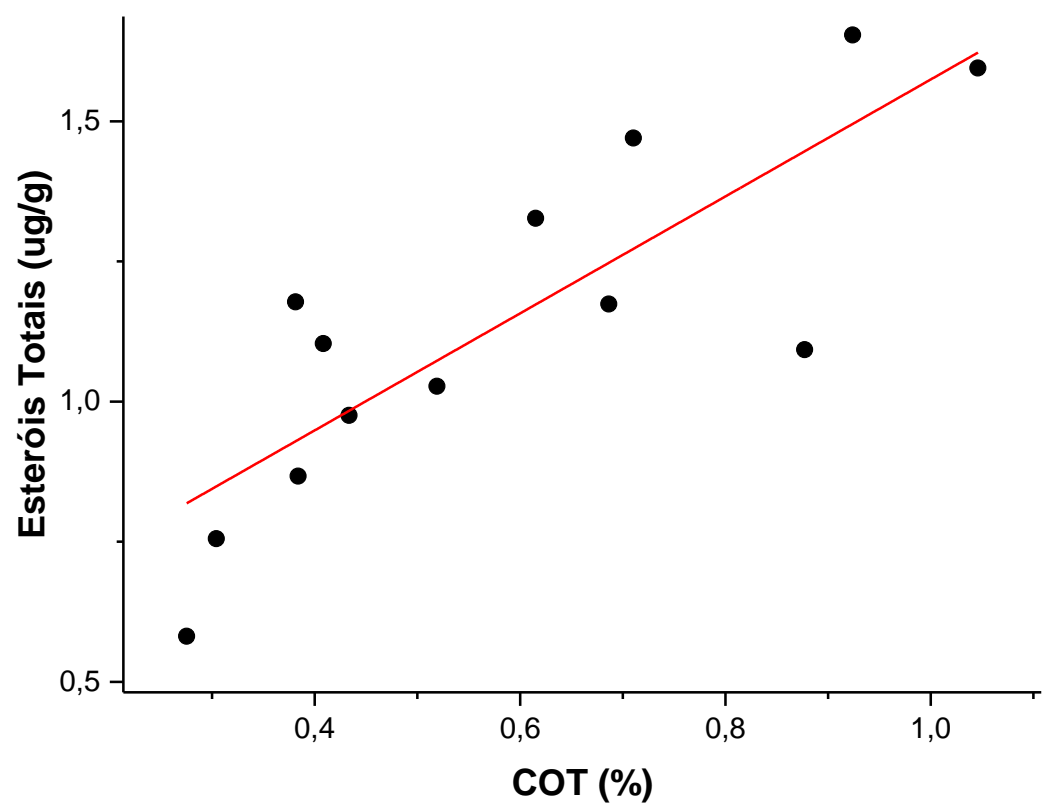

Figura 23 - Correlação linear entre o carbono orgânico total (\%) e esteróis totais $\mu \mathrm{g} / \mathrm{g}$.

Como os esteróis não insaturados podem ser formados nos sedimentos marinhos como resultado da redução bacteriana de esteróis, ou ainda, pela hidrogenação bacteriana de moléculas parentais, estes compostos são utilizados na caracterização de processos de degradação e preservação da matéria orgânica sedimentar (GAGOSIAN et al., 1980; JENG et al., 2001).

Neste trabalho foram utilizadas as razões colestanol/colesterol (JENG et al., 1996) e sitostanol/sitosterol (MUDGE et al., 1999) as quais, altos valores sugerem transformações diagenéticas (hidrogenação do composto parental por ação bacteriana). Ainda, a utilização de razões entre os esteróis parentais e seus isômeros saturados permite avaliar o caráter óxico/anóxico dos sedimentos, pois a presença dos esteróis saturados indica processos de redução bacteriana da matéria orgânica (VOLKMAN, 2005; WAKEHAM et al., 
2006). As razões que foram possíveis de serem calculadas tiveram valores abaixo de 1,0, sugerindo que a matéria orgânica presente nos sedimentos superficiais sofreram pouca transformações diagenéticas, apresentando caráter óxido, ou seja, há um quadro de deposição de matéria orgânica recente.

Por fim, os esteróis saturados, geralmente produtos de degradação bacteriana de homólogos insaturados foram encontrados em baixas concentrações, indicando que não há transformação diagenética significativa de esteróis no sedimento superficial da área de estudo.

\subsubsection{3. Álcoois}

Os resultados dos álcoois lineares foram agrupados de acordo com o número de átomos de carbono na cadeia, separados em álcoois lineares de cadeia curta ou leves e de cadeia longa ou pesados. Os álcoois identificados nas amostras sedimentares variaram de $\mathrm{C}_{14}-\mathrm{OH}$ a $\mathrm{C}_{30}-\mathrm{OH}$, com o predomínio dos homólogos com número par de átomos de carbono, apresentando uma predominância de álcoois de cadeia longa em relação aos álcoois de cadeia curta (Tabela 12). 
Tabela 12 - Concentrações dos álcoois analisados em $\left(\mu \mathrm{g} \mathrm{g}^{-1}\right)$ e parâmetros de avaliação da origem e transformação da matéria orgânica. <LDM: abaixo do limite de detecção.

\begin{tabular}{|c|c|c|c|c|c|c|c|c|c|c|c|c|c|}
\hline & 249 & 250 & 253 & 254 & 255 & 256 & 257 & 258 & 259 & 260 & 262 & 263 & 264 \\
\hline $\mathrm{C}_{12}-\mathrm{OH}$ & $<$ LDM & $<$ LDM & $<$ LDM & $<$ LDM & $<\mathrm{LDM}$ & $<$ LDM & $<$ LDM & $<$ LDM & $<$ LDM & $<\mathrm{LDM}$ & $<$ LDM & $<\mathrm{LDM}$ & $<$ LDM \\
\hline $\mathrm{C}_{13}-\mathrm{OH}$ & $<\mathrm{LDM}$ & $<$ LDM & $<$ LDM & $<$ LDM & $<\mathrm{LDM}$ & $<$ LDM & $<$ LDM & $<$ LDM & $<$ LDM & $<\mathrm{LDM}$ & $<\mathrm{LDM}$ & $<\mathrm{LDM}$ & $<\mathrm{LDM}$ \\
\hline $\mathrm{C}_{14}-\mathrm{OH}$ & $<\mathrm{LDM}$ & $<$ LDM & $<$ LDM & $<$ LDM & $<\mathrm{LDM}$ & $<$ LDM & $<$ LDM & $<$ LDM & $<$ LDM & $<\mathrm{LDM}$ & $<\mathrm{LDM}$ & 0,05 & $<\mathrm{LDM}$ \\
\hline $\mathrm{C}_{15}-\mathrm{OH}$ & $<\mathrm{LDM}$ & $<$ LDM & $<$ LDM & $<$ LDM & $<\mathrm{LDM}$ & $<$ LDM & $<$ LDM & $<$ LDM & $<$ LDM & $<\mathrm{LDM}$ & $<\mathrm{LDM}$ & $<\mathrm{LDM}$ & $<\mathrm{LDM}$ \\
\hline $\mathrm{C}_{16}-\mathrm{OH}$ & $<\mathrm{LDM}$ & $<$ LDM & 0,04 & 0,06 & 0,10 & $<$ LDM & 0,06 & 0,08 & 0,04 & 0,05 & $<\mathrm{LDM}$ & $<\mathrm{LDM}$ & $<$ LDM \\
\hline $\mathrm{C}_{17}-\mathrm{OH}$ & $<\mathrm{LDM}$ & $<$ LDM & $<$ LDM & $<$ LDM & $<\mathrm{LDM}$ & $<\mathrm{LDM}$ & $<$ LDM & $<$ LDM & $<$ LDM & $<\mathrm{LDM}$ & $<$ LDM & $<\mathrm{LDM}$ & $<$ LDM \\
\hline $\mathrm{C}_{18}-\mathrm{OH}$ & $<\mathrm{LDM}$ & $<$ LDM & $<$ LDM & $<$ LDM & 0,13 & $<$ LDM & $<$ LDM & 0,03 & 0,13 & 0,04 & $<$ LDM & 0,14 & $<$ LDM \\
\hline $\mathrm{C}_{19}-\mathrm{OH}$ & $<\mathrm{LDM}$ & $<$ LDM & $<$ LDM & $<$ LDM & $<\mathrm{LDM}$ & $<\mathrm{LDM}$ & $<$ LDM & 0,00 & $<$ LDM & $<\mathrm{LDM}$ & $<$ LDM & $<\mathrm{LDM}$ & $<$ LDM \\
\hline $\mathrm{C}_{20}-\mathrm{OH}$ & $<\mathrm{LDM}$ & $<$ LDM & $<$ LDM & $<$ LDM & 0,05 & $<\mathrm{LDM}$ & $<$ LDM & 0,02 & 0,06 & $<\mathrm{LDM}$ & $<$ LDM & 0,06 & $<$ LDM \\
\hline $\mathrm{C}_{21}-\mathrm{OH}$ & $<\mathrm{LDM}$ & $<$ LDM & $<$ LDM & $<$ LDM & $<\mathrm{LDM}$ & $<\mathrm{LDM}$ & $<$ LDM & 0,00 & $<$ LDM & $<\mathrm{LDM}$ & $<$ LDM & $<\mathrm{LDM}$ & $<$ LDM \\
\hline $\mathrm{C}_{22}-\mathrm{OH}$ & $<$ LDM & $<$ LDM & 0,04 & 0,07 & $<\mathrm{LDM}$ & $<$ LDM & 0,04 & 0,04 & 0,06 & 0,07 & $<$ LDM & 0,09 & $<$ LDM \\
\hline $\mathrm{C}_{23}-\mathrm{OH}$ & $<$ LDM & $<$ LDM & $<$ LDM & $<$ LDM & $<\mathrm{LDM}$ & $<$ LDM & $<$ LDM & $<$ LDM & $<$ LDM & $<$ LDM & $<$ LDM & $<\mathrm{LDM}$ & $<$ LDM \\
\hline $\mathrm{C}_{24}-\mathrm{OH}$ & $<\mathrm{LDM}$ & $<$ LDM & $<$ LDM & $<$ LDM & $<\mathrm{LDM}$ & $<$ LDM & $<$ LDM & $<$ LDM & 0,09 & 0,05 & $<$ LDM & 0,08 & $<$ LDM \\
\hline $\mathrm{C}_{25}-\mathrm{OH}$ & $<$ LDM & $<$ LDM & $<$ LDM & 0,04 & 0,13 & $<$ LDM & $<$ LDM & $<$ LDM & $<$ LDM & 0,07 & $<$ LDM & $<$ LDM & $<$ LDM \\
\hline $\mathrm{C}_{26}-\mathrm{OH}$ & $<$ LDM & $<$ LDM & $<$ LDM & $<$ LDM & $<\mathrm{LDM}$ & $<$ LDM & $<$ LDM & $<$ LDM & $<$ LDM & $<$ LDM & $<$ LDM & $<$ LDM & $<$ LDM \\
\hline $\mathrm{C}_{27}-\mathrm{OH}$ & $<$ LDM & $<$ LDM & $<$ LDM & $<$ LDM & 0,05 & $<$ LDM & $<$ LDM & $<$ LDM & 0,05 & 0,02 & $<$ LDM & $<$ LDM & $<$ LDM \\
\hline $\mathrm{C}_{28}-\mathrm{OH}$ & $<$ LDM & $<$ LDM & 0,07 & $<$ LDM & 0,10 & 0,05 & 0,08 & 0,06 & 0,14 & 0,19 & 0,06 & 0,06 & 0,06 \\
\hline $\mathrm{C}_{29}-\mathrm{OH}$ & $<$ LDM & $<$ LDM & $<$ LDM & $<$ LDM & $<$ LDM & $<$ LDM & $<$ LDM & $<$ LDM & 0,03 & 0,05 & 0,08 & $<$ LDM & $<$ LDM \\
\hline $\mathrm{C}_{30}-\mathrm{OH}$ & 0,26 & 0,17 & 0,24 & 0,30 & 0,40 & 0,31 & 0,25 & 0,18 & 0,08 & 0,11 & 0,17 & 0,17 & 0,17 \\
\hline $\mathrm{C}_{31}-\mathrm{OH}$ & $<\mathrm{LDM}$ & $<$ LDM & $<$ LDM & $<$ LDM & $<\mathrm{LDM}$ & $<$ LDM & $<$ LDM & $<$ LDM & $<$ LDM & $<$ LDM & $<$ LDM & $<$ LDM & $<$ LDM \\
\hline $\mathrm{C}_{32}-\mathrm{OH}$ & $<$ LDM & $<$ LDM & $<$ LDM & $<$ LDM & $<$ LDM & $<$ LDM & $<$ LDM & $<$ LDM & $<$ LDM & $<$ LDM & $<$ LDM & $<$ LDM & $<$ LDM \\
\hline Álcoois totais & 0,41 & 0,26 & 0,53 & 0,64 & 1,24 & 0,49 & 0,58 & 0,50 & 0,80 & 0,73 & 0,45 & 0,83 & 0,37 \\
\hline
\end{tabular}


A concentração de álcoois totais variou de 0,26 a $1,24 \mu \mathrm{g} \mathrm{g}{ }^{-1}$ nas estações 250 e 255, respectivamente. As maiores concentrações foram observadas tanto ao sul como ao norte da área de estudo, porém as menores concentrações foram constatadas nos diápiros, localizados ao sul da área de estudo, exceto na amostra 263, onde se observou concentrações maiores em relação aos outros diápiros (Figura 24).
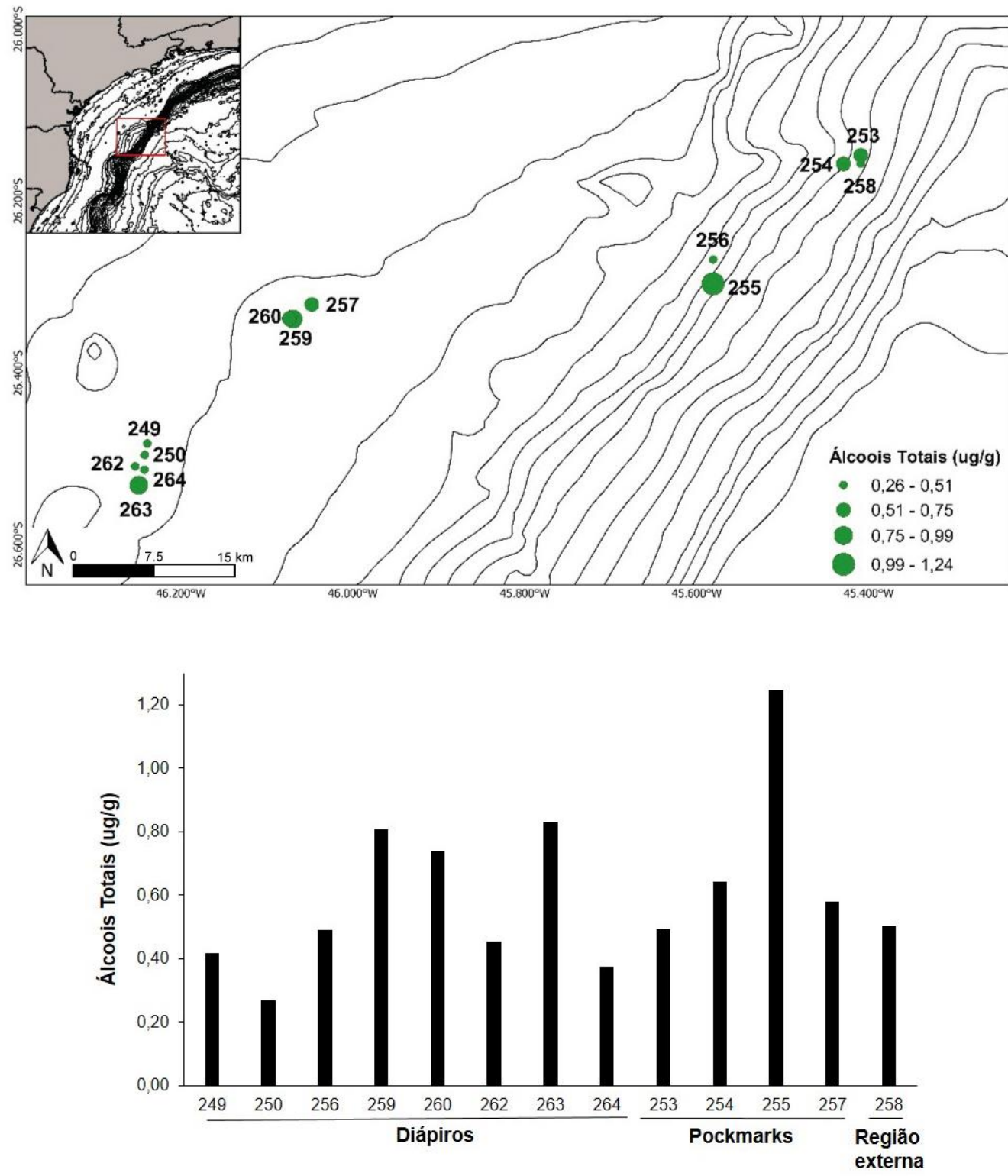

Figura 24 - Concentrações de álcoois totais em $\left(\mu g g^{-1}\right)$ ao longo da área de estudo.

Os álcoois de cadeia curta $\mathrm{C}_{14}-\mathrm{OH}, \mathrm{C}_{16}-\mathrm{OH}$ e $\mathrm{C}_{18}-\mathrm{OH}$ apresentaram as menores concentrações, variando de $<$ LDM a $0,14 \mu \mathrm{g} \mathrm{g}^{-1}$ (estação 263), indicando a presença de detritos de zooplâncton e da possível origem 
bacteriana e de algas ao sistema. O álcool pesado identificado em maior concentração em todas as amostras foi o $\mathrm{C}_{30}-\mathrm{OH}\left(0,25 \mu \mathrm{g} \mathrm{g}^{-1}\right)$, presente em toda a área de estudo, seguido do $\mathrm{C}_{28}-\mathrm{OH}\left(0,14 \mu \mathrm{g} \mathrm{g}^{-1}\right)$, estes compostos são mais resistentes e estão presentes em ceras epicuticulares de plantas, indicando a predominância do aporte de vegetais terrestre nos pockmarks e diápiros da região.

5.2. Amostras de sedimentos ao longo dos testemunhos.

Foi utilizado o box-plot com o intuito de interpretar as variações dos dados entre todas as estações, fornecendo informações sobre a variabilidade e valores extremos (atípicos) dos dados.

Em relação aos teores de lama (silte + argila), foi possível observar que $75 \%$ dos dados ficaram abaixo $\sim 74,7 \%$ de lama (silte+argila), nos testemunhos 254 e 257 (pockmarks), porém não houve muita variabilidade entre os pontos e não é possível observar distinção entre pockmarks e diápiros (Figura 25).

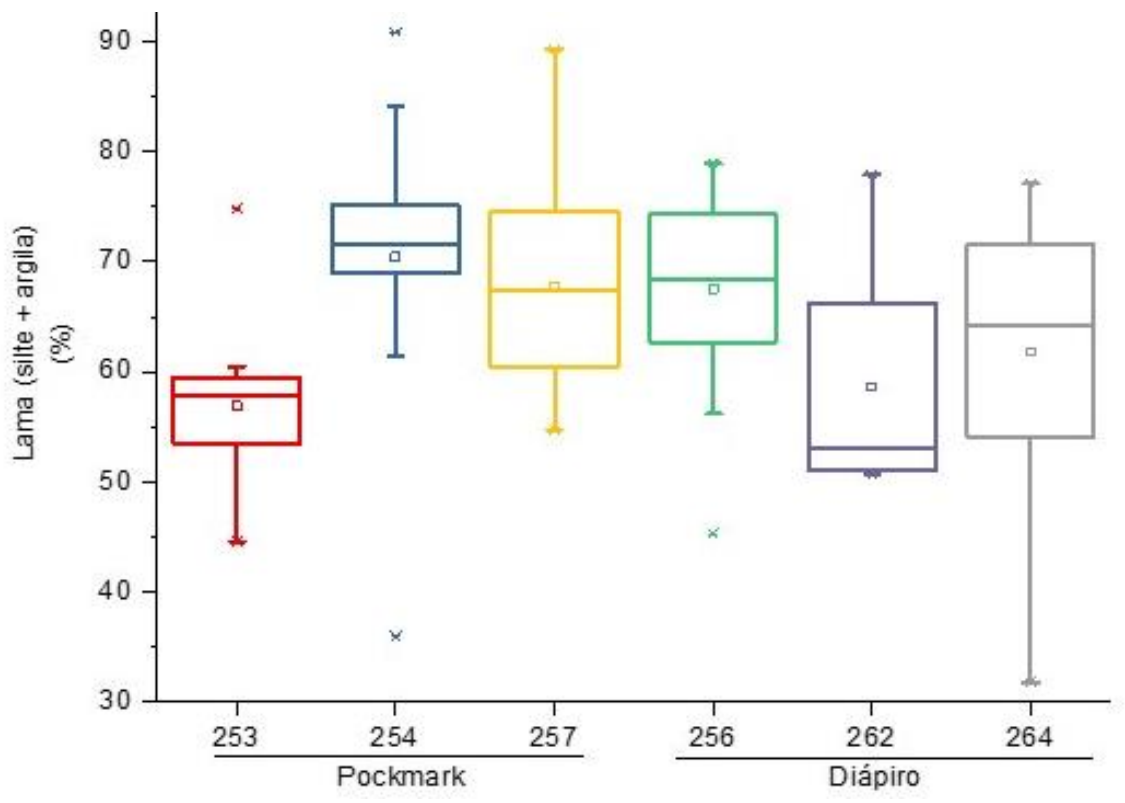

Figura 25 - Box-Plot da \% de lama (silte + argila) nas estações 253, 254, 257, 256, 262 e 264. 
Pelo box-plot da Figura 26, que apresenta os dados de $\mathrm{CaCO}_{3}$, foi possível constatar que, embora o valor médio seja diferente entre os testemunhos, verificou-se que há uma menor variabilidade para as amostras estabelecidas nos pockmarks, devido as menores médias ( $254 \mathrm{Q} 2=25,5 \%$ ). As médias dos teores de $\mathrm{CaCO}_{3}$ foram maiores nos diápiros, mostrando as maiores variabilidades das porcentagens nas estações 256 e 264 .

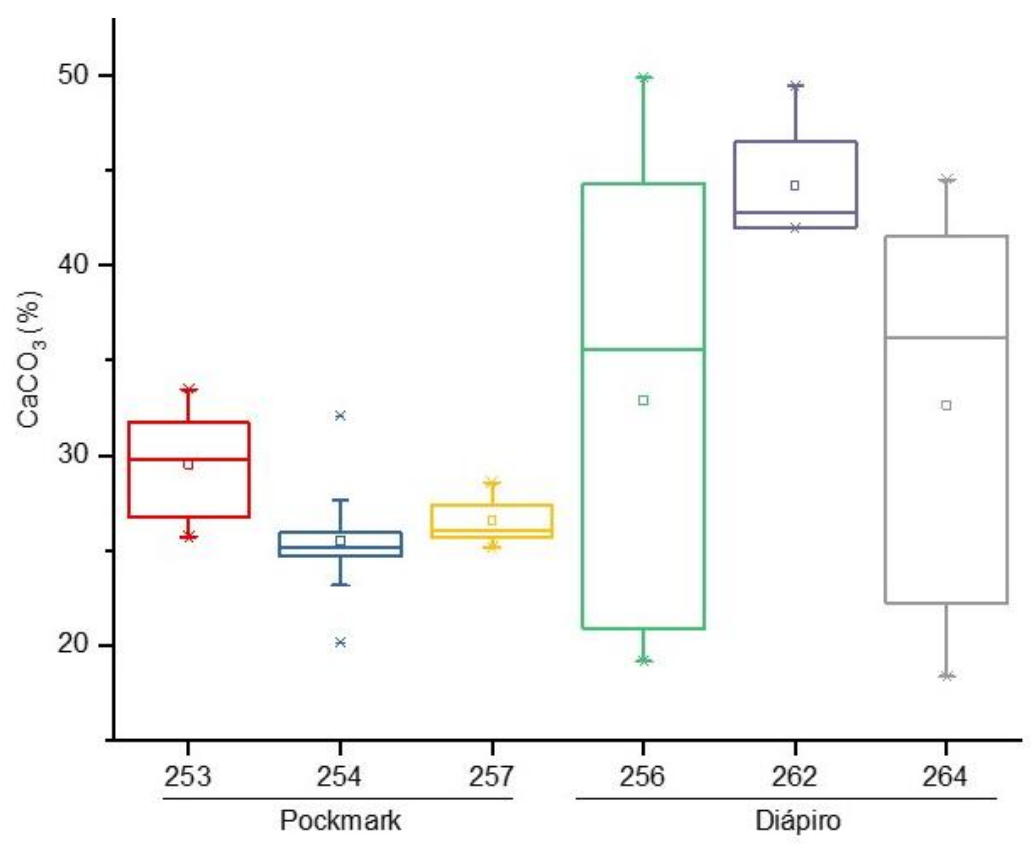

Figura 26 - Box-Plot da \% de $\mathrm{CaCO}_{3}$ nas estações 253, 254, 257, 256, 262 e 264.

Os resultados das porcentagens de $\mathrm{CaCO}_{3}$ entre os testemunhos foram semelhantes aos encontrados nos sedimentos superficiais, sendo as menores porcentagens associadas aos pockmarks, devido a maior deposição de sedimentos finos, ocasionando a maior diluição de $\mathrm{CaCO}_{3}$ nas depressões. Já os maiores teores foram estabelecidos nos diápiros, que podem estar associados a forma cilíndrica e a atuação da ACAS, carreando os sedimentos mais finos para outros locais e permanecendo as areias finas e detritos de $\mathrm{CaCO}_{3}$.

Através do box-plot da figura 27 sobre os teores de COT, foi possível observar uma distinção entre os testemunhos dos pockmarks e diápiros. A estação 257 apresentou $75 \%$ dos dados abaixo de $0,86 \%$ de COT, seguida das 
estações 253 ( $Q 3=0,64 \%$ ) e 254 ( $Q 3=0,76 \%$ ), demonstrando que todos os testemunhos coletados nos pockmarks apresentaram os maiores teores de COT. O maior acúmulo de matéria orgânica nas depressões, pode ser proveniente de sua geometria mais côncava, suas dimensões e ao enfraquecimento da atuação da corrente de fundo concentrando sedimentos e detritos autóctones e alóctones para a região.

A estação 262 apresentou $75 \%$ dos dados abaixo de $0,36 \%$ de COT, seguido da estação $264(0,43 \%)$ e $256(0,51 \%)$. A menor presença do teor de COT nos diápiros pode ser resultante da atuação mais forte das correntes de fundo, que carregam os sedimentos e os compostos orgânicos para outras regiões, devido a sua característica cilíndrica. Os valores de COT foram parecidos em relação as amostras encontradas nos sedimentos superficiais.

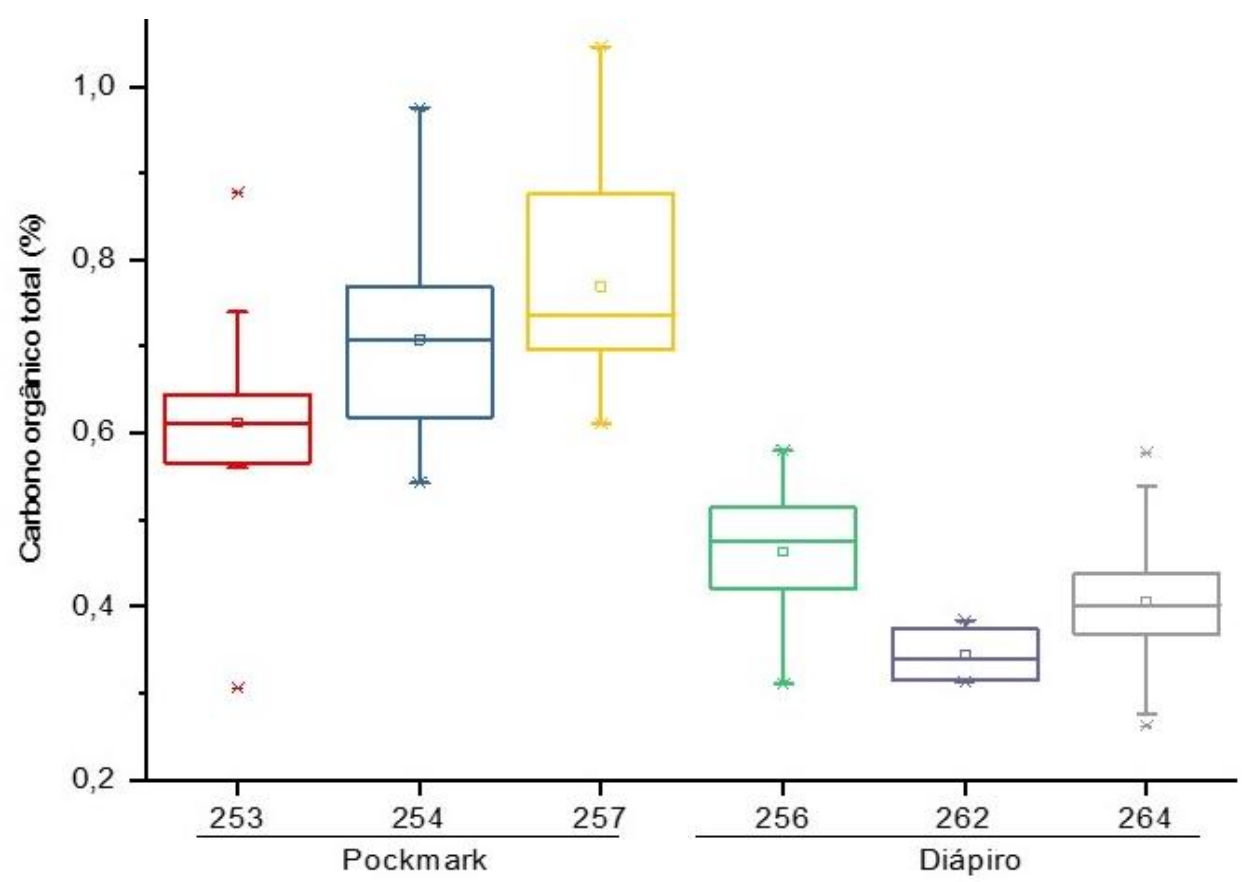

Figura 27 - Box-Plot da \% de COT nas estações 253, 254, 257, 256, 262 e 264.

A relação entre os teores de COT e NT presentes nas amostras podem indicar a predominância do nitrogênio orgânico. Foi possível observar que apenas uma pequena quantidade da variação dos dados do nitrogênio total pode ser explicada pelo carbono orgânico total $\left(r^{2}=0,51\right)$, indicando que 0 
nitrogênio presente nas amostras também é inorgânico (Figura 28). Dessa forma, os valores de nitrogênio total, da razão $\mathrm{C} / \mathrm{N}$ e da razão isotópica do nitrogênio não serão utilizados, considerando apenas os valores do carbono orgânico total e a razão isotópica do carbono.

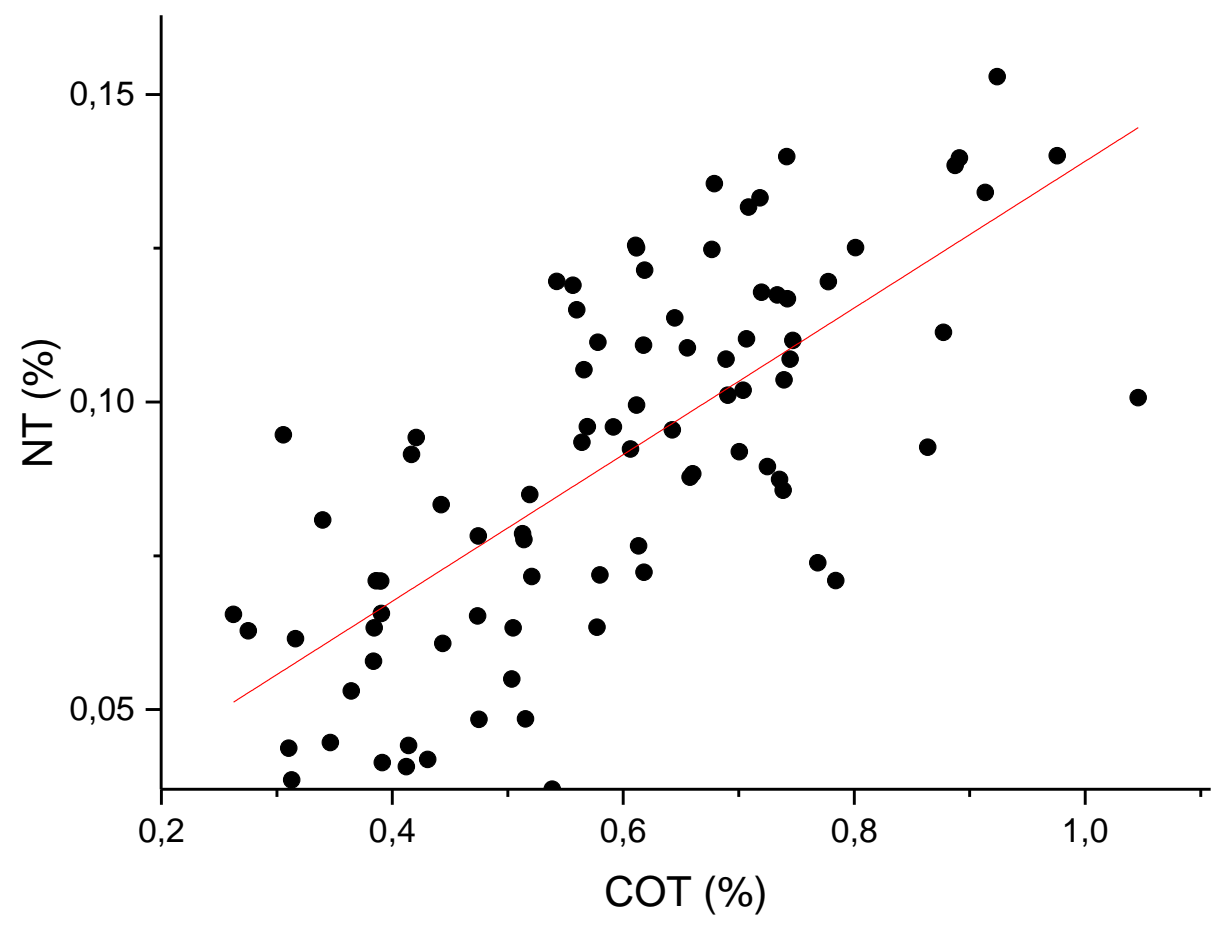

Figura 28 - Correlação linear entre o carbono orgânico total e o nitrogênio total.

Os valores médios de $\delta^{13} \mathrm{C}$ variaram entre $-22,0$ a $-20,04 \%$ nas estações 264 e 254, respectivamente (Figura 29). Os valores obtidos mostraram que o carbono orgânico é predominantemente fitoplantônico (MEYERS, 1994) em todas as amostras dos testemunhos, associando ao aporte de matéria orgânica presente na coluna d'água para a plataforma e talude continental. A produção primária nas águas superficiais pode ser advinda da penetração sazonal de águas frias, pouco salinas e ricas em nutrientes provenientes das drenagens de importantes rios (PIOLA et al., 2008; CAMPOS et al., 2013). 


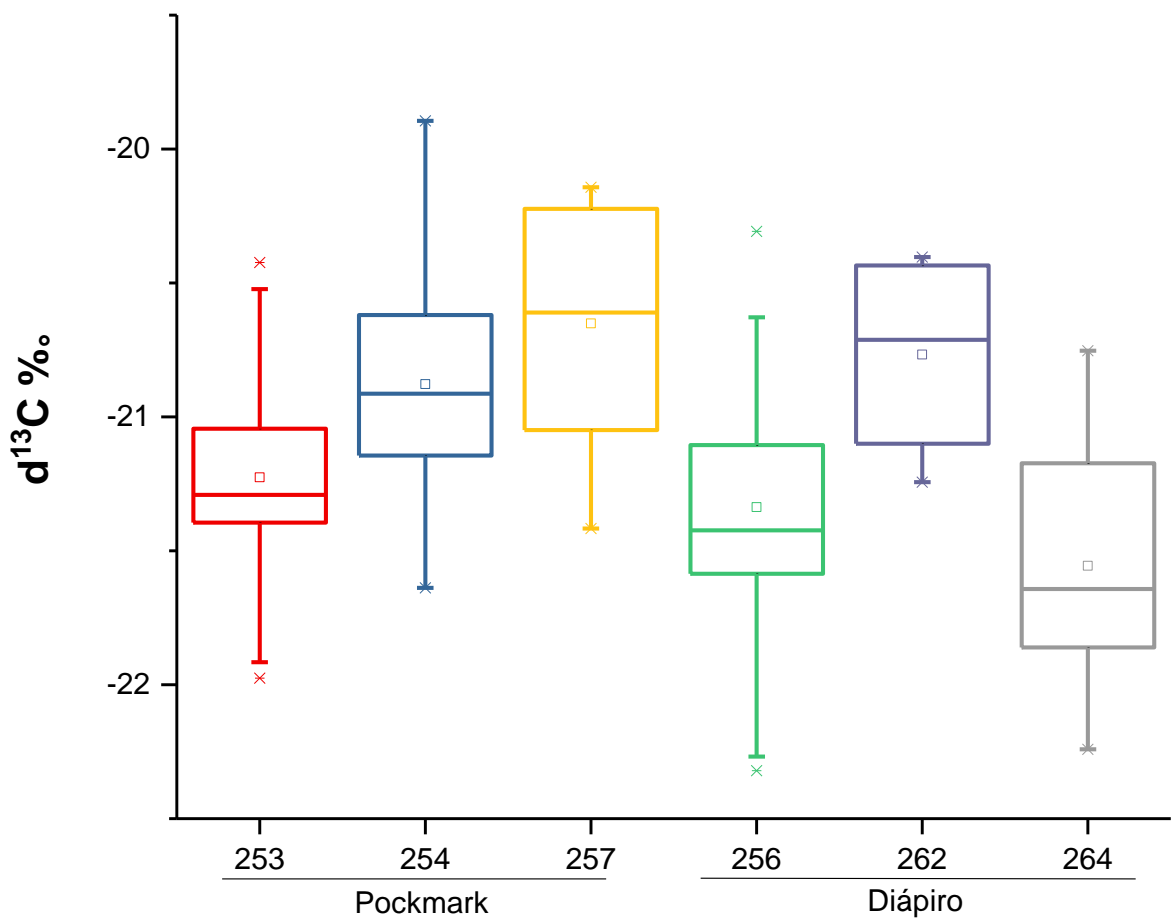

Figura 29 - Box-Plot do teor de $\delta^{13} \mathrm{C}$ nas estações $253,254,257,256,262$ e 264.

Foi possível observar, através das análises dos box-plots relativas às concentrações de HAs totais e $n$-alcanos totais, que não houve uma distinção entre pockmarks e diápiros. A estação 264 apresentou a maior variabilidade entre os dados, já a estação 262 exibiu as menores variações (Figura 30). 


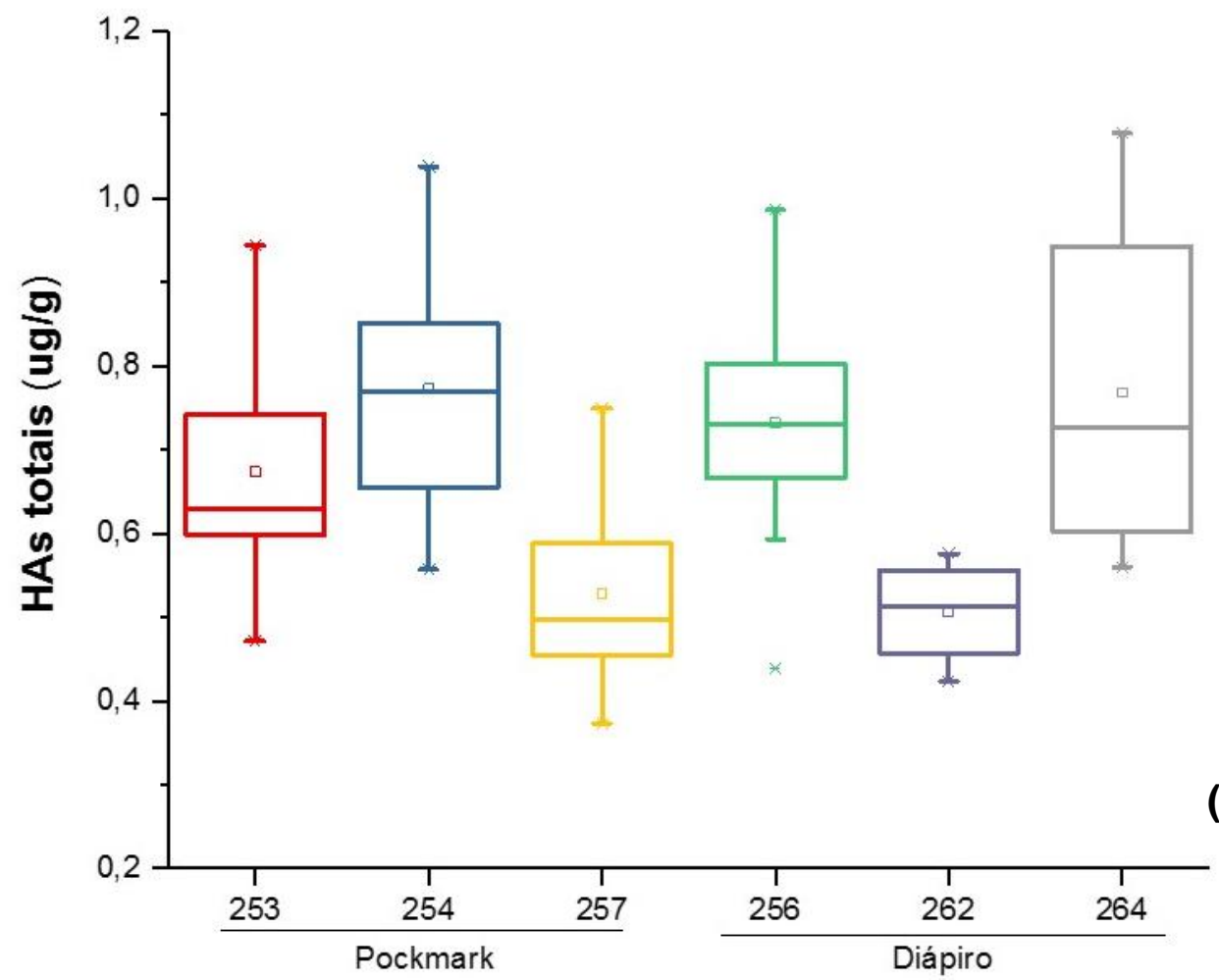

(a)

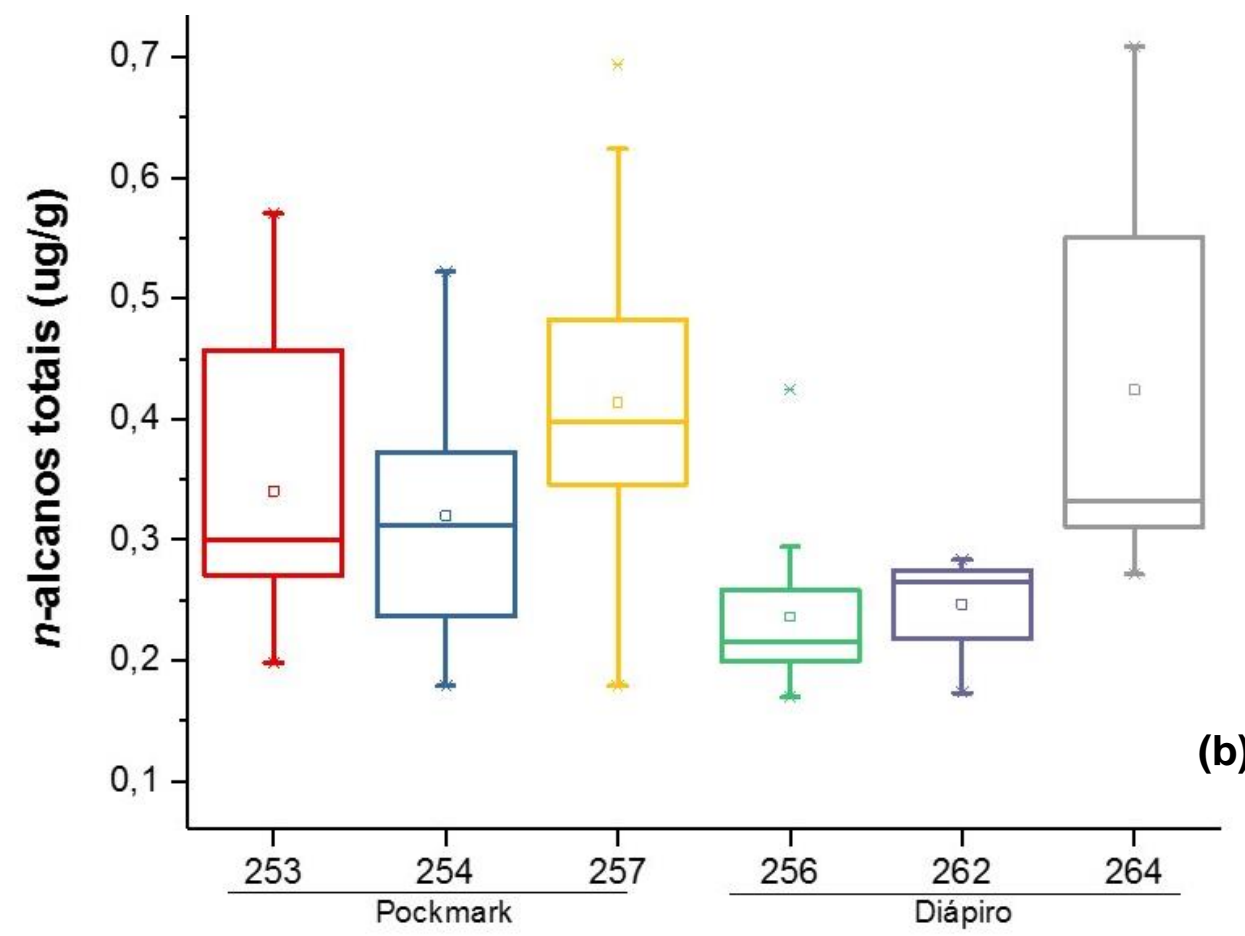

Figura 30 - Box-Plot das concentrações de HAs totais (a) e $n$-alcanos totais (b) nas estações 253, 254, 257, 256, 262 e 264.

Em todas as amostras houve uma maior contribuição dos $n$-alcanos pesados, principalmente $0 n$ - $\mathrm{C}_{29}, n-\mathrm{C}_{31}$ e $n-\mathrm{C}_{33}$ do que os $n$-alcanos leves, caracterizando a contribuição de matéria orgânica biogênica de origem 
terrígena (Figura 31). A influência de $n$-alcanos de cadeia longa em amostras de sedimento é comum, pois são compostos mais resistentes, permanecendo nos sedimentos por longos períodos de tempo. Além disso, representam uma maior parcela da biomassa de plantas superiores, se comparados aos hidrocarbonetos do fitoplâncton (BIANCHI \& CANUEL, 2011). Não é descartada a ocorrência das contribuições marinhas na área de estudo, uma vez que, em função massa molecular, ocorre uma maior degradação dos $n$ alcanos leves (SINGER \& FINNERTY, 1984). Apesar dos $n$-alcanos apontarem uma origem terrígena da matéria orgânica, outros parâmetros indicaram forte presença da matéria orgânica de origem marinha. Os valores encontrados para os isótopos estáveis de carbono estiveram em sua maioria dentro do intervalo entre -22 e $-20 \%$, considerados tipicamente fitoplanctônica ao longo de todos os testemunhos analisados. 

256

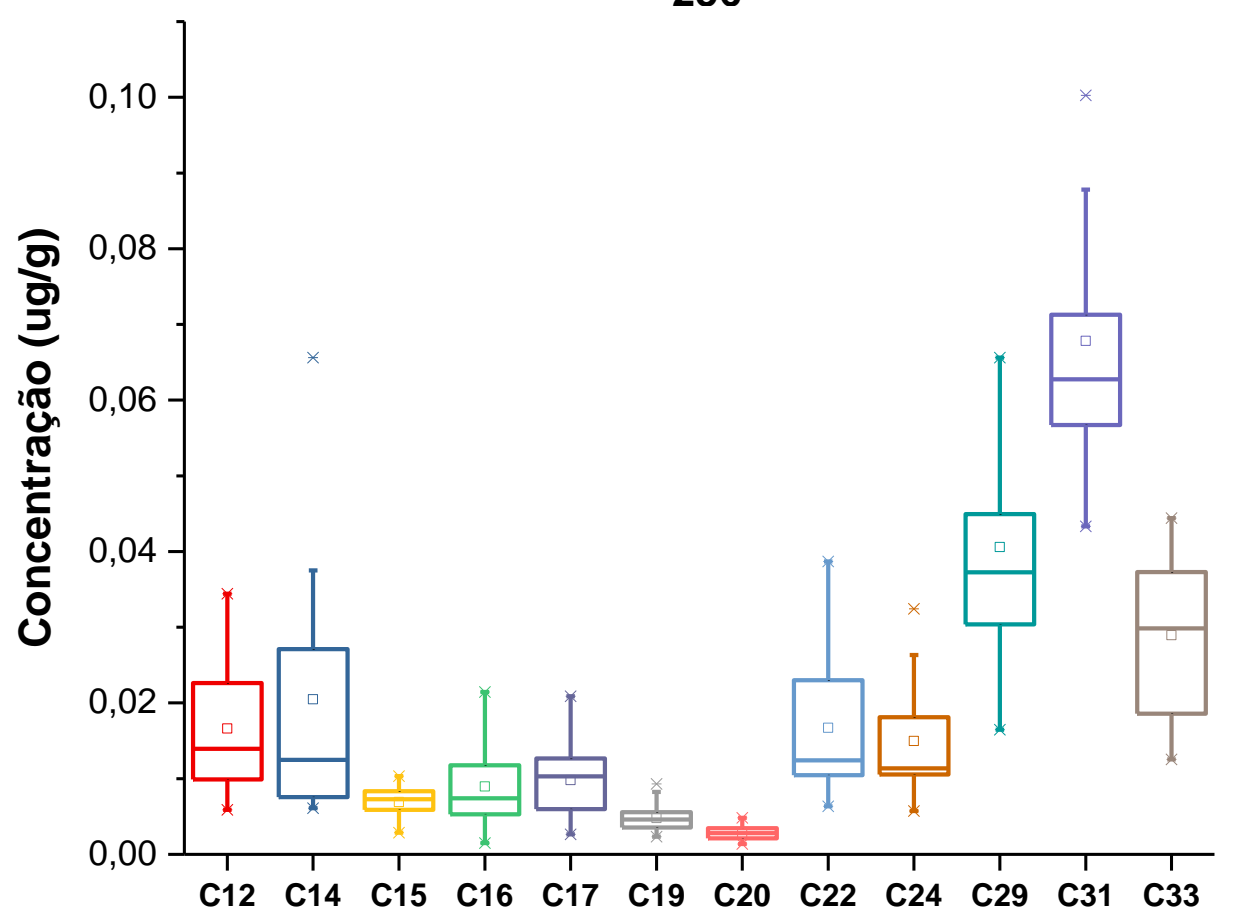

257

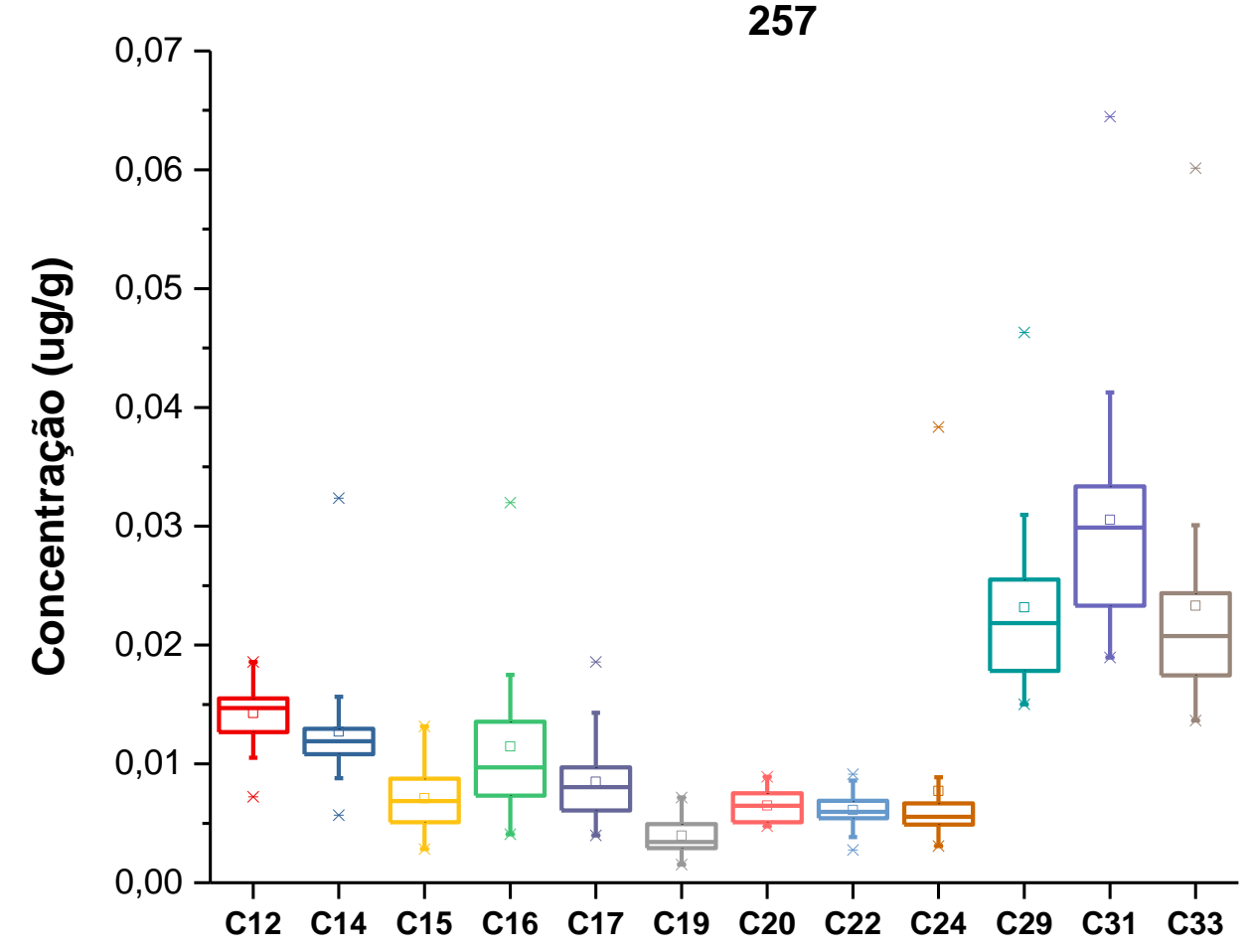



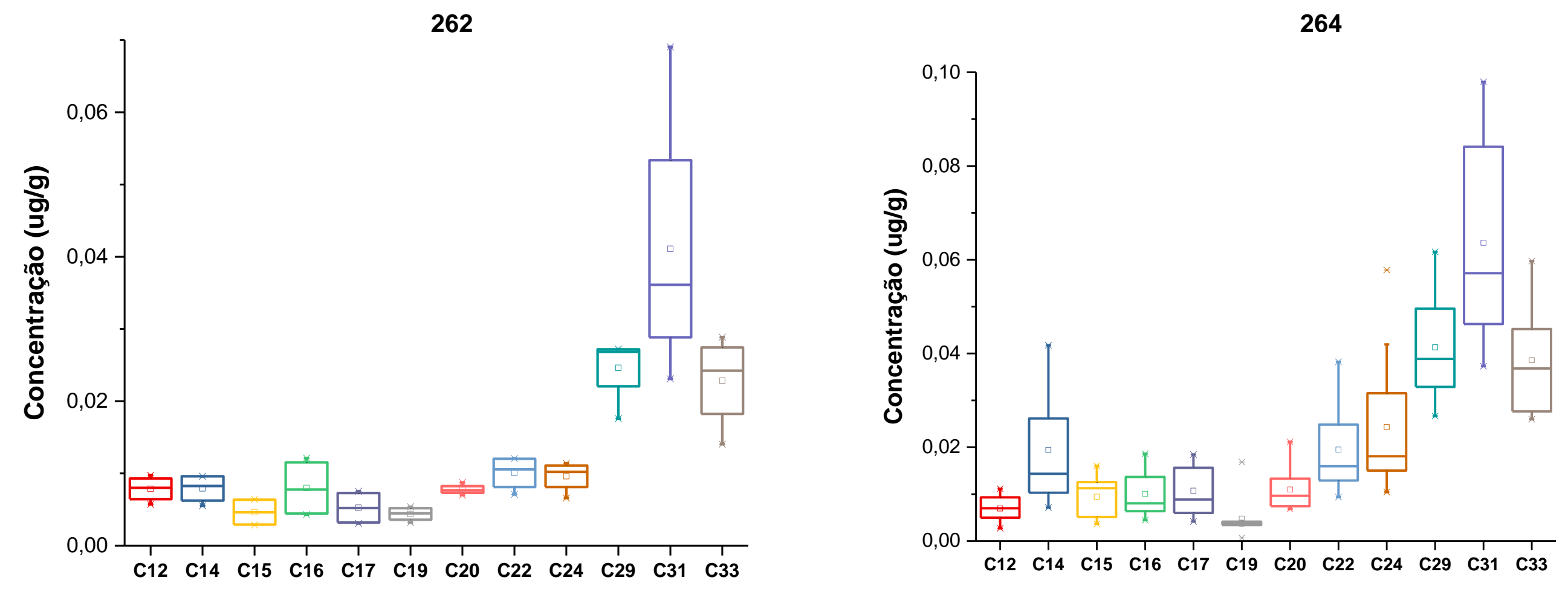

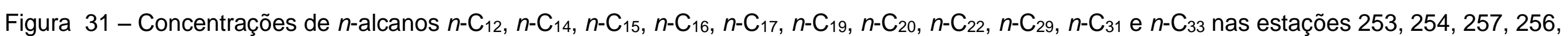
262 e 264. 
A presença de $n$-alcanos leves com a predominância ímpar ( $n$ - $\mathrm{C}_{15}, n$ $\mathrm{C}_{17}, n-\mathrm{C}_{19}$ ), foram observadas na maioria das estações, sendo associadas ao fitoplâncton, zooplâncton e algas. Essa contribuição pode ser proveniente do fluxo de detritos orgânicos da coluna d'água para a plataforma e no talude continental. A presença de fitoplâncton e zooplâncton pode ser resultado da influência da pluma do Rio da Prata, onde a entrada de material orgânico alóctone fornece substratos orgânicos adicionais, possibilitando a produtividade na área de estudo (CIOTTI et al., 1995).

As concentração dos $n$-alcanos leves pares entre $n$ - $\mathrm{C}_{14}$ a $n$ - $\mathrm{C}_{22}$ foram relativamente maiores entre os $n$-alcanos leves. Nas estações 254, 256 e 264, além de exibir $n$-alcanos pesados, foi possível observar a presença relativamente maior de $n$-alcanos pares $\left(n-\mathrm{C}_{14}, n-\mathrm{C}_{16}, n\right.$ - $\mathrm{C}_{20}, n$ - $\left.\mathrm{C}_{22}, n-\mathrm{C}_{24}\right)$, que pode indicar um aumento de bactérias (VENKATESAN \& KAPLAN, 1982; COLOMBO et al., 1989; ABOUL-KASSIM \& SIMONEIT, 1995; 1996; STOUT et al., 2001). Isso pode ser uma evidência da possível atividade de pockmarks e diápiros, através dos quais são exalados compostos que sustentam ecossistemas quimiossintéticos. A presença de bactérias associadas às emanações frias, próximos à região de estudo, são descritos por GIONGO et al., (2016) e FUJIKURA et al., (2017). Evidências de exsudações próximos à área foram descritos por KOWSMANN \& CARVALHO, (2002).

Em todas as amostras, houve o predomínio de $n$-alcanos de cadeia longa com o número ímpar de átomos de carbono ( $n-\mathrm{C}_{29}, n-\mathrm{C}_{31}$ e $n-\mathrm{C}_{33}$ ), indicando a presença de fontes de origem biogênica terrígena, associadas às plantas superiores. A entrada do material terrígeno para a região de estudo pode ser proveniente da pluma do Rio da Prata, que consiste principalmente da água do Rio Paraná, com uma pequena contribuição da Lagoa dos Patos (63 $\mathrm{km}^{3} \mathrm{ano}^{-1}$ ) (CAMPOS et al., 2013).

O índice Alcano (IA) é estimado através da diferença entre os $n-C_{29} \mathrm{e}$ $n$ - $\mathrm{C}_{31}$. Os valores, ao longo de todos os testemunhos, apresentaram valores acima de 0,5 , indicando a presença de plantas do tipo $\mathrm{C}_{4}$, associados as pradarias, vegetação encontrada mais ao sul do Rio Grande do Sul, atingindo o Uruguai e a Argentina.

As concentrações dos alcanos isoprenóides pristano e fitano variaram entre $<$ LDM a $0,019 \mu \mathrm{mg} \mathrm{g}^{-1}$ e $<$ LDM a $0,013 \mu \mathrm{mg} \mathrm{g}^{-1}$, respectivamente. Foi 
possível verificar que as concentrações de pristano foram maiores que o fitano na maioria das amostras, indicando a presença de condições oxidantes na área de estudo.

Os valores da relação pristano/fitano não puderam ser calculadas em algumas estações, devido às baixas concentrações do pristano e fitano nas amostras. No geral a razão apresentou valores acima de 1, determinando um ambiente óxico, exceto na amostra $253(6-8 \mathrm{~cm})$, que atingiu o valor de 0,5 para a razão. A presença da condição redutora na amostra 253 pode ser relacionados a maior presença de $n$-alcanos e álcoois de maior massa molar, indicando a presença de degradação bacteriana da matéria orgânica vegetal, que consome o oxigênio durante o processo, aumentando o potencial de redução neste local.

Através das análises de esteróis plotados nos box-plots da Figura 32, não foi possível distinguir os testemunhos entre pockmarks e diápiros, devido as baixas variabilidades entre as estações. A análise individual dos compostos por estação mostrou maior contribuição de esteróis de origem terrestre (sitosterol, campesterol e estigmasterol), quando comparados aos organismos marinhos (colesterol e brassicasterol). No geral, as maiores concentrações de esteróis totais foram observadas no topo dos testemunhos.

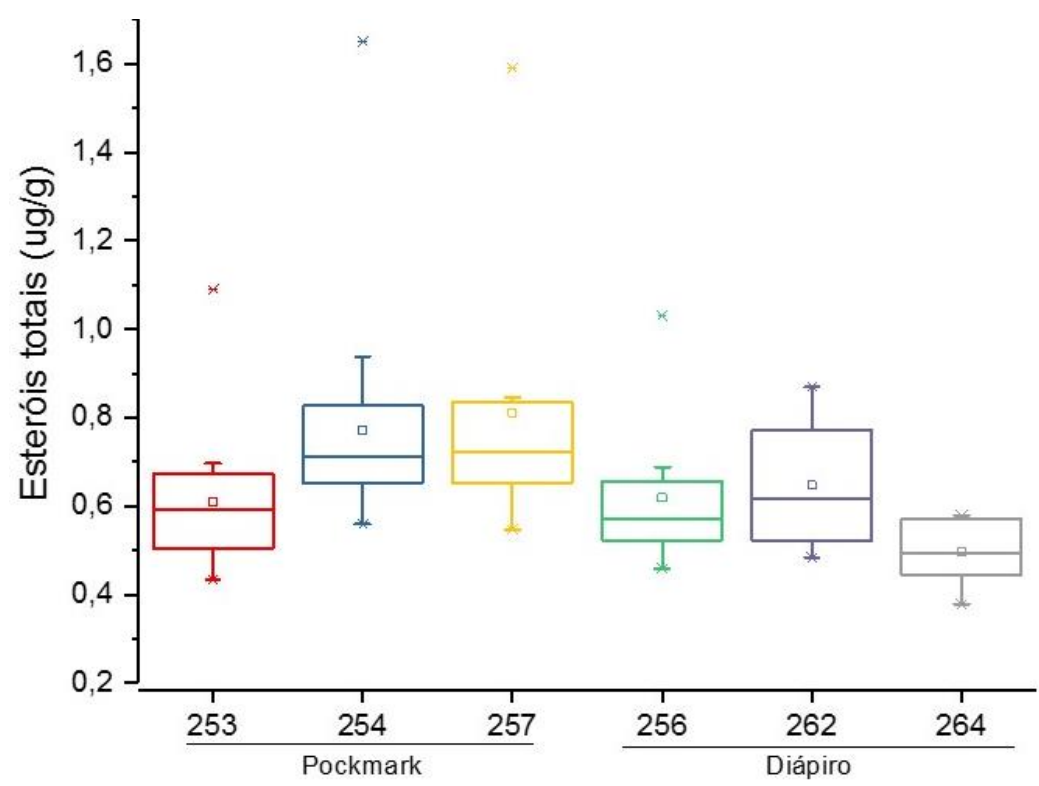

Figura 32 - Box-Plot das concentrações de Esteróis Totais nas estações $253,254,257,256,262$ e 264. 
A partir das proporções entre as diversas fontes de esteróis (Figura 33), foi possível inferir a origem da matéria orgânica. $O \beta$-sitosterol esteve presente em todas as amostras, contribuindo com as concentrações mais altas entre os esteróis avaliados ao longo de todos os testemunhos. O predomínio deste composto indica tanto contribuições autóctones (fitoplâncton, zooplâncton, macroalgas e bactérias), como alóctones (plantas vasculares) (VOLKMAN, 1986; VOLKMAN et al., 2008) para a área de estudo, indicando o possível aprisionamento de sedimentos e o acúmulo de detritos de origem terrígena e marinha nos pockmarks.

O colesterol foi o esterol marinho encontrado em maiores concentrações nas estações 253, 254, 256 e 262, apontando também a presença de detritos de microalgas, cianobactérias e zooplâncton para essas regiões.

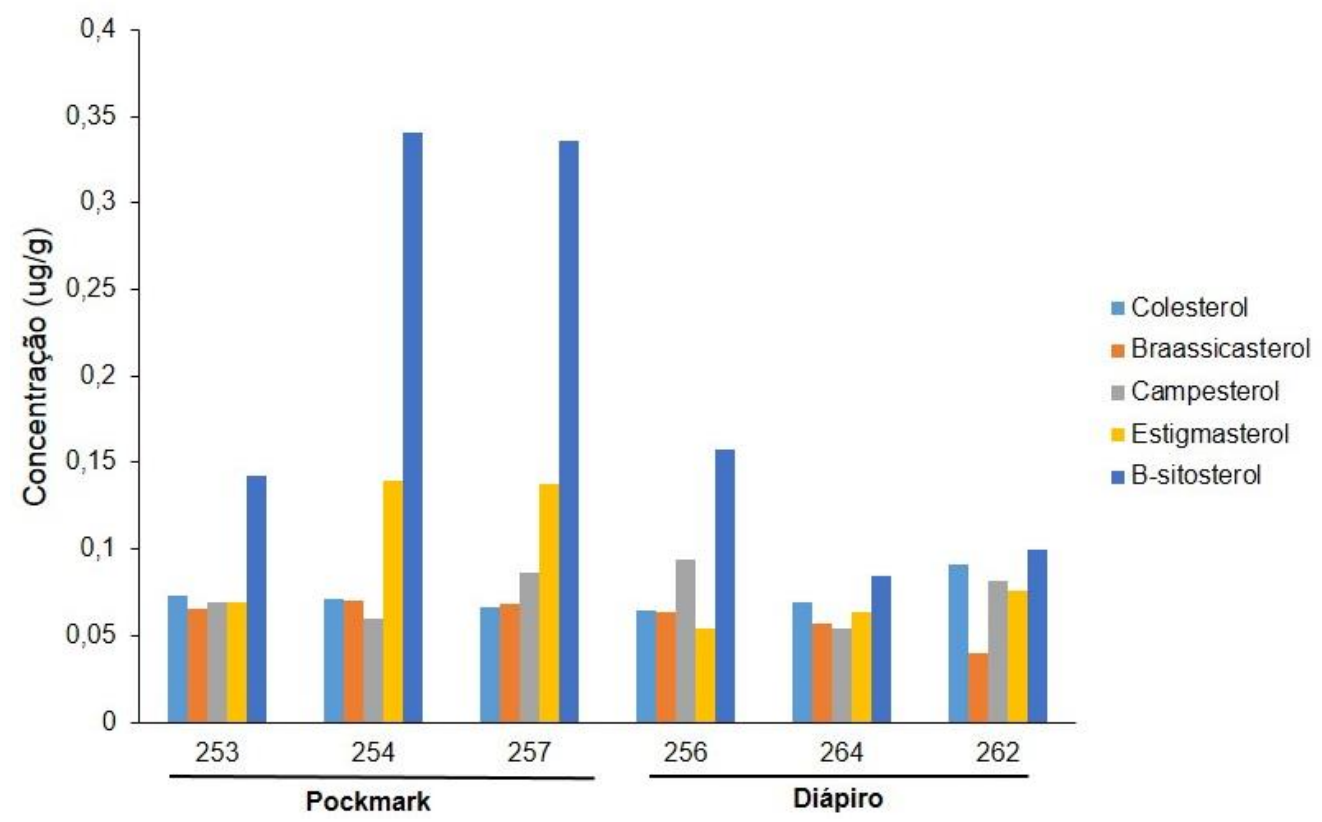

Figura 33 - Médias das concentrações de Colesterol, Brassicasterol, Campesterol, Estigmasterol e de $\beta$-sitosterol nas estações 253, 254, 255, 256, 257, 262 e 264.

O $\beta$-sitosterol associado com o colesterol através da razão colesterol/ $\beta$-sitosterol pode indicar se a matéria orgânica é de origem marinha ou terrestre. Valores próximos a zero indicam a matéria orgânica de origem terrígena, enquanto que valores acima de 1 apontam para origem planctônica 
(MUDGE \& LINTERN, 1999). Todos os valores desta razão exibiram valores abaixo de 1 , determinando que a matéria orgânica encontrada nos sedimentos possuem influência de aportes terrígenos em toda a região.

Os esteróis saturados, geralmente produtos de degradação bacteriana de homólogos insaturados foram encontrados em baixas concentrações, indicando que não há transformação diagenética significativa de esteróis entre os testemunhos.

Por meio das análises dos álcoois totais, não houve uma distinção entre os pockmarks e diápiros. As estações 256 e 264 apresentaram as maiores variabilidades entre os dados, sendo compostas pelas maiores concentrações ( $Q 3=0,76 ; \mathrm{Q} 3=0,61$ ) (Figura 34).

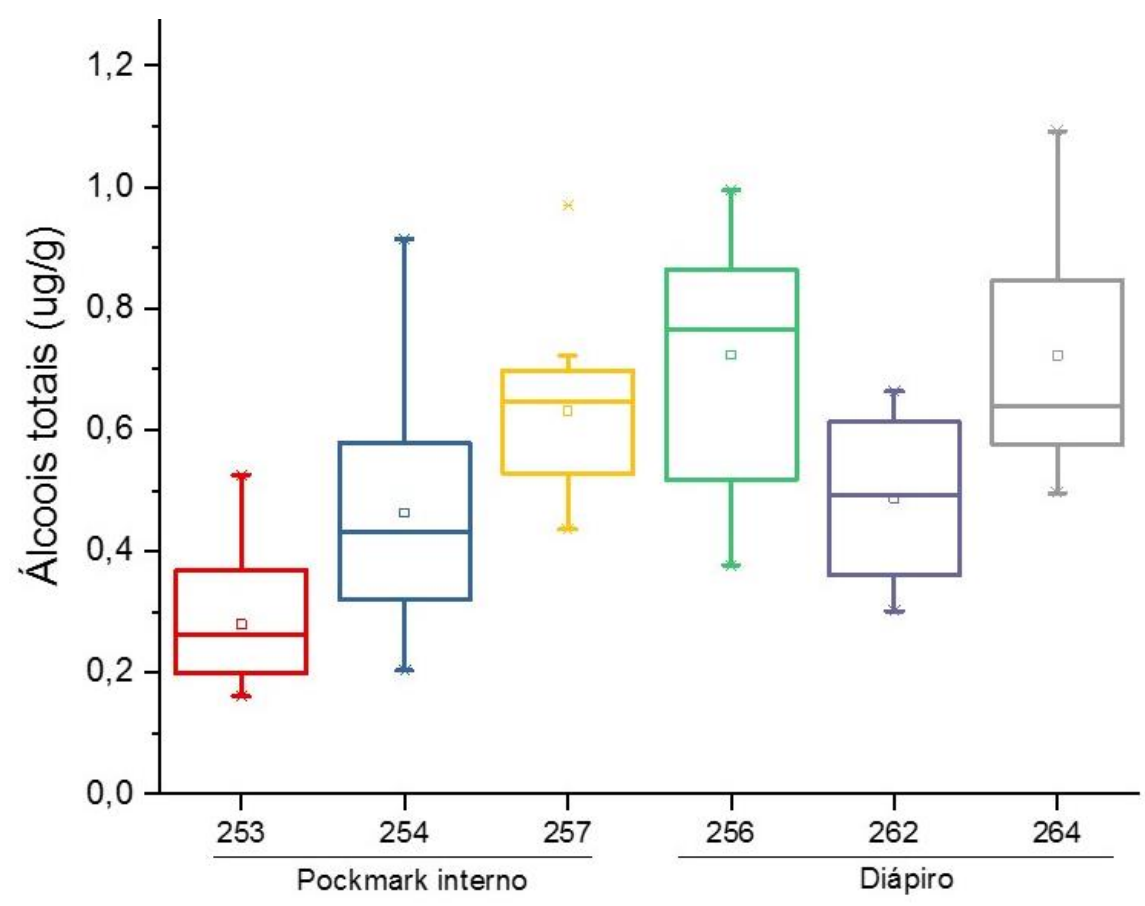

Figura 34 - Box-Plot da concentração de Álcoois totais nas estações 253, 254, 257, 256, 262 e 264.

Em todas as amostras houve maior contribuição dos álcoois pesados $\left(>\mathrm{C}_{22}-\mathrm{OH}\right)$, do que os álcoois leves $\left(<\mathrm{C}_{22}-\mathrm{OH}\right)$, caracterizando que há contribuição terrígena, estes compostos são mais resistentes e estão presentes em ceras epicuticulares de plantas. Além de exibir álcoois lineares pesados, houve a presença relevante de álcoois leves $\left(\mathrm{C}_{16}-\mathrm{OH}\right.$ e $\left.\mathrm{C}_{18}-\mathrm{OH}\right)$. A origem bacteriana ou de algas também pode ser um indicativo da presença de 
álcoois de cadeia $\mathrm{C}_{16}-\mathrm{OH}$ nos sedimentos marinhos (MURI et al., 2004). Os compostos de cadeia $\mathrm{C}_{18} \mathrm{OH}$ podem ser atribuídos ao zooplâncton (FERNANDES et al., 1999; ROBISON et al., 1984). A entrada do material terrígeno para a região de estudo pode ser proveniente da pluma do Rio da Prata, que consiste principalmente da água do Rio Paraná, com uma pequena contribuição da Lagoa dos Patos (63 $\mathrm{km}^{3}$ ano-1) (CAMPOS et al., 2013). A presença de detritos de fitoplâncton e zooplâncton pode ser resultado da influência da pluma do Rio da Prata, disponibilizando nutrientes para região de estudo.

As Figuras XIX a XXII no apêndice, apresentam os perfis dos parâmetros avaliados para todos os testemunhos. De modo geral, foram observadas poucas variações ao longo dos perfis, entretanto alguns parâmetros puderam ser destacados, onde foi possível, em alguns casos, observar algumas variações importantes.

De modo geral, observou-se a presença de $n$-alcanos de origem terrígena ( $n-\mathrm{C}_{29}, n-\mathrm{C}_{31}$ e $n-\mathrm{C}_{33}$ ) para todas as amostras (Figura 31). Entretanto alguns testemunhos mostraram um aumento relativo de $n$-alcanos de cadeias curtas pares ( $n-\mathrm{C}_{12}, n-\mathrm{C}_{14}$ e $n$ - $\mathrm{C}_{16}$ ) em relação aos de cadeias longas ímpares

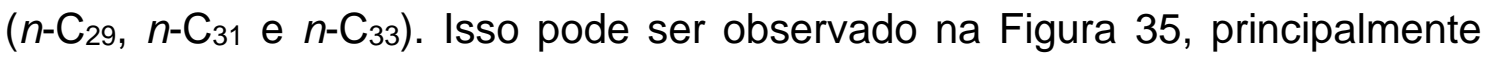
nos testemunhos 254 e 256, localizados no pockmark e diápiro, respectivamente. 


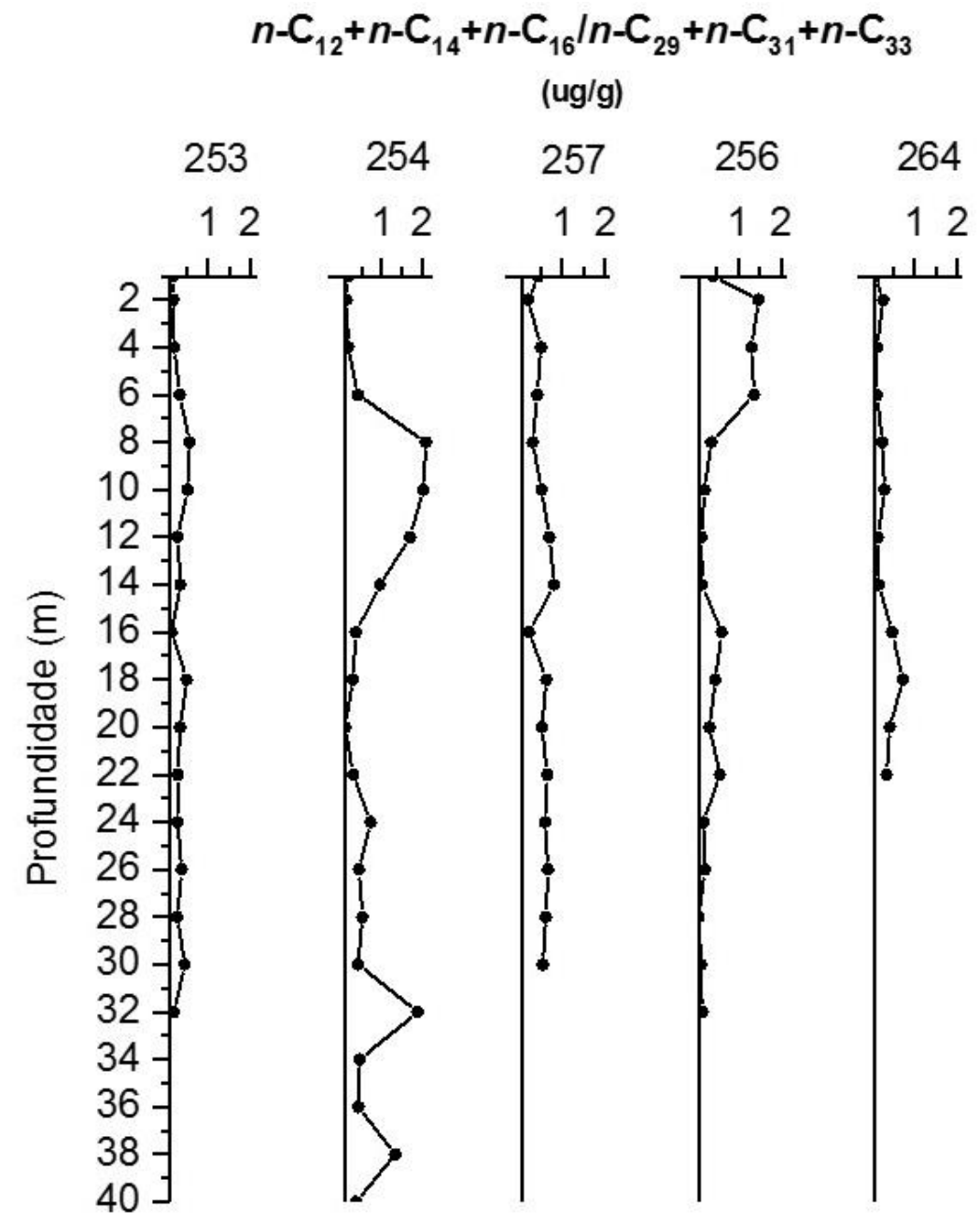

Figura 35 - Relação entre os $n$-alcanos $n$ - $\mathrm{C}_{12}, n-\mathrm{C}_{14}$ e $n$ - $\mathrm{C}_{16}$ sobre os $n$ alcanos $n-\mathrm{C}_{29}, n-\mathrm{C}_{31}$ e $n$-C $\mathrm{C}_{33}$ nos testemunhos 253, 254, 256, 257 e 264.

A presença relativamente maior de $n-C_{12}, n-C_{14}, n-C_{16}$ nas profundidades 8 a $14 \mathrm{~cm}$ (testemunho 254) e 0 a $6 \mathrm{~cm}$ (testemunho 256) indicam o aumento de atividade bacteriana. Essa origem bacteriana pode ser comprovada pelo aparecimento de álcoois de cadeias curtas pares, principalmente $0 \mathrm{C}_{16}-\mathrm{OH}$, nas profundidades de 0 a 4 e 16 a $18 \mathrm{~cm}$ (testemunho 256) (Figura 36). Essas características podem ser um indicativo de atividades dos pockmarks e diápiros em um determinado tempo, sustentando comunidades quimiossintéticas, uma vez que as zonas de emissões de gases no fundo o mar, sustentam ecossistemas biológicos que obtêm nutrientes através da síntese de elementos químicos. 


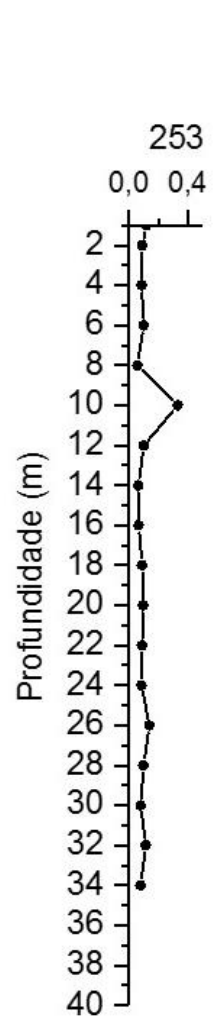

$n$-alcanos leves $\left(<n-C_{22}\right)$

(ug/g)

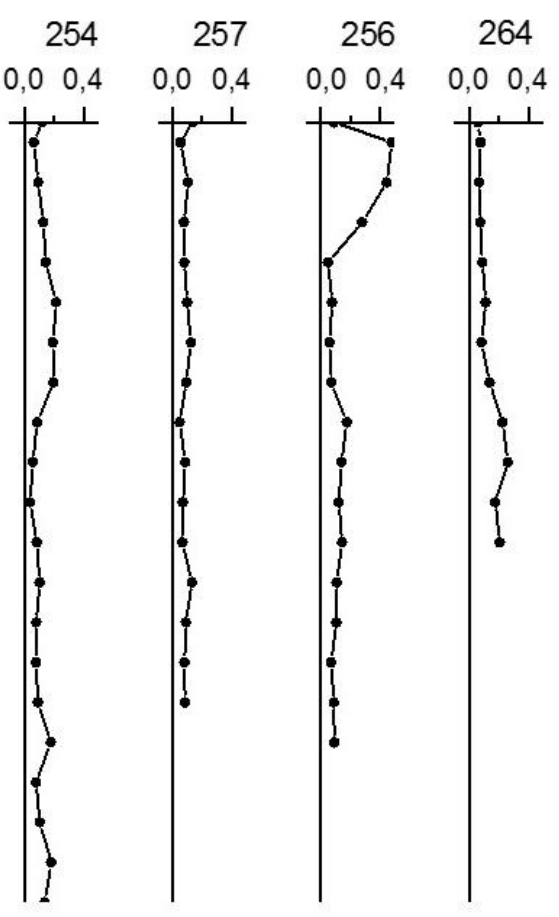

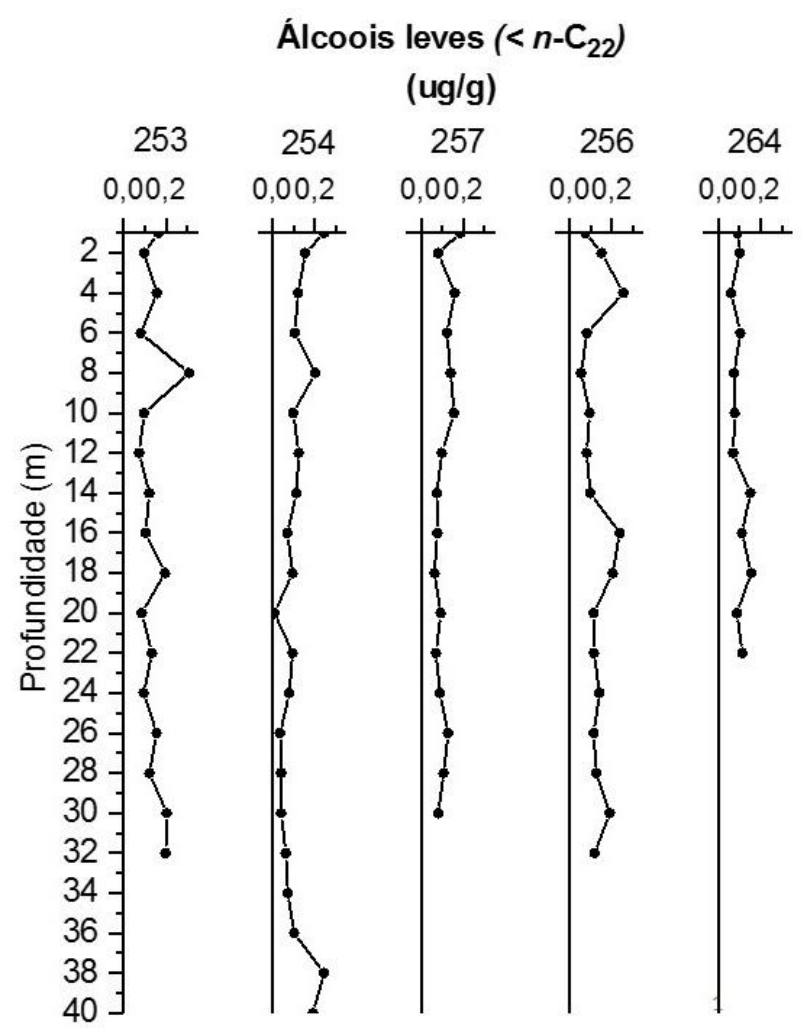

Figura 36 - Perfil dos $n$-alcanos e álcoois leves $(\mu \mathrm{g} / \mathrm{g})$, analisados nos testemunhos 253, 254, 256, 257 e 264.

Nos demais testemunhos, não houve contribuições consideráveis em relação aos demais parâmetros, deste modo os resultados obtidos para cada amostra podem ser encontradas nas tabelas II a XVIII e nas figuras XIX a XXII, inseridos em apêndice.

\section{CONCLUSÕES}

Através da avaliação dos marcadores orgânicos moleculares ( $n$ alcanos, esteróis e álcoois) e os demais marcadores geoquímicos $\left(\mathrm{CaCO}_{3}\right.$, COT e $\delta^{13} \mathrm{C}$ ), foi possível observar a presença de matéria orgânica de origem marinha e terrestre na maioria das amostras.

No geral, tanto nas amostras superficiais como ao longo dos testemunhos, houve o maior acúmulo de COT nas amostras coletadas dentro dos pockmarks, associadas ao possível acúmulo de sedimentos e de matéria orgânica dentro das depressões mais profundas. Os menores teores de COT 
foram observados nos diápiros, resultante da sua característica cilíndrica que corrobora para a maior deposição de areia. Foi possível observar a correlação significativa do COT com os esteróis totais nas amostras superficiais, indicando fontes autóctones e alóctones, principalmente no interior das concavidades, devido as maiores concentrações do $\beta$-sitosterol, campesterol e brassicasterol. Porém, não foi possível obter uma correlação positiva entre os teores de COT em relação aos outros marcadores (HAs e Álcoois) tanto nas amostras superficiais como ao longo dos testemunhos.

O nitrogênio total, razão isotópica do nitrogênio total $\left(\delta^{15} \mathrm{~N}\right)$ e razão $\mathrm{C} / \mathrm{N}$ não foram utilizadas neste trabalho, uma vez que, uma pequena quantidade da variação dos dados do nitrogênio total pode ser explicada pelo carbono orgânico total, considerando apenas os valores do carbono orgânico total e a razão isotópica do carbono. As análises de $\delta^{13} \mathrm{C}$ indicaram que o carbono orgânico é tipicamente fitoplantônico em todas as amostras analisadas, não havendo evidência atual de escape de gás/fluidos nos diápiros e pockmarks da área de estudo.

Em relação aos marcadores orgânicos geoquímicos, todas as amostras apresentaram maior contribuição dos $n$-alcanos e álcoois pesados, sitosterol e campesterol, caracterizando a contribuição de matéria orgânica biogênica de origem terrígena, que pode ser proveniente principalmente pelo aporte continental do rio da Prata. $O$ transporte de sedimentos terrígenos é carregada para norte pela Corrente Costeira do Brasil (CCB), consequentemente, a presença de cânions submarinos na área de estudo, atuam no transporte de sedimentos depositados na plataforma para o talude continental. Através do Índice Alcano, foi possível observar que a predominância terrígena se deve à contribuição de pradarias, típica vegetação do Uruguai e do Rio Grande do Sul.

As contribuições de $n$-alcanos e álcoois leves junto com a presença de brassicasterol e colesterol indicaram detritos de fitoplâncton, zooplâncton e bactérias. A matéria orgânica proveniente do fitoplâncton e zooplâncton é transportada da coluna d'água para a plataforma e talude continental, podendo ser advinda das descargas fluviais do Rio da Prata, sendo responsáveis pela produtividade primária, devido ao aporte de nutrientes.

Embora não tenha sido observado nenhum indicativo de atividade nas amostras superficiais foi possível verificar a presença relativamente maior de $n$ - 
alcanos leves com número par de átomos de carbono ao longo dos perfis sedimentares. Essa presença pode indicar períodos de possíveis liberações de gás/fluido, que sustentaram ecossistemas quimiossintéticos nos testemunhos 254 e 256 (pockmark e diápiro, respectivamente). 


\section{REFERÊNCIAS BIBLIOGRÁFICAS}

ABOUL-KASSIM, T. A. T.; SIMONEIT, B. R. T. 1995. Petroleum hydrocarbon fingerprinting and sediment transport assessed by molecular biomarker and multivariate statistical analyses in the eastern harbour of Alexandria. Egypt Marine Pollution Bulletin, v. 30, p. 63-73.

ALVES, C. A.; GONÇALVES, C.; EVTYUGINA, M.; PIO, C. A.; MIRANTE, F.; PUXBAUM, H. 2010. Particulate organic compounds emitted from experimental wild land fires in a Mediterranean ecosystem. Atmospheric Environment, v. 44, p. 2750-2759.

ANDERSSON, R. A.; MEYERS, P. A. 2012. Effect of climate change on delivery and degradation of lipid biomarkers in a Holocene peat sequence in the Eastern European Russian Arctic. Organic Geochemistry, v. 53, p. 63-72.

AZEVEDO, D. A. 2003. A preliminary investigation of the polar lipids in recent tropical sediments from aquatic environments at Campos dos Goytacazes, Brazil. Journal of Brazilian Chemical Society, v. 14, p. 97-106.

BATISTA NETO, J. A.; SILVA, C. G. 2004. Morfologia do Fundo Oceânico. In: BATISTA NETO, J. A.; PONZI, V. R. A.; SICHEL, S. E. 2004. Introdução a geologia marinha. Rio de Janeiro: Interciência, p. 3151.

BENNETT, B. A.; SMITH, C. R., GLASER, B.; MAYBAUM, H. L. 1994. Faunal community structure of a chemoautotrophic assemblage on whale bones in the deep northeast Pacific Ocean. The Marine Ecology Progress Series, v. 108, p. 205-223.

BIANCHI, T. S.; CANUEL, E. A. 2011. Chemical biomarkers in aquatic ecosystems. New Jersey: Princeton University Press.

BLUMER, M.; GUILLARD, R. R. L.; CHASE, T. 1971. Hydrocarbons of marine phytoplankton. Marine Biology, v. 8, p. 183-189.

BOUILLON, S.; CONNOLLY, J. P.; GILLINKIN, D. P. 2011. Use of Stable Isotopes to Understand Food Webs and Ecosystem Functioning in Estuaries. In: E. Wolanski; McLusky D. S. Estuarine and Coastal Science, v. 7, p. 143-173.

BRASSEL, S. C. 1993. Application of biomarkers for delineating marine paleoclimatic fluctuations during the Pleistocene. In: ENGEL, M. H.; MACKO, S. A. (Ed.). Organic Geochemistry: principles and applications, New York: Plenum, p. 699-738. 
BRAUN, J. F. M. 2006. Uso de esteróides na avaliação de aportes antrópicos e naturais da matéria orgânica no Complexo Estuarino de Paranaguá. Tese (Mestrado em Oceanografia). Programa de Pós-Graduação em Oceanografia Física, Química e Geológica, Fundação Universidade Federal do Rio Grande, Rio Grande, Rio Grande do Sul, Brasil.

BRAY, E.E, \& E.D EVANS. 1961. Distribution of n-paraffins as a clue to recognition of source beds. Geochimica et Cosmochimica Acta, v. 22, p. 2-15.

BROTHERS, L. L.; KELLEY, J. T.; BELKNAP, D. F.; BARNHARDT, W. A.; ANDREWS, B. D.; LEGERE, C.; HUGHESCLARKE, J. E. 2012. Shallow stratigraphic control on pockmark distribution in north temperate estuaries. Marine Geology, v. 329-331, p. 34-45.

BROTHERS, L. L.; KELLEY, J. T.; BELKNAP, D. F.; BARNHARDT, W. A.; ANDREWS, B. D.; MAYNARD, M. L. 2011. More than a century of bathymetric observations and present-day shallows ediment characterization in Belfast Bay, Maine, USA: implications for pockmark field longevity. Geo-Marine Letters, v. 31, p. 237-248.

CALDICOTT, A. B., AND EGLINTON, G. 1973. Surface waxes; In "Phytochemistry 3, Inorganic Elements and Special Groups of Chemicals." (L.P. Miller, Ed.). Van Nostrand Reinhold, New York, p. 162-194.

CAMPOS, E. J. D. 2006. Equatorward translation of the Vitoria Eddy in a numerical simulation. Geophysical Research Letters, p. 33.

CAMPOS, P. C., MÖLLER, O.O., PIOLA, A.R., PALMA, E.D. 2013. Seasonal variability and coastal upwelling near Cape Santa Marta (Brazil). Journal of Geophysical Research, v. 118, p. 1420-1433.

CARREIRA, R. S., WAGENER, A. L. R., READMAN, J.W., FILEMAN, T.W., MACKO, S.A, VEIGA, A. 2002. Changes in the sedimentary organic carbon pool of a fertilized tropical estuary, Guanabara Bay, Brazil: an elemental, isotopic and molecular marker approach. Marine Chemistry, v. 79, p. 207-227.

CASTRO, B. M. LORENZETTI, J.A., SILVEIRA, I.C.DA \& MIRANDA, L. B. 2006. Estrutura termohalina e circulação na região entre o Cabo de São Tomé (RJ) e o Chuí (RS). In: Rossi-Wongtschowski, C. L.D. B.\& Madureira, L. S. P. (orgs). O ambiente oceanográfico da Plataforma continental e do talude na região sudeste-sul do Brasil. São Paulo.

CELINO, J. J.; QUEIROZ, A.F.S.; TRIGUIS, J.A.; OLIVEIRA, O. M. C.; SANTIAGO, J. S. 2007. Fonte de matéria orgânica e grau de contaminação por hidrocarbonetos totais de petróleo (HTP) em sedimentos de manguezais na porção norte da Baía de Todos os Santos, Bahia. In: Congresso Brasileiro de Pesquisa em Petróleo e 
Gás, Campinas. Campinas, UNICAMP. Departamento de Engenharia do Petróleo.

CHAPMAN, R. E. 1983. Diapirs, Diapirism and Growth Strutures. In: Petroleum Geology. Netherlands: Developments in Petroleum Science. Elsevier Science Publisher, v. 16, p. 325-348.

CIOTTI, Á.; ODEBRECHT, C.; FILLMANN, G.; MOLLER, O. 1995. Freshwater outflow and Subtropical Convergence influence on phytoplankton biomass on the southern Brazilian continental shelf. Continental Shelf Research, v. 14, p. 1737-1756,.

CITAC/EURACHEM. 2002. Guide to quality in analytical chemistry. Prepared jointly by: CITAC (The Cooperation on International Tracebility in Analytical Chemistry) and EURACHEM (A Focus for Analytical Chemistry in Europe).

COLOMBO, J. C.; PELLETIER, E.; BROCHU, C.; KHALIL, M.; CATOGGIO, J. A. 1989. Determination of hydrocarbon sources using n-alkane and polyaromatic hydrocarbon distribution indexes. Case study: Rio de la Plata Estuary, Argentina. Environmental Science \& Technology, v. 23, p. 888-894.

COSTA, T. L. F.; ARAUJO, M. P. 2010. Lipídios como indicadores de fontes e distribuição de matéria orgânica particulada em um complexo estuarino-lagunar tropical (Mundaú-Manguaba, AL). Química Nova, v. 33, p. 1915-1922.

CRANWELL, P. A. 1976. Decomposition of aquatic biota and sediment formation: organic compounds in detritus resulting from microbial attack on the alga Ceratium hirundinella. Freshwater Biology, v. 6, p. $481-488$.

CRANWELL, P. A.; EGLINTON, G.; ROBINSON, N. 1987. Lipids of aquatic organisms as potential contributors to lacustrine sediments - II. Organic Geochemistry, v. 11, p. 513-527.

CRIPPS, G.C. 1989. Problems in the identification of anthropogenic hydrocarbons against natural background levels in Antarctic. Antarctic Science, v. 1, p. 307-312.

DAMUTH, J. E. 1975. Quaternary climate change as revealed by calcium carbonate fluctuations in western Equatorial Atlantic sediments. Deep-Sea Research, v. 22, p. 725-743.

DANDO, P. R.; AUSTEN, M.; BURKE, R.; KENDALL, M.; KENNICUTT, M.; JUDD, A. G.; MOORER, D.; O'HARA, S.; SCHMALJOHANN, R.; SOUTHWARD, A. 1991. Ecology of a North Sea pockmark with an active methane seep. Marine Ecology Progress Series, v. 70, p. 49-63. 
DAVISJ . B. 1968. Paraffinich ydrocarbonsi $n$ the sulfate-reducing bacterium DesulJovibriod esulfuricans. Chemical Geology, v. 3, p.155-160.

DENOUX, G. J., GARDINALI, P., \& WADE, T. L. 1998. Quantitative determination of polynuclear aromatic hydrocarbons by gas chromatography/mass spectrometry (GC/MS)-selected ion monitoring (SIM) mode.

DITTERT, N.; BAUMANN, K.H.; BICKERT, T.; HENRICH, R.; HUBER, R.; KINKEL, H.; MEGGERS, H. Carbonate Dissolution in the Deep-Sea: Methods, Quantification and Paleoceanographic Application. In: FISCHER, G.; WEFER, G. (ed.). Use of Proxies in Paleoceanography: Examples from the South Atlantic. Berlin, Springer, p. 255-284.

DUAN, Y. 2000. Organic geochemistry of recent marine sediments from the Nansha Sea, China. Organic Geochemistry, v. 31, p. 159-167.

EGLINTON, G.; HAMILTON R. J. 1967. Leaf epicuticular waxes. Science, v.156, p. 1322-1334.

EKPO, B. O.; OYO-ITA, O.E., WEHNER, H. 2005. Even-n-alkane/alkene predominances in surface sediments from the Calabar River, SE Niger Delta, Nigeria. Naturwissenschaften, v. 92, p. 341-346.

EMERSON, S. R.; HEDGES, J. I. 2008. Chemical Oceanography and the Marine Carbon Cycle. 1st ed. Cambridge, U.K.: Cambridge University Press.

ESCUDERO, R.; BRUSSA, C.A. 2004. Subcomponente bosque nativo. Proyecto Combinado GEF/IBRD "Manejo Integrado de Ecosistemas y Recursos Naturales en Uruguay" Componente "Manejo y Conservación de la Diversidad Biológica".

FADER G. B. J. 1991. Gas-related sedimentary features from the eastern Canadian continental shelf. Continental Shelf Research, v. 11, p. 1123-1153.

FERNANDES, M. B.; ELIAS, V. O.; CARDOSO, J. N.; CARVALHO, M. S. 1999. Sources and fate of nalkanols and sterols in sediments of the Amazon shelf. Organic Geochemistry, v.30, p.1075-1087.

FIGUEIREDO JR, A. G.; TESSLER, M. G. 2004. Topografia e composição do substrato marinho da Região Sudeste-Sul do Brasil. São Paulo, Instituto Oceanográfico, USP. Série Documentos Revizee - Score Sul, p. 64. 
FISHERD, J.; HOLLOWAYP, J.; RICHMOND, V. 1972. Fatty acid and hydrocarbon constituents of the surface and wall lipids of some fungal spores. Journal of General Microbiology, v. 72, p. 71-78,.

FREUDENTHAL, T.; WAGNER, T.; WENZHÖFER, F.; ZABEL, M.; WEFER, G. 2001 Early diagenesis of organic matter from sediments of the eastern subtropical Atlantic: evidence from stable nitrogen and carbon isotopes. Geochimica et Cosmochimia Acta, v. 65, p. 1795-1808.

FRY B. 2006. Stable isotope ecology. New York: Springer.

FUJIKURA, K.; YAMANAKA, T.; SUMIDA, P.Y.G.; BERNARDINO, A.F.; PEREIRA, O.S.; KANEHARA, T.; NAGANO, Y.; NAKAYAMA, C.R.; NOBREGA II, M.; PELLIZARI, V.H.; SHIGENO, S.; YOSHIDA, T.; ZHANG, J. \& KITAZATO, H. 2017. Discovery of asphalt seeps in the deep Southwest Atlantic off Brazil. Deep-Sea Research II, v. 146, p. 35-44.

GAETA, S. A \& BRANDINI, F. P. 2006. Produção primária do fitoplâncton na região entre o Cabo de São Tomé (RJ) e o Chuí (RS). In: RossiWongtschowski CLDB and Madureira LS (Eds), O ambiente oceanográfico da plataforma continental e do talude na região sudeste-sul do Brasil, São Paulo, SP, Brasil, EDUSP, p. 219-264.

GAGOSIAN, R. B.; SMITH, S. O.; LEE C.; FARRINGTON, J. W.; FREW, N. M. 1980. Steroid transformations in recent marine sediments. In: Douglas, A. G. and Maxwell J. R. (eds.), Advances in Organic Geochemistry, Pergamon Press, p. 407-419.

GARCÍA, M.; ERCILLA, G.; ALONSO, B. 2009. Morphology and sedimentary systems in the Central Bransfield Basin, Antarctic Peninsula: sedimentary dynamics from shelf to basin. Basin Research, v. 21, p. 295-314.

GASALLA, M. L. A.; VELASCO, G.; ROSSI-WONGTSCHOWSKI C. L. D. B., HAIMOVICI, M.; MADUREIRA, L. S. P. 2007. Modelo de equilíbrio de biomassas Região Sudeste-Sul do Brasil entre 100-1000 m de profundidade. Instituto Oceanográfico, USP, São Paulo.

GAY, A.; LOPEZ M.; ONDREAS, H.; CHARLOU, J. L.; SERMONDADAZ, G.; COCHONAT, P. 2006. Seafloor facies related to upward methane flux within a Giant Pockmark of the Lower Congo Basin. Marine Geology, v. 226, p. 81-95.

GAYE-HAAKE, B.; LAHAJNAR, N.; EMEIS, K.-CH.; UNGER, D.; RIXEN, T.; SUTHHOF, A.; RAMASWAMY, V.; SCHULZ, H., PAROPKARI, A.L.; GUPTHA, M.V.S.; ITTEKKOT, V. 2005. Stable nitrogen isotopic 
ratios of sinking particles and sediments from the northern Indian Ocean. Marine Chemistry, v. 96, p. 243-255,.

GELPI, E.; SCHNEIDER, J.; MANN., ORÓ, J. 1970. Hydrocarbons of geochemical significance in microscopic algae. Phitochemistry. 9, 603-612.

GIONGO, A.; HAAG, T.; SIMÃO, T.L.L.; MEDINA-SILVA, R.; UTZ, L.R.P.; BOGO, M.R.; BONATTO, S.L.; ZAMBERLAN, P.M.; AUGUSTIN, A.H.; LOUREGA, R.V.; RODRIGUES, L.F.; SBRISSA, G.F.; KOWSMANN, R.O.; FREIRE, A.F.M.; MILLER, D.J.; VIANA, A.R.; KETZER, J.M.M. \& EIZIRIK, E. 2016. Discovery of a chemosynthesis-based community in the western South Atlantic Deep-Sea Research I, v. 112, p. 45-56.

GRIMALT, J. O.; FERNÁNDEZ, P.; BAYONA, J. M.; ALBAIGÉS, J. 1990. Assessment of fecal sterols and ketones as indicators of urban sewage inputs to coastal waters. Environmental Science \& Technology, v. 42.

GRIMALT, J., ALBAIGÉS, J. 1987. Sources and occurrence of $\mathrm{C}_{12}-\mathrm{C}_{22} n$ alkane distributions with even carbon-number preference in sedimentary environments. Geochimica Et Cosmochimica Acta, v. 51 , p. $1379-1384$.

GRIMALT, J.; ALSAAD, H. T.; DOUABUL, A. A. Z.; ALBAIGES, J. 1985. Normal-alkane distributions in surface sediments from the Arabian Gulf. Naturwissenschaften, v. 72, p. 35-37.

GRJMALT, J., ALBAIGÉS, J. 1986. Predominance of even carbon numbered $n$ alkanes in coal samples of Nograd Basin (Hungary). Naturwissenschaften, v. 73, p. 729-73.

HAN, J. \& CALVIN, M. 1969. Hydrocarbon distribution of algae and bacteria, and microbiological activity in sediments. Proceedings of the National Academy of Sciences. USA v. 64, p. 436-443.

HARADA N., HANDA N., FUKUCHI M., ISHIWATARI R. 1995. Source of hydrocarbons in marine sediments in Liitzow-Holm Bay, Antarctica. Organic Geochemistry, v. 23, p. 229-273.

HARVEY, H. R. 1994. Fatty acids and sterols as source markers of organic matter in sediments of North Carolina continental slope. Deep-Sea Research II, v. 41, p. 783-796.

HAYES, J.M. 1993. Factors controlling ${ }^{13} \mathrm{C}$ contents of sedimentary organic compounds: Principles and evidences. Marine Geology, v. 113, p. 111-125. 
HORIKAWA, K.; MURAYAMA, M.; MINAGAWA, M.;KATO, Y.; SAGAWA, T. 2010. Latitudinal and down core $(0-750 \mathrm{ka})$ changes in $\mathrm{n}$-alkane chain lengths in the eastern equatorial Pacific. Quartenary Research, v. 73, p. 573-582.

HOVLAND, M. \& JUDD, A. G. 1988. Seabed Pockmarks and Seepages. Impact on Geology, Biology and the Marine Environment. London, Graham \& amp; Trotman Ltd,.

HOVLAND, M. 2002. On the self-sealing nature of marine seeps. Continental Shelf Research, v. 22, p. 2387-2394.

HOVLAND, M.; TALBOT, M.; QVALE, H.; OLAUSSEN, S.; AASBERG, L. 1987. Methane-related carbonate cements in pockmarks of the North Sea. Journal of Sedimentary Petrology, v. 57, p. 881-892.

HUANG, W. Y.; MEINSCHEIN, W. G. 1979. Sterols as ecological indicators. Geochimica et Cosmochimica Acta, v. 43, p. 739-745.

HUDEC, M.R., JACKSON, M.P.A., 2011. The Salt Mine: a Digital Atlas of Salt Tectonics. Udden Book Series No. 5. In: AAPG Memoir, vol. 99. The University of Texas at Austin, Bureau of Economic Geology, p. 305.

HUDSON, E. D.; PARRISH, C. C.; HELLEUR, R. J. 2001. Biogeochemistry of sterols in plankton, settling particles and recent sediments in a cold ocean ecosystem (Trinity Bay, Newfoundland). Marine Chemistry, v. 76 , p. 253-270.

JAFFÉ, R.; MEAD, R.; HERNANDEZ, M. E.; PERALBA, M. C.; DiGUIDA, O. A. 2001. Origin and transport of sedimentary organic matter in two subtropical estuaries: a comparative, a biomarker-based study. Organic Geochemistry, v. 32, p. 507-526.

JENG, W. L.; HUH C. A. 2001. Comparative study of sterols in shelf and slope sediments off northeastern Taiwan. Applied Geochemistry, v. 16, p. 95-108.

JENG, W. L.; HUH, C. A. 2004. Lipids in suspended matter and sediments from the East China Sea Shelf. Organic Geochemistry, v. 35, p. 647660 .

JENG, W.-L.; HAN, B.C. 1996. Coprostanol in a Sediment Core from the Anoxic Tan-Shui Estuary, Taiwan. Estuarine, Coastal and Shelf Science, v. 42, p. 727-735.

JONES G. B. 1969 Studies on lipids of soil micro-organisms with particular reference to hydrocarbons. J. lien. Microbial, v. 59, p. 145-152. 
JONES, J. G.; YOUNG, B. V. 1970. Major paraffin constituents of microbial cells with particular references to Chromatium sp. Archives of Microbiology, v. 70, p. 82-88,.

JUDD, A.G., HOVLAND, M. 2007. Seabed Fluid Flow: The Impact on Geology, Biology and the Marine Environment. Cambridge University Press, p. 441.

KAWAMURA, K.; ISHIWATARI, R.; OGURA, K. 1987. Early diagenesis of matter in the water column and sediments: Microbial degradation and resynthesis of lipids in Lake Haruna. Organic Geochemistry, v. 11, p. 251-264.

KELLEY, J. T.; DICKSON, S. M.; BELKNAP, D. F.; BARNHARDT, W. A.; HENDERSON, M. 1994. Giant sea-bed pockmarks: Evidence for gas escape from Belfast Bay. Marine Geology, v. 22, p. 59-62.

KING, L. H.; MACLEAN, B. 1970. Pockmarks on the Scotian Shelf. Geological Society of America Bulletin, v. 81, p. 3141-3148.

KOWSMANN, R.O. E COSTA, M.O.A. 1979. Sedimentação quaternária da margem continental brasileira e das áreas oceânicas adjacentes. In: REMAC PROJECT. Petrobras Rio de Janeiro. p. 1-55.

KOWSMANN, R.O., CARVALHO, M.D. 2002. Erosional event causing gasventing on the upper continental slope, Campos Basin, Brazil. Continental Shelf Research, v. 22, p. 2345-2354.

KOWSMANN, R.O.; MACHADO, L.C.R.; VIANA, A.R.; ALMEIDA JR., W. 2002. Controls on Mass-Wasting in Deep Water of the Campos Basin. Offshore Technology Conference, Houston, p. 1-11.

LARSONNEUR, C. 1977. La cartographie des depbts meubles sur le plateau continental franqais: methode mise au point et utilisee en Manche. Journal de Recherche Océanographique, v. 2, p. 34-39.

LASTRAS, G.; ARZOLA, R.G.; MASSON, D.G.; WYNN, R.B.; HUVENNE, V.A.I.; HÜHNERBACH, V.; CANALS, M. 2009. Geomorphology and sedimentary features in the Central Portuguese submarine canyons, Western Iberian margin. Geomorphology, v. 103, p. 310-329.

LAUREILLARD, J.; SALIOT, A. 1993. Biomarkers in organic matter produced in estuaries: a case study of the Krka estuary (Adriatic Sea) using the sterol marker series. Marine Chemistry, v.43, p.247-261.

LEHNINGER, A. L. 1982. Principles of biochemistry. New York: Worth,.

LOURENÇO, R.A. 2007. Aplicação de Marcadores Orgânicos Moleculares em estudos oceanográficos e paleoceanográficos: Estudo de caso na Margem Continental Superior do Sudeste do Brasil. Tese 
(Doutorado) - Instituto Oceanográfico, Universidade de São Paulo, f. 158.

MADUREIRA, L. A. S. 2002. Compostos orgânicos em sedimentos marinhos: uma viagem ao fundo do oceano atlântico norte. Química Nova, 25, №. 5, p. 814-824.

MAGNOU, A. P. 2016. Biogeoquímica de la materia orgánica y grupos metabólicos microbianos en sedimentos superficiales del margen continental uruguayo $\left(36^{\circ} 54^{\prime}-34^{\circ} 64^{\prime} \mathrm{S}, 53^{\circ} 71^{\prime}-51^{\circ} 66^{\prime} \mathrm{W}\right)$. Tese (Doutorado) - Universidade da República, Uruguai.

MAHIQUES MM, SOUSA SH, BURONE L, NAGAI RH, SILVEIRA IC, FIGUEIRA RC, SOUTELINO RG, PONSONI L. 2011. Radiocarbon geochronology of the sediments of the São Paulo Bight (southern Brazilian upper margin). Anais da Academia Brasileira de Ciências, v. 83, p. 817-834.

MAHIQUES, M. M.; TESSLER, M. G.; CIOTTI, A. M.; SILVEIRA, I. C. A.; SOUSA, S. H. M.; FIGUEIRA, R. C. L.; TASSINARI, C. C. G.; FURTADO, V. V.; PASSOS, R. F. 2004. Hydrodynamically driven patterns of recent sedimentation in the shelf and upper slope off Southeast Brazil. Continental Shelf Research, v. 24, p. 1685-1697.

MAHIQUES, M.M.; SCHATTNER, U.; LAZAR, M.; SUMIDA, P.Y.G. \& SOUZA, L.A.P. 2017. An extensive pockmark field on the upper Atlantic margin of Southeast Brazil: spatial analysis and its relationship with salt diapirism. Heliyon, v. 3, e00257.

MANLEY, P. L.; MANLEY, T. O.; WATZIN, M. C.; GUTIERREZ, J. 2004. Lakebed pockmarks in Burlington Bay, Lake Champlain: I. Hydrodynamics and implications of origin. In: Manley TO, Manley PL, Mihuc TB (eds) Lake Champlain: partnerships and research in the new millennium. Springer, p. 299-330.

MEDEIROS, P. M.; BÍCEGO, M. C.; CASTELAO, R. M.; ROSSO, C. D.; FILLMANN, G.; ZAMBONI, J. 2005. Natural and anthropogenic hydrocarbon inputs to sediments of Patos Lagoon Estuary, Brazil. Environment International, v. 31, p. 77-87.

MÉMERY, L., ARTHAN, M., ALVAREZ-SALGADO, X. A. 2000. "The water masses along the western boundary of the south and equatorial Atlantic", Progress in Oceanography, n. 47, p. 69-98.

MERINERO, R. 2008. Procesos mineralógicos y geoquímicos en chimeneas submarinas de carbonatos metanógenos del Golfo de Cádiz: biogeomarcadores framboidales en sulfuros y oxihidróxidos de hierro. Tesis Doctoral, Universidad Complutense de Madrid. 
MEYERS, P. A. 1997. Organic geochemical proxies of paleoceanographic, paleolimnologic, and paleoclimatic processes. Organic Geochimistry, v. 27, n. 5/6, p. 213-250.

MEYERS, P. A. 1994. Preservation of elemental and isotopic source identification of sedimentary organic matter. Chemical Geology, v. 114, n. 3/4, p. 289-302.

MIRANDA L. B. 1982. Análise de massa de 'agua de plataforma continental e da região oceânica adjacente: Cabo de São Tomé (RJ) a llha de São Sebastião (SP). São Paulo. Tese (Livre Docência) - Instituto oceanográfico, Universidade de São Paulo, p. 194.

MÖLLER, O.O. JR.; PIOLA, A.R.; FREITAS, A.C.; CAMPOS, E.J.D. 2008. The effects of river discharge and seasonal winds on the shelf off southeastern South America. Continental Shelf Research, v. 28, p. 1607-1624.

MOSS, G. P. 1989. Nomenclature of steroids. Purê \& Applied Chemistry, v. 61, p. $1783-1822$.

MOUNTJOY, J.J.; BARNES, P.M.; PETTINGA, J.R. 2009. Morphostructure and evolution of submarine canyons across an active margin: Cook Strait sector of the Hikurangi Margin, New Zealand. Marine Geology, v. 260 , p. $45-68$.

MUDGE, S. M.; BEBIANNO, M. J. A F.; EAST, J. A.; BARREIRA, L. A. 1999. Sterols in the Ria Formosa lagoon, Portugal. Water Research, v. 33, n. 4 , p. $1038-1048$.

MUDGE, S. M.; LINTERN, D.G. 1999. Comparison of sterol biomarkers for sewage with other measures in Victoria Harbour, B.C. Canada. Estuarine, Coastal and Shelf Science, v. 48, p. 27-38.

MÜLLER, T.J.; IKEDA, Y.; ZANGENBERG, N.; NONATO, L.V. 1998. Direct measurements of western boundary currents off Brazil between $20^{\circ}$ S and $28^{\circ}$ S. Journal of Geophysical Research, v. 103, p. 54295437.

MURI, G.; WAKEHAM, S.G.; PEASE, T.K.; FAGANELI, J. 2004. Organic Geochemistry, v. 35, p. 1083-1093.

NACCARATO W. F., GILBERTON J. R. and GELMAN R. A. 1974. Effects of different culture media and oxygen upon lipids of Escherichia coli K12. Lipids, v.9, p. 322-347.

NAGAI, R. H. ; ANDRADE, P. C. ; CHIESSI, C. M. ; BÍCEGO, M. C. ; SOUSA, S. H. M. E. ; MAHIQUES, M. M. 2010. Salinity changes in the 
Southeastern Brazilian shelf during the Holocene: impact of the La Plata River discharge. The International Symposium on Foraminifera, Bonn.

NAGAI, R. H.; SOUSA, S. H. M.; BURONE, L.; MAHIQUES, M. M. 2009. Paleoproductivity changes during the Holocene in the inner shelf of Cabo Frio, southeastern Brazilian continental margin: Benthic foraminifera and sedimentological proxies. Quaternary International, v. 206, p. 62-71.

NGUYEN, D.; BRUCHET A.; ARPINO, P. 1995. Determination of sterols in sewage sludge by combined in situ trimethylsilylation/supercritical fluid extraction and CG/MS. Environmental Science \& Technology, v. 29 , p. $1686-1690$.

NISHIMURA, M. \& BAKER, E. W. 1986. Possible origin of $n$-alkanes with a remarkable even-to-odd predominance in recent marine sediments. Geochimica et Cosmochimica Acta, v. 50, p. 299-305.

ODEBRECHT, C.; CASTELLO, J. P. 2001. The convergence ecosystem in Southwest Atlantic. Costa marine ecosystems of Latin America, v. 144 , p. $147-165$.

ONDRÉAS, H.; OLU, K.; FOUQUET, Y.; CHARLOU, J. L.; GAY, A.; DENNIELOU, B.; DONVAL, J. P.; FIFIS, A.; NADALIG, T.; COCHONAT, P.; CAUQUIL, E.; BOURILLET, J.; MOIGNE, J.; SIBUET, M. 2005. ROV study of a giant pockmark on the Gabon continental margin. Geo-Marine Letters, v. 25, p. 281-292.

PANCOST, R. D.; PAGANI, M. 2006. Controls on the carbono isotopic composition of lipids in marine environment. In: VOLKMAN, J. K. (Ed.). Marine organic matter: biomarkers, isotopes and DNA. Berlin: Springer, p. 209-249.

PAU, M.; GISLER, G.; HAMMER, Ø. 2013. Experimental investigation of the hydrodynamics in pockmarks using particle tracking velocimetry. Geo-Marine Letters, v. 34, p. 11-19.

PAYTAN, A. 2006. Ocean Paleoproductivity. In: Encyclopedia of Paleoclimatology and Ancient Environments. Gornitz, V. (Ed). Encyclopedia of Earth Science Series. Kluwer Academic Publishers.

PENG, X.; ZHANG, G.; MAI, B.; HU, J.; LI, K.; WANG, Z. 2005. Tracing anthropogenic contamination in the Pearl River estuarine and marine environment of South China Sea using sterols and other organic molecular markers. Marine Pollution Bulletin, v. 50, p. 856-865.

PEREIRA, M.J. \& FEIJÓ, F.J. 1994. Bacia de Santos. Boletim de Geociências da Petrobrás, v. 8, p. 219-234. 
PHILP, R. P. 1985. Fossil fuel biomarkers. Applications and spectra. Elsevier Science Ltd, New York, NY, p. 306.

PILCHER, R.; ARGENT, J. 2007. Mega-pockmarks and linear pockmark trains on the West African continental margin. Marine Geology, v. 244, p. 15-32.

PIOLA A, CAMPOS E, MÖllER O, CHARO M, MARTINEZ C. 2000. Subtropical Shelf Front off eastern South America. Geophysical Research, v. 105, p. 6565,

PIOLA AR, MÔLLER Jr OO \& ELBIO DP. 2005. O impacto do Rio da Prata no Oceano Atlântico. Ciência Hoje, v. 36, p. 30-37.

PIOLA, A.R.; ROMERO, S.I.; ZAJACZKOVSKI, U. 2008. Space-time variability of the Plata plume inferred from ocean color. Continental Shelf Research, v. 28, p. 1556-1567.

PONZI, V. R. A. 2004. Morfologia do fundo oceânico. In: Introdução à Geologia Marinha. Neto,J. A. B., V. R. A. Ponzi \& S. E. Sichel (Eds). INTERCIÊNCIA, Rio de Janeiro, p. 219-242

PRAHL, F. G.; BENNETT, J. T.; CARPENTER, R. 1980. The early diagenisis of aliphatic hydrocarbons and organic matter in sedimentary particulates from Dabob Bay, Washington. Geochimica et Cosmochimica Acta, v. 44, p. 1967-1976,.

RAMIREZ-LLODRA, E.; BRANDT, A.; DANOVARO, R.; DE MOL, B.; ESCOBAR, E.; GERMAN, C. R.; LEVIN, L. A.; MARTINEZ ARBIZU, P.; MENOT, L.; BUHLMORTENSEN, P.; NARAYANASWAMY, B. E.; SMITH, C. R.; TITTENSOR, D. P.; TYLER, P. A.; VANREUSEL, A.; VECCHIONE, M. 2010. Deep, diverse and definitely different: unique attributes of the world's largest ecosystem. Biogeosciences, v.7, p. 2851-2899.

RASHID, M. A. 1985. Geochemistry of marine humic compounds. New York, Springer-Verlag, p. 300.

READMAN, J. W.; FILLMAN, G.; TOLOSA, I.; BARTOCCI, J.; VILLENEUVE, J.P.; CANTINI, C.; MEE, L. D. 2002. Marine Pollution Bulletin, v. 44, p. $48-62$, .

RIBANI, M.; BOTTOLI, C. B. G.; COLLINS, C. H.; JARDIM, C. S. F. 2004. Validação em Métodos Cromatográficos e Eletroforéticos. Química Nova, v. 27 p.771-780.

RIBOULOT, V.; CATTANEO, A.; SULTAN, N.; GARZIGLIA, S.; KER, S.; IMBERT, P.; VOISSET, M. 2013. Sea-level change and free gas occurrence influencing a submarine landslide and pockmark 
formation and distribution in deepwater Nigeria. Earth and Planetary Science Letters, v. 375, p. 78-91.

ROCHA, J. M.; MILLIMAN, J. D.; SANTANA, C. I. \& VICALVI, M. A. 1975. Southern Brazil. In: Contributions to Sedimentology. Stuttgart, 4: Upper continental margin sedimentation off Brazil. p.117-150.

ROLLET, N.; LOGAN, G. A.; KENNARD, J. M.; O'BRIEN, P. E.; JONES, A. T.; SEXTON, M. 2006. Characterisation and correlation of active hydrocarbon seepage using geophysical data sets: An example from the tropical, carbonate Yampi Shelf, Northwest Australia. Marine and Petroleum Geology, v. 23, p. 145-164.

ROMMERSKIRCHEN F., EGLINTON G., DUPONT L., GUNTER U., WENZEL C. AND RULLKOTTER J. 2003. A north to south transect of Holocene southeast Atlantic continental margin sediments: relationship between aerosol transport and compound-specific d13C land plant biomarker and pollen records. Geochem. Geophys. Geosyst. 4, 1101-1128.

RÜHLEMANN, C., MÜLLER, P. J., SCHNEIDER, R. R. 1999. Organic carbon and carbonate as palaeoproductivity proxies: examples from high and low productivity areas of the tropical Atlantic. In: Fischer, G., Wefer, G. (Eds.), Use of Proxies in Oceanography. Springer, p. 315-344.

RULLKÖTTER, J. 2006. Organic matter: the driving force for early diagenesis. In: SCHULZ, H. D.; ZABEL, M. (Ed.). Marine Geochemistry, v. 4, p. 125-146.

SACHSE, D.; RADKE, J.; GLEIXNER, G. 2006. $\delta D$ values of individual nalkanes from terrestrial plants along a climatic gradient: implications for the sedimentary biomarker record. Organic Geochemistry, v. 37, n. 4. p. $469-483$.

SAHLING, H.; BOHRMANN, G.; SPIESS, V. 2008. Pockmarks in the Northern Congo Fan area, SW Africa: Complex seafloor features shaped by fluid flow. Marine Geology, v. 249, p. 206-225.

SALIOT, A.; LAUREILLARD, J.; SCRIBE, P.; SICRE, M. A. 1991. Evolutionary trends in the lipid biomarker approach for investigating the biogeochemistry of organic matter in the marine environment. Marine Chemistry, v. 36, p. 233-248.

SALIOT, A.; PARRISH, C. C.; SADOUNI, N.; BOULOUBASSI, I.; FILLAUX, J.; CAUWET, G. 2002. Transport and fate of Danube Delta terrestrial organic matter in the Northwest Black Sea mixing zone. Marine Chemistry, v. 79 , n. 3-4, p. 243-259. 
SANTOS NETO, E. V. 2004. Geoquímica de gases: uma nova tecnologia em avaliação de sistemas petrolíferos, in B. Geociências, Petrobras, Rio de Janeiro, v.12, p. 357-383.

SCHATTNER, U.; LAZAR, M.; SOUZA, L. A. P.; TEN, B. U.; MAHIQUES, M. M. 2016. Pockmark asymmetry and seafloor currents in the Santos Basin offshore Brazil, Geo-Marine Letters., v. 36, p. 457-464.

SCHUBERT, C. J.; CALVERT, S. E. 2001. Nitrogen and carbon isotopic composition of marine and terrestrial organic matter in Arctic Ocean sediments: implications for nutrient utilization and organic matter composition. Deep-Sea Research Part I, v. 48, p. 789-810.

SEGUEL, C. G.; MUDGE, S. M.; SALGADO, C.; TOLEDO, M. 2001. Tracing sewage in the marine environment: altered signatures in concepcíon Bay Chile. Water Research, v. 35, n. 17, p. 4166-4174.

SILLIMAN, J. E.; SCHELSKE, C. L. 2003. Saturated hydrocarbons in the sediments of Lake Apopka, Florida. Organic Geochemistry, v. 34, p. 253-260.

SILVEIRA, I. C. A.; SCHMIDT, A. C. K.; CAMPOS, E. J. D.; GODOI, S. S.; IKEDA, Y. 2000. A corrente do Brasil ao Largo da Costa Leste Brasileira. Brazilian Journal of Oceanography, v. 48, n. 2, p. 171183.

SOLHEIM, A.; ELVERHØI, A. 1985. A pockmark field in the Central Barents Sea; gas from a petrogenic source? Polar Research, v. 3, p. 11-19.

SINGER, M. E.; FINNERTY, W. R. 1984. Microbial metabolism of straightchain and branched alkanes. In: Atlas RM (ed). Petroleum microbiology, Macmillan, New York, p. 1-59.

SOUZA, R.B. \& ROBINSON, I.S. 2004. Lagrangian and satellite observations of the Brazilian Coastal Current. Continental Shelf Research, 24: 241262.

STEIN, R. 1991. Accumulation of organic carbon in marine sediments. Lecture, notes in Earth Sciences. Berlin, Springer-Verlag, p. 217.

STOUT, S. A.; UHLER, R. M.; MCCARTHY, K. J. 2001. A strategy and methodology for defensibly correlating spilled oil to source candidates. Environmental Forensics, v. 2, p. 87-98.

StRAMMA, L.; R. G. PETERSON. 1990. The South Atlantic Current. J. Physical Oceanography, v. 20, p. 846-859. 
SUMIDA, P. Y. G.; YOSHINAGA, M. Y.; MADUREIRA, L. A. S. P.; HOVLAND, M. 2004. Seabed pockmarks associated with deep water corals off SE Brazilian continental slope, Santos Basin. Marine Geology, v. 207, p. 159-167.

TAYLOR, M. H.; DILLON, W. P.; PECHER, I. A. 2000. Trapping and migration of methane associated with the gas hydrate stability zone at the Blake Ridge Diapir: new insights from seismic data. Marine Geology, v. 164, p. 79-89.

THIEL, V.; PECKMANN, J.; SEIFET, R., WEHRUNG, P., REITNER, J., MICHAELIS, W. 1999. Highly isotopically depleted isoprenoids: molecular markers for ancient methane venting. Geochimica et Cosmochimica Acta, v. 63, p. 3959-3966.

TISSOT, A. P.; WELTE, D. H. 1978. Petroleum formation and occurrence. Berlin: Spinger-Verlag.

TOLOSA, I.; MORA, S.; SHEIKHOLESLAMI, M.R.; VILLENEUVE, J.; BARTOCCI, J.; CATTINI, C.; Marine Pollution Bulletin, p.48, p. 4460, 2004.

TREIGNIER, C.; DERENNE, S.; SALIOT, A. 2006. Terrestrial and marine nalcohol inputs and degradation processes relating to a sudden turbidity current in the Zaire canyon. Organic Geochemistry, v.37, p.1170-1184.

TSUCHIYA, M., TALLEY, L. D., MCCARTNEY, M. S. 1994. "Water-mass distributions in the western South Atlantic; A section from South Georgia Island (54S) northward across the equator". Journal of Marine Research, v. 52, p. 55-81.

TURNER, R. D. 1985. Notes on mollusks of deep-sea vents and reducing sediments. American Malacological Bulletin, v.1, p. 23-34.

USSLER, W; PAULL, C. K.; BOUCHER, J.; FRIEDERICH, G. E.; THOMAS, D. J. 2003. Submarine pockmarks: a case study from Belfast Bay, Maine. Marine Geology, v. 202, p. 175-192.

VENKATESAN, M. I.; KAPLAN, R. I. 1982. Distribution and transport of hydrocarbons in surface sediments of the Alaskan outer continental shelf. Geochimica Cosmochimica Acta, v.46, p. 2135-2149.

VOLAT, J-L.; PASTOURET, L.; VERGNAUD-GRAZZINI, C. 1980. Dissolution and carbonate fluctuations in Pleistocene deep-sea cores: a review. Marine Geology, v. 34, p. 1-28.

VOLKMAN, J. K. 1986. A review of sterol markers for marine and terrigenous organic matter. Organic Geochemistry, v. 9, p. 83-99. 
VOLKMAN, J. K. 2006. Lipid markers for marine organic matter. Handbook of Environmental Chemistry, v. 2 N, n. October 2005, p. 27-70.

VOLKMAN, J. K. 2005. Sterols and other triterpenoids: source specificity and evolution of biosynthetic pathways. Organic Geochemistry, v. 36, p. 139-159.

VOLKMAN, J. K. 2003. Sterols in microorganisms. Applied microbiology and biotechnology, v. 6, n. 5, p. 495-506.

VOLKMAN, J. K.; HOLDSWORTH, D. G.; NEILL, G. P.; BAVOR, H. J. 1992. Identification of natural, anthropogenic and petroleum hydrocarbons in aquatic sediments. The Science of the total environment, v. 112 , p. 203-219.

VOLKMAN, J. K.; REVILL, A. T.; HOLDSWORTH, D. G.; FREDERICKS, D. 2008. Organic matter sources in an enclosed coastal inlet assessed using lipid biomarkers and stable isotopes. Organic Geochemistry, v. 39, p. $689-710$.

WADE, T. L., \& CANTILLO, A. Y. 1994. Use of standards and reference materials in the measurement of chlorinated hydrocarbon residues. Chemistry Workbook. Silver Spring: US Department of Commerce, NOAA Technical Memorandum NOS ORCA, v. 77.

WAKEHAM, S. G.; CANUEL, E. A. 2006. Degradation and Preservation of Organic Matter in Marine Sediments. Environmental Chemistry, v. 2, p. 295-321.

WAKEHAM, S. G.; SCHAFFNER, C.; GIGER, W. 1980. Polycyclic aromatic hydrocarbons in Recent lake sediments - II. Compounds derived from biogenic precursors during early diagenesis. Geochimica et Cosmochimica Acta, v.44, p.415-429.

WALKER J. D. and COONEY J. J. 1973. Aliphatic Hydrocarbons of Cladosporium resinae. Cultured on Glucose, Glutamic Acid, and. Hydrocarbons. Journal of Applied Microbiology, v. 26, p. 705-708.

WANG, X., YANG, H., GONG, P., ZHAO, X., WU, G., TURNER, S., YAO, T. 2010, One century sedimentary records of polycyclic aromatic hydrocarbons, mercury and trace elements in the Qinghai Lake, Tibetan Plateau. Environmental Pollution, v. 158, p. 3065-3070.

WEBB, K. E.; HAMMER, Ø.; LEPLAND, A.; GRAY, J. S. Pockmarks in the Inner Oslofjord, Norway. Geo-Marine Letters, v. 29, p. 111-124, 2009.

WELTE, DIETRICH H., GÖTZ EBHARDT. 1968. Distribution of longe nparaffins and $n$-fatty acids in sediments from the Persian Gulf. Geochimica, v. 32: p. 465-66. 
WHITICAR, M.J., FABER, E., SCHOELL, M., 1986. Biogenic methane formation in marine and freshwater environments: $\mathrm{CO}_{2}$ reduction vs. acetate fermentation - Isotope evidence. Geochimica Cosmochimica Acta, v. 50, p. 693-709.

WRAY, G. A. 1995. Evolution of larvae and developmental modes. In: MCEDWARDS, L. (ed.) Ecology of marine invertebrate larvae. Boca Raton: CRC Press, p. 413-447.

YOUNGBLOD, W.H., BLUMER, M., GUILLARD, R.R.L. FIORE, F. 1971. Saturated and unsaturated hydrocarbons in marine benthic algae. Marine Biology, v. 8, p. 190-201.

YOUNGBLOOD, W. H., BLUMER, M. 1973. Alkanes and alkenes in marine benthic algae. Marine Biology, v. 21, p. 163-172.

YUNKER, M. B.; MACDONALD, R. W. 2003. Organic Geochemistry, v. 34, p. 1429-1454,.

ZECH, M., BUGGLE, B., LEIBER, K., MARKOVIC, S., GLASER, B., HAMBACH, U., HUWE, B., STEVENS, T., SÜMEGI, P., WIESENBERG, G., AND ZÖLLER, L. 2009. Reconstructing Quaternary vegetation history in the Carpathian Basin, SE Europe, using n-alkane biomarkers as molecular fossils, E\&G Quaternary Sci. J., v. 58, p. $148-155$.

ZHANG, Z.; ZHAOA, M.; EGLINTONA, G.; LUD, H.; HUANG, C-Y. 2006. Leaf wax lipids as paleovegetational and paleoenvironmental proxies for the Chinese Loess Plateau over the last $170 \mathrm{kyr}$. Quaternary Science Reviews, v. 25, p. 575-94.

ZHOU, J.; WU, Y; ZHANG, J; KANG, Q; LIU, Z. 2006. Carbon and nitrogen composition and stable isotopes as potencial indicators of source and fate of organic matter in salt marsh of the Changjiang Estuary, China. Chemosphere, v. 65, p. 310-317. 


\section{APÊNDICE}

Tabela I. - Parâmetros de caracterização da matéria orgânica sedimentar ao longo dos testemunhos.

\begin{tabular}{|c|c|c|c|c|c|c|}
\hline Profundidade (m) & Estação & $\begin{array}{c}\mathrm{CaCO}_{3} \\
(\%)\end{array}$ & $\begin{array}{l}\text { Corg Total } \\
(\%)\end{array}$ & $\begin{array}{c}\delta{ }^{13} \mathrm{C} \\
(\%))\end{array}$ & $\begin{array}{l}\text { Nit Total } \\
(\%)\end{array}$ & $\begin{array}{l}\delta^{15} \mathrm{~N} \\
(\% 0)\end{array}$ \\
\hline 1 & \multirow{12}{*}{249} & 32 & 0,433 & $-21,718$ & 0,085 & 5,441 \\
\hline 2 & & 29 & 0,394 & $-20,276$ & 0,077 & 6,471 \\
\hline 4 & & 28 & 0,400 & $-20,951$ & 0,082 & 6,749 \\
\hline 6 & & 30 & 0,564 & $-20,851$ & 0,079 & 6,430 \\
\hline 8 & & 30 & 0,244 & $-22,667$ & 0,090 & 5,207 \\
\hline 10 & & 57 & 0,148 & $-22,214$ & 0,087 & 4,687 \\
\hline 12 & & 32 & 0,538 & $-20,621$ & 0,081 & 4,544 \\
\hline 14 & & 30 & 0,319 & $-21,371$ & 0,069 & 5,288 \\
\hline 16 & & 32 & 0,319 & $-21,058$ & 0,063 & 6,944 \\
\hline 18 & & 31 & 0,387 & $-21,855$ & 0,058 & 6,536 \\
\hline 20 & & 30 & 0,253 & $-22,113$ & 0,059 & 5,910 \\
\hline 22 & & 31 & 0,212 & $-20,762$ & 0,058 & 7,199 \\
\hline 1 & \multirow{11}{*}{250} & 53 & 0,304 & $-20,95$ & 0,046 & 3,096 \\
\hline 2 & & 25 & 0,551 & $-21,062$ & 0,054 & 4,739 \\
\hline 4 & & 46 & 0,382 & $-21,033$ & 0,070 & 5,709 \\
\hline 6 & & 45 & 0,367 & $-21,405$ & 0,062 & 3,536 \\
\hline 8 & & 48 & 0,330 & $-21,692$ & 0,056 & 4,174 \\
\hline 10 & & 47 & 0,372 & $-21,934$ & 0,057 & 6,270 \\
\hline 12 & & 47 & 0,292 & $-21,859$ & 0,059 & 4,072 \\
\hline 14 & & 44 & 0,271 & $-22,163$ & 0,051 & 6,400 \\
\hline 16 & & 44 & 0,190 & $-22,391$ & 0,044 & 6,847 \\
\hline 18 & & 46 & 0,285 & $-20,557$ & 0,050 & 7,034 \\
\hline 20 & & 43 & 0,333 & $-21,627$ & 0,047 & 6,935 \\
\hline 1 & \multirow{17}{*}{253} & 33 & 0,877 & $-21,36$ & 0,111 & 5,023 \\
\hline 2 & & 32 & 0,739 & $-21,225$ & 0,104 & 5,301 \\
\hline 4 & & 33 & 0,560 & $-20,424$ & 0,115 & 5,713 \\
\hline 6 & & 32 & 0,643 & $-21,044$ & 0,095 & 5,133 \\
\hline 8 & & 26 & 0,566 & $-21,321$ & 0,105 & 4,938 \\
\hline 10 & & 27 & 0,618 & $-21,291$ & 0,072 & 3,886 \\
\hline 12 & & 26 & 0,592 & $-21,554$ & 0,096 & 6,696 \\
\hline 14 & & 27 & 0,645 & $-20,523$ & 0,114 & 4,876 \\
\hline 16 & & 32 & 0,725 & $-20,672$ & 0,089 & 4,902 \\
\hline 18 & & 30 & 0,606 & $-21,596$ & 0,092 & 5,006 \\
\hline 20 & & 31 & 0,704 & $-20,846$ & 0,102 & 4,631 \\
\hline 22 & & 30 & 0,564 & $-21,916$ & 0,093 & 5,614 \\
\hline 24 & & 27 & 0,306 & $-21,305$ & 0,095 & 5,403 \\
\hline 26 & & 27 & 0,612 & $-21,16$ & 0,125 & 6,213 \\
\hline 28 & & 30 & 0,612 & $-21,225$ & 0,099 & 6,291 \\
\hline 30 & & 29 & 0,417 & $-21,975$ & 0,091 & 6,103 \\
\hline 32 & & 31 & 0,613 & $-21,395$ & 0,077 & 4,922 \\
\hline 1 & & 26 & 0,924 & $-20,913$ & 0,153 & 6,143 \\
\hline 2 & 254 & 26 & 0,976 & $-21,042$ & 0,140 & 6,112 \\
\hline
\end{tabular}


Tabela I (Continuação) - Parâmetros de caracterização da matéria orgânica sedimentar ao longo dos testemunhos.

\begin{tabular}{|c|c|c|c|c|c|c|}
\hline $\begin{array}{l}\text { Profundidade } \\
\text { (m) }\end{array}$ & Estação & $\begin{array}{c}\mathrm{CaCO}_{3} \\
(\%)\end{array}$ & $\begin{array}{c}\text { Corg Total } \\
(\%)\end{array}$ & $\begin{array}{c}\delta \delta^{13} \mathrm{C} \\
(\%)\end{array}$ & $\begin{array}{c}\text { Nit Total } \\
(\%)\end{array}$ & $\begin{array}{l}\delta^{15} \mathrm{~N} \\
(\% 0)\end{array}$ \\
\hline 4 & \multirow{19}{*}{254} & 20 & 0,679 & $-20,364$ & 0,136 & 7,040 \\
\hline 6 & & 23 & 0,677 & $-19,895$ & 0,125 & 6,571 \\
\hline 8 & & 25 & 0,744 & $-21,009$ & 0,107 & 5,128 \\
\hline 10 & & 25 & 0,778 & $-20,696$ & 0,120 & 5,868 \\
\hline 12 & & 25 & 0,801 & $-20,601$ & 0,125 & 5,436 \\
\hline 14 & & 25 & 0,689 & $-20,855$ & 0,107 & 4,795 \\
\hline 16 & & 24 & 0,656 & $-20,62$ & 0,109 & 6,801 \\
\hline 18 & & 26 & 0,619 & $-21,062$ & 0,121 & 7,183 \\
\hline 20 & & 24 & 0,720 & $-21,374$ & 0,118 & 6,828 \\
\hline 22 & & 26 & 0,557 & $-20,043$ & 0,119 & 5,525 \\
\hline 24 & & 25 & 0,769 & $-20,791$ & 0,074 & 5,918 \\
\hline 26 & & 25 & 0,784 & $-21,144$ & 0,071 & 5,785 \\
\hline 28 & & 24 & 0,747 & $-20,19$ & 0,110 & 5,008 \\
\hline 30 & & 25 & 0,733 & $-21,084$ & 0,117 & 4,765 \\
\hline 32 & & 32 & 0,578 & $-21,422$ & 0,110 & 5,526 \\
\hline 34 & & 28 & 0,707 & $-21,28$ & 0,110 & 5,507 \\
\hline 36 & & 29 & 0,569 & $-21,579$ & 0,096 & 4,783 \\
\hline 38 & & 25 & 0,618 & $-20,838$ & 0,109 & 5,675 \\
\hline 40 & & 29 & 0,542 & $-21,638$ & 0,120 & 5,368 \\
\hline 1 & \multirow{13}{*}{255} & 41 & 0,710 & $-21,568$ & 0,100 & 6,360 \\
\hline 2 & & 39 & 0,554 & $-21,431$ & 0,087 & 5,912 \\
\hline 4 & & 39 & 0,493 & $-21,255$ & 0,098 & 5,614 \\
\hline 6 & & 36 & 0,477 & $-21,591$ & 0,075 & 5,129 \\
\hline 8 & & 37 & 0,403 & $-21,205$ & 0,065 & 5,069 \\
\hline 10 & & 37 & 0,410 & $-21,378$ & 0,071 & 4,349 \\
\hline 12 & & 36 & 0,430 & $-21,64$ & 0,078 & 6,378 \\
\hline 14 & & 39 & 0,458 & $-20,538$ & 0,065 & 5,385 \\
\hline 16 & & 42 & 0,476 & $-21,406$ & 0,073 & 4,435 \\
\hline 18 & & 38 & 0,428 & $-21,356$ & 0,086 & 5,490 \\
\hline 20 & & 39 & 0,608 & $-21,409$ & 0,088 & 5,574 \\
\hline 22 & & 39 & 0,377 & $-20,386$ & 0,084 & 5,521 \\
\hline 24 & & 42 & 0,522 & $-21,668$ & 0,075 & 5,398 \\
\hline 1 & \multirow{15}{*}{256} & 50 & 0,519 & $-21,424$ & 0,085 & 5,572 \\
\hline 2 & & 47 & 0,421 & $-21,523$ & 0,094 & 4,796 \\
\hline 4 & & 44 & 0,475 & $-20,332$ & 0,078 & 5,008 \\
\hline 6 & & 37 & 0,386 & $-21,191$ & 0,071 & 4,891 \\
\hline 8 & & 45 & 0,475 & $-21,236$ & 0,048 & 5,882 \\
\hline 10 & & 42 & 0,504 & $-22,321$ & 0,055 & 6,729 \\
\hline 12 & & 45 & 0,310 & $-20,307$ & 0,044 & 6,245 \\
\hline 14 & & 36 & 0,474 & $-21,105$ & 0,065 & 4,502 \\
\hline 16 & & 41 & 0,384 & $-21,061$ & 0,063 & 3,657 \\
\hline 18 & & 24 & 0,521 & $-21,219$ & 0,072 & 4,609 \\
\hline 20 & & 27 & 0,340 & $-20,628$ & 0,081 & 4,829 \\
\hline 22 & & 20 & 0,580 & $-21,471$ & 0,072 & 6,075 \\
\hline 24 & & 23 & 0,513 & $-21,586$ & 0,079 & 4,415 \\
\hline 26 & & 21 & 0,515 & $-21,733$ & 0,048 & 4,540 \\
\hline 28 & & 20 & 0,442 & $-22,268$ & 0,083 & 4,055 \\
\hline
\end{tabular}


Tabela I (Continuação) - Parâmetros de caracterização da matéria orgânica sedimentar ao longo dos testemunhos.

\begin{tabular}{|c|c|c|c|c|c|c|}
\hline $\begin{array}{l}\text { Profundidade } \\
\text { (m) }\end{array}$ & Estação & $\begin{array}{c}\mathrm{CaCO}_{3} \\
(\%)\end{array}$ & $\begin{array}{c}\text { Corg Total } \\
(\%)\end{array}$ & $\begin{array}{c}\delta^{{ }^{13} \mathrm{C}} \\
(\%)\end{array}$ & $\begin{array}{c}\text { Nit } \\
\text { Total } \\
(\%)\end{array}$ & $\begin{array}{l}\delta^{15} \mathrm{~N} \\
(\%)\end{array}$ \\
\hline 30 & & 19 & 0,514 & $-21,85$ & 0,078 & 4,798 \\
\hline 32 & 256 & 19 & 0,505 & $-21,474$ & 0,063 & 5,038 \\
\hline 1 & & 27 & 1,046 & $-21,12$ & 0,101 & 5,383 \\
\hline 2 & & 26 & 0,691 & $-20,978$ & 0,101 & 6,177 \\
\hline 4 & & 26 & 0,718 & $-20,145$ & 0,133 & 5,411 \\
\hline 6 & & 27 & 0,742 & $-20,809$ & 0,140 & 4,896 \\
\hline 8 & & 25 & 0,887 & $-20,219$ & 0,138 & 5,573 \\
\hline 10 & & 26 & 0,660 & $-20,439$ & 0,088 & 6,037 \\
\hline 12 & & 26 & 0,891 & $-20,227$ & 0,140 & 5,445 \\
\hline 14 & 257 & 26 & 0,914 & $-20,671$ & 0,134 & 5,557 \\
\hline 16 & & 29 & 0,739 & $-20,549$ & 0,086 & 5,899 \\
\hline 18 & & 28 & 0,735 & $-20,143$ & 0,087 & 5,525 \\
\hline 20 & & 28 & 0,658 & $-20,22$ & 0,088 & 5,605 \\
\hline 22 & & 25 & 0,864 & $-20,682$ & 0,093 & 6,070 \\
\hline 24 & & 25 & 0,709 & $-21,16$ & 0,132 & 5,384 \\
\hline 26 & & 27 & 0,611 & $-20,273$ & 0,125 & 4,864 \\
\hline 28 & & 26 & 0,742 & $-21,417$ & 0,117 & 6,897 \\
\hline 30 & & 27 & 0,701 & $-21,366$ & 0,092 & 6,852 \\
\hline 1 & & 43 & 0,615 & $-21,175$ & 0,101 & 5,789 \\
\hline 2 & & 41 & 0,455 & $-20,498$ & 0,080 & 5,649 \\
\hline 4 & & 38 & 0,415 & $-21,223$ & 0,084 & 5,839 \\
\hline 6 & & 42 & 0,391 & $-20,867$ & 0,066 & 5,494 \\
\hline 8 & & 38 & 0,355 & $-21,368$ & 0,057 & 5,221 \\
\hline 10 & & 38 & 0,264 & $-21,656$ & 0,059 & 4,866 \\
\hline 12 & & 37 & 0,252 & $-21,586$ & 0,045 & 4,399 \\
\hline 14 & & 34 & 0,245 & $-21,573$ & 0,049 & 4,659 \\
\hline 16 & 258 & 31 & 0,328 & $-22,645$ & 0,068 & 3,936 \\
\hline 18 & & 27 & 0,384 & $-21,399$ & 0,076 & 5,376 \\
\hline 20 & & 34 & 0,385 & $-21,64$ & 0,091 & 4,858 \\
\hline 22 & & 35 & 0,142 & $-21,526$ & 0,093 & 5,214 \\
\hline 24 & & 44 & 0,398 & $-22,145$ & 0,098 & 6,652 \\
\hline 26 & & 29 & 0,592 & $-21,795$ & 0,077 & 6,771 \\
\hline 28 & & 27 & 0,413 & $-21,86$ & 0,079 & 6,208 \\
\hline 30 & & 31 & 0,516 & $-20,872$ & 0,079 & 6,397 \\
\hline 1 & & 55 & 0,408 & $-20,855$ & 0,085 & 4,459 \\
\hline 2 & & 45 & 0,423 & $-21,205$ & 0,074 & 5,121 \\
\hline 4 & & 47 & 0,652 & $-20,365$ & 0,076 & 6,633 \\
\hline 6 & & 47 & 0,303 & $-21,79$ & 0,069 & 6,306 \\
\hline 8 & & 54 & 0,380 & $-21,609$ & 0,071 & 5,135 \\
\hline 10 & & 51 & 0,504 & $-21,047$ & 0,082 & 6,106 \\
\hline 12 & 259 & 53 & 0,327 & $-20,692$ & 0,071 & 5,089 \\
\hline 14 & & 49 & 0,300 & $-21,021$ & 0,063 & 4,941 \\
\hline 16 & & 46 & 0,373 & $-21,597$ & 0,062 & 4,947 \\
\hline 18 & & 45 & 0,327 & $-21,725$ & 0,070 & 6,766 \\
\hline
\end{tabular}


Tabela I (Continuação) - Parâmetros de caracterização da matéria orgânica sedimentar ao longo dos testemunhos.

\begin{tabular}{|c|c|c|c|c|c|c|}
\hline $\begin{array}{l}\text { Profundidade } \\
\text { (m) }\end{array}$ & Estação & $\begin{array}{c}\mathrm{CaCO}_{3} \\
(\%)\end{array}$ & $\begin{array}{c}\text { Corg Total } \\
(\%)\end{array}$ & $\begin{array}{c}\delta{ }^{13} \mathrm{C} \\
(\% 0)\end{array}$ & $\begin{array}{c}\text { Nit } \\
\text { Total } \\
(\%)\end{array}$ & $\begin{array}{l}\delta^{15} \mathrm{~N} \\
(\% 0)\end{array}$ \\
\hline 20 & & 45 & 0,362 & $-20,787$ & 0,069 & 7,090 \\
\hline 22 & & 33 & 0,375 & $-22,114$ & 0,057 & 6,263 \\
\hline 24 & 259 & 33 & 0,417 & $-21,484$ & 0,059 & 3,951 \\
\hline 26 & & 33 & 0,421 & $-21,128$ & 0,066 & 5,186 \\
\hline 1 & & 69 & 0,381 & $-20,855$ & 0,106 & 4,807 \\
\hline 2 & & 56 & 0,259 & $-21,23$ & 0,059 & 6,072 \\
\hline 4 & & 46 & 0,631 & $-20,652$ & 0,097 & 5,452 \\
\hline 6 & & 44 & 0,522 & $-20,469$ & 0,060 & 6,808 \\
\hline 8 & & 48 & 0,210 & $-21,594$ & 0,092 & 5,593 \\
\hline 10 & & 53 & 0,311 & $-20,96$ & 0,058 & 4,100 \\
\hline 12 & & 40 & 0,306 & $-21,424$ & 0,061 & 3,628 \\
\hline 14 & & 32 & 0,323 & $-21,548$ & 0,067 & 3,111 \\
\hline 16 & & 35 & 0,299 & $-21,396$ & 0,053 & 6,246 \\
\hline 18 & 260 & 50 & 0,225 & $-21,22$ & 0,051 & 6,420 \\
\hline 20 & & 41 & 0,247 & $-20,75$ & 0,051 & 6,294 \\
\hline 22 & & 39 & 0,195 & $-22,684$ & 0,053 & 6,634 \\
\hline 24 & & 37 & 0,227 & $-21,071$ & 0,040 & 6,875 \\
\hline 26 & & 34 & 0,214 & $-22,007$ & 0,049 & 4,445 \\
\hline 28 & & 23 & 0,297 & $-21,361$ & 0,069 & 5,392 \\
\hline 30 & & 35 & 0,331 & $-21,895$ & 0,042 & 4,332 \\
\hline 1 & & 42 & 0,384 & $-20,403$ & 0,058 & 5,674 \\
\hline 3 & & 42 & 0,365 & $-20,467$ & 0,053 & 6,477 \\
\hline 5 & & 49 & 0,316 & $-21,244$ & 0,062 & 4,890 \\
\hline 7 & & 44 & 0,313 & $-20,957$ & 0,039 & 6,466 \\
\hline 1 & & 29 & 0,686 & $-20,86$ & 0,071 & 3,454 \\
\hline 2 & & 29 & 0,646 & $-21,355$ & 0,074 & 3,862 \\
\hline 4 & & 28 & 0,723 & $-20,797$ & 0,071 & 2,207 \\
\hline 6 & & 39 & 0,595 & $-20,909$ & 0,061 & 4,741 \\
\hline 8 & & 28 & 0,739 & $-21,028$ & 0,074 & 6,179 \\
\hline 10 & 262 & 28 & 0,545 & $-20,988$ & 0,079 & 6,688 \\
\hline 12 & & 28 & 0,425 & $-20,412$ & 0,073 & 3,629 \\
\hline 14 & & 28 & 0,661 & $-21,059$ & 0,075 & 6,172 \\
\hline 16 & & 29 & 0,533 & $-21,664$ & 0,071 & 4,543 \\
\hline 18 & & 29 & 0,434 & $-21,797$ & 0,072 & 4,487 \\
\hline 20 & & 30 & 0,377 & $-21,007$ & 0,073 & 3,955 \\
\hline 1 & & 44 & 0,275 & $-21,935$ & 0,063 & 3,579 \\
\hline 2 & & 42 & 0,444 & $-21,787$ & 0,061 & 7,253 \\
\hline 4 & & 41 & 0,391 & $-21,34$ & 0,066 & 5,040 \\
\hline 6 & & 41 & 0,577 & $-22,093$ & 0,063 & 5,527 \\
\hline 8 & & 40 & 0,390 & $-22,241$ & 0,071 & 3,968 \\
\hline 10 & 264 & 45 & 0,263 & $-20,963$ & 0,065 & 4,462 \\
\hline 12 & & 33 & 0,346 & $-21,006$ & 0,045 & 4,195 \\
\hline 14 & & 26 & 0,412 & $-21,688$ & 0,041 & 5,137 \\
\hline 16 & & 23 & 0,414 & $-21,598$ & 0,044 & 4,723 \\
\hline
\end{tabular}


Tabela I (Continuação) - Parâmetros de caracterização da matéria orgânica sedimentar ao longo dos testemunhos.

\begin{tabular}{ccrrrrr}
\hline $\begin{array}{c}\text { Profundidade } \\
(\mathbf{m})\end{array}$ & Estação & $\begin{array}{c}\mathrm{CaCO}_{3} \\
(\%)\end{array}$ & $\begin{array}{c}\text { Corg Total } \\
(\%)\end{array}$ & $\begin{array}{c}\boldsymbol{\delta}{ }^{13} \mathbf{C} \\
(\%)\end{array}$ & $\begin{array}{c}\text { Nit } \\
\text { Total } \\
(\%)\end{array}$ & $\begin{array}{c}\mathbf{\delta}^{15} \mathbf{N} \\
(\%)\end{array}$ \\
\hline $\mathbf{1 8}$ & \multirow{2}{*}{$\mathbf{\%})$} & 21 & 0,539 & $-21,728$ & 0,037 & 3,872 \\
$\mathbf{2 0}$ & 264 & 19 & 0,431 & $-20,753$ & 0,042 & 3,622 \\
$\mathbf{2 2}$ & & 18 & 0,319 & $-21,542$ & 0,041 & 3,948 \\
\hline
\end{tabular}


Tabela II. - Concentrações dos $n$-alcanos, alcanos isoprenóides, MCNR, em $\mu g^{-1}$, e parâmetros de avaliação de fontes de hidrocarbonetos alifáticos.< LDM: abaixo do limite de detecção; Alcanos totais: somatório dos compostos $n-\mathrm{C}_{12}$ ao $n-\mathrm{C}_{35}$; Pris/Fit: razão entre o pristano e o fitano, IA= $\left(n-\mathrm{C}_{31} / n-\mathrm{C}_{31}+n-\mathrm{C}_{29}\right)$, ao longo do testemunho 253.

\begin{tabular}{|c|c|c|c|c|c|c|c|c|c|c|c|c|c|c|c|c|c|}
\hline & \multicolumn{17}{|c|}{ Profundidade $(\mathrm{cm})$} \\
\hline & 1 & 2 & 4 & 6 & 8 & 10 & 12 & 14 & 16 & 18 & 20 & 22 & 24 & 26 & 28 & 30 & 32 \\
\hline$n-C_{12}$ & 0,009 & 0,011 & 0,011 & 0,009 & 0,010 & 0,009 & 0,006 & 0,010 & 0,006 & 0,017 & 0,011 & 0,009 & 0,008 & 0,008 & 0,008 & 0,009 & 0,008 \\
\hline$n-C_{13}$ & 0,005 & 0,006 & 0,007 & 0,006 & 0,006 & 0,009 & 0,004 & 0,005 & 0,003 & 0,008 & 0,006 & 0,006 & 0,009 & 0,007 & 0,006 & 0,008 & 0,005 \\
\hline$n-C_{14}$ & 0,007 & 0,009 & 0,010 & 0,007 & 0,013 & 0,017 & 0,006 & 0,009 & 0,005 & 0,011 & 0,009 & 0,008 & 0,014 & 0,011 & 0,009 & 0,010 & 0,007 \\
\hline$n-C_{15}$ & 0,006 & 0,006 & 0,007 & 0,004 & 0,010 & 0,009 & $<$ LDM & 0,005 & $<$ LDM & 0,006 & 0,006 & 0,005 & 0,029 & 0,016 & 0,006 & 0,014 & 0,005 \\
\hline$n-C_{16}$ & 0,006 & 0,008 & 0,010 & 0,005 & 0,016 & 0,014 & 0,005 & 0,008 & 0,005 & 0,009 & 0,013 & 0,010 & 0,012 & 0,012 & 0,008 & 0,012 & 0,009 \\
\hline$n-C_{17}$ & 0,008 & 0,009 & 0,010 & 0,005 & 0,024 & 0,011 & 0,005 & 0,007 & 0,005 & 0,010 & 0,011 & 0,011 & 0,011 & 0,013 & 0,008 & 0,014 & 0,012 \\
\hline$n-C_{18}$ & 0,006 & 0,007 & 0,007 & 0,003 & 0,047 & 0,006 & 0,004 & 0,005 & 0,004 & 0,007 & 0,006 & 0,007 & 0,005 & 0,008 & 0,005 & 0,013 & 0,007 \\
\hline$n-C_{19}$ & 0,005 & 0,005 & 0,006 & $<$ LDM & 0,082 & 0,004 & & $<\mathrm{LDM}$ & $<\mathrm{LDM}$ & 0,005 & $<$ LDM & 0,006 & 0,005 & 0,005 & $<\mathrm{LDM}$ & 0,005 & 0,007 \\
\hline$n-C_{20}$ & 0,010 & 0,008 & 0,008 & $<$ LDM & 0,072 & $<\mathrm{LDM}$ & $<$ LDM & $<$ LDM & 0,011 & $<$ LDM & $<$ LDM & $<$ LDM & 0,009 & $<$ LDM & $<$ LDM & $<$ LDM & 0,008 \\
\hline$n-C_{21}$ & 0,013 & $<\mathrm{LDM}$ & 0,011 & $<$ LDM & 0,033 & $<\mathrm{LDM}$ & $<$ LDM & $<\mathrm{LDM}$ & 0,019 & $<\mathrm{LDM}$ & $<$ LDM & $<$ LDM & 0,013 & $<\mathrm{LDM}$ & $<\mathrm{LDM}$ & $<$ LDM & $<$ LDM \\
\hline$n-C_{22}$ & & 0,009 & 0,014 & 0,007 & 0,015 & & 0,014 & 0,005 & 0,027 & 0,009 & 0,009 & 0,008 & 0,024 & 0,009 & 0,012 & 0,013 & 0,006 \\
\hline$n-C_{23}$ & 0,017 & 0,009 & 0,015 & 0,007 & 0,009 & 0,011 & 0,015 & 0,006 & 0,027 & 0,010 & 0,010 & 0,010 & 0,039 & 0,013 & 0,015 & 0,016 & 0,007 \\
\hline$n-C_{24}$ & 0,015 & 0,010 & 0,013 & 0,006 & 0,009 & 0,013 & 0,014 & $<$ LDM & 0,022 & 0,009 & 0,012 & 0,008 & 0,049 & 0,014 & 0,015 & 0,018 & $<$ LDM \\
\hline$n-C_{25}$ & $<$ LDM & $<$ LDM & $<$ LDM & $<$ LDM & $<$ LDM & $<\mathrm{LDM}$ & $<$ LDM & $<\mathrm{LDM}$ & $<$ LDM & $<$ LDM & $<\mathrm{LDM}$ & $<$ LDM & 0,046 & $<\mathrm{LDM}$ & $<$ LDM & $<$ LDM & $<$ LDM \\
\hline$n-C_{26}$ & 0,025 & 0,021 & 0,022 & 0,016 & 0,017 & 0,017 & 0,021 & 0,018 & 0,026 & 0,021 & 0,020 & 0,019 & 0,045 & 0,021 & 0,026 & 0,022 & 0,019 \\
\hline$n-C_{27}$ & & & $<$ LDM & & $<$ LDM & & & $<$ LDM & $<$ LDM & $<$ LDM & $<$ LDM & $<$ LDM & $<$ LDM & $<$ LDM & $<$ LDM & & $<$ LDM \\
\hline$n-C_{28}$ & $<$ LDM & $<$ LDM & $<$ LDM & $<$ LDM & $<$ LDM & $<$ LDM & $<$ LDM & $<$ LDM & $<$ LDM & $<$ LDM & $<$ LDM & $<$ LDM & $<$ LDM & $<$ LDM & $<$ LDM & $<$ LDM & $<$ LDM \\
\hline$n-C_{29}$ & 0,053 & 0,044 & 0,052 & $<\mathrm{LDM}$ & $<\mathrm{LDM}$ & $<$ LDM & $<$ LDM & $<\mathrm{LDM}$ & 0,043 & $<$ LDM & 0,034 & 0,032 & 0,043 & 0,027 & 0,030 & $<\mathrm{LDM}$ & 0,046 \\
\hline$n-C_{30}$ & $<\mathrm{LDM}$ & $<\mathrm{LDM}$ & $<$ LDM & $<\mathrm{LDM}$ & $<$ LDM & $<$ LDM & $<$ LDM & $<\mathrm{LDM}$ & $<\mathrm{LDM}$ & $<$ LDM & $<\mathrm{LDM}$ & $<$ LDM & $<\mathrm{LDM}$ & $<\mathrm{LDM}$ & $<\mathrm{LDM}$ & $<\mathrm{LDM}$ & $<$ LDM \\
\hline$n-C_{31}$ & 0,051 & 0,063 & 0,067 & 0,026 & 0,030 & 0,029 & 0,026 & 0,033 & 0,051 & 0,028 & 0,042 & 0,042 & 0,052 & 0,036 & 0,038 & 0,030 & 0,053 \\
\hline$n-C_{32}$ & $<$ LDM & $<\mathrm{LDM}$ & $<$ LDM & $<\mathrm{LDM}$ & $<$ LDM & $<$ LDM & $<$ LDM & $<\mathrm{LDM}$ & $<$ LDM & $<$ LDM & $<\mathrm{LDM}$ & $<$ LDM & $<\mathrm{LDM}$ & $<$ LDM & $<$ LDM & $<$ LDM & $<$ LDM \\
\hline
\end{tabular}


Tabela II (Continuação) - Concentrações dos $n$-alcanos, alcanos isoprenóides, MCNR, em $\mu g g^{-1}$, e parâmetros de avaliação de fontes de hidrocarbonetos alifáticos.< LDM: abaixo do limite de detecção; Alcanos totais: somatório dos compostos $n-\mathrm{C}_{12}$ ao $n-\mathrm{C}_{35}$; Pris/Fit: razão entre o pristano e o fitano, IA= $\left(n-\mathrm{C}_{31} / n-\right.$ $\mathrm{C}_{31}+n-\mathrm{C}_{29)}$, ao longo do testemunho 253.

\begin{tabular}{|c|c|c|c|c|c|c|c|c|c|c|c|c|c|c|c|c|c|}
\hline \multicolumn{18}{|c|}{ Protundidade (cm) } \\
\hline & 1 & 2 & 4 & 6 & 8 & 10 & 12 & 14 & 16 & 18 & 20 & 22 & 24 & 26 & 28 & 30 & 32 \\
\hline$n-C_{33}$ & 0,053 & 0,065 & 0,054 & 0,022 & 0,020 & 0,026 & 0,019 & 0,024 & 0,039 & 0,026 & 0,029 & 0,031 & 0,032 & 0,024 & 0,028 & 0,021 & 0,038 \\
\hline$n-C_{34}$ & 0,018 & 0,037 & 0,021 & $<$ LDM & $<$ LDM & 0,012 & $<$ LDM & $<$ LDM & $<$ LDM & $<$ LDM & $<$ LDM & $<$ LDM & 0,012 & $<$ LDM & $<$ LDM & $<$ LDM & 0,003 \\
\hline$n-C_{35}$ & 0,032 & 0,064 & 0,029 & $<$ LDM & $<$ LDM & $<$ LDM & $<$ LDM & $<$ LDM & $<$ LDM & $<$ LDM & $<$ LDM & $<$ LDM & 0,012 & $<$ LDM & $<$ LDM & $<$ LDM & $<$ LDM \\
\hline Pristano & $<$ LDM & $<$ LDM & $<$ LDM & $<$ LDM & 0,019 & 0,014 & $<$ LDM & $<$ LDM & $<$ LDM & $<$ LDM & $<$ LDM & $<$ LDM & $<$ LDM & $<$ LDM & $<$ LDM & $<$ LDM & $<$ LDM \\
\hline Fitano & 0,003 & 0,004 & 0,004 & 0,002 & 0,034 & 0,011 & 0,002 & 0,003 & $<$ LDM & 0,006 & 0,002 & 0,003 & 0,003 & 0,003 & 0,002 & 0,005 & 0,004 \\
\hline $\begin{array}{c}\text { n-alcanos } \\
\text { Totais }\end{array}$ & 0,438 & 0,479 & 0,457 & 0,198 & 0,479 & 0,271 & 0,242 & 0,214 & 0,3802 & 0,259 & 0,289 & 0,278 & 0,570 & 0,290 & 0,305 & 0,300 & 0,302 \\
\hline $\begin{array}{c}\text { Alifáticos } \\
\text { Totais }\end{array}$ & 0,817 & 0,943 & 0,835 & 0,471 & 0,813 & 0,642 & 0,506 & 0,582 & 0,7415 & 0,582 & 0,599 & 0,609 & 0,845 & 0,611 & 0,629 & 0,598 & 0,725 \\
\hline MCNR & $<$ LDM & $<$ LDM & $<$ LDM & $<$ LDM & $<$ LDM & $<$ LDM & $<$ LDM & $<$ LDM & $<$ LDM & $<$ LDM & $<$ LDM & $<$ LDM & $<$ LDM & $<$ LDM & $<$ LDM & $<$ LDM & $<$ LDM \\
\hline Tetradeceno & 0,206 & 0,206 & 0,207 & 0,203 & 0,184 & 0,233 & 0,204 & 0,236 & 0,229 & 0,238 & 0,222 & 0,234 & 0,224 & 0,200 & 0,203 & 0,201 & 0,223 \\
\hline Hexadeceno & 0,125 & 0,125 & 0,125 & 0,125 & 0,125 & 0,125 & 0,125 & 0,125 & 0,125 & 0,125 & 0,125 & 0,125 & 0,125 & 0,125 & 0,125 & 0,125 & 0,125 \\
\hline Eicoseno & 0,125 & 0,125 & 0,125 & 0,125 & 0,125 & 0,125 & 0,125 & 0,125 & 0,125 & 0,125 & 0,125 & 0,125 & 0,125 & 0,125 & 0,125 & 0,125 & 0,125 \\
\hline Recuperação & $61 \%$ & $61 \%$ & $61 \%$ & $62 \%$ & $68 \%$ & $54 \%$ & $61 \%$ & $53 \%$ & $55 \%$ & $53 \%$ & $56 \%$ & $53 \%$ & $56 \%$ & $62 \%$ & $62 \%$ & $62 \%$ & $56 \%$ \\
\hline \multicolumn{18}{|c|}{ PARÂMETROS DE AVALIAÇÃO } \\
\hline IA & 0,490 & 0,587 & 0,566 & 0,573 & 0,582 & 0,538 & 0,530 & 0,551 & 0,542 & 0,555 & 0,553 & 0,565 & 0,545 & 0,568 & 0,553 & 0,575 & 0,535 \\
\hline \multirow{2}{*}{$\begin{array}{c}\text { Pris/Fit } \\
\text { Pristano/n- } \\
\mathrm{C}_{17}\end{array}$} & $<$ LDM & $<$ LDM & $<$ LDM & $<$ LDM & 0,551 & 1,232 & $<$ LDM & $<$ LDM & $<$ LDM & $<$ LDM & $<$ LDM & $<$ LDM & $<$ LDM & $<$ LDM & $<$ LDM & $<$ LDM & $<$ LDM \\
\hline & $<\mathrm{LDM}$ & $<$ LDM & $<$ LDM & $<$ LDM & 0,774 & 1,260 & $<$ LDM & $<$ LDM & $<$ LDM & $<$ LDM & $<$ LDM & $<$ LDM & $<$ LDM & $<$ LDM & $<$ LDM & $<$ LDM & $<$ LDM \\
\hline
\end{tabular}


Tabela II - Concentrações dos n-alcanos, alcanos isoprenóides, MCNR, em $\mu \mathrm{g} \mathrm{g}^{-1}$, e parâmetros de avaliação de fontes de hidrocarbonetos alifáticos.< LDM: abaixo do limite de detecção; Alcanos totais: somatório dos compostos $n-C_{12}$ ao $n-C_{35}$; Pris/Fit: razão entre o pristano e o fitano, $\mathrm{I}=\left(n-\mathrm{C}_{31} / n-\mathrm{C}_{31}+n-\mathrm{C}_{29}\right)$ ao longo do testemunho 254.

\begin{tabular}{|c|c|c|c|c|c|c|c|c|c|c|c|}
\hline & \multicolumn{5}{|c|}{ Profundidade $(\mathrm{cm})$} & \multirow[b]{2}{*}{10} & \multirow[b]{2}{*}{12} & \multirow[b]{2}{*}{14} & \multirow[b]{2}{*}{16} & \multirow[b]{2}{*}{18} & \multirow[b]{2}{*}{20} \\
\hline & 1 & 2 & 4 & 6 & 8 & & & & & & \\
\hline$n-C_{12}$ & 0,008 & 0,005 & 0,004 & 0,005 & 0,055 & 0,114 & 0,070 & 0,059 & 0,008 & 0,007 & $<$ LDM \\
\hline$n-C_{13}$ & 0,008 & 0,003 & 0,003 & 0,003 & 0,006 & 0,006 & 0,004 & 0,011 & 0,006 & 0,004 & 0,003 \\
\hline$n-C_{14}$ & 0,011 & 0,006 & 0,007 & 0,007 & 0,028 & 0,078 & 0,052 & 0,038 & 0,010 & 0,008 & 0,004 \\
\hline$n-C_{15}$ & 0,010 & 0,005 & 0,007 & 0,019 & 0,005 & 0,006 & 0,007 & 0,007 & 0,008 & 0,005 & $<$ LDM \\
\hline$n-C_{16}$ & 0,017 & 0,006 & 0,011 & 0,037 & 0,010 & 0,013 & 0,014 & 0,012 & 0,012 & 0,007 & $<$ LDM \\
\hline$n-C_{17}$ & 0,018 & 0,008 & 0,012 & 0,023 & 0,007 & 0,007 & 0,009 & 0,011 & 0,010 & 0,006 & 0,006 \\
\hline$n-C_{18}$ & 0,013 & 0,011 & 0,014 & 0,011 & 0,007 & 0,007 & 0,008 & 0,011 & 0,008 & 0,005 & 0,006 \\
\hline$n-C_{19}$ & 0,014 & 0,010 & 0,018 & 0,008 & 0,003 & 0,008 & 0,011 & 0,007 & 0,012 & 0,006 & $<$ LDM \\
\hline$n-C_{20}$ & $<$ LDM & $<\mathrm{LDM}$ & $<\mathrm{LDM}$ & $<$ LDM & $<$ LDM & $<$ LDM & $<\mathrm{LDM}$ & 0,011 & $<$ LDM & $<$ LDM & $<$ LDM \\
\hline$n-C_{21}$ & $<$ LDM & $<\mathrm{LDM}$ & $<$ LDM & $<$ LDM & 0,005 & LDM & LDM & 0,012 & LDM & LDM & LDM \\
\hline$n-C_{22}$ & 0,007 & 0,006 & 0,005 & 0,007 & 0,007 & 0,009 & 0,009 & 0,017 & 0,006 & 0,004 & 0,004 \\
\hline$n-C_{23}$ & 0,008 & 0,006 & 0,006 & 0,008 & 0,008 & 0,010 & 0,008 & 0,018 & 0,008 & $<$ LDM & $<$ LDM \\
\hline$n-C_{24}$ & 0,011 & 0,008 & 0,008 & 0,092 & 0,008 & 0,012 & 0,008 & 0,017 & 0,010 & 0,007 & $<$ LDM \\
\hline$n-C_{25}$ & $<$ LDM & $<$ LDM & $<$ LDM & $<$ LDM & 0,007 & $<$ LDM & $<$ LDM & $<$ LDM & $<$ LDM & $<$ LDM & $<$ LDM \\
\hline$n-C_{26}$ & $<$ LDM & $<\mathrm{LDM}$ & $<\mathrm{LDM}$ & 0,011 & 0,016 & 0,007 & $<$ LDM & 0,025 & $<$ LDM & $<$ LDM & 0,014 \\
\hline$n-C_{27}$ & $<$ LDM & $<\mathrm{LDM}$ & $<$ LDM & $<$ LDM & 0,007 & $<\mathrm{LDM}$ & $<$ LDM & $<$ LDM & $<$ LDM & $<\mathrm{LDM}$ & $<$ LDM \\
\hline$n-C_{28}$ & $<$ LDM & $<$ LDM & $<$ LDM & 0,054 & 0,005 & $<$ LDM & $<$ LDM & $<$ LDM & $<$ LDM & $<$ LDM & $<$ LDM \\
\hline$n-C_{29}$ & 0,063 & 0,043 & 0,044 & $<$ LDM & 0,014 & $<\mathrm{LDM}$ & $<$ LDM & 0,040 & $<$ LDM & $<\mathrm{LDM}$ & 0,031 \\
\hline$n-C_{30}$ & $<$ LDM & $<$ LDM & $<$ LDM & $<$ LDM & 0,004 & $<\mathrm{LDM}$ & $<$ LDM & $<$ LDM & $<$ LDM & $<$ LDM & $<$ LDM \\
\hline$n-C_{31}$ & 0,090 & 0,063 & 0,058 & 0,054 & 0,019 & 0,033 & 0,033 & 0,047 & 0,032 & 0,029 & 0,035 \\
\hline$n-C_{32}$ & $<$ LDM & $<\mathrm{LDM}$ & $<\mathrm{LDM}$ & $<$ LDM & 0,003 & $<\mathrm{LDM}$ & $<\mathrm{LDM}$ & $<$ LDM & $<$ LDM & $<$ LDM & $<$ LDM \\
\hline$n-C_{33}$ & 0,072 & 0,053 & 0,043 & 0,057 & 0,011 & 0,022 & 0,020 & 0,028 & 0,027 & 0,025 & 0,015 \\
\hline$n-C_{34}$ & 0,022 & 0,019 & 0,013 & $<$ LDM & 0,002 & $<\mathrm{LDM}$ & $<$ LDM & $<$ LDM & $<$ LDM & $<$ LDM & $<$ LDM \\
\hline$n-C_{35}$ & 0,035 & 0,027 & 0,020 & 0,042 & 0,003 & $<$ LDM & $<\mathrm{LDM}$ & $<$ LDM & $<$ LDM & $<\mathrm{LDM}$ & $<$ LDM \\
\hline
\end{tabular}


Tabela II (Continuação) - Concentrações dos $n$-alcanos, alcanos isoprenóides, MCNR, em $\mu g g^{-1}$, e parâmetros de avaliação de fontes de hidrocarbonetos alifáticos.< LDM: abaixo do limite de detecção; Alcanos totais: somatório dos compostos $n$ - $\mathrm{C}_{12}$ ao $n$ - $\mathrm{C}_{35}$; Pris/Fit: razão entre o pristano e o fitano, $\mathrm{IA}=\left(n-\mathrm{C}_{31} / n-\mathrm{C}_{31}+n-\mathrm{C}_{29}\right)$ ao longo do testemunho 254.

\begin{tabular}{|c|c|c|c|c|c|c|c|c|c|c|c|}
\hline \multicolumn{12}{|c|}{ Profundidade $(\mathrm{cm})$} \\
\hline & 1 & 2 & 4 & 6 & 8 & 10 & 12 & 14 & 16 & 18 & 20 \\
\hline Pristano & 0,009 & $<$ LDM & $<$ LDM & 0,014 & 0,005 & $<$ LDM & $<$ LDM & $<$ LDM & $<$ LDM & $<$ LDM & $<L D M$ \\
\hline Fitano & 0,006 & 0,003 & 0,007 & 0,006 & 0,003 & 0,003 & 0,003 & 0,005 & 0,004 & $<$ LDM & $<$ LDM \\
\hline n-alcanos Totais & 0,516 & 0,356 & 0,351 & 0,522 & 0,258 & 0,430 & 0,342 & 0,457 & 0,243 & 0,196 & 0,179 \\
\hline Alifáticos Totais & 1,343 & 0,967 & 0,939 & 0,938 & 0,557 & 0,920 & 0,851 & 0,781 & 0,730 & 0,654 & 0,599 \\
\hline MCNR & $<$ LDM & $<$ LDM & $<$ LDM & $<$ LDM & $<$ LDM & $<$ LDM & $<$ LDM & $<$ LDM & $<$ LDM & $<$ LDM & $<$ LDM \\
\hline Tetradeceno & 0,323 & 0,321 & 0,347 & 0,351 & 0,203 & 0,348 & 0,376 & 0,200 & 0,375 & 0,367 & 0,174 \\
\hline Hexadeceno & 0,250 & 0,250 & 0,250 & 0,250 & 0,125 & 0,250 & 0,250 & 0,125 & 0,250 & 0,250 & 0,125 \\
\hline Eicoseno & 0,250 & 0,250 & 0,250 & 0,250 & 0,125 & 0,250 & 0,250 & 0,125 & 0,250 & 0,250 & 0,125 \\
\hline Recuperação & $77 \%$ & $78 \%$ & $72 \%$ & $71 \%$ & $62 \%$ & $72 \%$ & $67 \%$ & $63 \%$ & $67 \%$ & $68 \%$ & $72 \%$ \\
\hline \multicolumn{12}{|c|}{ PARÂMETROS DE AVALIAÇÃO } \\
\hline IA & 0,586 & 0,596 & 0,567 & 0,860 & 0,574 & 0,553 & 0,546 & 0,545 & 0,542 & 0,518 & 0,525 \\
\hline Pris/Fit & 1,448 & $<$ LDM & $<$ LDM & 2,381 & 1,472 & $<$ LDM & $<$ LDM & $<$ LDM & $<$ LDM & $<$ LDM & $<$ LDM \\
\hline Pristano/n- $\mathrm{C}_{17}$ & 0,493 & $<$ LDM & $<$ LDM & 0,600 & 0,642 & $<L D M$ & $<$ LDM & $<$ LDM & $<$ LDM & $<L D M$ & $<L D M$ \\
\hline
\end{tabular}


Tabela II (Continuação) - Concentrações dos $n$-alcanos, alcanos isoprenóides, MCNR, em $\mu g^{-1}$, e parâmetros de avaliação de fontes de hidrocarbonetos alifáticos.< LDM: abaixo do limite de detecção; Alcanos totais: somatório dos compostos $n-\mathrm{C}_{12}$ ao $n-\mathrm{C}_{35}$; Pris/Fit: razão entre 0 pristano e o fitano, $\mathrm{IA}=\left(n-\mathrm{C}_{31} / n-\mathrm{C}_{31}+n-\mathrm{C}_{29}\right)$ ao longo do testemunho 254.

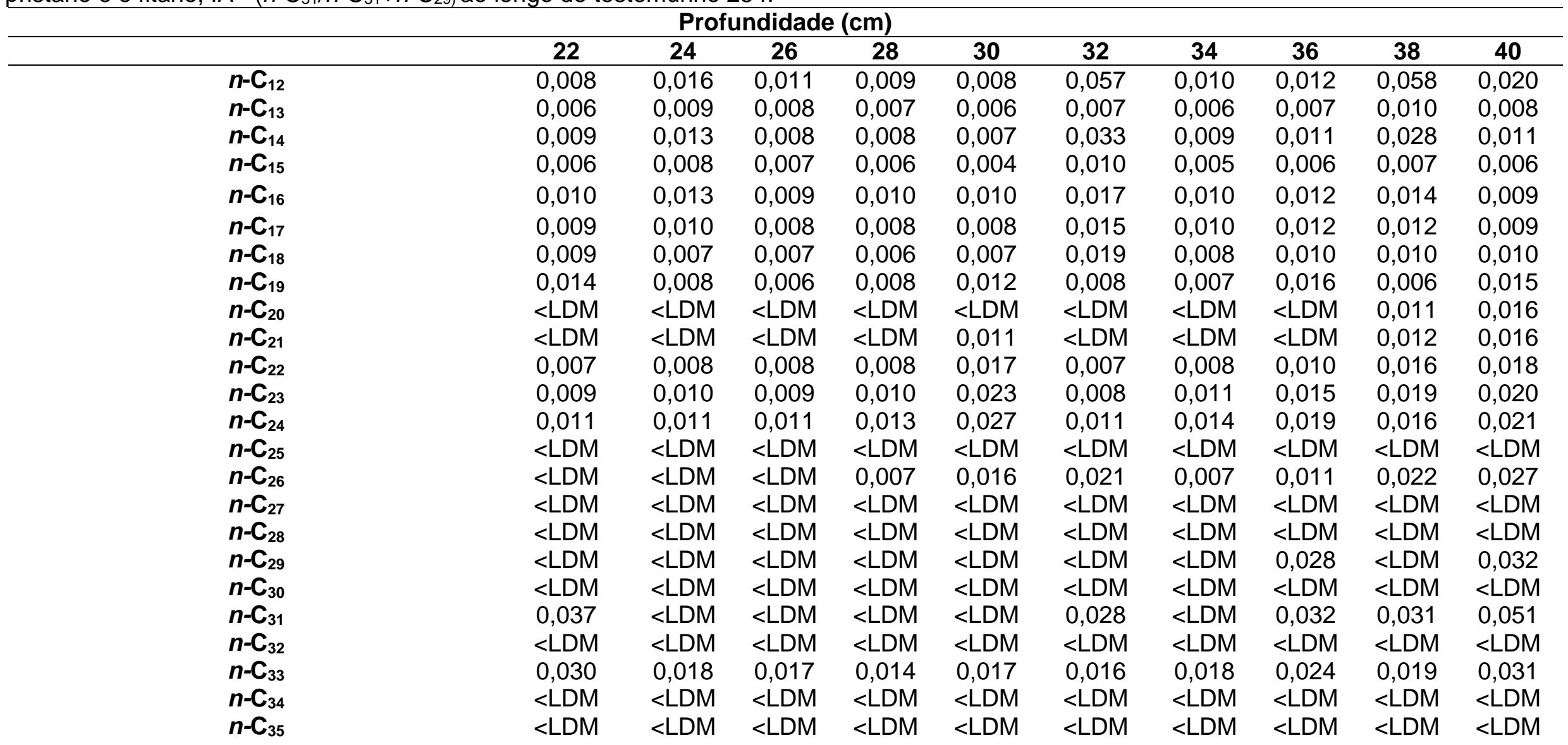


Tabela II (Continuação) - Concentrações dos $n$-alcanos, alcanos isoprenóides, MCNR, em $\mu g^{-1}$, e parâmetros de avaliação de fontes de hidrocarbonetos alifáticos. <LDM: abaixo do limite de detecção; Alcanos totais: somatório dos compostos $n$ - $\mathrm{C}_{12}$ ao $n$ - $\mathrm{C}_{35}$; Pris/Fit: razão entre o pristano e o fitano, $\mathrm{IA}=\left(n-\mathrm{C}_{31} / n-\mathrm{C}_{31}+n-\mathrm{C}_{29}\right)$ ao longo do testemunho 254.

\begin{tabular}{|c|c|c|c|c|c|c|c|c|c|c|}
\hline \multicolumn{11}{|c|}{ Profundidade (cm) } \\
\hline & 22 & 24 & 26 & 28 & 30 & 32 & 34 & 36 & 38 & 40 \\
\hline Pristano & $<$ LDM & $<$ LDM & $<$ LDM & $<$ LDM & $<$ LDM & $<$ LDM & $<$ LDM & $<$ LDM & $<$ LDM & $<$ LDM \\
\hline Fitano & 0,004 & 0,003 & $<$ LDM & $<$ LDM & 0,003 & 0,005 & 0,004 & 0,005 & 0,004 & 0,013 \\
\hline n-alcanos Totais & 0,256 & 0,236 & 0,217 & 0,211 & 0,312 & 0,319 & 0,228 & 0,312 & 0,373 & 0,408 \\
\hline Alifáticos Totais & 0,770 & 0,774 & 0,697 & 0,634 & 0,760 & 0,844 & 0,686 & 0,794 & 0,635 & 0,651 \\
\hline MCNR & $<$ LDM & $<$ LDM & $<$ LDM & $<$ LDM & $<$ LDM & $<$ LDM & $<$ LDM & $<$ LDM & $<$ LDM & $<$ LDM \\
\hline Tetradeceno & 0,389 & 0,409 & 0,374 & 0,359 & 0,370 & 0,412 & 0,363 & 0,380 & 0,196 & 0,188 \\
\hline Hexadeceno & 0,250 & 0,250 & 0,250 & 0,250 & 0,250 & 0,250 & 0,250 & 0,250 & 0,125 & 0,125 \\
\hline Eicoseno & 0,250 & 0,250 & 0,250 & 0,250 & 0,250 & 0,250 & 0,250 & 0,250 & 0,125 & 0,125 \\
\hline Recuperação & $64 \%$ & $61 \%$ & $67 \%$ & $70 \%$ & $68 \%$ & $61 \%$ & $69 \%$ & $66 \%$ & $64 \%$ & $67 \%$ \\
\hline \multicolumn{11}{|c|}{ PARÂMETROS DE AVALIAÇÃO } \\
\hline IA & 0,556 & 0,571 & 0,526 & $0,538^{3}$ & 0,546 & 0,710 & 0,495 & 0,539 & 0,556 & 0,617 \\
\hline Pris/Fit & $<$ LDM & $<$ LDM & $<$ LDM & $<$ LDM & $<$ LDM & $<$ LDM & $<$ LDM & $<$ LDM & $<$ LDM & $<$ LDM \\
\hline $\begin{array}{l}\text { Pristano } \\
\text { /n-C }_{17}\end{array}$ & $<$ LDM & $<$ LDM & $<$ LDM & $<$ LDM & $<$ LDM & $<$ LDM & $<$ LDM & $<$ LDM & $<$ LDM & $<$ LDM \\
\hline
\end{tabular}


Tabela III. - Concentrações dos n-alcanos, alcanos isoprenóides, MCNR, em $\mu \mathrm{g} \mathrm{g}^{-1}$, e parâmetros de avaliação de fontes de hidrocarbonetos alifáticos. <LDM: abaixo do limite de detecção; Alcanos totais: somatório dos compostos $n-\mathrm{C}_{12}$ ao $n$ - $\mathrm{C}_{35}$; Pris/Fit: razão entre o pristano e o fitano, $\mathrm{IA}=\left(n-\mathrm{C}_{31} / n-\mathrm{C}_{31}+n-\mathrm{C}_{29}\right)$ ao longo do testemunho 256 .

\begin{tabular}{|c|c|c|c|c|c|c|c|c|c|c|c|c|c|c|c|c|c|}
\hline \multicolumn{18}{|c|}{ Profundidade $(\mathrm{cm})$} \\
\hline & 1 & 2 & 4 & 6 & 8 & 10 & 12 & 14 & 16 & 18 & 20 & 22 & 24 & 26 & 28 & 30 & 32 \\
\hline$n-C_{12}$ & 0,009 & 0,052 & 0,051 & 0,047 & 0,008 & 0,011 & 12 & 010 &, 033 &, 026 & 0,028 & 0,034 & 0,015 &, 014 &, 006 &, 008 & 200 \\
\hline$n-C_{13}$ & 008 & 0,017 & 022 & 010 & 0,003 & 008 & 006 & 006 & 013 & 006 & 006 & 011 & 013 & 015 & 005 & 006 & 000 \\
\hline & & & 061 & 066 & 0,007 & 008 & & & & & 016 & & & & & 008 & \\
\hline$n-C_{15}$ & 007 & 0,00 & 0,010 & 0,006 & $<\mathrm{LD}$ & 004 & 4 & 0,0 & & & 06 & 008 & & & 07 & 07 & \\
\hline$n-C_{16}$ & 013 & 0,020 & 0,021 & 0,011 & 0,004 & 0,002 & 0,002 & 0,005 & 0,016 & 0,011 & 0,007 & 0,012 & 0,007 & 0,006 & 0,002 & 0,006 & 0,006 \\
\hline$n-C_{17}$ & 06 & 0,007 & 0,010 & $<$ LDM & $<$ LDM & $<$ LDM & $<$ LDM & 0,006 & 0,021 & 0,019 & 0,011 & 0,013 & 0,010 & 0,011 & 0,015 & 0,012 & 0,013 \\
\hline$n-C$ & 004 & 0,006 & 0,008 & 0,004 & 0,002 & 0,003 & 0,003 & 0,004 & 0,021 & 0,024 & 0,011 & 009 & 0,007 & 0,006 & 008 & 0,010 & 0,0 \\
\hline$n-C_{19}$ & 05 & 0,005 & 006 & 0,004 & $<$ LDM & DM & $<L \square$ & $<$ LDM & 05 & 0,0 & 05 & M & 06 & M & 5 & & \\
\hline & & & DM & & & & & & & & & & & & & M & \\
\hline & & & $<\mathrm{LD}$ & & & & & & & & & & & & & & \\
\hline & & 0,020 & 0,013 & 0,019 & & 0,018 & & & & & & & & & & & \\
\hline$n-C_{23}$ & & 0,026 & 0,015 & 0,030 & 0,008 & 0,021 & & & & & & & & & & & \\
\hline$n-C_{24}$ & 26 & 0,024 & 0,011 & 0,032 & 0,008 & 0,017 & & & 0,0 & & & 0,0 & & & & & \\
\hline$n-C_{25}$ & DM & $<$ LDM & $<$ LDM & $<$ LDM & $<$ LDM & $<$ LDM & $<\mathrm{LL}$ & $<$ LDM & $<$ LDM & $<$ LDM & $<$ LDM & $<$ LDM & $<$ LDM & $<$ LDM & $<$ LDM & $<$ LDM & $<$ LDM \\
\hline$n-C_{26}$ & 007 & $<$ LDM & $<$ LDM & 0,010 & 0,019 & 0,007 & & 0,0 & $<$ LDM & 0,007 & 0,010 & 0,007 & 0,0 & 0,00 & & & $<L L$ \\
\hline & DM & $<$ LDM & $<$ LDM & $<$ LDM & $<$ LDM & $<$ LDM & & $<L L$ & $<$ LDM & $<$ LDM & & $<$ LDM & 0,036 & $<L D$ & & $<$ LDM & $<$ LDM \\
\hline$n-C_{28}$ & DM & $<$ LDM & $<$ LDM & $<$ LDM & $<$ LDM & $<$ LDM & & $<$ LDM & $<$ LDM & $<$ LDM & & $<$ LDM & $<$ LDM & $<L D$ & & $<\mathrm{LL}$ & $<L D M$ \\
\hline & 031 & 0,028 & 0,029 & & $<$ LDM & & & & & & & & & & & & \\
\hline & & $<$ LDM & $<$ LDM & $<$ LDM & $<$ LDM & & & & & & & & $<$ LDM & & & & $<$ LDM \\
\hline$n-C_{31}$ & ,042 & 0,039 & 0,043 & 0,037 & $<$ LDM & 0,043 & & 0,067 & 0,059 & 0,054 & 0,068 & 0,054 & 0,100 & 0,088 & 0,097 & 0,095 & 0,071 \\
\hline$n-C_{32}$ & $<$ LDM & $<$ LDM & $<$ LDM & $<$ LDM & $<$ LDM & 0,009 & 0,009 & $<$ LDM & $<$ LDM & $<$ LDM & $<$ LDM & $<$ LDM & $<$ LDM & $<$ LDM & $<$ LDM & $<$ LDM & $<$ LDM \\
\hline$n-C_{33}$ & 0,031 & 0,028 & 0,030 & 0,025 & 0,013 & 0,027 & 0,036 & 0,040 & 0,038 & 0,035 & 0,044 & 0,037 & 0,019 & 0,016 & 0,017 & 0,017 & 0,038 \\
\hline$n-C_{34}$ & $<$ LDM & $<$ LDM & $<$ LDM & $<$ LDM & $<$ LDM & $<$ LDM & $<$ LDM & $<$ LDM & $<$ LDM & $<$ LDM & $<L D$ & $<$ LDM & $<$ LDM & $<$ LDM & $<$ LDM & $<$ LDM & $<$ LDM \\
\hline$n-C_{35}$ & 0,014 & $<$ LDM & $<$ LDM & $<$ LDM & $<$ LDM & $<$ LDM & $<$ LDM & 0,012 & $<$ LDM & $<$ LDM & $<$ LDM & $<$ LDM & 0,017 & 0,014 & 0,017 & 0,017 & 0,012 \\
\hline
\end{tabular}


Tabela III (Continuação) - Concentrações dos $n$-alcanos, alcanos isoprenóides, MCNR, em $\mu g^{-1}$, e parâmetros de avaliação de fontes de hidrocarbonetos alifáticos. <LDM: abaixo do limite de detecção; Alcanos totais: somatório dos compostos $n$ - $\mathrm{C}_{12}$ ao $n$ - $\mathrm{C}_{35}$; Pris/Fit: razão entre o pristano e o fitano, $\mathrm{IA}=\left(n-\mathrm{C}_{31} / n-\mathrm{C}_{31}+n-\mathrm{C}_{29}\right)$ ao longo do testemunho 256.

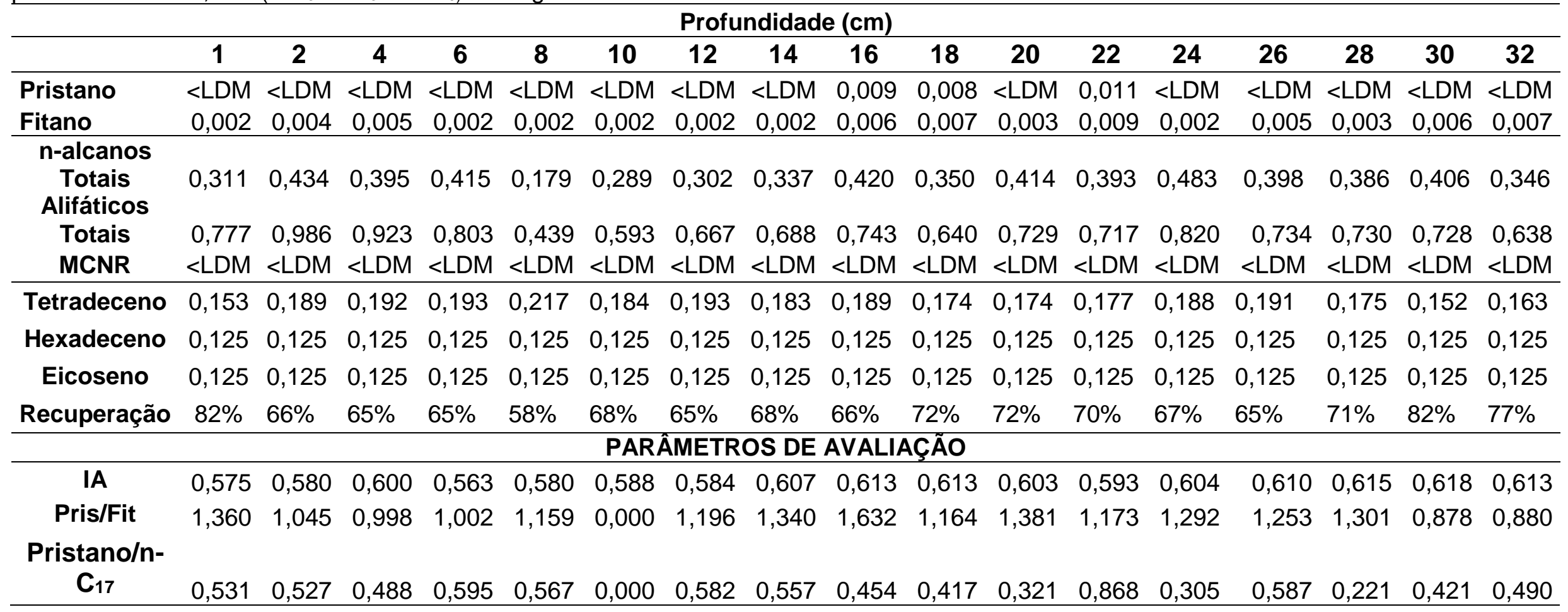


Tabela IV. - Concentrações dos $n$-alcanos, alcanos isoprenóides, MCNR, em $\mu \mathrm{g} \mathrm{g}{ }^{-1}$, e parâmetros de avaliação de fontes de hidrocarbonetos alifáticos.< LDM: abaixo do limite de detecção; Alcanos totais: somatório dos compostos $n-\mathrm{C}_{12}$ ao $n-\mathrm{C}_{35}$; Pris/Fit: razão entre o pristano e o fitano, $\mathrm{IA}=\left(n-\mathrm{C}_{31} / n-\right.$ $\left.\mathrm{C}_{31}+n-\mathrm{C}_{29}\right)$ ao longo do testemunho 257.

\begin{tabular}{|c|c|c|c|c|c|c|c|c|c|c|c|c|c|c|c|c|}
\hline \multicolumn{17}{|c|}{ Profundidade (cm) } \\
\hline & 1 & 2 & 4 & 6 & 8 & 10 & 12 & 14 & 16 & 18 & 20 & 22 & 24 & 26 & 28 & 30 \\
\hline$n-C_{12}$ & 0,013 & 0,007 & 0,015 & 0,011 & 0,013 & 0,014 & 0,018 & 0,015 & 0,011 & 0,019 & 0,018 & 0,015 & 0,0141 & 0,016 & 0,015 & 0,015 \\
\hline$n-C_{13}$ & 0,011 & 0,004 & 0,010 & 0,007 & 0,009 & 0,009 & 0,012 & 0,009 & 0,004 & 0,008 & 0,010 & 0,008 & 0,0097 & 0,010 & 0,008 & 0,008 \\
\hline$n-C_{14}$ & 0,012 & 0,006 & 0,013 & 0,011 & 0,011 & 0,013 & 0,016 & 0,012 & 0,006 & 0,013 & 0,012 & 0,011 & 0,0157 & 0,013 & 0,011 & 0,009 \\
\hline$n-C_{15}$ & 0,009 & 0,004 & 0,009 & 0,007 & 0,007 & 0,011 & 0,009 & 0,007 & $<$ LDM & 0,006 & 0,005 & 0,005 & 0,0131 & 0,009 & 0,006 & 0,005 \\
\hline$n-C_{16}$ & 0,012 & 0,005 & 0,012 & 0,008 & 0,009 & 0,015 & 0,017 & 0,012 & 0,004 & 0,010 & 0,007 & 0,007 & 0,0168 & 0,011 & 0,009 & 0,007 \\
\hline$n-C_{17}$ & 0,009 & 0,005 & 0,011 & 0,007 & 0,007 & 0,011 & 0,014 & 0,009 & 0,004 & 0,007 & 0,005 & 0,006 & 0,0186 & 0,009 & 0,009 & 0,007 \\
\hline$n-C_{18}$ & 0,005 & 0,003 & 0,012 & 0,004 & 0,004 & 0,006 & 0,009 & 0,006 & 0,003 & 0,006 & 0,003 & 0,003 & 0,0149 & 0,006 & 0,008 & 0,007 \\
\hline$n-C_{19}$ & 0,005 & $<$ LDM & 0,007 & $<\mathrm{LDM}$ & $<\mathrm{LDM}$ & $<\mathrm{LDM}$ & $<$ LDM & $<\mathrm{LDM}$ & $<$ LDM & $<$ LDM & $<$ LDM & $<\mathrm{LDM}$ & 0,0069 & $<\mathrm{LDM}$ & $<$ LDM & 0,007 \\
\hline$n-C_{20}$ & $<$ LDM & 0,008 & 0,008 & $<\mathrm{LDM}$ & $<$ LDM & $<\mathrm{LDM}$ & 0,009 & $<$ LDM & $<$ LDM & $<$ LDM & $<$ LDM & $<\mathrm{LDM}$ & 0,0075 & $<\mathrm{LDM}$ & $<$ LDM & 0,008 \\
\hline$n-C_{21}$ & $<$ LDM & $<$ LDM & $<$ LDM & $<$ LDM & $<$ LDM & $<$ LDM & $<$ LDM & $<$ LDM & $<$ LDM & $<$ LDM & $<$ LDM & $<$ LDM & 0,0055 & $<$ LDM & $<$ LDM & $<$ LDM \\
\hline$n-C_{22}$ & 0,007 & 0,005 & 0,006 & 0,007 & 0,007 & 0,005 & 0,009 & 0,008 & 0,005 & 0,006 & 0,003 & 0,004 & 0,0086 & 0,006 & 0,005 & 0,006 \\
\hline$n-C_{23}$ & 0,008 & 0,005 & 0,006 & 0,006 & 0,007 & 0,006 & 0,009 & 0,007 & 0,007 & 0,007 & 0,004 & 0,005 & 0,0093 & 0,007 & 0,006 & 0,006 \\
\hline$n-C_{24}$ & 0,008 & 0,005 & 0,005 & 0,005 & 0,007 & 0,005 & 0,007 & 0,005 & 0,006 & 0,006 & 0,003 & 0,004 & 0,0089 & 0,006 & 0,007 & 0,005 \\
\hline$n-C_{25}$ & 0,010 & 0,005 & 0,00 & & 0,007 & 0,006 & 0,0 & 0,005 & 0,007 & 0,0 & 0,005 & & 0,0 & 0,007 & & 0,006 \\
\hline$n-C_{26}$ & 0,021 & 0,015 & 0,016 & 0,016 & 0,017 & 0,016 & 0,017 & 0,015 & 0,017 & 0,016 & 0,015 & 0,015 & 0,0198 & 0,017 & 0,016 & 0,016 \\
\hline$n-C_{27}$ & 0,017 & 0,009 & 0,008 & 0,009 & 0,012 & 0,010 & 0,010 & 0,007 & 0,011 & 0,009 & 0,008 & 0,007 & 0,0128 & 0,008 & 0,007 & 0,008 \\
\hline$n-C_{28}$ & 0,014 & 0,006 & 0,005 & 0,005 & 0,007 & 0,005 & 0,006 & 0,003 & 0,006 & 0,005 & 0,004 & 0,004 & 0,0081 & 0,005 & 0,004 & 0,006 \\
\hline$n-C_{29}$ & & & & & 0,031 & & & & & & & $<$ LDM & & $<$ LDM & $<$ LDM & $<$ LDM \\
\hline$n-C_{30}$ & 0,013 & 0,006 & 0,005 & 0,004 & 0,005 & 0,004 & 0,006 & 0,003 & 0,006 & 0,004 & 0,003 & 0,003 & 0,0065 & 0,005 & 0,003 & 0,003 \\
\hline$n-C_{31}$ & 0,064 & 0,033 & 0,032 & 0,031 & 0,041 & 0,034 & 0,029 & $<$ LDM & 0,035 & 0,026 & 0,027 & 0,020 & 0,0304 & 0,024 & 0,023 & 0,021 \\
\hline$n-C_{32}$ & 0,017 & 0,006 & 0,006 & 0,005 & 0,006 & 0,005 & 0,005 & 0,003 & 0,005 & 0,004 & 0,003 & 0,003 & 0,0037 & 0,004 & 0,003 & 0,003 \\
\hline$n-C_{33}$ & 0,060 & 0,029 & 0,023 & 0,021 & 0,030 & 0,020 & 0,021 & 0,014 & 0,026 & 0,019 & 0,021 & 0,015 & 0,0222 & 0,018 & 0,017 & 0,017 \\
\hline$n-C_{34}$ & 0,020 & 0,007 & 0,006 & 0,003 & 0,004 & 0,002 & 0,003 & 0,001 & 0,002 & 0,002 & 0,001 & 0,001 & 0,0016 & 0,002 & 0,002 & 0,002 \\
\hline$n-C_{35}$ & 0,029 & 0,009 & 0,009 & 0,006 & 0,008 & 0,006 & 0,006 & 0,003 & 0,006 & 0,005 & 0,004 & 0,004 & 0,0052 & 0,004 & 0,004 & 0,004 \\
\hline
\end{tabular}


Tabela IV (Continuação) - Concentrações dos $n$-alcanos, alcanos isoprenóides, MCNR, em $\mu g g^{-1}$, e parâmetros de avaliação de fontes de hidrocarbonetos alifáticos. <LDM: abaixo do limite de detecção; Alcanos totais: somatório dos compostos $n-C_{12}$ ao $n-C_{35}$; Pris/Fit: razão entre o pristano e o fitano, $\mathrm{IA}=\left(n-\mathrm{C}_{31} / n-\mathrm{C}_{31}+n-\mathrm{C}_{29}\right)$ ao longo do testemunho 257.

\begin{tabular}{|c|c|c|c|c|c|c|c|c|c|c|c|c|c|c|c|c|}
\hline \multicolumn{17}{|c|}{ Profundidade (cm) } \\
\hline & 1 & 2 & 4 & 6 & 8 & 10 & 12 & 14 & 16 & 18 & 20 & 22 & 24 & 26 & 28 & 30 \\
\hline Pristano & $<$ LDM & $<$ LDM & $<$ LDM & $<$ LDM & $<$ LDM & $<$ LDM & $<$ LDM & $<$ LDM & $<$ LDM & $<$ LDM & $<$ LDM & $<$ LDM & 0,009 & $<$ LDM & $<$ LDM & $<$ LDM \\
\hline Fitano & 0,003 & 0,002 & 0,007 & 0,003 & 0,003 & 0,005 & 0,004 & 0,003 & 0,000 & 0,003 & 0,000 & 0,000 & 0,006 & 0,003 & 0,003 & 0,006 \\
\hline $\begin{array}{l}\text { n-alcanos } \\
\text { Totais }\end{array}$ & 0,425 & 0,212 & 0,254 & 0,217 & 0,262 & 0,245 & 0,273 & 0,194 & 0,211 & 0,215 & 0,191 & 0,169 & 0,2943 & 0,216 & 0,200 & 0,200 \\
\hline $\begin{array}{c}\text { Alifáticos } \\
\text { Totais }\end{array}$ & 0,749 & 0,477 & 0,565 & 0,581 & 0,679 & 0,582 & 0,635 & 0,461 & 0,518 & 0,452 & 0,424 & 0,373 & 0,5941 & 0,474 & 0,432 & 0,458 \\
\hline MCNR & $<$ LDM & $<$ LDM & $<$ LDM & $<$ LDM & $<$ LDM & $<$ LDM & $<$ LDM & $<$ LDM & $<$ LDM & $<$ LDM & $<$ LDM & $<$ LDM & $<$ LDM & $<$ LDM & $<$ LDM & $<$ LDM \\
\hline Tetradeceno & 0,165 & 0,177 & 0,194 & 0,194 & 0,189 & 0,165 & 0,207 & 0,198 & 0,206 & 0,192 & 0,172 & 0,156 & 0,214 & 0,201 & 0,202 & 0,208 \\
\hline Hexadeceno & 0,125 & 0,125 & 0,125 & 0,125 & 0,125 & 0,125 & 0,125 & 0,125 & 0,125 & 0,125 & 0,125 & 0,125 & 0,125 & 0,125 & 0,125 & 0,125 \\
\hline Eicoseno & 0,125 & 0,125 & 0,125 & 0,125 & 0,125 & 0,125 & 0,125 & 0,125 & 0,125 & 0,125 & 0,125 & 0,125 & 0,125 & 0,125 & 0,125 & 0,125 \\
\hline $\begin{array}{c}\text { Recuperaçã } \\
\text { o }\end{array}$ & $76 \%$ & $70 \%$ & $65 \%$ & $64 \%$ & $66 \%$ & $76 \%$ & $60 \%$ & $63 \%$ & $61 \%$ & $65 \%$ & $73 \%$ & $80 \%$ & $58 \%$ & $62 \%$ & $62 \%$ & $60 \%$ \\
\hline \multicolumn{17}{|c|}{ PARÂMETROS DE AVALIAÇÃO } \\
\hline IA & 0,582 & 0,588 & 0,597 & 0,581 & 0,571 & 0,551 & 0,574 & 0,558 & 0,564 & 0,555 & 0,552 & 0,557 & 0,5587 & 0,569 & 0,569 & 0,537 \\
\hline Pris/Fit & $<$ LDM & $<$ LDM & $<$ LDM & $<$ LDM & $<$ LDM & $<$ LDM & $<$ LDM & $<$ LDM & $<$ LDM & $<\mathrm{LDM}$ & $<$ LDM & $<$ LDM & 1,3922 & $<\mathrm{LDM}$ & $<$ LDM & $<$ LDM \\
\hline $\begin{array}{c}\text { Pristano/n- } \\
\mathrm{C}_{17}\end{array}$ & $<$ LDM & $<$ LDM & $<$ LDM & $<$ LDM & $<$ LDM & $<$ LDM & $<$ LDM & $<$ LDM & $<$ LDM & $<$ LDM & $<$ LDM & $<$ LDM & 0,4898 & $<\mathrm{LDM}$ & $<\mathrm{LDM}$ & $<$ LDM \\
\hline
\end{tabular}


Tabela V. - Concentrações dos $n$-alcanos, alcanos isoprenóides, MCNR, em $\mu \mathrm{g} \mathrm{g}^{-1}$, e parâmetros de avaliação de fontes de hidrocarbonetos alifáticos.< LDM: abaixo do limite de detecção; Alcanos totais: somatório dos compostos $n$ - $\mathrm{C}_{12}$ ao $n$ - $\mathrm{C}_{35}$; Pris/Fit: razão entre o pristano e o fitano, $\mathrm{I} A=\left(n-\mathrm{C}_{31} / n-\mathrm{C}_{31}+n-\mathrm{C}_{29}\right)$ ao longo do testemunho 262

\begin{tabular}{|c|c|c|c|c|}
\hline & \multicolumn{2}{|c|}{ Profundidade $(\mathrm{cm})$} & \multirow[b]{2}{*}{5} & \multirow[b]{2}{*}{7} \\
\hline & 1 & 3 & & \\
\hline$n-C_{12}$ & 0,009 & 0,010 & 0,006 & 0,007 \\
\hline$n-C_{13}$ & 0,006 & 0,005 & 0,003 & 0,004 \\
\hline$n-C_{14}$ & 0,010 & 0,010 & 0,006 & 0,007 \\
\hline$n-C_{15}$ & 0,006 & 0,006 & $<$ LDM & $<$ LDM \\
\hline$n-C_{16}$ & 0,012 & 0,011 & 0,005 & 0,004 \\
\hline$n-C_{17}$ & 0,008 & 0,007 & $<$ LDM & $<$ LDM \\
\hline$n-C_{18}$ & 0,005 & 0,005 & 0,003 & 0,004 \\
\hline$n-C_{19}$ & 0,005 & 0,004 & $<$ LDM & 0,005 \\
\hline$n-C_{20}$ & 0,009 & 0,008 & $<$ LDM & 0,008 \\
\hline$n-C_{21}$ & $<$ LDM & $<$ LDM & $<$ LDM & $<$ LDM \\
\hline$n-C_{22}$ & 0,012 & 0,009 & 0,012 & 0,007 \\
\hline$n-C_{23}$ & 0,014 & 0,011 & 0,014 & 0,007 \\
\hline$n-C_{24}$ & 0,011 & 0,010 & 0,011 & 0,007 \\
\hline$n-C_{25}$ & $<$ LDM & $<$ LDM & $<$ LDM & $<$ LDM \\
\hline$n-C_{26}$ & 0,018 & 0,017 & 0,017 & 0,015 \\
\hline$n-\mathrm{C}_{27}$ & $<$ LDM & $<$ LDM & $<$ LDM & $<$ LDM \\
\hline$n-\mathrm{C}_{28}$ & $<$ LDM & $<$ LDM & $<$ LDM & $<$ LDM \\
\hline$n-C_{29}$ & $<$ LDM & $<$ LDM & $<$ LDM & $<$ LDM \\
\hline$n-C_{30}$ & $<$ LDM & $<$ LDM & $<$ LDM & $<$ LDM \\
\hline$n-C_{31}$ & 0,035 & 0,038 & 0,069 & $<$ LDM \\
\hline$n-C_{32}$ & $<$ LDM & $<$ LDM & $<$ LDM & $<$ LDM \\
\hline$n-C_{33}$ & 0,029 & 0,026 & 0,022 & 0,014 \\
\hline$n-C_{34}$ & $<$ LDM & $<$ LDM & $<$ LDM & $<$ LDM \\
\hline$n-C_{35}$ & $<$ LDM & $<\mathrm{LDM}$ & $<$ LDM & $<$ LDM \\
\hline
\end{tabular}




\begin{tabular}{|c|c|c|c|c|}
\hline \multicolumn{5}{|c|}{ Profundidade (cm) } \\
\hline & 1 & 3 & 5 & 7 \\
\hline Pristano & $<\mathrm{LDM}$ & $<$ LDM & $<$ LDM & $<$ LDM \\
\hline Fitano & 0,004 & 0,004 & 0,002 & 0,003 \\
\hline n-alcanos Totais & 0,284 & 0,266 & 0,263 & 0,173 \\
\hline Alifáticos Totais & 0,575 & 0,490 & 0,536 & 0,424 \\
\hline MCNR & $<$ LDM & $<$ LDM & $<$ LDM & $<$ LDM \\
\hline Tetradeceno & 0,185 & 0,185 & 0,207 & 0,197 \\
\hline Hexadeceno & 0,125 & 0,125 & 0,125 & 0,125 \\
\hline Eicoseno & 0,125 & 0,125 & 0,125 & 0,125 \\
\hline Recuperação & $68 \%$ & $67 \%$ & $60 \%$ & $63 \%$ \\
\hline \multicolumn{5}{|c|}{ PARÂMETROS DE AVALIAÇÃO } \\
\hline IA & 0,566 & 0,580 & 0,718 & 0,568 \\
\hline Pris/Fit & $<$ LDM & $<$ LDM & $<$ LDM & $<$ LDM \\
\hline Pristano/n- $\mathrm{C}_{17}$ & $<$ LDM & $<$ LDM & $<$ LDM & $<$ LDM \\
\hline
\end{tabular}


Tabela VI. - Concentrações dos $n$-alcanos, alcanos isoprenóides, MCNR, em $\mu \mathrm{g} \mathrm{g}^{-1}$, e parâmetros de avaliação de fontes de hidrocarbonetos alifáticos.< LDM: abaixo do limite de detecção; Alcanos totais: somatório dos compostos $n-\mathrm{C}_{12}$ ao $n$ - $\mathrm{C}_{35}$; Pris/Fit: razão entre o pristano e o fitano, IA= $\underline{\left(n-\mathrm{C}_{31} / n-\mathrm{C}_{31}+n-\mathrm{C}_{29}\right) \text { ao longo do testemunho } 264 .}$

\begin{tabular}{|c|c|c|c|c|c|c|c|c|c|c|c|c|}
\hline \multicolumn{13}{|c|}{ Profundidade $(\mathrm{cm})$} \\
\hline & 1 & 2 & 4 & 6 & 8 & 10 & 12 & 14 & 16 & 18 & 20 & 22 \\
\hline$n-C_{12}$ & 0,003 & 0,009 & 0,003 & 0,006 & 0,011 & 0,010 & 0,007 & 0,009 & 0,046 & 0,047 & 0,024 & 0,027 \\
\hline$n-C_{13}$ & 0,003 & 0,005 & 0,002 & 0,004 & 0,006 & 0,007 & 0,005 & 0,008 & 0,007 & 0,017 & 0,010 & 0,010 \\
\hline$n-C_{14}$ & 0,005 & 0,010 & 0,005 & 0,007 & 0,010 & 0,011 & 0,006 & 0,013 & 0,042 & 0,041 & 0,021 & 0,024 \\
\hline$n-C_{15}$ & 0,004 & 0,005 & 0,004 & 0,005 & 0,011 & 0,014 & 0,006 & 0,013 & 0,012 & 0,016 & 0,012 & 0,012 \\
\hline$n-C_{16}$ & 0,004 & 0,007 & 0,007 & 0,006 & 0,006 & 0,009 & 0,006 & 0,013 & 0,017 & 0,019 & 0,012 & 0,014 \\
\hline$n-C_{17}$ & $<$ LDM & 0,005 & 0,006 & 0,006 & 0,008 & 0,010 & 0,008 & 0,016 & 0,015 & 0,018 & 0,015 & 0,017 \\
\hline$n-C_{18}$ & 0,003 & 0,005 & 0,005 & 0,006 & 0,006 & 0,009 & 0,007 & 0,013 & 0,011 & 0,019 & 0,012 & 0,016 \\
\hline$n-C_{19}$ & $<$ LDM & $<$ LDM & $<$ LDM & $<$ LDM & $<$ LDM & 0,011 & 0,008 & 0,010 & 0,010 & 0,024 & 0,014 & 0,017 \\
\hline$n-C_{20}$ & $<\mathrm{LDM}$ & $<\mathrm{LDM}$ & $<\mathrm{LDM}$ & $<$ LDM & $<$ LDM & 0,012 & 0,008 & 0,011 & 0,011 & 0,021 & 0,014 & 0,017 \\
\hline$n-C_{21}$ & $<$ LDM & $<$ LDM & $<$ LDM & $<$ LDM & $<$ LDM & $<$ LDM & $<$ LDM & 0,014 & 0,016 & 0,016 & 0,015 & 0,020 \\
\hline$n-C_{22}$ & 0,013 & 0,014 & 0,016 & 0,016 & 0,012 & 0,009 & 0,012 & 0,020 & 0,038 & 0,023 & 0,027 & 0,033 \\
\hline$n-C_{23}$ & 0,016 & 0,019 & 0,021 & 0,019 & 0,014 & 0,010 & 0,015 & 0,024 & 0,067 & 0,033 & 0,041 & 0,048 \\
\hline$n-C_{24}$ & 0,016 & 0,015 & 0,020 & 0,017 & 0,015 & 0,010 & 0,014 & 0,022 & 0,058 & 0,029 & 0,034 & 0,042 \\
\hline$n-C_{25}$ & $<$ LDM & $<$ LDM & $<$ LDM & $<$ LDM & $<$ LDM & $<$ LDM & $<$ LDM & $<$ LDM & 0,038 & $<$ LDM & $<$ LDM & 0,030 \\
\hline$n-C_{26}$ & 0,008 & $<$ LDM & 0,023 & 0,009 & 0,010 & 0,007 & 0,023 & 0,017 & 0,017 & 0,011 & 0,013 & 0,014 \\
\hline$n-C_{27}$ & $<$ LDM & $<$ LDM & $<$ LDM & $<$ LDM & $<$ LDM & $<$ LDM & $<$ LDM & $<$ LDM & $<$ LDM & $<$ LDM & $<$ LDM & $<$ LDM \\
\hline$n-C_{28}$ & $<\mathrm{LDM}$ & $<$ LDM & $<\mathrm{LDM}$ & $<$ LDM & $<$ LDM & $<$ LDM & $<$ LDM & $<$ LDM & $<$ LDM & $<$ LDM & $<$ LDM & $<$ LDM \\
\hline$n-C_{29}$ & 0,040 & $<$ LDM & 0,036 & 0,031 & 0,035 & 0,031 & 0,039 & 0,058 & 0,062 & 0,041 & 0,039 & 0,058 \\
\hline$n-C_{30}$ & $<$ LDM & $<$ LDM & $<\mathrm{LDM}$ & $<$ LDM & $<$ LDM & $<$ LDM & $<$ LDM & $<$ LDM & $<$ LDM & $<$ LDM & $<$ LDM & $<$ LDM \\
\hline$n-C_{31}$ & 0,057 & 0,037 & 0,047 & 0,094 & 0,045 & 0,041 & 0,056 & 0,091 & 0,098 & 0,063 & 0,057 & 0,077 \\
\hline$n-C_{32}$ & $<\mathrm{LDM}$ & $<\mathrm{LDM}$ & $<\mathrm{LDM}$ & $<$ LDM & $<$ LDM & $<$ LDM & $<$ LDM & $<$ LDM & $<$ LDM & $<$ LDM & $<\mathrm{LDM}$ & $<$ LDM \\
\hline$n-C_{33}$ & 0,042 & 0,032 & 0,028 & 0,026 & 0,026 & 0,027 & 0,035 & 0,058 & 0,060 & 0,043 & 0,039 & 0,048 \\
\hline$n-C_{34}$ & $<\mathrm{LDM}$ & $<$ LDM & $<\mathrm{LDM}$ & $<$ LDM & $<$ LDM & $<$ LDM & $<$ LDM & $<$ LDM & $<$ LDM & $<$ LDM & $<$ LDM & $<$ LDM \\
\hline$n-C_{35}$ & 0,016 & $<$ LDM & 0,012 & $<$ LDM & $<$ LDM & $<$ LDM & $<$ LDM & 0,015 & 0,013 & $<$ LDM & $<$ LDM & $<$ LDM \\
\hline
\end{tabular}


Tabela VI (Continuação) - Concentrações dos $n$-alcanos, alcanos isoprenóides, MCNR, em $\mu$ g g ${ }^{-1}$, e parâmetros de avaliação de fontes de hidrocarbonetos alifáticos. <LDM: abaixo do limite de detecção; Alcanos totais: somatório dos compostos $n$ - $\mathrm{C}_{12}$ ao $n$ - $\mathrm{C}_{35}$; Pris/Fit: razão entre o pristano e o fitano, $\mathrm{IA}=\left(n-\mathrm{C}_{31} / n-\mathrm{C}_{31}+n-\mathrm{C}_{29}\right)$ ao longo do testemunho 264

\begin{tabular}{|c|c|c|c|c|c|c|c|c|c|c|c|c|}
\hline \multicolumn{13}{|c|}{ Profundidade (cm) } \\
\hline & 1 & 2 & 4 & 6 & 8 & 10 & 12 & 14 & 16 & 18 & 20 & 22 \\
\hline Pristano & $<$ LDM & $<$ LDM & $<$ LDM & $<$ LDM & $<$ LDM & $<$ LDM & $<\mathrm{LDM}$ & 0,008 & $<$ LDM & 0,009 & $<$ LDM & 0,009 \\
\hline Fitano & $<\mathrm{LDM}$ & 0,003 & 0,003 & 0,003 & $<$ LDM & 0,004 & 0,003 & 0,005 & 0,002 & 0,009 & 0,003 & 0,008 \\
\hline $\begin{array}{c}\text { n-alcanos } \\
\text { Totais }\end{array}$ & 0,330 & 0,271 & 0,325 & 0,334 & 0,297 & 0,292 & 0,330 & 0,536 & 0,709 & 0,566 & 0,490 & 0,612 \\
\hline $\begin{array}{l}\text { Alifáticos } \\
\text { Totais }\end{array}$ & 0,715 & 0,560 & 0,861 & 0,629 & 0,590 & 0,560 & 0,664 & 0,951 & 1,078 & 0,936 & 0,789 & 0,983 \\
\hline MCNR & $<$ LDM & $<$ LDM & $<$ LDM & $<$ LDM & $<$ LDM & $<$ LDM & $<$ LDM & $<$ LDM & $<$ LDM & $<$ LDM & $<$ LDM & $<$ LDM \\
\hline Tetradeceno & 0,188 & 0,187 & 0,322 & 0,167 & 0,186 & 0,183 & 0,197 & 0,188 & 0,179 & 0,192 & 0,162 & 0,191 \\
\hline Hexadeceno & 0,125 & 0,125 & 0,125 & 0,125 & 0,125 & 0,125 & 0,125 & 0,125 & 0,125 & 0,125 & 0,125 & 0,125 \\
\hline Eicoseno & 0,125 & 0,125 & 0,125 & 0,125 & 0,125 & 0,125 & 0,125 & 0,125 & 0,125 & 0,125 & 0,125 & 0,125 \\
\hline $\begin{array}{c}\text { Recuperaçã } \\
0\end{array}$ & $66 \%$ & $67 \%$ & $39 \%$ & $75 \%$ & $67 \%$ & $68 \%$ & $63 \%$ & $66 \%$ & $70 \%$ & $65 \%$ & $77 \%$ & $66 \%$ \\
\hline \multicolumn{13}{|c|}{ PARÂMETROS DE AVALIAÇÃO } \\
\hline IA & 0,587 & 0,583 & 0,569 & 0,752 & 0,564 & 0,573 & 0,589 & 0,611 & 0,614 & 0,602 & 0,595 & 0,572 \\
\hline $\begin{array}{c}\text { Pris/Fit } \\
\text { Pristano/n- }\end{array}$ & $<$ LDM & $<$ LDM & $<$ LDM & $<$ LDM & $<$ LDM & $<$ LDM & $<$ LDM & 1,437 & $<$ LDM & 1,028 & $<$ LDM & 1,046 \\
\hline $\mathrm{C}_{17}$ & $<$ LDM & $<$ LDM & $<$ LDM & $<$ LDM & $<$ LDM & $<$ LDM & $<$ LDM & 0,481 & $<$ LDM & 0,500 & $<$ LDM & 0,515 \\
\hline
\end{tabular}


Tabela VII. - Concentrações dos esteróis analisados em $\left(\mu \mathrm{g} \mathrm{g}^{-1}\right)$ e parâmetro de avaliação da origem e transformação da matéria orgânica. <LDM: abaixo do limite de detecção, ao longo do testemunho 253.

\begin{tabular}{|c|c|c|c|c|c|c|c|c|c|c|c|c|c|c|c|c|c|}
\hline \multicolumn{18}{|c|}{ Profundidade $(\mathrm{cm})$} \\
\hline & 1 & 2 & 4 & 6 & 8 & 10 & 12 & 14 & 16 & 18 & 20 & 22 & 24 & 26 & 28 & 30 & 32 \\
\hline Colesterol & 0,09 & & 0,098 & 0,053 & 0,062 & 0,055 & 0,062 &, 080 & 0,056 & 0,073 & 0,096 & 0,069 & 0,075 & 0,089 & 0,075 & 0,051 & 0,077 \\
\hline Colestanol & _DM & LDM & $<\mathrm{LDM}$ & $<\mathrm{LDM}$ & $<$ LDM & $<$ LDM & $<$ LDM & $<$ LDM & $<$ LDM & $<$ LDM & $<$ LDM & $<$ LDM & $<$ LDM & $<\mathrm{LDM}$ & $<\mathrm{LDM}$ & $<\mathrm{LDM}$ & $<$ LDM \\
\hline Braassicasterol & 0,05 & 0,065 & 0,078 & 0,086 & 0,059 & 0,047 & 0,063 & 099 & 0,061 & 0,043 & 0,058 & & 0,066 & & 0,076 &, 062 &, 062 \\
\hline Brassicastanol & $<$ LDM & $<$ LDM & $<$ LDM & $<$ LDM & $<$ LDM & $<$ LDM & $<$ LDM & $<$ LDM & $<$ LDM & $<$ LDM & $<$ LDM & $<$ LDM & $<$ LDM & $<$ LDM & $<$ LDM & $<$ LDM & $<$ LDM \\
\hline Campesterol & 0,09 & 0,086 & 0,080 & 0,061 & 0,074 & 0,078 & 0,069 & 0,085 & 0,064 & 0,074 & 0,042 & 0,063 & 0,073 & 0,083 & 0,062 & 0,041 & 0,058 \\
\hline Campestanol & $<$ LDM & $<$ LDM & $<$ LDM & $<$ LDM & $<$ LDM & $<$ LDM & $<$ LDM & $<$ LDM & $<$ LDM & $<$ LDM & $<$ LDM & $<$ LDM & $<$ LDM & $<$ LDM & $<$ LDM & $<$ LDM & $<$ LDM \\
\hline Estigmasterol & & & 0,087 & 0,072 & 0,093 & 0,069 & 0,071 & 0,097 & 0,067 & 0,043 & 0,054 & 0,044 & 0,057 & 0,043 & & 0,049 & 0,071 \\
\hline Estigmastanol & LDM & LDM & $<$ LDM & $<$ LDM & $<$ LDM & $<$ LDM & $<$ LDM & $<$ LDM & $<$ LDM & $<$ LDM & $<$ LDM & $<$ LDM & $<$ LDM & $<\mathrm{LDM}$ & $<\mathrm{LDM}$ & $<$ LDM & $<$ LDM \\
\hline B-sitosterol & 0,16 & 0,126 & 0,195 & 0,147 & 0,154 & 0,129 & 0,132 & 0,129 & 0,154 & 0,127 & 0,153 & 0,139 & 0,157 & 0,125 & 0,104 & 0,138 & 0,154 \\
\hline B-sitostanol & $<$ LDM & $<$ LDM & $<$ LDM & $<$ LDM & $<$ LDM & $<$ LDM & $<$ LDM & $<$ LDM & $<$ LDM & $<$ LDM & $<$ LDM & $<$ LDM & $<$ LDM & $<$ LDM & $<$ LDM & $<$ LDM & $<$ LDM \\
\hline Esteróis Totais & 1,09 & 0,593 & 0,697 & 0,505 & 0,690 & 0,458 & 0,472 & 0670 & 0,638 & 0,545 & 0,674 & 0,634 & 0,682 & 0,533 & & 0,434 & 0,563 \\
\hline Androstanol & 0,125 & 0,125 & 0,125 & 0,125 & 0,125 & 0,125 & 0,125 & 0,125 & 0,125 & 0,125 & 0,125 & 0,125 & 0,125 & 0,125 & 0,125 & 0,125 & 0,125 \\
\hline 5a-colestano & 0,197 & 0,171 & 0,151 & 0,148 & 0,153 & 0,147 & 0,166 & 0,163 & 0,171 & 0,144 & 0,159 & 0,141 & 0,152 & 0,163 & 0,152 & 0,167 & 0,148 \\
\hline Recuperação & $63 \%$ & $73 \%$ & $83 \%$ & $84 \%$ & $82 \%$ & $85 \%$ & $75 \%$ & $77 \%$ & $73 \%$ & $87 \%$ & $79 \%$ & $89 \%$ & $82 \%$ & $77 \%$ & $82 \%$ & $75 \%$ & $85 \%$ \\
\hline \multicolumn{18}{|c|}{ PARÂMETRO DE AVALIAÇÃO } \\
\hline & 0,563 & 0,609 & 0,502 & 0,362 & 0,405 & 0,424 & 0,470 & 0,622 & 0,364 & 0,575 & 0,627 & 0,496 & 0,478 & 0,712 & 0,719 & 0,370 & 0,500 \\
\hline
\end{tabular}


Tabela VIII. - Concentrações dos esteróis analisados em $\left(\mu \mathrm{g} \mathrm{g}^{-1}\right)$ e parâmetro de avaliação da origem e transformação da matéria orgânica. <LDM: abaixo do limite de detecção, ao longo do testemunho 254.

\begin{tabular}{|c|c|c|c|c|c|c|c|c|c|c|c|}
\hline \multicolumn{12}{|c|}{ Profundidade $(\mathrm{cm})$} \\
\hline & 1 & 2 & 4 & 6 & 8 & 10 & 12 & 14 & 16 & 18 & 20 \\
\hline Colesterol & 0,08 & 0,094 & 0,073 & 0,087 & 0,071 & 0,044 & 0,057 & 0,085 & 0,077 & 0,065 & 0,081 \\
\hline Colestanol & $<$ LDM & $<$ LDM & $<$ LDM & $<$ LDM & $<$ LDM & $<$ LDM & $<$ LDM & $<$ LDM & $<$ LDM & $<$ LDM & $<$ LDM \\
\hline Braassicasterol & 0,02 & 0,068 & 0,059 & 0,075 & 0,056 & 0,048 & 0,069 & 0,076 & 0,061 & 0,088 & 0,074 \\
\hline Brassicastanol & $<$ LDM & $<$ LDM & $<$ LDM & $<$ LDM & $<$ LDM & $<$ LDM & $<$ LDM & $<$ LDM & $<$ LDM & $<$ LDM & $<$ LDM \\
\hline Campesterol & 0,09 & 0,072 & 0,063 & 0,096 & 0,097 & 0,082 & 0,042 & $<$ LDM & 0,049 & 0,058 & 0,043 \\
\hline Campestanol & $<$ LDM & $<$ LDM & $<$ LDM & $<$ LDM & $<$ LDM & $<$ LDM & $<$ LDM & $<$ LDM & $<$ LDM & $<$ LDM & $<$ LDM \\
\hline Estigmasterol & 0,1 & 0,109 & 0,116 & 0,156 & 0,145 & 0,134 & 0,117 & 0,155 & 0,124 & 0,167 & 0,174 \\
\hline Estigmastanol & $<$ LDM & $<$ LDM & $<$ LDM & $<$ LDM & $<$ LDM & $<$ LDM & $<$ LDM & $<$ LDM & $<$ LDM & $<$ LDM & $<$ LDM \\
\hline B-sitosterol & 0,59 & 0,432 & 0,536 & 0,405 & 0,569 & 0,335 & 0,326 & 0,214 & 0,238 & 0,247 & 0,364 \\
\hline B-sitostanol & $<$ LDM & $<$ LDM & $<$ LDM & $<$ LDM & $<$ LDM & $<$ LDM & $<$ LDM & $<$ LDM & $<$ LDM & $<$ LDM & $<$ LDM \\
\hline Esteróis Totais & 1,652 & 0,888 & 0,844 & 0,874 & 0,939 & 0,712 & 0,623 & 0,651 & 0,662 & 0,787 & 0,827 \\
\hline Androstanol & 0,250 & 0,250 & 0,250 & 0,250 & 0,250 & 0,250 & 0,250 & 0,250 & 0,250 & 0,250 & 0,250 \\
\hline 5a-colestano & 0,323 & 0,325 & 0,312 & 0,313 & 0,318 & 0,316 & 0,323 & 0,314 & 0,325 & 0,324 & 0,303 \\
\hline Recuperação & $77 \%$ & $77 \%$ & $80 \%$ & $80 \%$ & $79 \%$ & $79 \%$ & $77 \%$ & $80 \%$ & $77 \%$ & $77 \%$ & $83 \%$ \\
\hline \multicolumn{12}{|c|}{ PARÂMETRO DE AVALIAÇÃO } \\
\hline $\begin{array}{l}\text { colesterol/ } \beta- \\
\text { sitosterol }\end{array}$ & 0,136 & 0,218 & & 0,215 & 0,125 & 0,131 & 0,175 & 0,397 & 0,324 & 0,263 & 0,223 \\
\hline
\end{tabular}


Tabela VIII (Continuação) - Concentrações dos esteróis analisados em ( $\left.\mu \mathrm{g} \mathrm{g}{ }^{-1}\right)$ e parâmetro de avaliação da origem e transformação da matéria orgânica. <LDM: abaixo do limite de detecção, ao longo do testemunho 254.

\begin{tabular}{|c|c|c|c|c|c|c|c|c|c|c|}
\hline \multicolumn{11}{|c|}{ Profundidade $(\mathrm{cm})$} \\
\hline & 22 & 24 & 26 & 28 & 30 & 32 & 34 & 36 & 38 & 40 \\
\hline Colesterol & 0,043 & 0,052 & 0,086 & 0,059 & 0,067 & 0,051 & 0,087 & 0,069 & 0,096 & 0,062 \\
\hline Colestanol & $<$ LDM & $<$ LDM & $<$ LDM & $<$ LDM & $<$ LDM & $<$ LDM & $<$ LDM & $<$ LDM & $<$ LDM & $<$ LDM \\
\hline Braassicasterol & 0,072 & 0,089 & 0,082 & 0,097 & 0,076 & 0,067 & 0,091 & 0,063 & 0,054 & 0,091 \\
\hline Brassicastanol & $<$ LDM & $<$ LDM & $<$ LDM & $<$ LDM & $<$ LDM & $<$ LDM & $<$ LDM & $<$ LDM & $<$ LDM & $<$ LDM \\
\hline Campesterol & $<$ LDM & 0,053 & $<$ LDM & $<$ LDM & 0,059 & 0,073 & 0,087 & 0,052 & 0,042 & 0,064 \\
\hline Campestanol & $<$ LDM & $<$ LDM & $<$ LDM & $<$ LDM & $<$ LDM & $<$ LDM & $<$ LDM & $<$ LDM & $<$ LDM & $<$ LDM \\
\hline Estigmasterol & 0,137 & 0,115 & 0,137 & 0,153 & 0,187 & 0,120 & 0,153 & 0,118 & 0,139 & 0,173 \\
\hline Estigmastanol & $<$ LDM & $<$ LDM & $<$ LDM & $<$ LDM & $<$ LDM & $<$ LDM & $<$ LDM & $<$ LDM & $<$ LDM & $<$ LDM \\
\hline B-sitosterol & 0,261 & 0,323 & 0,334 & 0,264 & 0,287 & 0,379 & 0,416 & 0,263 & 0,134 & 0,227 \\
\hline B-sitostanol & $<$ LDM & $<$ LDM & $<$ LDM & $<$ LDM & $<$ LDM & $<$ LDM & $<$ LDM & $<$ LDM & $<$ LDM & $<$ LDM \\
\hline Esteróis Totais & 0,731 & 0,698 & 0,687 & 0,623 & 0,704 & 0,782 & 0,805 & 0,573 & 0,559 & 0,602 \\
\hline Androstanol & 0,250 & 0,250 & 0,250 & 0,250 & 0,250 & 0,250 & 0,250 & 0,250 & 0,250 & 0,250 \\
\hline 5a-colestano & 0,323 & 0,353 & 0,347 & 0,311 & 0,317 & 0,313 & 0,312 & 0,341 & 0,369 & 0,346 \\
\hline Recuperação & $77 \%$ & $71 \%$ & $72 \%$ & $80 \%$ & $79 \%$ & $80 \%$ & $80 \%$ & $73 \%$ & $68 \%$ & $72 \%$ \\
\hline \multicolumn{11}{|c|}{ PARÂMETRO DE AVALIAÇÃO } \\
\hline $\begin{array}{c}\text { colesterol/ } \beta- \\
\text { sitosterol }\end{array}$ & 0,165 & 0,161 & 0,257 & 0,223 & 0,233 & 0,135 & 0,209 & 0,262 & 0,716 & 0,273 \\
\hline
\end{tabular}


Tabela IX. - Concentrações dos esteróis analisados em $\left(\mu \mathrm{g} \mathrm{g}^{-1}\right)$ e parâmetro de avaliação da origem e transformação da matéria orgânica. <LDM: abaixo do limite de detecção, ao longo do testemunho 256.

\begin{tabular}{|c|c|c|c|c|c|c|c|c|c|c|c|c|c|c|c|c|c|}
\hline \multicolumn{18}{|c|}{ Protunalaaae (cm) } \\
\hline & 1 & 2 & 4 & 6 & 8 & 10 & 12 & 14 & 16 & 18 & 20 & 22 & 24 & 26 & 28 & 30 & 32 \\
\hline $\begin{array}{l}\text { Colesterol } \\
\text { Colestanol }\end{array}$ & $\begin{array}{c}0,07 \\
<\text { LDM }\end{array}$ & $\begin{array}{l}087 \\
\text { LDM }\end{array}$ & $\begin{array}{r}0,058 \\
<\text { LDM }\end{array}$ & $\begin{array}{r}0,095 \\
<\text { LDM }\end{array}$ & $\begin{array}{l}0,047 \\
<\text { LDM }\end{array}$ & & $\begin{array}{r}0,042 \\
<\text { LDM }\end{array}$ & & $\begin{array}{r}0,084 \\
<\text { LDM }\end{array}$ & & & & & & & & $\begin{array}{r}0,094 \\
<\text { LDM }\end{array}$ \\
\hline $\begin{array}{l}\text { Braassicasterol } \\
\text { Brassicastanol }\end{array}$ & $\begin{array}{l}<\text { LDM } \\
<\text { LDM }\end{array}$ & $\begin{array}{l}, 078 \\
\text { LDM }\end{array}$ & & & & & & & & & & & & & & & \\
\hline & & & & & & & & & & & & & & & & & \\
\hline $\begin{array}{l}\text { Estigm } \\
\text { Estigm }\end{array}$ & & & & & & & & & & & & & & & & & \\
\hline & $\begin{aligned} & 0,2 \\
< & \text { LDM }\end{aligned}$ & & & & & & & & & & & & & & & & \\
\hline Esterói & & 0,962 & & 0,689 & 0,524 & 0,638 & 0,459 & & & & & & & & & & 71 \\
\hline & & & & & & & & & & & & & & & & & \\
\hline $\begin{array}{l}\text { 5a-colestano } \\
\text { Recuperação }\end{array}$ & & $\begin{array}{r}0,148 \\
84 \% \\
\end{array}$ & $82 \%$ & & & $\frac{0,156}{80 \%}$ & $\frac{0,146}{86 \%}$ & $85 \%$ & $93 \%$ & & & & & & & & $38 \%$ \\
\hline \multicolumn{18}{|c|}{ PARÂMETRO DE AVALIAÇÃO } \\
\hline & 0,350 & 0,375 & 0,301 & 0,389 & 0,343 & 0,274 & 0,207 & 0,371 & 0,571 & 0,523 & 0,431 & 0,612 & 0,490 & 0,477 & 0,393 & 0,419 & 0,895 \\
\hline
\end{tabular}


Tabela X. - Concentrações dos esteróis analisados em $\left(\mu \mathrm{g} \mathrm{g}^{-1}\right)$ e parâmetro de avaliação da origem e transformação da matéria orgânica. <LDM: abaixo do limite de detecção, ao longo do testemunho 257.

\begin{tabular}{|c|c|c|c|c|c|c|c|c|c|c|c|c|c|c|c|c|}
\hline \multicolumn{17}{|c|}{ Profundidade (cm) } \\
\hline & 1 & 2 & 4 & 6 & 8 & 10 & 12 & 14 & 16 & 18 & 20 & 22 & 24 & 26 & 28 & 30 \\
\hline Colesterol & 0,04 & 0,057 & 0,048 & 0,072 & 0,075 & 0,067 & 0,086 & 0,053 & 0,042 & 0,069 & 0,097 & 0,063 & 0,052 & 0,078 & 0,093 & 0,074 \\
\hline Colestanol & 0,03 & $<$ LDM & $<$ LDM & $<$ LDM & $<$ LDM & $<$ LDM & $<$ LDM & & & & $<$ LDM & & & & & $<$ LDM \\
\hline Braassicasterol & 0,02 & 0,049 & 0,062 & 0,056 & & & & & & & & & & & & \\
\hline Brassicastanol & $<$ LDM & $<$ LDM & $<$ LDM & $<$ LDM & $<$ LDM & $<$ LDM & $<$ LDM & $<$ LDM & $<$ LDM & $<$ LDM & $<$ LDM & $<$ LDM & & $<$ LDM & $<L$ & $<$ LDM \\
\hline Campesterol & 0,15 & 0,134 & 0,103 & 0,102 & 0,091 & 0,065 & 0,097 & 0,076 & 0,051 & & 0,063 & & & & & \\
\hline Campestanol & $<$ LDM & $<$ LDM & $<$ LDM & $<$ LDM & $<$ LDM & $<$ LDM & $<$ LDM & $<$ LDM & $<$ LDM & & & & & & & $<$ LDM \\
\hline Estigmasterol & 0,18 & 0,233 & 0,151 & 0,133 & 0,152 & 0,138 & 0,147 & 0,122 & 0,094 & 0,127 & & & & & & \\
\hline Estigmastanol & $<\mathrm{LDM}$ & $<$ LDM & $<$ LDM & $<$ LDM & $<$ LDM & $<$ LDM & $<$ LDM & $<$ LDM & $<$ LDM & $<$ LDM & $<$ LDM & & & & & $<$ LDM \\
\hline B-sitosterol & 0,52 & 0,504 & 0,472 & 0,437 & 0,421 & 0,371 & 0,492 & 0,358 & 0,246 & 0,287 & 0,264 & 0,157 & 0,132 & 0,203 & 0,241 & 0,264 \\
\hline B-sitostanol & $<$ LDM & $<$ LDM & $<$ LDM & $<$ LDM & $<$ LDM & $<$ LDM & $<$ LDM & $<$ LDM & $<$ LDM & $<$ LDM & $<$ LDM & $<$ LDM & $<$ LDM & $<$ LDM & $<$ LDM & $<$ LDM \\
\hline Esteróis Totais & 1,592 & 1,373 & 0,843 & 0,828 & 0,806 & 0,734 & 0,846 & 0,628 & 0,697 & 0,695 & 0,762 & 0,642 & 0,547 & 0,628 & 0,663 & 0,714 \\
\hline Androstanol & 0,125 & 0,125 & 0,125 & 0,125 & 0,125 & 0,125 & 0,125 & 0,125 & 0,125 & 0,125 & 0,125 & 0,125 & & 0,125 & & 0,125 \\
\hline $5 a-c o$ & 0,163 & 0,148 & 0,164 & 0,146 & 0,151 & 0,177 & 0,142 & 0,174 & 0,173 & 0,167 & 0,183 & 0,174 & 0,170 & 0,153 & 0,192 & 0,141 \\
\hline Recuperação & $77 \%$ & $85 \%$ & $76 \%$ & $86 \%$ & $83 \%$ & $71 \%$ & $88 \%$ & $72 \%$ & $72 \%$ & $75 \%$ & $68 \%$ & $72 \%$ & $73 \%$ & $82 \%$ & $65 \%$ & $88 \%$ \\
\hline \multicolumn{17}{|c|}{ PARÂMETRO DE AVALIAÇÃO } \\
\hline $\begin{array}{c}\text { colesterol/ } \beta- \\
\text { sitosterol }\end{array}$ & 0,077 & 0,113 & 0,102 & 0,165 & 0,178 & 0,181 & 0,175 & 0,148 & 0,171 & 0,240 & 0,367 & 0,401 & 0,394 & 0,384 & 0,386 & 0,280 \\
\hline
\end{tabular}


Tabela XI. - Concentrações dos esteróis analisados em $\left(\mu \mathrm{g} \mathrm{g}{ }^{-1}\right)$ e parâmetro de avaliação da origem e transformação da matéria orgânica. <LDM: abaixo do limite de detecção, ao longo do testemunho 262.

\begin{tabular}{|c|c|c|c|c|}
\hline \multicolumn{5}{|c|}{ Profundidade (cm) } \\
\hline & 1 & 3 & 5 & 7 \\
\hline Colesterol & 0,09 & 0,083 & 0,094 & 0,097 \\
\hline Colestanol & 0,02 & $<$ LDM & $<$ LDM & $<$ LDM \\
\hline Braassicasterol & $<$ LDM & 0,056 & 0,042 & 0,053 \\
\hline Brassicastanol & $<$ LDM & $<$ LDM & $<$ LDM & $<$ LDM \\
\hline Campesterol & 0,09 & 0,087 & 0,063 & 0,085 \\
\hline Campestanol & $<$ LDM & $<$ LDM & $<$ LDM & $<$ LDM \\
\hline Estigmasterol & 0,07 & 0,092 & 0,047 & 0,094 \\
\hline Estigmastanol & $<$ LDM & $<$ LDM & $<$ LDM & $<$ LDM \\
\hline B-sitosterol & 0,12 & 0,096 & 0,084 & 0,098 \\
\hline B-sitostanol & $<$ LDM & $<$ LDM & $<$ LDM & $<$ LDM \\
\hline Esteróis Totais & 0,87 & 0,675 & 0,484 & 0,559 \\
\hline Androstanol & 0,125 & 0,125 & 0,125 & 0,125 \\
\hline 5a-colestano & 0,161 & 0,145 & 0,157 & 0,181 \\
\hline Recuperação & 0,778 & 0,863 & 0,798 & 0,692 \\
\hline \multicolumn{5}{|c|}{ PARÂMETRO DE AVALIAÇÃO } \\
\hline $\begin{array}{c}\text { colesterol/ } \beta- \\
\text { sitosterol }\end{array}$ & 0,750 & 0,865 & 1,119 & 0,990 \\
\hline
\end{tabular}


Tabela XII. - Concentrações dos esteróis analisados em $\left(\mu \mathrm{g} \mathrm{g}^{-1}\right)$ e parâmetro de avaliação da origem e transformação da matéria orgânica. <LDM: abaixo do limite de detecção, ao longo do testemunho 264.

\begin{tabular}{|c|c|c|c|c|c|c|c|c|c|c|c|c|}
\hline \multicolumn{13}{|c|}{ Profundidade (cm) } \\
\hline & 1 & 2 & 4 & 6 & 8 & 10 & 12 & 14 & 16 & 18 & 20 & 22 \\
\hline $\begin{array}{l}\text { Colesterol } \\
\text { Colestanol }\end{array}$ & $\begin{array}{c}0,09 \\
<\text { LDM }\end{array}$ & $\begin{array}{l}0,084 \\
<\text { LDM }\end{array}$ & $\begin{array}{l}0,083 \\
<\text { LDM }\end{array}$ & $\begin{array}{l}0,046 \\
<\text { LDM }\end{array}$ & $\begin{array}{l}0,067 \\
<\text { LDM }\end{array}$ & $\begin{array}{l}0,056 \\
<\text { LDM }\end{array}$ & $\begin{array}{l}0,096 \\
<\text { LDM }\end{array}$ & $\begin{array}{l}0,082 \\
<\text { LDM }\end{array}$ & $\begin{array}{l}0,071 \\
<\text { LDM }\end{array}$ & $\begin{array}{l}0,052 \\
<\text { LDM }\end{array}$ & $\begin{array}{l}0,041 \\
<\text { LDM }\end{array}$ & $\begin{array}{l}0,058 \\
<\text { LDM }\end{array}$ \\
\hline $\begin{array}{l}\text { Braassicasterol } \\
\text { Brassicastanol }\end{array}$ & $\begin{array}{l}<\text { LDM } \\
<\text { LDM }\end{array}$ & $\begin{array}{l}0,067 \\
<\text { LDM }\end{array}$ & $\begin{array}{l}0,051 \\
<\text { LDM }\end{array}$ & $\begin{array}{l}0,041 \\
<\text { LDM }\end{array}$ & $\begin{array}{l}0,052 \\
<\text { LDM }\end{array}$ & $\begin{array}{l}0,064 \\
<\text { LDM }\end{array}$ & $\begin{array}{l}0,088 \\
<\text { LDM }\end{array}$ & $\begin{array}{l}0,047 \\
<\text { LDM }\end{array}$ & $\begin{array}{l}0,064 \\
<\text { LDM }\end{array}$ & $\begin{array}{l}0,051 \\
<\text { LDM }\end{array}$ & $\begin{array}{l}0,052 \\
<\text { LDM }\end{array}$ & $\begin{array}{l}0,047 \\
<\text { LDM }\end{array}$ \\
\hline $\begin{array}{l}\text { Campesterol } \\
\text { Campestanol }\end{array}$ & $\begin{array}{l}<\text { LDM } \\
<\text { LDM }\end{array}$ & $\begin{array}{l}0,053 \\
<\text { LDM }\end{array}$ & $\begin{array}{l}0,063 \\
<\text { LDM }\end{array}$ & $\begin{array}{l}0,058 \\
<\text { LDM }\end{array}$ & $\begin{array}{l}0,061 \\
<\text { LDM }\end{array}$ & $\begin{array}{l}0,047 \\
<\text { LDM }\end{array}$ & $\begin{array}{l}0,038 \\
<\text { LDM }\end{array}$ & $\begin{array}{l}0,043 \\
<\text { LDM }\end{array}$ & $\begin{array}{l}0,052 \\
<\text { LDM }\end{array}$ & $\begin{array}{l}0,063 \\
<\text { LDM }\end{array}$ & $\begin{array}{l}0,057 \\
<\text { LDM }\end{array}$ & $\begin{array}{l}0,063 \\
<\text { LDM }\end{array}$ \\
\hline $\begin{array}{l}\text { Estigmasterol } \\
\text { Estigmastanol }\end{array}$ & $\begin{array}{c}0,07 \\
<\text { LDM }\end{array}$ & $\begin{array}{l}0,098 \\
<\text { LDM }\end{array}$ & $\begin{array}{l}0,068 \\
<\text { LDM }\end{array}$ & $\begin{array}{l}0,057 \\
<\text { LDM }\end{array}$ & $\begin{array}{l}0,046 \\
<\text { LDM }\end{array}$ & $\begin{array}{l}0,063 \\
<\text { LDM }\end{array}$ & $\begin{array}{l}0,057 \\
<\text { LDM }\end{array}$ & $\begin{array}{l}0,063 \\
<\text { LDM }\end{array}$ & $\begin{array}{l}0,043 \\
<\text { LDM }\end{array}$ & $\begin{array}{l}0,067 \\
<\text { LDM }\end{array}$ & $\begin{array}{l}0,078 \\
<\text { LDM }\end{array}$ & $\begin{array}{l}0,054 \\
<\text { LDM }\end{array}$ \\
\hline $\begin{array}{l}\text { B-sitosterol } \\
\text { B-sitostanol }\end{array}$ & $\begin{array}{l}0,09 \\
0,06 \\
\end{array}$ & $\begin{array}{l}0,078 \\
<\text { LDM }\end{array}$ & $\begin{array}{l}0,095 \\
<\text { LDM }\end{array}$ & $\begin{array}{l}0,096 \\
<\text { LDM }\end{array}$ & $\begin{array}{l}0,084 \\
<\text { LDM }\end{array}$ & $\begin{array}{l}0,087 \\
<\text { LDM }\end{array}$ & $\begin{array}{l}0,094 \\
<\text { LDM }\end{array}$ & $\begin{array}{l}0,082 \\
<\text { LDM }\end{array}$ & $\begin{array}{l}0,094 \\
<\text { LDM }\end{array}$ & $\begin{array}{l}0,075 \\
<\text { LDM }\end{array}$ & $\begin{array}{l}0,063 \\
<\text { LDM }\end{array}$ & $\begin{array}{l}0,074 \\
<\text { LDM }\end{array}$ \\
\hline Esteróis Totais & 0,58 & 0,523 & 0,574 & 0,436 & 0,467 & 0,379 & 0,574 & 0,513 & 0,567 & 0,473 & 0,451 & 0,437 \\
\hline Androstanol & 0,125 & 0,125 & 0,125 & 0,125 & 0,125 & 0,125 & 0,125 & 0,125 & 0,125 & 0,125 & 0,125 & 0,125 \\
\hline 5a-colestano & 0,142 & 0,127 & 0,141 & 0,154 & 0,142 & 0,180 & 0,144 & 0,187 & 0,160 & 0,173 & 0,141 & 0,142 \\
\hline Recuperação & 0,882 & 0,982 & 0,883 & 0,809 & 0,878 & 0,696 & 0,870 & 0,667 & 0,781 & 0,723 & 0,887 & 0,880 \\
\hline \multicolumn{13}{|c|}{ PARÂMETRO DE AVALIAÇÃO } \\
\hline lesterol/ $\beta$-sitosterol & 1,000 & 1,077 & 0,874 & 0,479 & 0,798 & 0,644 & 1,021 & 1,000 & 0,755 & 0,693 & 0,651 & 0,784 \\
\hline
\end{tabular}


Tabela XIII. - Concentrações dos álcoois analisados em $\left(\mu \mathrm{g} \mathrm{g}^{-1}\right)$ e parâmetro de avaliação da origem e transformação da matéria orgânica. <LDM: abaixo do limite de detecção, ao longo do testemunho 253.

\begin{tabular}{|c|c|c|c|c|c|c|c|c|c|c|c|c|c|c|c|c|c|}
\hline \multicolumn{18}{|c|}{ Profundidade $(\mathrm{cm})$} \\
\hline & 1 & 2 & 4 & 6 & 8 & 10 & 12 & 14 & 16 & 18 & 20 & 22 & 24 & 26 & 28 & 30 & 32 \\
\hline $\mathrm{C}_{12}-\mathrm{OH}$ & $<\mathrm{LDM}$ & $<$ LDM & $<$ LDM & $<\mathrm{LDM}$ & $<$ LDM & $<$ LDM & $<$ LDM & $<$ LDM & $<$ LDM & $<$ LDM & $<\mathrm{LDM}$ & $<$ LDM & $<$ LDM & $<\mathrm{LDM}$ & $<$ LDM & $<\mathrm{LDM}$ & $<$ LDM \\
\hline $\mathrm{C}_{13}-\mathrm{OH}$ & LDM & $<$ LDM & $<$ LDM & $<$ LDM & $<$ LDM & $<$ LDM & $<$ LDM & $<$ LDM & $<$ LDM & $<$ LDM & $<$ LDM & $<$ LDM & $<$ LDM & $<$ LDM & $<$ LDM & $<$ LDM & $<$ LDM \\
\hline $\mathrm{C}_{14-} \mathrm{OH}$ & LDM & $<$ LDM & $<$ LDM & $<$ LDM & 0,183 & $<$ LDM & $<$ LDM & $<$ LDM & $<$ LDM & $<$ LDM & $<$ LDM & $<$ LDM & $<$ LDM & $<$ LDM & $<$ LDM & $<$ LDM & $<$ LDM \\
\hline $\mathrm{C}_{15}-\mathrm{OH}$ & DM & $<$ LDM & $<$ LDM & $<$ LDM & $<$ LDM & LDM & LDM & $<$ LDM & $<$ LDM & $<$ LDM & $<$ LDM & $<$ LDM & $<$ LDM & $<$ LDM & LDM & $<$ LDM & $<$ LDM \\
\hline $\mathrm{C}_{16}-\mathrm{OH}$ & DM & $<$ LDM & 0,050 & $<$ LDM & 0,050 & LDM & LDM & 0,041 & $<$ LDM & 0,092 & -DM & 048 & $<$ LDM & 0,066 & 0,063 &, 094 &, 076 \\
\hline $\mathrm{C}_{17}-\mathrm{OH}$ & LDM & $<$ LDM & $<$ LDM & $<$ LDM & $<$ LDM & LDM & $<$ LDM & $<$ LDM & $<$ LDM & $<$ LDM & $<$ LDM & $<$ LDM & $<$ LDM & $<$ LDM & $<$ LDM & $<$ LDM & $<$ LDM \\
\hline $\mathrm{C}_{18}-\mathrm{OH}$ & LDM & $<$ LDM & $<$ LDM & $<$ LDM & $<$ LDM & $<$ LDM & $<$ LDM & $<$ LDM & $<$ LDM & $<$ LDM & $<$ LDM & $<$ LDM & $<$ LDM & $<$ LDM & $<$ LDM & $<$ LDM & $<$ LDM \\
\hline $\mathrm{C}_{19}-\mathrm{OH}$ & DM & $<$ LDM & $<$ LDM & $<$ LDM & $<$ LDM & LDM & $<$ LDM & $<$ LDM & $<$ LDM & $<$ LDM & $<$ LDM & $<$ LDM & $<$ LDM & $<$ LDM & LLDM & $<$ LDM & $<$ LDM \\
\hline & LDM & $<$ LDM & $<$ LDM & $<$ LDM & $<$ LDM & $<$ LDM & $<$ LDM & $<$ LDM & $<$ LDM & $<$ LDM & $<$ LDM & $<$ LDM & $<$ LDM & $<$ LDM & $<$ LDM & $<$ LDM & $<$ LDM \\
\hline $\mathrm{C}_{21}-\mathrm{OH}$ & $<$ LDM & $<$ LDM & $<$ LDM & $<$ LDM & $<$ LDM & $<$ LDM & $<$ LDM & $<$ LDM & $<$ LDM & $<$ LDM & $<$ LDM & $<$ LDM & $<$ LDM & $<$ LDM & $<$ LDM & $<$ LDM & $<$ LDM \\
\hline $\mathrm{C}_{22}-\mathrm{OH}$ & $<$ LDM & $<$ LDM & $<$ LDM & $<$ LDM & $<$ LDM & $<$ LDM & $<$ LDM & $<$ LDM & $<$ LDM & $<$ LDM & $<$ LDM & $<$ LDM & $<$ LDM & $<$ LDM & $<$ LDM & $<$ LDM & 0,042 \\
\hline $\mathrm{C}_{23}-\mathrm{OH}$ & LDM & $<$ LDM & $<$ LDM & $<$ LDM & $<$ LDM & $<$ LDM & $<$ LDM & $<$ LDM & $<$ LDM & $<$ LDM & $<$ LDM & $<$ LDM & $<$ LDM & $<$ LDM & $<$ LDM & $<$ LDM & $<$ LDM \\
\hline $\mathrm{C}_{24}-\mathrm{OH}$ & LDM & $<$ LDM & $<$ LDM & $<$ LDM & $<$ LDM & $<$ LDM & $<$ LDM & $<$ LDM & $<$ LDM & $<$ LDM & $<$ LDM & $<$ LDM & $<$ LDM & $<$ LDM & $<$ LDM & $<$ LDM & $<$ LDM \\
\hline $\mathrm{C}_{25}-\mathrm{OH}$ & $<$ LDM & $<$ LDM & $<$ LDM & $<$ LDM & $<$ LDM & $<$ LDM & $<$ LDM & $<$ LDM & $<$ LDM & $<$ LDM & $<$ LDM & $<$ LDM & $<$ LDM & $<$ LDM & $<$ LDM & $<$ LDM & $<$ LDM \\
\hline $\mathrm{C}_{26}-\mathrm{OH}$ & $<$ LDM & $<$ LDM & $<$ LDM & $<$ LDM & $<$ LDM & $<$ LDM & $<$ LDM & $<$ LDM & $<$ LDM & $<$ LDM & $<$ LDM & $<$ LDM & $<$ LDM & $<$ LDM & $<$ LDM & $<$ LDM & $<$ LDM \\
\hline $\mathrm{C}_{27}-\mathrm{OH}$ & $<$ LDM & $<$ LDM & $<$ LDM & $<$ LDM & $<$ LDM & $<$ LDM & $<$ LDM & $<$ LDM & $<$ LDM & $<$ LDM & $<$ LDM & $<$ LDM & $<$ LDM & $<$ LDM & $<$ LDM & $<$ LDM & $<$ LDM \\
\hline $\mathrm{C}_{28}-\mathrm{OH}$ & 0,066 & 0,042 & 0,044 & 0,039 & 0,040 & 0,027 & 0,046 & 0,073 & 0,087 & 0,077 & 0,016 & 0,058 & 0,077 & 0,061 & 0,048 & 0,056 & 0,109 \\
\hline $\mathrm{C}_{29}-\mathrm{OH}$ & $<$ LDM & 0,019 & 0,013 & $<$ LDM & $<$ LDM & $<$ LDM & $<$ LDM & $<$ LDM & $<$ LDM & $<$ LDM & $<$ LDM & $<$ LDM & $<$ LDM & $<$ LDM & $<$ LDM & $<$ LDM & 0,014 \\
\hline & ,242 & 0,058 & 0,111 & 0,141 & 0,120 & 0,093 & 0,100 & 0,199 & 0,202 & 0,225 & 0,121 & 0,151 & 0,224 & 0,160 & 0,116 & 0,141 & 0,317 \\
\hline $\mathrm{C}_{31}-\mathrm{OH}$ & LDM & $<$ LDM & $<$ LDM & $<$ LDM & $<$ LDM & $<$ LDM & $<$ LDM & $<$ LDM & $<$ LDM & $<$ LDM & $<$ LDM & $<$ LDM & $<$ LDM & $<$ LDM & $<$ LDM & $<$ LDM & $<$ LDM \\
\hline $\mathrm{C}_{32}-\mathrm{OH}$ & $<$ LDM & $<$ LDM & $<$ LDM & $<$ LDM & $<$ LDM & $<$ LDM & $<$ LDM & $<$ LDM & $<$ LDM & $<$ LDM & $<$ LDM & $<$ LDM & $<$ LDM & $<$ LDM & $<$ LDM & $<$ LDM & $<$ LDM \\
\hline $\begin{array}{l}\text { Álcoois } \\
\text { Totais }\end{array}$ & 0,532 & 0,258 & 0,376 & 0,295 & 0,506 & 0,276 & 0,270 & 0,461 & 0,475 & 0,571 & 0,273 & 0,402 & 0,477 & 0,451 & 0,323 & 0,466 & 0,724 \\
\hline
\end{tabular}


Tabela XIV. - Concentrações dos álcoois analisados em $\left(\mu \mathrm{g} \mathrm{g}^{-1}\right)$ e parâmetro de avaliação da origem e transformação da matéria orgânica. <LDM: abaixo do limite de detecção, ao longo do testemunho 254.

\begin{tabular}{|c|c|c|c|c|c|c|c|c|c|c|c|}
\hline \multicolumn{12}{|c|}{ Profundidade (cm) } \\
\hline & 1 & 2 & 4 & 6 & 8 & 10 & 12 & 14 & 16 & 18 & 20 \\
\hline $\mathrm{C}_{12}-\mathrm{OH}$ & $<$ LDM & $<$ LDM & $<$ LDM & $<$ LDM & $<$ LDM & $<$ LDM & $<$ LDM & $<$ LDM & $<$ LDM & $<$ LDM & $<$ LDM \\
\hline $\mathrm{C}_{13}-\mathrm{OH}$ & $<$ LDM & $<$ LDM & $<$ LDM & $<$ LDM & $<$ LDM & $<$ LDM & $<$ LDM & $<$ LDM & $<$ LDM & $<$ LDM & $<$ LDM \\
\hline $\mathrm{C}_{14}-\mathrm{OH}$ & $<$ LDM & $<$ LDM & $<$ LDM & $<$ LDM & $<$ LDM & $<$ LDM & $<$ LDM & $<$ LDM & $<$ LDM & $<$ LDM & $<$ LDM \\
\hline $\mathrm{C}_{15}-\mathrm{OH}$ & $<$ LDM & $<$ LDM & $<$ LDM & $<$ LDM & $<$ LDM & $<$ LDM & $<$ LDM & $<$ LDM & $<$ LDM & $<$ LDM & $<$ LDM \\
\hline $\mathrm{C}_{16}-\mathrm{OH}$ & 0,058 & $<$ LDM & $<$ LDM & $<$ LDM & 0,068 & $<$ LDM & $<$ LDM & 0,043 & $<$ LDM & $<$ LDM & $<$ LDM \\
\hline $\mathrm{C}_{17}-\mathrm{OH}$ & $<$ LDM & $<$ LDM & $<$ LDM & $<$ LDM & $<$ LDM & $<$ LDM & $<$ LDM & $<$ LDM & $<$ LDM & $<$ LDM & $<$ LDM \\
\hline $\mathrm{C}_{18}-\mathrm{OH}$ & $<$ LDM & $<$ LDM & $<$ LDM & $<$ LDM & $<$ LDM & $<$ LDM & $<$ LDM & $<$ LDM & $<$ LDM & $<$ LDM & $<$ LDM \\
\hline $\mathrm{C}_{19}-\mathrm{OH}$ & $<$ LDM & $<$ LDM & $<$ LDM & $<$ LDM & $<$ LDM & $<$ LDM & $<$ LDM & $<$ LDM & $<$ LDM & $<$ LDM & $<$ LDM \\
\hline $\mathrm{C}_{20}-\mathrm{OH}$ & $<$ LDM & $<$ LDM & $<$ LDM & $<$ LDM & $<$ LDM & $<$ LDM & $<$ LDM & $<$ LDM & $<$ LDM & $<$ LDM & $<$ LDM \\
\hline $\mathrm{C}_{21}-\mathrm{OH}$ & $<$ LDM & $<$ LDM & $<$ LDM & $<$ LDM & $<$ LDM & $<$ LDM & $<$ LDM & $<$ LDM & $<$ LDM & $<$ LDM & $<$ LDM \\
\hline $\mathrm{C}_{22}-\mathrm{OH}$ & 0,065 & 0,051 & 0,051 & 0,045 & $<$ LDM & $<$ LDM & $<$ LDM & $<$ LDM & $<$ LDM & $<$ LDM & $<$ LDM \\
\hline $\mathrm{C}_{23}-\mathrm{OH}$ & $<$ LDM & $<$ LDM & $<$ LDM & $<$ LDM & $<$ LDM & $<$ LDM & $<$ LDM & $<$ LDM & $<$ LDM & $<$ LDM & $<$ LDM \\
\hline $\mathrm{C}_{24}-\mathrm{OH}$ & 0,039 & $<$ LDM & $<$ LDM & $<$ LDM & $<$ LDM & $<$ LDM & $<$ LDM & $<$ LDM & $<$ LDM & $<$ LDM & $<$ LDM \\
\hline $\mathrm{C}_{25}-\mathrm{OH}$ & 0,040 & $<$ LDM & $<$ LDM & $<$ LDM & $<$ LDM & $<$ LDM & $<$ LDM & $<$ LDM & $<$ LDM & $<$ LDM & $<$ LDM \\
\hline $\mathrm{C}_{26}-\mathrm{OH}$ & $<$ LDM & $<$ LDM & $<$ LDM & $<$ LDM & $<$ LDM & $<$ LDM & $<$ LDM & $<$ LDM & $<$ LDM & $<$ LDM & $<$ LDM \\
\hline $\mathrm{C}_{27}-\mathrm{OH}$ & $<$ LDM & $<$ LDM & $<$ LDM & $<$ LDM & $<$ LDM & $<$ LDM & $<$ LDM & $<$ LDM & $<$ LDM & $<$ LDM & $<$ LDM \\
\hline $\mathrm{C}_{28}-\mathrm{OH}$ & $<$ LDM & 0,077 & 0,059 & 0,056 & 0,068 & 0,027 & 0,028 & 0,054 & 0,058 & 0,047 & $<$ LDM \\
\hline $\mathrm{C}_{29}-\mathrm{OH}$ & $<$ LDM & $<$ LDM & 0,015 & 0,013 & 0,010 & $<$ LDM & $<$ LDM & $<$ LDM & $<$ LDM & $<$ LDM & 0,010 \\
\hline $\mathrm{C}_{30}-\mathrm{OH}$ & 0,301 & 0,281 & 0,144 & 0,130 & 0,152 & 0,066 & 0,059 & 0,129 & 0,120 & 0,102 & $<$ LDM \\
\hline $\mathrm{C}_{31}-\mathrm{OH}$ & $<$ LDM & $<$ LDM & $<$ LDM & $<$ LDM & $<$ LDM & $<$ LDM & $<$ LDM & $<$ LDM & $<$ LDM & $<$ LDM & $<$ LDM \\
\hline $\mathrm{C}_{32}-\mathrm{OH}$ & $<$ LDM & $<$ LDM & $<$ LDM & $<$ LDM & $<$ LDM & $<$ LDM & $<$ LDM & $<$ LDM & $<$ LDM & $<$ LDM & $<$ LDM \\
\hline Álcoois Totais & 0,642 & 0,594 & 0,407 & 0,367 & 0,484 & 0,237 & 0,255 & 0,362 & 0,270 & 0,296 & 0,049 \\
\hline
\end{tabular}


Tabela XIV (Continuação) - Concentrações dos álcoois analisados em $\left(\mu \mathrm{g} \mathrm{g}^{-1}\right)$ e parâmetro de avaliação da origem e transformação da matéria orgânica. <LDM: abaixo do limite de detecção, ao longo do testemunho 254.

\begin{tabular}{|c|c|c|c|c|c|c|c|c|c|c|}
\hline \multicolumn{11}{|c|}{ Profundidade $(\mathrm{cm})$} \\
\hline & 22 & 24 & 26 & 28 & 30 & 32 & 34 & 36 & 38 & 40 \\
\hline $\mathrm{C}_{12}-\mathrm{OH}$ & $<$ LDM & $<$ LDM & $<$ LDM & $<$ LDM & $<$ LDM & $<$ LDM & $<$ LDM & $<$ LDM & $<$ LDM & $<$ LDM \\
\hline $\mathrm{C}_{13}-\mathrm{OH}$ & $<$ LDM & $<$ LDM & $<$ LDM & $<$ LDM & $<$ LDM & $<$ LDM & $<$ LDM & $<$ LDM & $<$ LDM & $<$ LDM \\
\hline $\mathrm{C}_{14}-\mathrm{OH}$ & $<$ LDM & $<$ LDM & $<$ LDM & $<$ LDM & $<$ LDM & $<$ LDM & $<$ LDM & $<$ LDM & $<$ LDM & $<$ LDM \\
\hline $\mathrm{C}_{15}-\mathrm{OH}$ & $<$ LDM & $<$ LDM & $<$ LDM & $<$ LDM & $<\mathrm{LDM}$ & $<$ LDM & $<$ LDM & $<$ LDM & $<$ LDM & $<$ LDM \\
\hline $\mathrm{C}_{16}-\mathrm{OH}$ & $<$ LDM & $<$ LDM & $<$ LDM & $<$ LDM & $<$ LDM & $<$ LDM & $<$ LDM & 0,044 & $<$ LDM & $<$ LDM \\
\hline $\mathrm{C}_{17}-\mathrm{OH}$ & $<$ LDM & $<$ LDM & $<$ LDM & $<$ LDM & $<$ LDM & $<$ LDM & $<$ LDM & $<$ LDM & $<$ LDM & 0,080 \\
\hline $\mathrm{C}_{18}-\mathrm{OH}$ & $<$ LDM & $<$ LDM & $<$ LDM & <LDM & $<\mathrm{LDM}$ & $<$ LDM & $<$ LDM & <LDM & 0,046 & $<$ LDM \\
\hline $\mathrm{C}_{19-} \mathrm{OH}$ & $<$ LDM & $<$ LDM & $<$ LDM & $<$ LDM & $<$ LDM & $<$ LDM & $<$ LDM & $<$ LDM & $<$ LDM & $<$ LDM \\
\hline $\mathrm{C}_{20}-\mathrm{OH}$ & $<$ LDM & $<$ LDM & $<$ LDM & $<$ LDM & $<$ LDM & $<$ LDM & $<$ LDM & <LDM & $<$ LDM & $<$ LDM \\
\hline $\mathrm{C}_{21}-\mathrm{OH}$ & $<$ LDM & $<$ LDM & $<$ LDM & $<$ LDM & $<\mathrm{LDM}$ & $<$ LDM & $<$ LDM & $<$ LDM & $<$ LDM & $<$ LDM \\
\hline $\mathrm{C}_{22}-\mathrm{OH}$ & $<$ LDM & $<$ LDM & $<$ LDM & <LDM & $<\mathrm{LDM}$ & $<$ LDM & $<$ LDM & <LDM & 0,060 & $<$ LDM \\
\hline $\mathrm{C}_{23}-\mathrm{OH}$ & $<$ LDM & $<$ LDM & $<$ LDM & $<$ LDM & $<$ LDM & $<$ LDM & $<$ LDM & $<$ LDM & $<$ LDM & $<$ LDM \\
\hline $\mathrm{C}_{24}-\mathrm{OH}$ & $<$ LDM & $<$ LDM & $<$ LDM & $<$ LDM & $<$ LDM & $<$ LDM & $<$ LDM & $<$ LDM & $<$ LDM & $<$ LDM \\
\hline $\mathrm{C}_{25} \mathrm{OH}$ & $<$ LDM & $<$ LDM & $<$ LDM & $<$ LDM & $<$ LDM & $<$ LDM & $<$ LDM & $<$ LDM & $<$ LDM & $<$ LDM \\
\hline $\mathrm{C}_{26}-\mathrm{OH}$ & $<$ LDM & $<$ LDM & $<$ LDM & $<$ LDM & $<\mathrm{LDM}$ & $<$ LDM & $<$ LDM & $<$ LDM & $<$ LDM & $<$ LDM \\
\hline $\mathrm{C}_{27}-\mathrm{OH}$ & $<$ LDM & $<$ LDM & $<$ LDM & $<$ LDM & $<$ LDM & $<$ LDM & $<$ LDM & $<$ LDM & $<$ LDM & $<$ LDM \\
\hline $\mathrm{C}_{28}-\mathrm{OH}$ & 0,058 & 0,033 & $<$ LDM & 0,022 & 0,020 & 0,033 & 0,034 & 0,043 & 0,082 & $<$ LDM \\
\hline $\mathrm{C}_{29}-\mathrm{OH}$ & 0,011 & 0,010 & $<$ LDM & $<$ LDM & $<$ LDM & $<$ LDM & $<$ LDM & $<$ LDM & 0,011 & $<$ LDM \\
\hline $\mathrm{C}_{30}-\mathrm{OH}$ & 0,145 & 0,066 & $<$ LDM & 0,056 & 0,040 & 0,070 & 0,078 & 0,102 & 0,193 & 0,040 \\
\hline $\mathrm{C}_{31}-\mathrm{OH}$ & $<$ LDM & $<$ LDM & $<$ LDM & $<$ LDM & $<$ LDM & $<$ LDM & $<$ LDM & $<$ LDM & $<$ LDM & $<$ LDM \\
\hline $\mathrm{C}_{32}-\mathrm{OH}$ & $<\mathrm{LDM}$ & $<$ LDM & $<\mathrm{LDM}$ & $<$ LDM & $<\mathrm{LDM}$ & $<$ LDM & $<$ LDM & $<$ LDM & $<$ LDM & $<$ LDM \\
\hline $\begin{array}{l}\text { Álcoois } \\
\text { Totais }\end{array}$ & 0,372 & 0,231 & 0,099 & 0,156 & 0,136 & 0,218 & 0,233 & 0,305 & 0,620 & 0,260 \\
\hline
\end{tabular}


Tabela XV. - Concentrações dos álcoois analisados em $\left(\mu \mathrm{g} \mathrm{g}^{-1}\right)$ e parâmetro de avaliação da origem e transformação da matéria orgânica. <LDM: abaixo do limite de detecção, ao longo do testemunho 256.

\begin{tabular}{|c|c|c|c|c|c|c|c|c|c|c|c|c|c|c|c|c|c|}
\hline \multicolumn{18}{|c|}{ Profundidade (cm) } \\
\hline & 1 & 2 & 4 & 6 & 8 & 10 & 12 & 14 & 16 & 18 & 20 & 22 & 24 & 26 & 28 & 30 & 32 \\
\hline $\mathrm{C}_{12}-\mathrm{OH}$ & $<$ LDM & $<$ LDM & $<$ LDM & $<$ LDM & $<$ LDM & $<$ LDM & $<$ LDM & $<$ LDM & $<$ LDM & $<$ LDM & $<$ LDM & $<$ LDM & $<$ LDM & $<$ LDM & $<$ LDM & $<$ LDM & $<$ LDM \\
\hline $\mathrm{C}_{13}-\mathrm{OH}$ & $<$ LDM & $<$ LDM & $<$ LDM & $<$ LDM & $<$ LDM & $<$ LDM & $<$ LDM & $<$ LDM & $<$ LDM & $<$ LDM & $<$ LDM & $<$ LDM & $<$ LDM & $<$ LDM & $<$ LDM & $<$ LDM & $<$ LDM \\
\hline $\mathrm{C}_{14-} \mathrm{OH}$ & $<$ LDM & $<$ LDM & $<$ LDM & $<$ LDM & $<$ LDM & LDM & $<$ LDM & $<$ LDM & $<$ LDM & $<$ LDM & $<$ LDM & $<$ LDM & $<$ LDM & $<$ LDM & & LDM & \\
\hline $\mathrm{C}_{15} \mathrm{OH}$ & $<$ LDM & $<$ LDM & $<$ LDM & $<$ LDM & $<$ LDM & $<$ LDM & $<$ LDM & $<$ LDM & $<\mathrm{LDM}$ & $<$ LDM & $<$ LDM & $<$ LDM & $<$ LDM & $<$ LDM & & $<$ LDM & $<$ LDM \\
\hline $\mathrm{C}_{16}-\mathrm{OH}$ & $<$ LDM & 0,063 & 0,163 & $<$ LDM & $<$ LDM & $<$ LDM & $<$ LDM & $<$ LDM & 0,124 & 0,104 & $<$ LDM & $<$ LDM & $<$ LDM & $<$ LDM & & 0,071 & 0,047 \\
\hline $\mathrm{C}_{17}-\mathrm{OH}$ & $<$ LDM & $<$ LDM & $<$ LDM & $<$ LDM & $<$ LDM & $<$ LDM & $<$ LDM & $<$ LDM & $<$ LDM & $<$ LDM & $<$ LDM & $<$ LDM & $<$ LDM & $<$ LDM & $<$ LDM & $<$ LDM & $<$ LDM \\
\hline $\mathrm{C}_{18} \mathrm{OH}$ & $<$ LDM & $<\mathrm{LDM}$ & $<$ LDM & $<$ LDM & $<$ LDM & LDM & $<$ LDM & $<$ LDM & $<$ LDM & $<$ LDM & $<$ LDM & $<$ LDM & $<$ LDM & $<$ LDM & $<$ LDM & $<$ LDM & $<$ LDM \\
\hline $\mathrm{C}_{19}-\mathrm{OH}$ & $<$ LDM & $<$ LDM & $<$ LDM & $<$ LDM & $<$ LDM & & $<$ LDM & $<$ LDM & $<$ LDM & $<$ LDM & $<$ LDM & $<$ LDM & & $<$ LDM & & $<$ LDM & $<$ LDM \\
\hline $\mathrm{C}_{20}-\mathrm{OH}$ & $<$ LDM & $<$ LDM & $<$ LDM & $<$ LDM & $<$ LDM & $<$ LDM & $<$ LDM & $<$ LDM & $<$ LDM & $<$ LDM & $<$ LDM & $<$ LDM & & $<$ LDM & & & $<$ LDM \\
\hline $\mathrm{C}_{21}-\mathrm{OH}$ & $<$ LDM & $<$ LDM & $<$ LDM & $<$ LDM & $<$ LDM & $<$ LDM & $<$ LDM & $<$ LDM & $<$ LDM & $<$ LDM & $<$ LDM & $<$ LDM & $<$ LDM & $<$ LDM & & & $<$ LDM \\
\hline $\mathrm{C}_{22}-\mathrm{OH}$ & $<$ LDM & $<$ LDM & $<$ LDM & $<$ LDM & $<$ LDM & $<$ LDM & $<$ LDM & $<$ LDM & $<$ LDM & $<$ LDM & $<$ LDM & $<$ LDM & $<L D$ & $<$ LDM & & & $<$ LDM \\
\hline $\mathrm{C}_{23}-\mathrm{OH}$ & $<$ LDM & $<$ LDM & $<$ LDM & $<$ LDM & $<$ LDM & $<$ LDM & $<$ LDM & $<$ LDM & $<$ LDM & $<$ LDM & $<$ LDM & $<$ LDM & & $<$ LDM & & & DM \\
\hline $\mathrm{C}_{24}-\mathrm{OH}$ & $<$ LDM & $<$ LDM & $<$ LDM & $<$ LDM & $<$ LDM & $<$ LDM & $<$ LDM & $<$ LDM & $<\mathrm{LDM}$ & $<$ LDM & $<$ LDM & 0,049 & 0,056 & 0,055 & 57 & 0,06 & 0,043 \\
\hline $\mathrm{C}_{25}-\mathrm{OH}$ & $<$ LDM & $<$ LDM & $<$ LDM & $<$ LDM & $<$ LDM & $<$ LDM & $<$ LDM & $<$ LDM & 0,048 & 0,042 & 0,049 & 0,054 & 0,080 & 0,079 & 0,0 & $0,0 \varepsilon$ & 0,064 \\
\hline $\mathrm{C}_{26}-\mathrm{OH}$ & $<\mathrm{LDM}$ & $<$ LDM & $<$ LDM & $<$ LDM & $<\mathrm{LDM}$ & $<\mathrm{LDM}$ & $<$ LDM & $<$ LDM & $<\mathrm{LDM}$ & $<$ LDM & $<$ LDM & $<$ LDM & $<$ LDM & $<$ LDM & & $<\mathrm{LD}$ & $<$ LDM \\
\hline $\mathrm{C}_{27}-\mathrm{OH}$ & & $<$ LDM & $<$ LDM & $<$ LDM & & & $<$ LDM & $<$ LDM & $<$ LDM & $<$ LDM & $<$ LDM & $<$ LDM & & & & & $<$ LDM \\
\hline $\mathrm{C}_{28} \mathrm{OH}$ & 0,049 & 0,041 & 0,045 & 0,038 & 0,028 & 0,038 & 0,064 & 0,094 & 0,106 & 0,088 & 0,109 & 0,113 & 0,179 & 0,163 & 0,183 & 0,191 & 0,141 \\
\hline $\mathrm{C}_{29}-\mathrm{OH}$ & $<$ LDM & $<$ LDM & $<$ LDM & $<$ LDM & $<$ LDM & $<$ LDM & $<$ LDM & $<$ LDM & $<$ LDM & $<$ LDM & $<$ LDM & $<$ LDM & $<$ LDM & $<$ LDM & $<$ LDM & $<$ LDM & $<$ LDM \\
\hline $\mathrm{C}_{30}-\mathrm{OH}$ & 0,307 & 0,118 & 0,117 & 0,074 & 0,068 & 0,098 & 0,142 & 0,251 & 0,279 & 0,191 & 0,272 & 0,288 & 0,434 & 0,398 & & & 0,380 \\
\hline $\mathrm{C}_{31}-\mathrm{OH}$ & $<$ LDM & $<$ LDM & $<$ LDM & $<$ LDM & $<$ LDM & & $<$ LDM & $<$ LDM & $<$ LDM & $<$ LDM & $<$ LDM & $<$ LDM & & & & & $<$ LDM \\
\hline $\mathrm{C}_{32}-\mathrm{OH}$ & $<\mathrm{LDM}$ & $<$ LDM & $<$ LDM & $<$ LDM & $<\mathrm{LDM}$ & $<\mathrm{LDM}$ & $<$ LDM & $<$ LDM & $<$ LDM & $<\mathrm{LDM}$ & $<$ LDM & $<$ LDM & $<\mathrm{LDM}$ & $<$ LDM & $<$ LDM & $<\mathrm{LDM}$ & $<\mathrm{LDM}$ \\
\hline $\begin{array}{l}\text { Álcoois } \\
\text { Totais }\end{array}$ & 0,490 & 0,359 & 0,460 & 0,239 & 0,187 & 0,277 & 0,354 & 0,533 & 0,732 & 0,582 & 0,612 & 0,650 & 0,929 & 0,848 & 0,973 & 1,079 & 0,779 \\
\hline
\end{tabular}


Tabela XVI. - Concentrações dos álcoois analisados em $\left(\mu \mathrm{g} \mathrm{g}^{-1}\right)$ e parâmetro de avaliação da origem e transformação da matéria orgânica. <LDM: abaixo do limite de detecção, ao longo do testemunho 257.

\begin{tabular}{|c|c|c|c|c|c|c|c|c|c|c|c|c|c|c|c|c|}
\hline \multicolumn{17}{|c|}{ Profundidade (cm) } \\
\hline & 1 & 2 & 4 & 6 & 8 & 10 & 12 & 14 & 16 & 18 & 20 & 22 & 24 & 26 & 28 & 30 \\
\hline $\mathrm{C}_{12}-\mathrm{OH}$ & $<$ LDM & $<$ LDM & $<$ LDM & $<$ LDM & $<$ LDM & $<$ LDM & $<$ LDM & $<$ LDM & $<$ LDM & $<$ LDM & $<$ LDM & $<$ LDM & $<$ LDM & $<$ LDM & $<$ LDM & $<$ LDM \\
\hline $\mathrm{C}_{13}-\mathrm{OH}$ & $<$ LDM & $<$ LDM & $<$ LDM & $<$ LDM & $<$ LDM & $<$ LDM & $<$ LDM & $<$ LDM & $<$ LDM & $<$ LDM & $<$ LDM & $<$ LDM & $<$ LDM & $<$ LDM & $<$ LDM & $<$ LDM \\
\hline $\mathrm{C}_{14-} \mathrm{OH}$ & $<$ LDM & $<$ LDM & $<$ LDM & $<$ LDM & $<$ LDM & $<$ LDM & $<$ LDM & $<$ LDM & $<$ LDM & $<$ LDM & $<$ LDM & $<$ LDM & $<$ LDM & $<$ LDM & $<$ LDM & $<$ LDM \\
\hline $\mathrm{C}_{15}-\mathrm{OH}$ & $<$ LDM & $<$ LDM & $<$ LDM & $<$ LDM & $<$ LDM & $<$ LDM & $<$ LDM & $<$ LDM & $<$ LDM & $<$ LDM & $<$ LDM & $<$ LDM & $<$ LDM & $<$ LDM & $<$ LDM & $<$ LDM \\
\hline $\mathrm{C}_{16}-\mathrm{OH}$ & 0,062 & $<$ LDM & 0,083 & 0,047 & 0,059 & 0,082 & $<$ LDM & $<$ LDM & $<$ LDM & $<$ LDM & $<$ LDM & $<$ LDM & $<$ LDM & 0,054 & 0,041 & $<$ LDM \\
\hline $\mathrm{C}_{17}-\mathrm{OH}$ & $<$ LDM & $<$ LDM & $<$ LDM & $<$ LDM & $<$ LDM & $<$ LDM & $<$ LDM & $<$ LDM & $<$ LDM & $<$ LDM & $<$ LDM & $<$ LDM & $<$ LDM & $<$ LDM & $<$ LDM & $<$ LDM \\
\hline $\mathrm{C}_{18}-\mathrm{OH}$ & $<$ LDM & $<$ LDM & $<$ LDM & $<$ LDM & $<$ LDM & $<$ LDM & $<$ LDM & $<$ LDM & $<$ LDM & $<$ LDM & $<$ LDM & $<$ LDM & 0,047 & $<$ LDM & $<$ LDM & $<$ LDM \\
\hline $\mathrm{C}_{19}-\mathrm{OH}$ & $<$ LDM & $<$ LDM & $<$ LDM & $<$ LDM & $<\mathrm{LDM}$ & $<$ LDM & $<$ LDM & $<\mathrm{LDM}$ & $<$ LDM & $<$ LDM & $<$ LDM & $<$ LDM & $<$ LDM & $<$ LDM & $<$ LDM & $<$ LDM \\
\hline $\mathrm{C}_{20}-\mathrm{OH}$ & $<$ LDM & $<$ LDM & $<$ LDM & $<$ LDM & $<$ LDM & $<$ LDM & $<$ LDM & $<$ LDM & $<$ LDM & $<$ LDM & $<$ LDM & $<$ LDM & $<$ LDM & $<$ LDM & $<$ LDM & $<$ LDM \\
\hline $\mathrm{C}_{21}-\mathrm{OH}$ & $<$ LDM & $<$ LDM & $<$ LDM & $<$ LDM & $<$ LDM & $<$ LDM & $<$ LDM & $<$ LDM & $<$ LDM & $<$ LDM & $<$ LDM & $<$ LDM & $<$ LDM & $<$ LDM & $<$ LDM & $<$ LDM \\
\hline $\mathrm{C}_{22}-\mathrm{OH}$ & 0,045 & $<$ LDM & $<$ LDM & $<$ LDM & $<\mathrm{LDM}$ & $<$ LDM & $<$ LDM & $<\mathrm{LDM}$ & $<$ LDM & $<\mathrm{LDM}$ & $<$ LDM & $<$ LDM & $<$ LDM & $<$ LDM & $<$ LDM & $<$ LDM \\
\hline $\mathrm{C}_{23}-\mathrm{OH}$ & $<$ LDM & $<$ LDM & $<$ LDM & $<$ LDM & $<$ LDM & $<$ LDM & $<$ LDM & $<$ LDM & $<$ LDM & $<$ LDM & $<$ LDM & $<$ LDM & $<$ LDM & $<$ LDM & $<$ LDM & $<$ LDM \\
\hline $\mathrm{C}_{24}-\mathrm{OH}$ & $<\mathrm{LDM}$ & $<\mathrm{LDM}$ & $<$ LDM & $<$ LDM & $<\mathrm{LDM}$ & $<\mathrm{LDM}$ & $<$ LDM & $<\mathrm{LDM}$ & $<$ LDM & $<$ LDM & $<$ LDM & $<$ LDM & $<$ LDM & $<$ LDM & $<$ LDM & $<$ LDM \\
\hline $\mathrm{C}_{25}-\mathrm{OH}$ & $<$ LDM & $<$ LDM & $<$ LDM & $<$ LDM & $<$ LDM & $<$ LDM & $<$ LDM & $<$ LDM & $<$ LDM & $<$ LDM & $<$ LDM & $<$ LDM & $<$ LDM & $<$ LDM & $<$ LDM & $<$ LDM \\
\hline $\mathrm{C}_{26}-\mathrm{OH}$ & $<$ LDM & $<\mathrm{LDM}$ & $<$ LDM & $<$ LDM & $<\mathrm{LDM}$ & $<$ LDM & $<$ LDM & $<\mathrm{LDM}$ & $<$ LDM & $<\mathrm{LDM}$ & $<$ LDM & $<$ LDM & $<$ LDM & $<$ LDM & $<$ LDM & $<$ LDM \\
\hline $\mathrm{C}_{27}-\mathrm{OH}$ & $<$ LDM & $<$ LDM & $<$ LDM & $<$ LDM & $<$ LDM & $<$ LDM & $<$ LDM & $<$ LDM & $<$ LDM & $<$ LDM & $<$ LDM & $<$ LDM & $<$ LDM & $<$ LDM & $<$ LDM & $<$ LDM \\
\hline $\mathrm{C}_{28} \mathrm{OH}$ & 0,077 & 0,035 & 0,030 & 0,041 & 0,053 & 0,036 & 0,026 & 0,057 & 0,058 & 0,053 & 0,051 & 0,039 & 0,050 & 0,052 & 0,049 & 0,043 \\
\hline $\mathrm{C}_{29}-\mathrm{OH}$ & $<$ LDM & $<$ LDM & 0,012 & $<$ LDM & $<$ LDM & $<$ LDM & $<$ LDM & $<$ LDM & $<$ LDM & $<$ LDM & $<$ LDM & $<$ LDM & $<$ LDM & $<$ LDM & $<$ LDM & $<$ LDM \\
\hline $\mathrm{C}_{30}-\mathrm{OH}$ & 0,253 & 0,147 & 0,112 & 0,164 & 0,187 & 0,134 & 0,067 & 0,154 & 0,143 & 0,130 & 0,133 & 0,111 & 0,126 & 0,160 & 0,160 & 0,136 \\
\hline $\mathrm{C}_{31}-\mathrm{OH}$ & $<$ LDM & $<$ LDM & $<$ LDM & $<$ LDM & $<$ LDM & $<$ LDM & $<$ LDM & $<$ LDM & $<$ LDM & $<$ LDM & $<$ LDM & $<$ LDM & $<$ LDM & $<$ LDM & $<$ LDM & $<$ LDM \\
\hline $\mathrm{C}_{32}-\mathrm{OH}$ & $<$ LDM & $<$ LDM & $<$ LDM & $<$ LDM & $<$ LDM & $<$ LDM & $<$ LDM & $<\mathrm{LDM}$ & $<$ LDM & $<$ LDM & $<$ LDM & $<$ LDM & $<$ LDM & $<\mathrm{LDM}$ & $<$ LDM & $<$ LDM \\
\hline $\begin{array}{c}\text { Álcoois } \\
\text { Totais }\end{array}$ & 0,581 & 0,305 & 0,345 & 0,386 & 0,458 & 0,367 & 0,224 & 0,349 & 0,340 & 0,298 & 0,331 & 0,266 & 0,326 & 0,406 & 0,377 & 0,312 \\
\hline
\end{tabular}


Tabela XVII. - Concentrações dos álcoois analisados em $\left(\mu \mathrm{g} \mathrm{g}^{-1}\right)$ e parâmetro de avaliação da origem e transformação da matéria orgânica. <LDM: abaixo do limite de detecção, ao longo do testemunho 262.

\begin{tabular}{|c|c|c|c|c|}
\hline \multicolumn{5}{|c|}{ Profundidade $(\mathrm{cm})$} \\
\hline & 1 & 3 & 5 & 7 \\
\hline $\mathrm{C}_{12}-\mathrm{OH}$ & $<$ LDM & $<$ LDM & $<$ LDM & $<$ LDM \\
\hline $\mathrm{C}_{13}-\mathrm{OH}$ & $<$ LDM & $<$ LDM & $<$ LDM & $<$ LDM \\
\hline $\mathrm{C}_{14-} \mathrm{OH}$ & $<$ LDM & $<$ LDM & $<$ LDM & $<$ LDM \\
\hline $\mathrm{C}_{15}-\mathrm{OH}$ & $<$ LDM & $<$ LDM & $<$ LDM & $<$ LDM \\
\hline $\mathrm{C}_{16}-\mathrm{OH}$ & $<$ LDM & 0,056 & $<$ LDM & $<$ LDM \\
\hline $\mathrm{C}_{17}-\mathrm{OH}$ & $<$ LDM & $<$ LDM & $<$ LDM & $<$ LDM \\
\hline $\mathrm{C}_{18-} \mathrm{OH}$ & $<$ LDM & $<$ LDM & $<$ LDM & $<$ LDM \\
\hline $\mathrm{C}_{19}-\mathrm{OH}$ & $<$ LDM & $<$ LDM & $<$ LDM & $<$ LDM \\
\hline $\mathrm{C}_{20}-\mathrm{OH}$ & $<$ LDM & $<$ LDM & $<$ LDM & $<$ LDM \\
\hline $\mathrm{C}_{21}-\mathrm{OH}$ & $<$ LDM & $<$ LDM & $<$ LDM & $<$ LDM \\
\hline $\mathrm{C}_{22}-\mathrm{OH}$ & $<$ LDM & $<$ LDM & $<$ LDM & $<$ LDM \\
\hline $\mathrm{C}_{23}-\mathrm{OH}$ & $<$ LDM & $<$ LDM & $<$ LDM & $<$ LDM \\
\hline $\mathrm{C}_{24}-\mathrm{OH}$ & $<$ LDM & $<$ LDM & $<$ LDM & $<$ LDM \\
\hline $\mathrm{C}_{25}-\mathrm{OH}$ & $<$ LDM & $<$ LDM & $<$ LDM & $<$ LDM \\
\hline $\mathrm{C}_{26}-\mathrm{OH}$ & $<$ LDM & $<$ LDM & $<$ LDM & $<$ LDM \\
\hline $\mathrm{C}_{27}-\mathrm{OH}$ & $<$ LDM & $<$ LDM & $<$ LDM & $<$ LDM \\
\hline $\mathrm{C}_{28}-\mathrm{OH}$ & 0,070 & 0,047 & 0,040 & 0,032 \\
\hline $\mathrm{C}_{29}-\mathrm{OH}$ & $<$ LDM & $<$ LDM & $<$ LDM & $<$ LDM \\
\hline $\mathrm{C}_{30}-\mathrm{OH}$ & 0,197 & 0,122 & 0,100 & 0,076 \\
\hline $\mathrm{C}_{31}-\mathrm{OH}$ & $<$ LDM & $<$ LDM & $<$ LDM & $<$ LDM \\
\hline $\mathrm{C}_{32}-\mathrm{OH}$ & $<$ LDM & $<$ LDM & $<$ LDM & $<$ LDM \\
\hline $\begin{array}{l}\text { Álcoois } \\
\text { Totais }\end{array}$ & 0,450 & 0,325 & 0,250 & 0,193 \\
\hline
\end{tabular}


Tabela XVIII. - Concentrações dos álcoois analisados em $\left(\mu \mathrm{g} \mathrm{g}^{-1}\right)$ e parâmetro de avaliação da origem e transformação da matéria orgânica. <LDM: abaixo do limite de detecção, ao longo do testemunho 264.

\begin{tabular}{|c|c|c|c|c|c|c|c|c|c|c|c|c|}
\hline \multicolumn{13}{|c|}{ Profundidade (cm) } \\
\hline & 1 & 2 & 4 & 6 & 8 & 10 & 12 & 14 & 16 & 18 & 20 & 22 \\
\hline $\mathrm{C}_{12}-\mathrm{OH}$ & $<$ LDM & $<$ LDM & $<$ LDM & $<$ LDM & $<$ LDM & $<$ LDM & $<$ LDM & $<$ LDM & $<$ LDM & $<$ LDM & $<$ LDM & $<$ LDM \\
\hline $\mathrm{C}_{13}-\mathrm{OH}$ & $<$ LDM & $<\mathrm{LDM}$ & $<$ LDM & $<$ LDM & $<$ LDM & $<$ LDM & $<$ LDM & $<$ LDM & $<$ LDM & $<$ LDM & $<$ LDM & $<$ LDM \\
\hline $\mathrm{C}_{14}-\mathrm{OH}$ & $<$ LDM & $<$ LDM & $<$ LDM & $<$ LDM & $<$ LDM & $<$ LDM & $<$ LDM & $<$ LDM & $<$ LDM & $<$ LDM & $<$ LDM & $<$ LDM \\
\hline $\mathrm{C}_{15}-\mathrm{OH}$ & $<$ LDM & $<$ LDM & $<$ LDM & $<$ LDM & $<$ LDM & $<$ LDM & $<$ LDM & $<$ LDM & $<$ LDM & $<$ LDM & $<$ LDM & $<$ LDM \\
\hline $\mathrm{C}_{16}-\mathrm{OH}$ & $<$ LDM & 0,043 & $<$ LDM & 0,048 & $<$ LDM & $<$ LDM & $<$ LDM & 0,071 & $<$ LDM & $<$ LDM & $<$ LDM & $<$ LDM \\
\hline $\mathrm{C}_{17} \mathrm{OH}$ & $<$ LDM & $<$ LDM & $<$ LDM & $<$ LDM & $<\mathrm{LDM}$ & $<$ LDM & $<$ LDM & $<$ LDM & $<\mathrm{LDM}$ & $<$ LDM & $<$ LDM & $<$ LDM \\
\hline $\mathrm{C}_{18}-\mathrm{OH}$ & $<$ LDM & $<$ LDM & $<$ LDM & $<$ LDM & $<$ LDM & $<$ LDM & $<$ LDM & $<$ LDM & $<$ LDM & $<$ LDM & $<$ LDM & $<$ LDM \\
\hline $\mathrm{C}_{19}-\mathrm{OH}$ & $<$ LDM & $<$ LDM & $<$ LDM & $<$ LDM & $<$ LDM & $<$ LDM & $<$ LDM & $<$ LDM & $<$ LDM & $<$ LDM & $<$ LDM & $<$ LDM \\
\hline $\mathrm{C}_{20}-\mathrm{OH}$ & $<$ LDM & $<\mathrm{LDM}$ & $<$ LDM & $<$ LDM & $<$ LDM & $<$ LDM & $<\mathrm{LDM}$ & $<$ LDM & $<$ LDM & $<$ LDM & $<$ LDM & $<$ LDM \\
\hline $\mathrm{C}_{21}-\mathrm{OH}$ & $<$ LDM & $<$ LDM & $<$ LDM & $<$ LDM & $<$ LDM & $<$ LDM & $<$ LDM & $<$ LDM & $<$ LDM & $<$ LDM & $<$ LDM & $<$ LDM \\
\hline $\mathrm{C}_{22}-\mathrm{OH}$ & $<$ LDM & $<$ LDM & $<$ LDM & $<$ LDM & $<$ LDM & $<$ LDM & $<$ LDM & $<$ LDM & $<$ LDM & $<$ LDM & $<$ LDM & $<$ LDM \\
\hline $\mathrm{C}_{23}-\mathrm{OH}$ & $<$ LDM & $<$ LDM & $<$ LDM & $<$ LDM & $<$ LDM & $<$ LDM & $<$ LDM & $<$ LDM & $<$ LDM & $<$ LDM & $<$ LDM & $<$ LDM \\
\hline $\mathrm{C}_{24}-\mathrm{OH}$ & $<$ LDM & $<$ LDM & $<$ LDM & $<$ LDM & $<$ LDM & $<$ LDM & $<$ LDM & $<$ LDM & 0,049 & 0,052 & 0,047 & 0,046 \\
\hline $\mathrm{C}_{25} \mathrm{OH}$ & $<$ LDM & $<$ LDM & $<$ LDM & $<$ LDM & $<$ LDM & $<$ LDM & $<$ LDM & 0,059 & 0,074 & 0,054 & 0,052 & 0,041 \\
\hline $\mathrm{C}_{26}-\mathrm{OH}$ & $<$ LDM & $<$ LDM & $<$ LDM & $<$ LDM & $<$ LDM & $<$ LDM & $<$ LDM & $<$ LDM & $<$ LDM & $<$ LDM & $<$ LDM & $<$ LDM \\
\hline $\mathrm{C}_{27}-\mathrm{OH}$ & $<$ LDM & $<$ LDM & $<$ LDM & $<$ LDM & $<$ LDM & $<$ LDM & $<$ LDM & $<$ LDM & $<$ LDM & $<$ LDM & $<$ LDM & $<$ LDM \\
\hline $\mathrm{C}_{28}-\mathrm{OH}$ & 0,060 & 0,038 & 0,045 & 0,055 & 0,056 & 0,061 & 0,074 & 0,152 & 0,182 & 0,116 & 0,119 & 0,082 \\
\hline $\mathrm{C}_{29}-\mathrm{OH}$ & $<$ LDM & $<$ LDM & $<$ LDM & $<$ LDM & 0,010 & $<$ LDM & $<$ LDM & $<$ LDM & $<$ LDM & 0,011 & $<$ LDM & $<$ LDM \\
\hline $\mathrm{C}_{30}-\mathrm{OH}$ & 0,173 & 0,120 & 0,117 & 0,132 & 0,102 & 0,154 & 0,164 & 0,330 & 0,360 & 0,220 & 0,262 & 0,166 \\
\hline $\mathrm{C}_{31}-\mathrm{OH}$ & $<$ LDM & $<$ LDM & $<$ LDM & $<$ LDM & $<$ LDM & $<$ LDM & $<$ LDM & $<$ LDM & $<$ LDM & $<$ LDM & $<$ LDM & $<$ LDM \\
\hline $\mathrm{C}_{32}-\mathrm{OH}$ & $<$ LDM & $<$ LDM & $<$ LDM & $<$ LDM & $<$ LDM & $<$ LDM & $<$ LDM & $<$ LDM & $<$ LDM & $<$ LDM & $<$ LDM & $<$ LDM \\
\hline $\begin{array}{l}\text { Álcoois } \\
\text { Totais }\end{array}$ & 0,374 & 0,295 & 0,262 & 0,335 & 0,295 & 0,352 & 0,376 & 0,760 & 0,823 & 0,633 & 0,603 & 0,474 \\
\hline
\end{tabular}




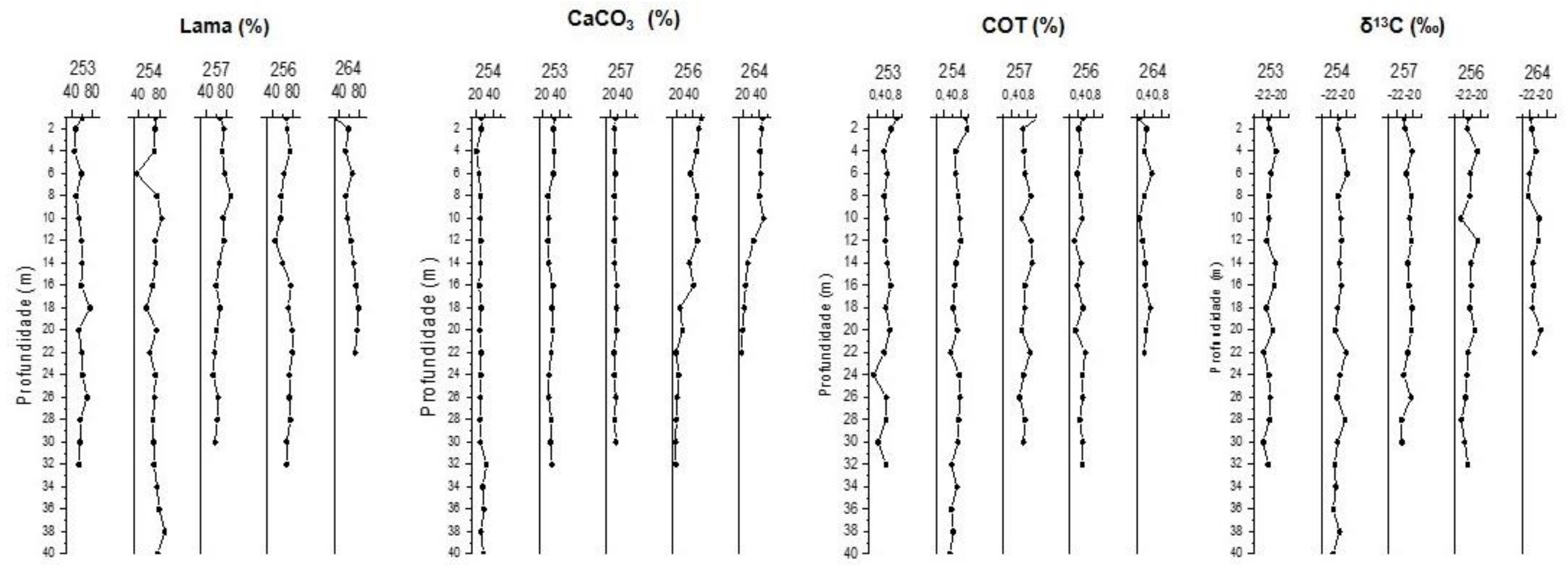

Figura XIX. - Perfis verticais dos parâmetros Lama (silte + argila), $\mathrm{CaCO}_{3}$, COT e $\delta^{13} \mathrm{C}$, analisados nos testemunhos $253,254,256,257$ e 264. 


\section{$n$-alcanos Totais $\left(\mu \mathrm{g} \mathrm{g}^{-1}\right)$}

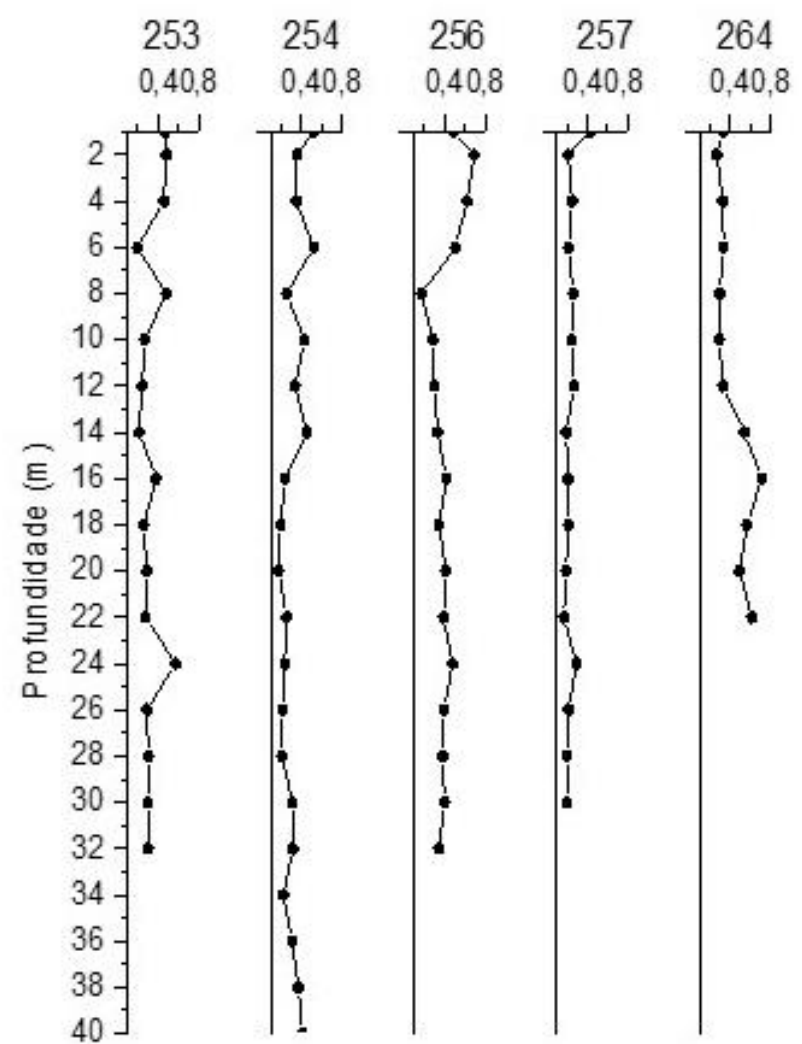

$n$-alcanos leves ( $\left.\mu \mathrm{g} \mathrm{g}^{-1}\right)$

( $<n-C_{22}$ )

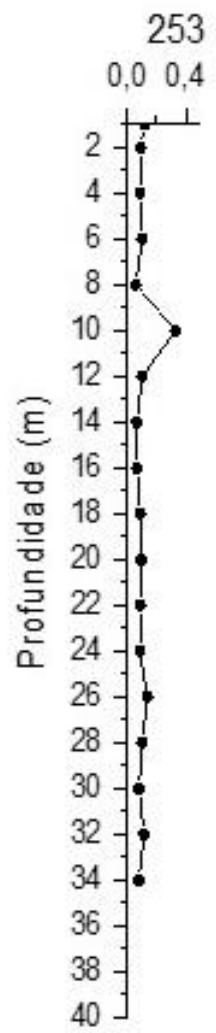

$n$-alcanos pesados $\left(\mu \mathrm{g} \mathrm{g} \mathrm{g}^{-1}\right)$ $\left(>n-C_{22}\right)$

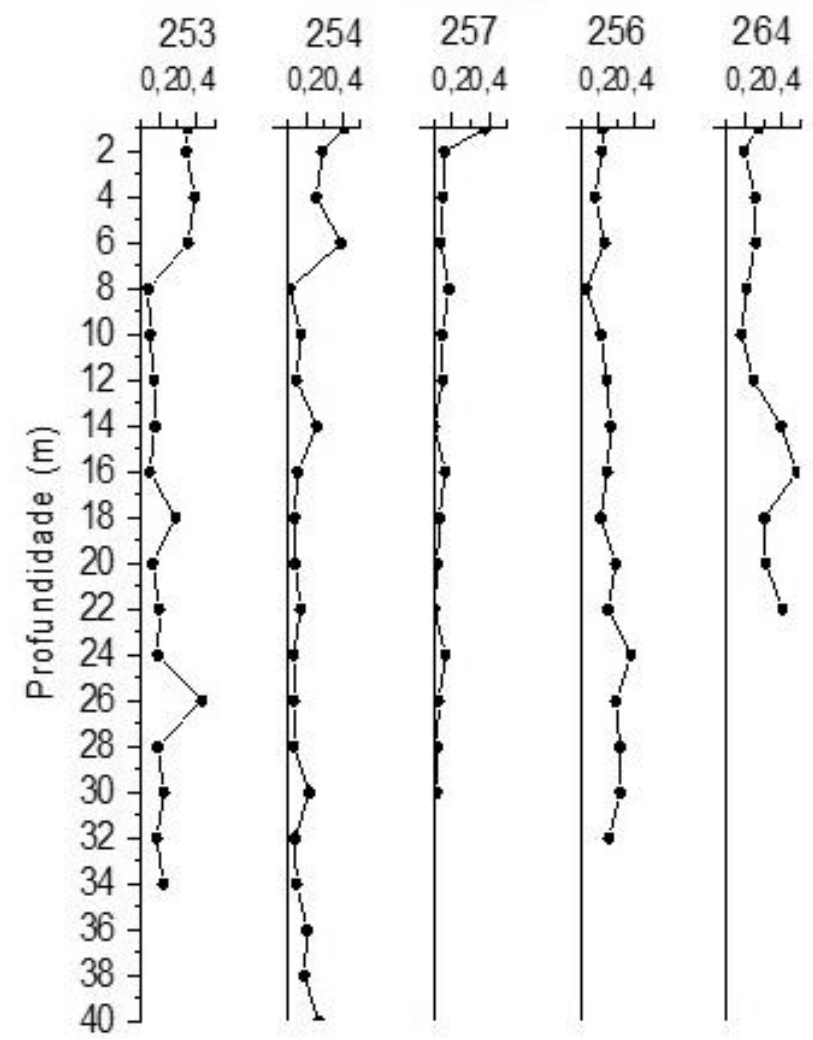

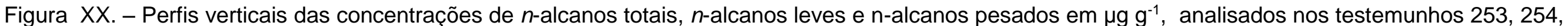
256, 257 e 264. 


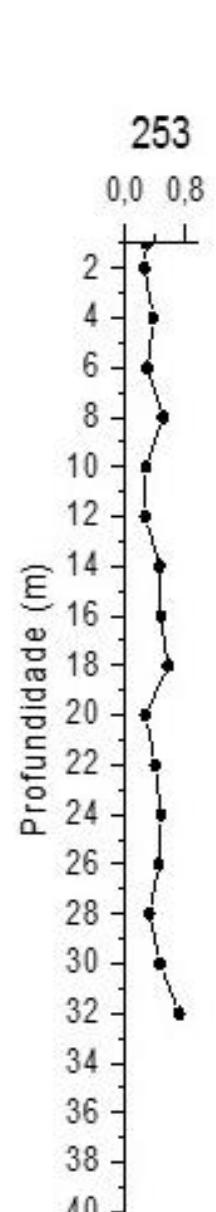

Álcoois Totais $\left(\mu \mathrm{g} \mathrm{g}^{-1}\right)$

Álcoois leves $\left(\mu \mathrm{g} \mathrm{g}^{-1}\right)$

$\left(>n-C_{22}\right.$ )
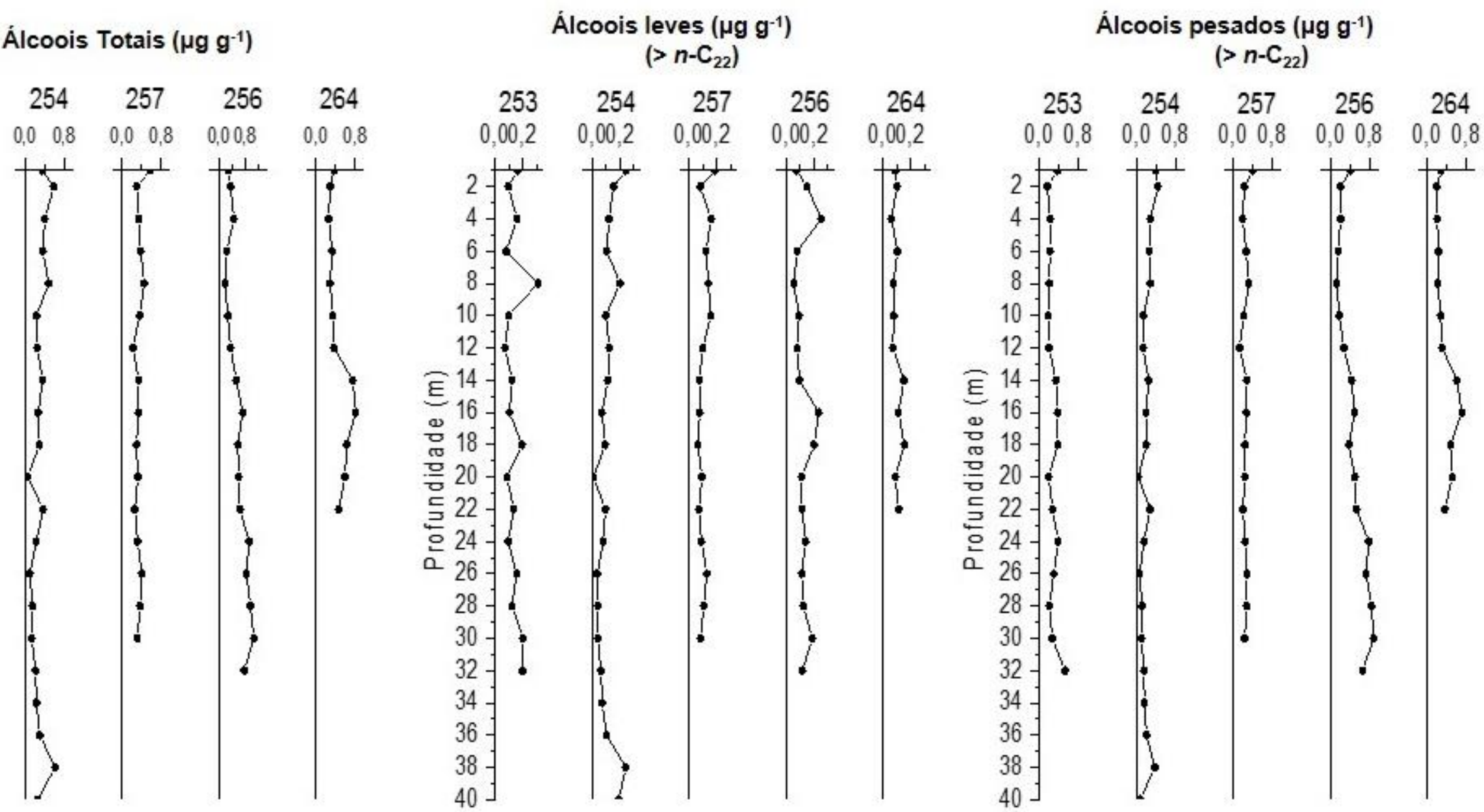

Figura XXI. - Perfis verticais das concentrações de Álcoois totais, Álcoois leves e Álcoois pesados em $\mu \mathrm{g} \mathrm{g}^{-1}$, analisados nos testemunhos $253,254,256$, 257 e 264. 


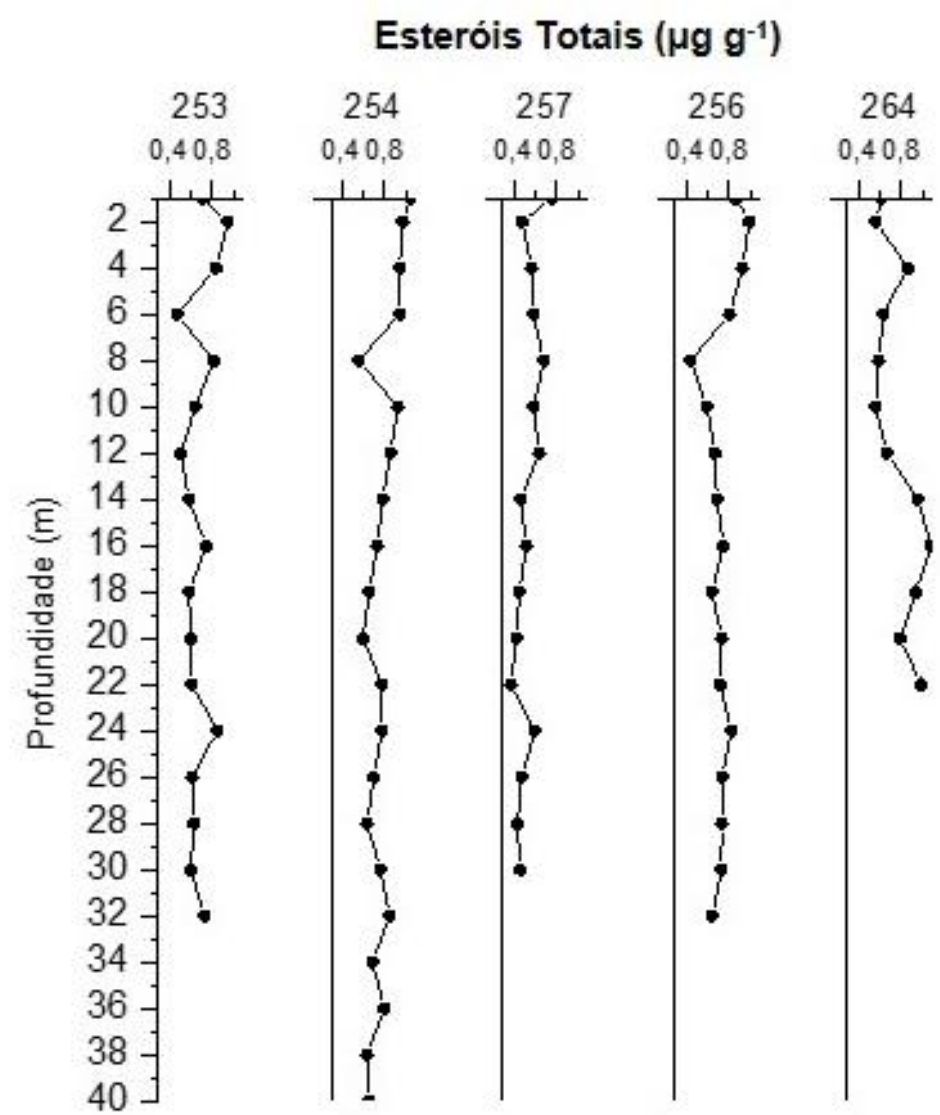

Figura XXII. - Perfis verticais das concentrações de Esteróis Totais em $\mu g \mathrm{~g}^{-1}$, analisados nos testemunhos 253, 254, 256, 257 e 264. 